Jan Høgelund

In Search of Effective

Disability Policy

Comparing the Developments and Outcomes

of Dutch and Danish Disability Policies

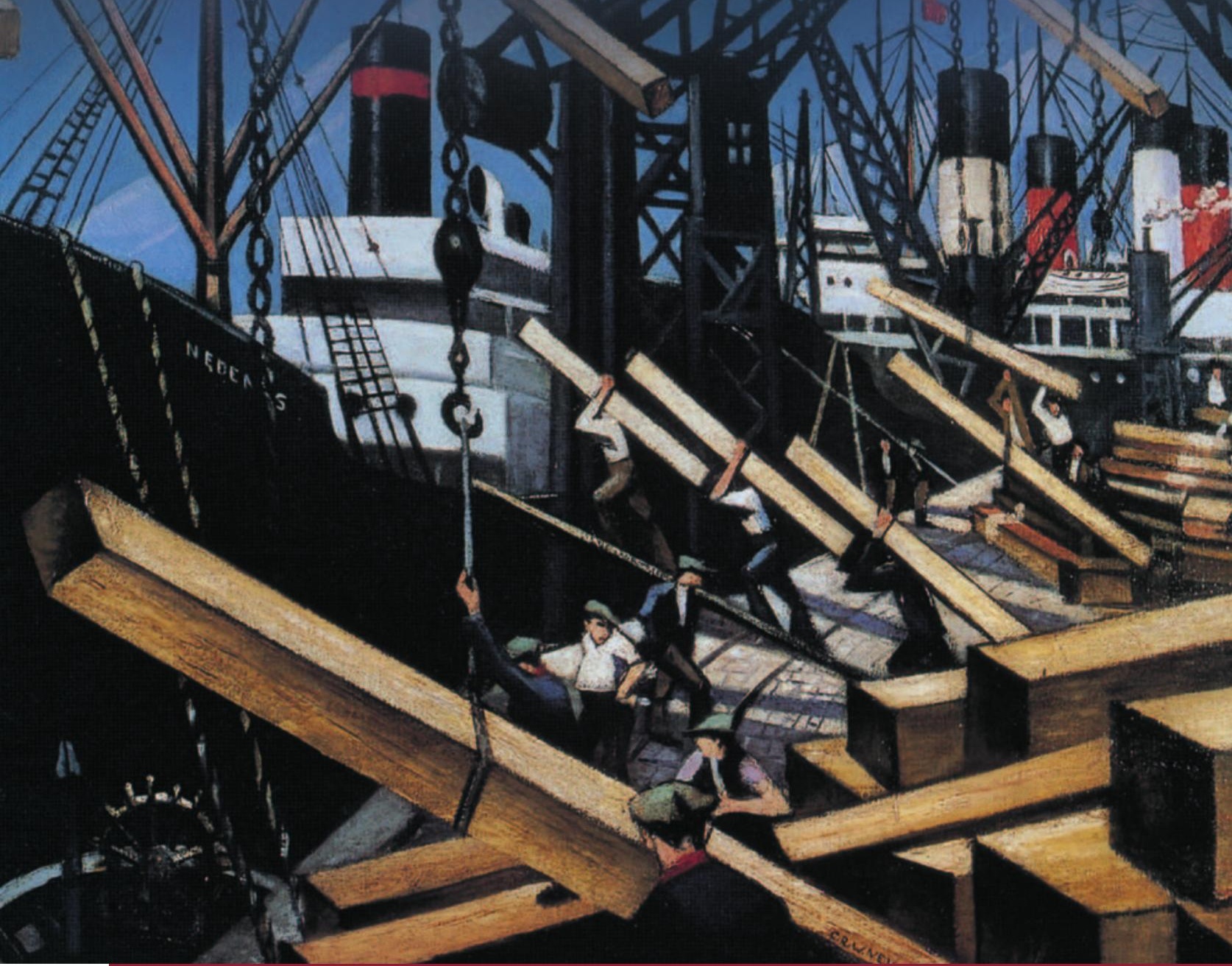

$\begin{array}{lllllllllllllllllllllllll}\text { A } & \text { M } & \text { S } & \text { T } & \text { E } & \text { R } & \text { D } & \text { A } & \text { M } & \text { U } & \text { N } & \text { I } & \text { V } & \text { E } & \text { R } & \text { S } & \text { I } & \text { T } & \text { Y } & & \text { P } & \text { R } & \text { E } & \text { S } & \text { S }\end{array}$ 
In Search of Effective Disability Policy 



\section{In Search of Effective Disability Policy}

Comparing the Developements and Outcomes of the Dutch and Danish Disability Policies

Jan $\mathrm{H} \phi$ gelund 
Cover illustration: C.R.W. Nevinson, Loading Timber at Southampton Docks, I9 16, Southampton City Art Gallery

Cover design: Jaak Crasborn BNo, Valkenburg a/d Geul Lay-out: Adriaan de Jonge

ISBN 9053566449

NUR 754

(C) Amsterdam University Press, Amsterdam, 2003

All rights reserved. Without limiting the rights under copyright reserved above, no part of this book may be reproduced, stored in or introduced into a retrieval system, or transmitted, in any form or by any means (electronic, mechanical, photocopying, recording or otherwise) without the written permission of both the copyright owner and the author of the book. 


\section{Contents}

\section{Acknowledgement / 9}

1 Disability Policies Under Pressure / 11

The welfare state under pressure / I 2

Similar pressures - different problems / I 4

Welfare states and disability programmes / I 8

The labour market and the disability pathway / i 9

The consequences of exogenous pressures / 20

Disability programmes and the disability pathway / 2 I

Disability policy responses / 24

The objective of this book / 25

How to study the outcomes of disability policies / 26

The structure of this book / 27

2 The Integration of Disabled People: What Do We Know? / 31

Clinical studies / 3 I

Economic studies / 36

Public policy studies / 4I

Sociological studies / 46

Summary and conclusions / $5 \mathrm{I}$

3 Bringing the Pieces Together: A Multidisciplinary Approach to Work Disability / 53

Choosing the approach / 53

A model for the labour market integration of disabled people / 55

The labour market attachment of workers with health problems / 62

Discussion and critique / 62 


\section{Economic Miracles Bypassing Disabled People / 65}

From economic growth to crisis / 65

Crisis management: paid exit and active labour market measures / 67 From crisis to recovery $/ 72$

\section{Dutch Disability Reforms: Redefining Responsibilities / 75}

A sick nation / 76

Ineffective changes / 82

The beginning of a reform $/ 83$

Redefining responsibilities / 85

Conclusion / 89

6 Danish Disability Policy: Small Steps, Big Change? / 93

Danish disability policy in the I 980 / $/ 93$

Defects in Danish disability policy / 96

Changes during the I980s: crisis management / 98

Changes during the I990s: increased emphasis on activation / Ioo

Dutch and Danish disability policies: different developments / I04

Dutch and Danish disability policies: different principles / I05

Conclusion / Io9

\section{Different Routes to Integration / 111}

The data / I 2

Dismissals during sick leave / I I 4

The supply of vocational rehabilitation measures / I I 8

Income protection during sick leave / I 2 I

Conclusion / I 24

Appendix A / I 26

Appendix B / I 28

\section{Different Policies-Different Outcomes / 135}

The return to work of long-term sick-listed workers / I 36

Dutch and Danish disability policies: a question of different rights? / I 45

Conclusion / I 47

Appendix C/ 150

Appendix D / I 54

Appendix E/ I 56 
9 Too Much and Too Little: Employers' Responsibility in Denmark and the Netherlands / 159

The disability figures reconsidered: an overestimated disability crisis / I 60 Policy changes - success or failure? / I 62

Explaining the developments / I 67

Disability policies in the context of future challenges / I 73

Towards a more effective disability policy / I 75

Tables and Figures / 179

Notes / 181

References / 187

Index of Subjects / 201

Index of Names / 205 



\section{Acknowledgements}

This book and my interest in disability policy originate from my participation in the crossnational study, Work Incapacity and Reintegration, carried out under the auspices of the International Social Security Association (ISSA). Most of the data used in this book are from this study. Seven years participation in the study taught me that doing crossnational research is difficult and frustrating but most of all inspiring and instructive. Thanks to all the participants and in particular to the Dutch team, Rienk Prins, Theo Veerman, Boukje Cuelenaere, and Anneke van der Giezen that provided useful information about the Dutch data and disability policy.

This book is an almost completely rewritten version of my $\mathrm{PhD}$ dissertation 'Bringing the Sick Back to Work. Labour Market Reintegration of the Long-Term Sick-Listed in the Netherlands and Denmark'. Chapter 2 is a revised version of 'Work Incapacity and Reintegration: A Literature Review' in Bloch, F.S. and Prins, R. (eds.): Who Returns to Work \& Why?, Transaction Publishers, 200I, pp. 27-54. Some of the analyses and ideas have appeared in 'Reintegration: Public or Private Responsibility? Consequences of Dutch and Danish Policies toward Work-Disabled Persons', International Journal of Health Services, Vol. 32, No. 3 pp. 467-487.

During four months at the faculty of Public Administration at Twente University, I experienced great hospitality. Willem Trommel and Jürgen Svensson answered innumerable questions way beyond the call of duty. They corrected several of my misunderstandings about the Dutch welfare state and their friendliness made the stay unforgettable. Also several other persons assisted me with information that significantly improved my knowledge about Dutch disability policy. Thanks to Miel Ausems, Pé Mullenders, Esther Bergsma, Hilbrand Bruinsma, Wim Zwinkels, Irene Houtman, Joseé Leontien, Casper Koene, and Gert Wolters.

Niels Michelsen, Staffan Marklund, and Romke van der Veen from my dissertation committee provided valuable critique and input for this book. I am grateful for support from my PhD supervisor Bent Greve, of the Department of Public Administration at Roskilde University, who kept my spirits 
up during hard times and learned me that mistakes are an important and unavoidable part of doing research. Too many serious mistakes are, however, nice to be avoided, and at an early stage in the project Gøsta Esping-Andersen helped me avoid one such mistake. Thanks to the participants, at the seminar on disability at the xI Nordic Social Policy Research Meeting in Helsinki, August 2002, for helpful comments to a previous version of chapter 3. This book has also benefited from valuable comments of Monroe Berkowitz and the statistical skills of Svend Kreiner and Anders Holm. Thanks also to Jens Modvig for introducing an economist to medical research.

Most of this book and my dissertation were written at the Danish National Institute of Social Research (SFI). I am grateful for stimulating discussions and advise from my colleagues, Henning Bjerregaard Bach, Ole Gregersen, and Pernille Hohnen. I am also grateful to Torben Tranæs who generously shared his considerably skills and whose input significantly improved important parts of the manuscript. I am deeply indebted to Jon Kvist that has been a constant source of inspiration. His skills and breadth of view helped me to keep focus on what is important, and his advice and encouragement have been of great significance for my work. It would have been impossible to write the dissertation and this book without financial support. Thanks to Jan Plovsing, Niels Ploug, Inger Koch-Nielsen, Ole Gregersen, and Jørgen Søndergaard for daring to fund the project at various stages. Thanks also to the Danish Health Insurance Foundation for financial support. Peter Abrahamson gave me an excellent opportunity to write this book when he invited me to stay a few months at the Department of Sociology at the University of Copenhagen.

It has been a pleasure to work with the people from AUP. Thanks to AUP's scientific committee for helpful comments to the manuscript and to the very kind editors, Jaap Wagenaar and Chantal Nicolaes. Marica Ognjenovic improved the language and Vibeke Tornhøj Christensen from SFI helped me with the indexes.

My greatest thanks and biggest debt belong to my wife Bente for her support and patience. And to my daughter Julie for showing me that there is more to life than research.

Copenhagen, August 2003 


\section{Disability Policies Under Pressure}

Effective disability policies are increasingly important for the sustainability of modern welfare states. How policies influence employers and disabled people is crucial for nations succeed in integrating disabled people into the labour market. Policies may motivate disabled people to participate actively in the labour market and provide them with skills and abilities that increase their employability. Policies also, in different ways and to varying degrees, motivate employers to employ disabled people. This may happen by demanding that employers have a certain number of disabled people in their staff, by forbidding the dismissal of sick-listed workers or by making it economically attractive to employ people with disabilities. By putting the focus on this last aspect, this book adds to the existing knowledge about the consequences of different disability policies. It outlines some of the different ways that disability policies influence employers, and how this in turn has important implications for the labour market attachment of disabled people.

Dutch and Danish disability policies are examples of two policies that rest on very different principles. In the Netherlands the responsibility for the integration of disabled people rests to a large extent on the individual employer. The policy not only gives employers huge incentives to limit work disability, it also legally requires employers to take on a considerable responsibility for the employment of disabled people. In Denmark employers are a protected species; they have almost no formal or economic responsibility for the integration of disabled people. Instead this responsibility rests with public authorities. This book analyses how differences in employers' responsibilities translate into differences in employers' costs, which in turn influences both how the integration of disabled people takes place and the chances for disabled people in the labour market. The main conclusion is that the Dutch policy reinforces the division between insiders and outsiders; it promotes the reintegration of sick-listed workers, but counteracts the integration of people without attachment to an employer. In contrast, the Danish policy facilitates the integration of disabled people without prior labour market attachment, but does not sufficiently support the reintegration in 
work of sick-listed workers. It is therefore argued that there is scope for improvement in both nations' disability policies and thus that more disabled people could participate in working life.

The need for welfare states to increase the labour market participation of people with health problems may become an even more greatly contested issue in the future than today. Globalisation, changing family patterns and labour market structures seem to make the 'average citizen' more exposed to social risks and labour market exclusion, while ageing populations at the same time make it increasingly important that people remain in the labour market during their adult working years. The analyses provided in this book indicate that the ability of national disability policies to cope with these pressures depends on how they define the responsibilities of employers. In this respect, the Dutch disability policy appears to be more vulnerable to future welfare state challenges than the Danish policy.

\section{The welfare state under pressure}

In the I970s and I980s the pressure on the modern welfare state was caused directly by economic problems. Reduced economic growth hampered nations' ability to increase employment and, coupled with an increasing labour supply, unemployment figures soared. As a consequence, governments' budgets became overloaded giving rise first to expansive Keynesian policies and later to retrenchment in order to limit social expenditure.

While the problems caused by persistent unemployment continued into the I990s and the beginning of the 2 Ist century, observers stress that the welfare state increasingly has to deal with other pressures. The most commonly cited pressures are increasing interdependency between nations and globalisation, changing social risks structures, and ageing populations. These pressures are qualitatively different from those experienced in the I970s and I980s. Whereas the pressures in the I970s and I980s were related to the welfare state itself, the present pressures are said to be exogenous. They are forced upon the welfare state from the outside and related to malfunctioning in the market and the family (e.g. Esping-Andersen, 1999).

\section{Globalisation}

Globalisation, which often refers to the increasing internationalisation of capital and trade and the deregulation of capital and currency markets, exerts pressure in several ways. Firstly, it is argued that in order to avoid capital 
fleet and currency speculation, nations to a certain extent have to abandon Keynesian demand policies that aim to stimulate employment and reduce income inequalities (Thompson, I997; Esping-Andersen, I996a; Standing, I999).

Secondly, it is argued that the internationalisation of capital increases the power of capital relatively to that of labour eroding the 'social contract' between capital and labour, where wage retainment is exchanged for economic growth (Rhodes, 1997). The capability of the corporatist welfare state to maximise employment and social security may therefore be hampered.

Thirdly, the increasing mobility of goods intensifies the competition from low wage nations able to produce industrial goods at much lower cost than developed countries. This competition drives up the unemployment rate of unskilled workers and eventually also of skilled workers. Western welfare states will in turn be forced to accept greater (wage) inequalities between unskilled workers and certain groups of skilled workers, on the one hand, and professionals and other groups of skilled workers, on the other hand (Rhodes, I997; Esping-Andersen, I996a; Navarro, I998). In other words, the mobility of goods will reinforce unemployment problems and increase wage inequalities in the advanced welfare states.

\section{Changing risk structures}

The today's post-industrial society increasingly involves social risks that our social security systems have not been designed to alleviate. The social security programmes, as we know them today, were devised in a period of relatively high economic growth, low unemployment and stable family and labour market patterns. During the I960s and I970s it could be expected that a male worker would be in stable employment, and thus contributing to the financing of public expenditure, from the age of $\mathrm{I} 8$ to 65 . It could also be expected that his wife would care for their children. Today, the typical employment pattern is considerably shorter because education is completed later and retirement begins earlier (Navarro, I999). In addition, the labour market is increasingly demanding flexible manpower, which makes periods of unemployment during the working years a more common event. A typical worker has therefore fewer productive years, more passive years that require financial support, and suffers a higher risk of becoming marginalised from the labour market. At the same time the female labour force participation is much higher than just a decade ago, resulting in an increased need for day care services.

Family patterns are also different today. On the one hand, the increasing 
female labour force participation means that the dual-income family is becoming more widespread. On the other hand, marriage is declining while divorce and separation are rising, indicating that single motherhood is becoming more and more common (cf. figure 6.3 in Hatland, 200I). This raises the demand for social security because single households and especially single parents are more vulnerable to poverty than the nuclear family. In other words, employment and family patterns are becoming less and less standard whereby new social needs arise, which undermine the foundation for the existing social security systems (e.g. European Commission, I993; Hatland, 200I).

\section{Ageing}

While it might be difficult to forecast future developments in globalisation, employment and family patterns, the development in age distribution is less uncertain: within the next few decades the number of old people will significantly increase relative to the number of people of working age. For every person above the age of 65 today within the OECD nations there are between four and five people aged between 20 and 64 years. This ratio will on average nearly double in 2050 (OECD, 200Ia). This development, which is caused by increased life expectancy and low fertility rates, is costly in terms of old age pensions, health care and social services. It is estimated that agerelated expenditures as a percentage of GDP will increase around 45 percent between 2000 and 2050 (ibid., table 4 ). In other words, an increasing dependency ratio will burden the welfare state.

\section{Similar pressures - different problems}

Although the pressures hit all modern nations, they may affect nations differently. It is persuading argued that welfare states cluster into (three or four) different regimes reflecting how the state, market and civil society interact (e.g. Esping-Andersen, I990; I996b; I999; Rhodes, I996). ${ }^{\text {I Within }}$ each regime, welfare is produced, financed and distributed differently and exogenous pressures therefore crystallize into different problems.

\section{Problems in the Liberal welfare state regime}

In the Liberal welfare state regime, which comprises the Anglo-Saxon nations, the state plays a relatively limited role. Social security programmes 
cover only a limited number of social risks and programmes are either universal with modest benefits or means tested, targeted at the most needy people. Instead coverage of social risks is very much left to market solutions in terms of private insurance and occupational benefit plans. The residual social security policy has its counterpart in a deregulated labour market with a very differentiated wage structure.

These features seem to cause both strengths and weaknesses with respect to the future challenges. On the one hand, the differentiated wage structure means that many low wage jobs are created, especially in the service sector. This seems to be good medicine for the malaise that may follow from increased competition from low-wage nations and the expulsion caused by changing labour market structures. Yet there are problems. The combination of low wages and the residual social security system means that a considerable number of workers have an income below the poverty line, so while the Liberal welfare state may avoid problems with too much inequality between people inside and outside the labour market, it may have problems with inequality between groups of wage earners within the labour market.

Furthermore, the low wage level for unskilled workers and negative income taxes make it more profitable for employers to hire more workers than to invest in capital and human resources. Consequently, the Liberal welfare state tends to end up in a low wage/low skill equilibrium which, in turn, makes the Liberal welfare state even more vulnerable to competition from nations with low-wage and low-technology production.

The residual nature of the Liberal welfare state may also be problematic in respect of changing family patterns. As day care is bought under market conditions without public subsidies many single mothers cannot afford it. Consequently, when the number of single mothers increases, poverty will rise.

\section{Problems in the Conservative welfare state regime}

The Conservative or Continental European regime is characterised by policies that favour familialization and status segmentation. Family benefits such as day care provisions and maternity benefits are limited in scope, which makes the family the primary provider of care for children (and the elderly) whilst also limiting female labour supply. The Conservative welfare state therefore favours a single-income female-care family. The public cash benefit programmes foster status segmentation because many programmes are organised according to occupation, and benefits are dependent on con- 
tributions. This is mirrored in a highly regulated labour market with a compressed wage structure and high job security. As a consequence, the predominantly male insiders enjoy high wages, good income protection and high job security, whereas the outsiders often have difficulty entering the labour market.

The Conservative welfare states seem to be ill-equipped to meet the challenges that may arise from globalisation, changing risk structures and ageing populations. The high wages for unskilled workers make it difficult to create jobs in the service sector. This seems to be fortified by the widespread singleincome female-care family that can produce service sector goods much more cheaply than they can be bought under market conditions. Hence it follows that globalisation and increased competition from low-wage nations may put the Conservative welfare states under extreme pressure.

Changing labour market structures seem also to be a serious problem for Conservative welfare states. The segregation between insiders and outsiders makes it difficult for weak groups to enter the labour market, and increasing risk of unemployment may therefore cause extensive expulsion from the labour market. In addition, increased female labour force participation may give rise to problems because a limited supply of public day care arrangements makes it difficult to reconcile family and working life. This is reflected in a record low fertility rate of $\mathrm{I} .45$ compared to I. 70 in the Scandinavian nations (own calculation based on table I in OECD, 200Ia). The pressure of ageing populations is therefore a more serious problem for Conservative welfare states than it is for the Liberal and Social Democratic welfare states.

\section{Problems in the Social Democratic welfare state regime}

The Social Democratic welfare state regime that includes the Nordic nations is characterised by publicly financed and administered universal social security schemes with quite generous benefits. Benefits in-kind in terms of extensive public day care coverage promote female labour force participation. High labour force participation rates for both women and men are also promoted by an active labour market policy where the receipt of social benefits is conditional upon participation in supported job training or education. At the same time a large part of the workforce, mainly unskilled female workers, is employed in public service jobs.

The Social Democratic model also cannot easily solve the problems that may follow from increased globalisation. Like the Continental European nations, the Scandinavian nations are characterised by a flat wage structure, which, in combination with the comprehensive public service sector em- 
ployment, gives rise to problems. On the one hand, the tax burden of a comprehensive public sector hinders further expansion of public service sector employment. On the other hand, a compressed wage structure excludes an expansion of service jobs in the private sector.

The Scandinavian nations seem, however, to have the potential to alleviate the negative consequences in terms of marginalization, that may follow globalisation and changing labour market structures. The Scandinavian policies promote a flexible labour market, while workers hit by unemployment are covered by generous benefits (Esping-Andersen, 1999). At the same time, active labour market measures recycle redundant labour, thus equalising the burden of unemployment. In addition, active labour market policies, high day-care coverage, and female public sector employment mean that the dual-income family is the norm, and this family group is less harmed than the single-income family when one of the adults is hit by unemployment.

The Scandinavian nations also seem to face less serious problems than other nations with regard to changing family patterns and the increasing risk of single motherhood. Comprehensive day care provision, active labour market policies and frequent female public employment mean that the employment rate of single mothers is high and close to that of other groups. And, if single mothers are affected by unemployment, generous unemployment benefits prevent them from suffering from poverty.

The problem of ageing populations is related to too low fertility rates, which in turn are related to how women manage to reconcile work and family obligations. In the Scandinavian nations, public day care facilities and generous maternity leave schemes imply that women can manage both.

In summary, problems in the Liberal welfare state are related to deregulated markets and a residual social security policy that creates a stratum of working poor and underinvestment in skills. In the Conservative welfare states exogenous pressures will fortify the problems associated with the single-income family, the insider-outsider divide and a compressed wage distribution. The latter also seems to be a central problem for the Social Democratic welfare state.

In other words, exogenous pressures and how they crystallize into different loads on the welfare states depends on, and involves, the entire institutional context of the welfare state and its policy areas. This book focuses on one policy area, disability policy, and seeks to shed light on how different policy responses to pressures within this area result in a different outcome in terms of inclusion and exclusion from the labour market. 


\section{Welfare states and disability programmes}

Historical evidence tells us that disability policies are affected when welfare states are under pressure. During the second half of the I970s until the midI990s the disability rolls kept growing in many western nations (Aarts, Burkhauser and de Jong, 1996). This development has been linked to pressures such as stagnating economic growth and an increasing supply of mainly female labour (Haveman, Halberstadt and Burkhauser, I984; Aarts, Burkhauser and de Jong, I996). Apparently the consequences of these pressures have varied across nations. For example, Germany experienced almost no growth in the number of disability beneficiaries, whereas the Netherlands was hit by soaring disability rolls (Aarts, Burkhauser and de Jong, I996). What are the mechanisms through which exogenous pressures translate into an increasing number of disability beneficiaries? In what ways do political strategies and institutional structures make a difference with respect to the consequences of exogenous pressures? Before these questions are addressed, it is fruitful to place disability programmes in the context of welfare state policies.

Cash benefit programmes may be considered as different pathways that can be used to withdraw, temporarily or permanently, from the labour market (Kohli and Rein, I99 I; de Vroom and Naschold, I993; Aarts, Burkhauser and de Jong, I996; Burkhauser, I998). In a very simplistic way, the main pathways are shown in Figure I.I. The normal pathway out of the labour force, the work pathway, is used when workers pass a certain age-limit and thereby become entitled to old age pension. The other exit pathways all involve receipt of social security benefits.

The majority of workers experience shorter or longer periods of unemployment (receiving either unemployment benefit or social assistance) and sickness absence during their working ages. In most cases they return to work and thus remain on the work pathway. Some workers do however leave the work force prematurely through one of the exit pathways. These may be old workers who retire after being unemployment, or workers with lasting health problems who after periods of sick leave enter the disability benefit scheme.

Active labour market policies aim to reverse the flow of people out of the labour force, cf. the dot-and-dash arrows in Figure I.I. Active employment policies concern the provision of active measures such as subsidised job training programmes, subsidised education, job search courses and so forth. In addition, other market interventions such as job protection legislation, quota jobs and wage-subsidised jobs may limit the outflow from the labour force. 


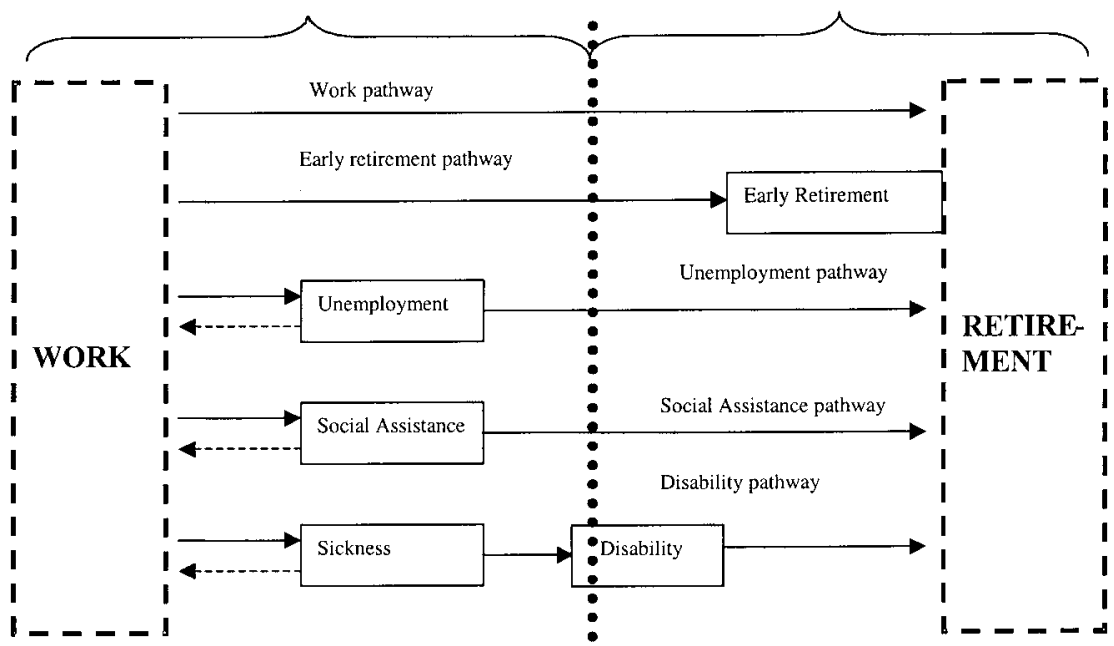

Figure 1.1 Exit pathways from the labour force.

Source: adapted from Aarts, Burkhauser and de Jong (1996)

The model in Figure I.I suggests that the load on the different pathways depends on the labour market on the one hand and the social security programmes on the other. Consequently, the analysis of exogenous pressures and labour market exclusions through the disability pathway must take account of labour market conditions related to institutional settings, labour market policies and disability policies.

\section{The labour market and the disability pathway}

Push factors

Pressures on the disability pathway caused by developments related to the labour market are often referred to as 'push factors', 'demand factors', or 'the exclusion model' (e.g. Marklund, I995; Rupp and Stapleton, I998; Stattin, I 998). Push factors include stagnating economic growth, rising unemployment, poor working conditions, increasing demand for flexible workers and changing labour market structures, e.g. where some economic sectors are declining while others are growing. Such conditions foster exclusion from the labour market either because it involves a decrease in the demand for certain groups of workers or because certain groups of workers cannot meet the demands of the labour market. For instance, rising unem- 
ployment leads to marginalisation and exclusion from the labour market and thus to a rise in disability applications and awards (e.g. Frick and Sadowski, I996; Rupp and Stapleton, I998). Similarly, structural changes make the demand for workers in certain sectors decrease, and if redundant workers cannot find employment in other sectors, it is likely that they sooner or later will be excluded from the labour market. As a result, more workers will leave the labour market through the disability pathway if it is available to them.

\section{The consequences of exogenous pressures}

The exogenous pressures of globalisation, new social risks and population ageing and their likely consequences for the load on the disability pathway can be understood in the light of the exclusion model.

Globalisation and the increasing competition from low-wage nations constitute a structural change in that the demand for unskilled production workers in particular will fall relative to the demand for other workers. The workers made redundant in the resulting adaptation will probably result in increased labour market exit and thus in pressure on the disability pathway.

Changing risks structures will probably also result in pressure on disability programmes. When the labour market calls for more flexible workers the number of people that cannot meet these demands and eventual become work disabled will increase. Changing family patterns and the rise in numbers of single earners and single parents may also raise the demand for disability benefits. Single-income families are more vulnerable to job loss than dual-income families, which in turn means that more people become at risk of being marginalized or excluded from the labour market.

Ageing is a structural change that alters the supply of labour. However, its effects may be contradictory. On the one hand, health problems and thus the demand for sickness and disability benefits increases with age, meaning that the pressure on the disability pathway will increase as the labour force grows older. On the other hand, when the number of working age people decreases, the (relative) demand for workers will increase meaning that employment prospects of older workers will improve. In other words, it is likely that the future labour market will absorb more workers with health problems.

The exogenous pressures on welfare states consequently seem to cause pressure towards more labour market exclusion and an increased use of the disability pathway. Certainly, this pressure is not solely directed at the disability pathway, but towards exit pathways in general. Yet it seems plausi- 
ble that pressures from ageing populations and the demand for a flexible work force more than other exogenous pressures will be directed towards the disability pathway. While age and too high job demands are known to be associated with poor health and work absence (for job demands see Karasek and Theorell, I990), marginalization caused by changing family patterns and unemployment in the production sector is not, at least in its origin, related to health problems.

In summary, the exogenous pressures seem to create pressure towards both exit and inclusion. Consequently, what are needed are responses that can prevent exclusion caused by globalisation, new social risks and an ageing workforce and at the same time provide a sufficient supply of labour. Before we turn to this question, we need to look at how conditions related to the disability pathway may influence the extend to which exit pressures translate into retirement via disability programmes.

\section{Disability programmes and the disability pathway}

Generous disability programmes have long been blamed for the growing number of disability beneficiaries throughout the western world. It is said that generous disability benefits and wide eligibility criteria reduce peoples' incentives to work; workers are pulled out of employment, so to speak. Yet explanations have also been sought elsewhere. The organisation and financial structure of benefit programmes and their impact on those who are not workers, e.g. employers and supervisors, have been emphasised. In addition, the problem of defining and verifying 'work disability' may facilitate excessive use of the disability pathway.

\section{Pull factors}

The assumption that people choose between work and cash transfers is at the heart of the pull model: benefit receipt is preferred to work when the utility from benefit receipt exceeds the utility from work. ${ }^{2}$ It follows that the number of disability beneficiaries grows when benefits are raised. Of course, while advocates of the importance of pull factors claim that such factors influence disability benefit awards, they normally also acknowledge the importance of other factors (e.g. Aarts and de Jong, I992; Stapleton et al., I998).

Like generous benefits, wide eligibility criteria may contribute to the use of the disability pathway. Eligibility criteria may concern requirements 
about age, work record, and work disability. When these criteria are relaxed the number applicants rises (e.g. Frick and Sadowski, I996; Stapleton et al., I998).

While criteria such as age and work record are easy to verify, a concept such as work disability, a crucial criterion in all disability programmes, is much harder to determine as it involves a great deal of subjectivity. Normally, the work disability criterion involves both a medical and an occupational aspect. In addition to a medical examination, the medical assessment must often rely on subjective patient statements, for example about pain and functional abilities. The occupational assessment is also not based on facts, there are no objective answers to questions such as whether the impairment leads to reduced work capacity, and if so, how much is the capacity for work or the earnings potential reduced. Thus, not only do both steps of the assessment involve discretion and subjectivity, they also involve several factors. This opens up the door for several pressures.

One such pressure stems from the applicants. A person who considers himself disabled will normally feel a legitimate right to disability benefit. There is a strong case, therefore, that applicants present their cases in the contact with medical experts in a way that enhances the chance of being awarded some form of benefit. That is, symptoms and disabling consequences will be emphasised more than conditions indicating work ability (Stone, 1984).3 Secondly, the medical experts involved also exert pressure because they are adverse to risk: if in doubt, they prefer to wrongly award (or recommend) benefit to an ineligible applicant rather than wrongly deny benefit to a deserving person (ibid.).

A third type of pressure stems from what is called the increasing medication of our society: more and more 'events' are related to medical circumstances such that the disability programmes tend to cover a wider spectrum of events (Lindqvist, I995). Whether or not this development is rooted in technological progress in the medical sphere, an expansion of the medical profession or the interplay between the medical sphere and other sectors in society, it probably widens the concept of disability in the population, adding to the push factors. This tendency will raise the claim for disability benefits.

Finally, it should be noted that the discretion involved in the application procedure allows pressures from the economic and political context to show through in the number of disability benefit awards. For instance, in many disability programmes, the applicant's occupational earnings potential is assessed by comparing the earnings potential of an imaginary person of the same age and educational background, with the income that the applicant is 
expected to earn in his present condition. When unemployment rises, the number of potential jobs available to the applicant decreases, and so do the potential earnings, hence that the applicant is considered to be more disabled. Consequently, the number of people eligible for benefit increases (e.g. Aarts and de Jong, I996). In a similar vein, when discretion is present, gatekeepers and administrative units may alter their award practice under influence of the signals they receive from the political level (Berkowitz and Burkhauser, 1996).

The financial and organisational structure of disability programmes

The vague boundaries of the category of disability make the inflow into disability programmes sensitive as to how they are organised and financed. The financial aspects concern the financial responsibility of benefit payments, while the organisation of programmes concerns those with whom the daily and overall administrative responsibility rests.

Just as the level of benefits may influence workers' incentives to apply for disability benefit, the financing of benefits may influence how other actors behave. For example, in the United States, state governments finance social assistance whereas the federal government finances the disability programme (SSI). Consequently, state governments have an incentive to promote enrolment in the disability benefit programme rather than the social assistance programme (Livermore, Stapleton and Zeuschner, I998).

One important qualitative difference between pull and push factors should be noted. Globalisation, changing social risks and ageing directly influence the future need for disability benefits, because they increase labour market exclusion and, as concerns ageing, also reduce the supply of labour. Being exogenous these pressures arise no matter what we do (but we can influence their consequences). In contrast, push factors such as the benefit level, eligibility criteria, the organisation and financing of disability programmes and the vague category of disability have been in play for a long time and therefore do not increase the pressure. Thus, maybe with the exception of the 'medication of society', which may increase in magnitude, the pressure from these sources will not significantly alter unless the policies themselves are changed. Yet they exert pressure and hold the potential for alleviating the negative consequences of the exogenous pressures. 


\section{Disability policy responses}

The exogenous pressures seem to call for a policy that at the same time limits the inflow into disability programmes and increases the labour supply. The above discussion suggests that two different strategies are at hand: a labour market strategy and a disability benefit strategy, and a combination of these.

A disability benefit strategy may limit exit through the disability pathway in three ways. Firstly, disability programmes can be made less generous by tightening eligibility criteria and reducing the level of benefits. Secondly, the organisational and financial structure of disability programmes can be altered, which may reduce the incentives of various actors involved in the programme administration to award benefits. A third possibility, related to the two others, is to change the medical and occupational disability assessment and thereby (try to) reduce subjectivity and discretion in the award procedure. However, given the nature of the disability concept, it may be difficult to reduce subjectivity and discretion, at least without significantly reducing the justification of the programmes. That is, standardized and objective procedures will yield 'incorrect' or 'unfair' results when in reality no available instruments exist that can objectively determine 'disability' and 'occupation potential'.

All three elements in the disability strategy may reduce the inflow into disability programmes either because fewer people are allowed benefit or because benefits become less attractive. To a certain extent this may lead to an increased supply of labour because some people with health problems, who would otherwise enter the disability pathway, will return to or remain in employment. However, many people will probably be unable to work and use either another exit pathway or leave the labour force without benefits. This is the Achilles' heel of the disability benefit strategy because the work potential of these people is left unused, and because it reflects a failure of the welfare state as people in need are denied support.

In contrast to the disability benefit strategy, the labour market strategy aims to reduce the need for exit pathways in the first place. This may happen either by preventing work-related disability from occurring, for example, by introducing measures that improve the work environment and reduce the risk of work-related injuries, or by facilitating workers' attachment to the work pathway despite their health problems. The latter policy, which is the focus of this book, involves two types of instruments. One type of instrument provides jobs with reduced demands that can be met by people with a reduced capacity for work. Workplace adaptations, wage subsidies, job- 
protection legislation and quota jobs are all examples of such measures. Another type of instrument seeks to improve the person's work capacity through measures such as job training and education and thereby increase the chance of finding ordinary employment. Thus, the labour market strategy may both limit the inflow into disability programmes and increase the labour supply: when people with health problems are kept in the work pathway, they are not a burden on disability programmes. In addition, the labour market strategy may in part solve the welfare failure of the disability benefit strategy because it may help unfit workers, who are ineligible for disability benefit, back to work.

\section{The objective of this book}

The Netherlands and Denmark are two prominent examples of nations that have applied a labour market strategy to improve the attachment of disabled people to the work pathway and reduce the inflow into disability programmes. Whilst these two nations have shared these goals, they have pursued them by very different means. The Netherlands has followed a policy that exhibits strong Conservative elements. Employers have considerable obligations for the integration of disabled people into the labour market. Employers' dismissal of sick-listed workers is difficult and costly, and individual employers are obliged to finance sickness benefits for up to a year and disability benefits for up to five years when a worker becomes disabled. With this strategy, it is expected that employers prevent sickness absenteeism and promote the reintegration of sick-listed workers.

Denmark, in contrast, has cultivated a typical Social Democratic approach with an extensive public responsibility. Public authorities have been delegated greater responsibilities and incentives to use active instruments such as vocational rehabilitation and subsidised employment in order to increase the employment of disabled people. At the same time the responsibility of employers is limited. They do not contribute to the financing of sickness benefits (except for the first two weeks of sick leave) and disability benefits, and the dismissal of sick-listed workers is easy. What is more, the participation of employers in the integration of disabled people is voluntary.

This book aims to shed light on the consequences of such crossnational differences in the responsibility of employers and the public sector. How does the division of responsibilities influence disabled peoples' chances of becoming and remaining attached to the labour market? What are the benefits and drawbacks of, respectively, a Social Democratic and a Conservative 
disability policy? And to what extent are these different strategies able to meet increasing pressures towards disability exit? By putting forward answers to these questions this book will hopefully be of inspiration in the search for effective disability policy.

\section{How to study the outcomes of disability policies}

The study of how national disability policies affect the welfare of citizens has so far received little attention. Despite a myriad of single-nation studies, little is known about the importance of institutional structures. There are two reasons for this. As we will see in Chapter 2, the majority of studies focus on how work-disabled peoples' individual characteristics affect their labour market attachment rather than focusing on the influence of institutional conditions. In addition, as institutional conditions seldom vary within nations, single-nation studies are often ill-equipped to shed light on how institutional conditions influence citizens' welfare. Crossnational studies, on the other hand, are nearly always based on macro-level data and therefore run into problems related to overdetermination and the 'black box problem' (see e.g. Esping-Andersen, 1993; Goldthorpe, I997). Overdetermination occurs when the number of potential explanatory variables is relatively high for the number of cases, which often is the case when the explanatory variable of interest is the 'nation' or 'benefit scheme'. In other words, when the analytical unit consists of a handful of nations, very few competing explanations can be simultaneously tested. The black box problem is present when a statistical significant association between two variables does not in itself explain the mechanisms through which the explanatory variable affects the dependent variable. For example, a negative association between public expenditure on active labour market measures and disability benefit awards says nothing about how active measures reduce disability benefit awards.

The analysis in the present study is based on a combined research strategy where macro- and micro-level analyses are combined (Ragin, I987, chapter 5). At the macro level an analysis of the Dutch and Danish disability policies aims to uncover important crossnational institutional differences. The consequences of these institutional differences are then studied using comparative micro-level data on 900 Dutch and Danish long-term sick-listed workers. ${ }^{4}$ With this research strategy it is possible to reduce some of the problems that previous disability studies have encountered. That is, the choice of two very different national disability policies should provide the institutional 
differences that many single-nation studies lack. With only two nations included, it should also be possible to enlighten more of the black box problem that prevails many of the comparative macro-level studies. The use of micro-level data solves the problem of overdetermination, in so far as important institutional structures can be operationalised at the micro level. Finally, the use of micro data allows for a rather detailed investigation of the mechanisms that influence peoples' attachment to the labour market pathway. A spin-off effect, therefore, is that the book sheds light not only on the importance of institutional conditions but also on other factors that may determine the labour market attachment of people with health problems.

\section{The structure of this book}

How can we explain why different disability policies yield different outcomes in terms of the integration of work-disabled people? In which ways do institutional conditions influence whether a work-disabled person remains attached to the work pathway or enters the disability pathway? To answer these questions, Chapter 2 looks at four important research traditions to see how they explain the labour market integration of work-disabled people and to what extent their theoretical assumptions are supported by empirical findings. Although the medical, economical, public policy and sociological research disciplines provide significant insights and findings, I argue that studies within these disciplines only integrate insights from other approaches to a very limited degree. Chapter 3 seeks to reduce this gap by proposing a model for labour market integration that draws on insights from different theoretical traditions.

Chapter 4 uses macro indicators to put the development of Dutch and Danish disability policies during the last few decades into a broader context. Like other Western nations the Netherlands and Denmark were hit by the economic recession during the I970s and I 980 . In the Netherlands this gave rise to a massive exit through the disability benefit scheme, whereas in Denmark the labour market exit was more limited and more evenly spread among different exit routes. However, although Denmark, like the Netherlands, recovered well from the recession, the disability benefit roll kept growing during the I990s. In other words, both nations have experienced pressures on the disability pathway, and in both nations labour market exit and the integration of work-disabled people have been on the political agenda.

Even though the political aims have been the same in the two nations, the 
political strategies have been very different. A comparison of the Dutch and the Danish disability policies in Chapters 5 and 6 reveals that Denmark has cultivated the existing policy. That is, while more emphasis has been put on vocational rehabilitation, the responsibility for labour market integration and the payment of sickness and disability benefits remains predominantly a public matter. In contrast, in the Netherlands these responsibilities have to a large extent been transferred from the public domain and the social partners to the individual employer.

The consequences that these differences have for the integration of workdisabled people are analysed in Chapters 7 and 8. The central question is: how does a policy that favours the responsibility of public authorities, respectively the responsibility of employers, influence the labour market integration of work-disabled people? I argue that an extensive employer responsibility makes it costly for Dutch employers to substitute sick-listed workers, and, therefore, also relatively attractive to reintegrate sick-listed workers. In contrast, in Denmark it is attractive for employers to substitute sicklisted workers because the responsibility of the employers is limited. The findings in Chapter 7 suggest that the institutional differences influence how integration takes place. The Dutch policy seems to prevent dismissals of long-term sick-listed workers, facilitate employers' efforts of retaining their sick-listed workers and thus advance reintegration with the old employer. In contrast, the Danish policy promotes integration with a new employer. The sick-listed workers are often dismissed, they often participate in publicly provided vocational rehabilitation measures and they often return to work with a new employer.

The institutional differences also appear to affect the outcomes of the integration process. The analysis in Chapter 8 indicates that the Dutch policy is more effective in returning the long-term sick-listed workers to work than the Danish policy. In Denmark the limited responsibility of employers leads to many dismissals and thus to the marginalization of sick-listed workers, who despite publicly provided reintegration instruments often remain without work. In contrast, as Dutch employers cannot dismiss sick-listed workers, employers have strong incentives to facilitate their return to work, even though the capacity for work of these workers may be considerably reduced.

The drawback of the Dutch policy seems to be that it makes the labour market integration of people without attachment to an employer difficult as it tends to create insider-outsider problems. Furthermore, even though the Dutch policy is effective in returning the long-term sick-listed to work, the Danish policy seems in the first place to be more effective in reducing the number of long-term sick-listed people. Accordingly, there are fewer long- 
term sick-listed workers that need to be integrated into the labour market. I suggest that this may be related to the fact that the Danish disability policy makes it less socially acceptable and more economically risky to be off work because of health problems. Taken together the Dutch policy therefore seems no more effective in integrating work-disabled people into the labour market than the Danish policy. The two nations' policies seem in other words to be associated with different advantages and drawbacks that make it difficult to provide an overall ranking of the two policies.

The final chapter, Chapter 9, looks at the Dutch and Danish policies from another angle and addresses two questions. Did the policy changes during r990s succeed in limiting entry into the disability benefit schemes, and to what extent will the two nations' disability policies be able to alleviate future welfare state pressures? The development in the number of disability benefit awards indicates that the Danish strategy of enhancing public authorities' incentives to apply active rather than passive measures has been much more successful than the Dutch strategy of improving employers' incentives to limit work disability. It is however likely that this conclusion underestimates the effects of the Dutch reforms. These reforms probably prevented further increases in the number of benefit awards that would otherwise have occurred because of an ageing population and increasing work demands. It also seems likely that changes to the unemployment policy during the I990s reduced exit through the social assistance and unemployment insurance pathways. This may have increased the load on the disability pathway, such that the Dutch disability reforms would probably have had a more visible effect without the changes to the unemployment policy.

Globalisation, changing social risk structures and ageing populations will probably cause more work disability in the coming years. Given the institutional differences between the Dutch and Danish disability policies, I argue that the Danish policy is better able than the Dutch policy to deal with increasing welfare state pressures. This is based on the assumption that the limit of the Dutch employer cost strategy has been reached. Further increases in employers' costs that will follow from rising welfare state pressures may therefore reduce the labour market integration of outsiders, as it will become even more expensive for employers to employ people with a high disability risk. At the same time increasing employer costs will not significantly counteract the increased marginalization of insiders that follows from increasing welfare state pressures. This is because considerable incentives for employers to retain sick-listed workers are already in place.

In Denmark an increased load on the disability pathway will not raise the individual employers' costs, and therefore not worsen the situation of out- 
siders. The increasing welfare state pressures may however increase the marginalization of insiders because the limited employer costs limit their incentives to retain sick-listed workers. The negative consequences, however, will to some extent be offset by a declining labour supply that follows from the ageing of the population. Thus, even though both policies suffer from drawbacks, future pressure towards policy changes will probably be more pronounced in the Netherlands than in Denmark. 


\section{The Integration of Disabled People: What Do We Know?}

In order to better understand how disability policies influence citizens' attachment to the labour market, we need to identify the conditions and mechanisms that determine why some people with health problems remain in the labour force whereas others enter a disability programme. The purpose of this and the next chapter is, therefore, to put forward a theoretical framework that can guide an analysis of the consequences of Dutch and Danish disability policies. This chapter reviews some of the literature within the area of the labour market integration of sick-listed workers. Against the background of this review the following chapter presents a theoretical model of labour market integration.

Labour market reintegration of sick-listed workers has been the subject of research in several research disciplines. This review includes contributions from four major disciplines: I) clinical studies; 2) economics; 3) public policy; and 4) sociological studies. Including research from several different disciplines makes it possible to propose a theoretical model for labour market integration based on a broad range of insights; as will be shown in the following sections, a multidisciplinary research strategy is necessary in order to illuminate the question of which factors affect the labour market integration of work-disabled people. One problem with this approach, however, is that the quantity of literature on work disability and labour market attachment is overwhelming. Therefore this review focuses mainly on studies with populations (workers sick-listed for more than $\mathrm{I}_{3}$ weeks) and outcome measures (return to work) that are close to those used in the analyses in this book. ${ }^{2}$

\section{Clinical studies}

One important aspect of the clinical approach to research on work disability concerns the relationship between pathology, impairment, functional limitations and work disability. Activation of the body's defence and coping 
mechanisms may be caused by an injury or a disease. This 'stage of active pathology' will result in an impairment, that is, a physiological or anatomical loss or other abnormality, which in turn can lead to functional limitations (Nagi, I965; Nagi, I969; Waddell, I987; Aarts and de Jong, I992). Functional limitations can be classified at different levels, e.g. at the level of organs and systems or at the level of activities and tasks. Work disability exists when the inability to perform certain activities or tasks interferes with the demands of the job, that is, activities or tasks that have to be carried out in order to perform a certain job.

In the area of low back pain, this so-called clinical pathology approach has focused on the physical as well as psychological dimensions of work disability. On the physical side, severe physical damage in the lower back is assumed to cause work disability. On the psychological side, work disability is thought to arise because of clear secondary psychopathological complications, such as depression or a number of psychosomatic disorders often labelled "compensation neurosis" (Frank et al., I995).

Another important aspect of clinical research on this subject concerns the psychosocial and behavioural aspects of low back pain (see, e.g. Frank et al., I995). This approach recognises that the clinical pathology approach, where physical or psychological abnormalities are assumed to cause work disability, is too narrow. Rather, it stresses the interplay between disease, psychological factors and social conditions that may cause individual differences in perceptions and responses to diseases (Waddell, I987). This approach overlaps to some extent with the micro-sociological approach, discussed below, where the emphasis is on the costs and benefits associated with the role of being disabled versus the role of worker.

\section{Return to work of chronic low back pain patients}

A number of clinical studies have investigated how different variables influence the resumption of work of long-term sick-listed workers with chronic low back pain (Hildebrandt et al., I997; Hazard, Bendix and Fenwick, I991; Gatchel, Polatin and Mayer, I994; Lacroix et al., I990; Kummel, I996; Sandström, I986; Sandström and Esbjörnsson, I986; Werneke, Harris and Lichter, I993; Veerman and Palmer, 200I). ${ }^{3}$ They all used the return to work as the outcome variable, but varied in several other dimensions, for instance, with regard to the duration of sick leave on admission to the study, the duration of the followup period and whether or not the subjects participated in a rehabilitation programme.

Each of these studies illustrates the importance of returning to work of 
one or more of the following groups of variables: socio-demographic variables, e.g. sex, age, education, and marital status; medical variables, e.g. muscle strength, lifting capacity, pain conditions; and psychological variables such as personality disorders, e.g. symptoms of depression or schizophrenia, and coping strategies. Furthermore, a few studies also include jobrelated variables, e.g. occupation, exposure to stress and physical job demands; and lifestyle variables, e.g. smoking habits. The findings of these studies are summarised in Table 2.I.

These studies provide mixed evidence. Several studies find that psychological conditions have a significant influence on the probability of returning to work (Hazard, Bendix and Fenwick, I99I; Kummel, 1996; Sandström, I986; Sandström and Esbjörnsson, I986; Werneke, Harris and Lichter, I993). For example, the patient's expectation about the possibility for resuming work as well as the patient's understanding of his or her medical condition appears to affect the probability of their returning to work. However, other studies find that psychological variables are insignificant (Lacroix et al., I990; Veerman and Palmer, 200I).

An almost similar picture applies to the importance of medical, socio-demographic, job-related and lifestyle conditions. These variables are found to be significant in a few of the studies, but in several cases this is not supported by findings from other studies. It is worth noting, however, that the findings of the highest quality study (in terms of the number of cases, the number of variables and the statistical method) by Veerman and Palmer (200I) provides strong support for the importance of socio-demographic variables (age), medical variables (e.g. pain intensity) and job-related variables (e.g. physical job demands). The study gives no support for the influence of lifestyle variables (smoking).

That socio-demographic, medical and job-related variables may be of importance for the return to work of people with health problems is supported by studies from the other reviewed disciplines and studies of populations other than long-term sick-listed workers with low back pain. Firstly, most of the reviewed studies from other research disciplines support the importance of age, with older people having a below-average chance of returning to work (e.g. Aarts and de Jong, I992; Marklund, I995; Oleinick, Gluck and Guire, I996; Johnson, Baldwin and Butler, I998). In general, neither marital status nor gender is found to be of importance. Secondly, some of the reviewed studies from other research disciplines also support the influence of health conditions (e.g. Aarts and de Jong, 1992). Thirdly, in a review of work disability and return to work, Krause and Lund (2002) conclude that workplace characteristics such as physical and psychological job demands 
Table 2.1 Selected clinical studies concerning the importance of socio-demographic, medical, psychological,job-related and lifestyle variables.

Study Cohort $\begin{aligned} & \text { Multi- } \\ & \text { size } \quad \text { variate } \\ & \text { analysis }\end{aligned}$

\begin{tabular}{lll}
\hline $\begin{array}{l}\text { Hildebrandt et al. 70 Yes } \\
\text { (1997) }\end{array}$ & $\begin{array}{l}\text { Socio-demographic:type of occupation (unskilled workers } \\
\text { have a low RTW rate) }\end{array}$
\end{tabular}

\begin{tabular}{lll}
\hline Hazard,Bendix $258 \quad$ No & Medical: physical endurance significant at 1-year but not at \\
and Fenwick (1991) & & 2-year followup (people with high physical endurance have a \\
& high RTw rate) \\
& Psychological: schizophrenia index and intelligent index sig- \\
& nificant at 1-year but not at 2-year followup \\
& Life style: Cigarette smoking significant at 1-year but not at 2- \\
& year followup (smokers have a low RTw rate)
\end{tabular}

\begin{tabular}{lccl}
\hline $\begin{array}{l}\text { Gatchel, Polatin } \\
\text { and Mayer (1994) }\end{array}$ & $152 \quad$ Yes & $\begin{array}{l}\text { Psychological: no positive findings: diagnosed psycho- } \\
\text { pathology (axis I clinical disorders and axis Il personality dis- } \\
\text { orders) had no influence on the RTW }\end{array}$ \\
\hline Sandström (1986) $52 \quad$ No $\quad \begin{array}{l}\text { Medical:previous back pain (low RTW rate) and the consump- } \\
\text { tion of analgesics (low RTW rate) } \\
\text { Psychological: } \text { Reported fatigue at the end of the working day } \\
\text { (low RTW rate) }\end{array}$
\end{tabular}

\begin{tabular}{lll}
\hline Sandström and $52 \quad$ Yes & Psychological: patient's attitude towards possibility \\
Esbjörnsson (1986) & & for work resumption (people not expecting work resumption \\
& & have low RTW rate)
\end{tabular}

\begin{tabular}{lll}
\hline $\begin{array}{l}\text { Lacroix et al. } \\
\text { (1990) }\end{array}$ & Noo No $\quad \begin{array}{l}\text { Psychological: non-organic signs had no influence on } \\
\text { the RTw. Patient's understanding of their medical condition } \\
\text { (people with a good understanding have a high RTW rate) }\end{array}$
\end{tabular}

\begin{tabular}{lccl}
\hline $\begin{array}{l}\text { Kummel } \\
(1996)\end{array}$ & 717 & No & $\begin{array}{l}\text { Psychological: non-organic signs (people with } \\
\text { non-organic signs have a low RTW rate) }\end{array}$ \\
\hline $\begin{array}{l}\text { Werneke, Harris } \\
\begin{array}{l}\text { and Lichter (1993) } \\
\text { non }\end{array}\end{array}$ & 183 & No & $\begin{array}{l}\text { Psychological: } \text { non-organic signs (people with non- } \\
\text { organic signs have a low RTW rate) }\end{array}$ \\
\hline
\end{tabular}

\begin{tabular}{lll}
\hline Veermanand & 2,106 Yes & Socio-demographic: age (older people have a low \\
Palmer(2001) & (from & RTw rate) \\
& Six & Medical: self-perceived work ability and pain intensity \\
& nations) & ty increases the RTw rate) \\
& Psychological: mental health index had no influence on the \\
& RTw \\
& Job-related variables: workers with low physical job demands \\
& and workers not separated from their employer during the \\
& first 4 months after reporting sick had a high RTw rate in three \\
& nations \\
& Lifestyle: smoking has no influence on the RTw
\end{tabular}

Note: RTW is an acronym for return to work. 
and company culture and organisation are of great importance in the return to work rate and the duration of work disability.

\section{The effects of interventions}

Apart from research on predictors for the resumption of work for long-term sick-listed workers, a considerable number of studies have been published concerning the effectiveness of clinical interventions aimed at the return to work.

Weide, Verbeek and Tulder (I997) produced a very comprehensive literature review of the vocational outcomes of clinical interventions for low back pain patients. The review was limited to randomised clinical trial studies with the return to work or other vocational status measures as the outcome variable. With regard to chronic low back pain (work incapacity lasting more than I 2 weeks), the authors considered the following interventions: antidepressants, non-steroidal anti-inflammatory drugs, spinal manipulation, back school or back exercises, behavioural therapy and case management methods. A number of interventions were not considered because no positive evidence of efficacy on the functional ability of patients with low back pain was found in the literature. Thus, studies on the use of analgesics, muscles relaxants, epidural and intra-articular injections, traction, orthoses, biofeedback, acupuncture and transcutaneous nerve stimulation were excluded. The authors only found limited evidence of efficacy for one type of intervention: the use of antidepressants. No randomised clinical trials were found on case management, and no evidence was found for the efficacy of other interventions.

These rather limited findings do not necessarily imply that various types of clinical interventions do not have an effect. The lack of evidence may result from a lack of studies fulfilling the scientific criteria used by the authors. As note above, no case management studies performed as a randomised clinical trial were found. Furthermore, although one study with positive results concerning the use of non-steroidal anti-inflammatory drugs and one study with positive outcomes of spinal manipulation were found, these studies were considered to be of low quality and it was therefore concluded that there was 'no evidence'. Accordingly, if the scientific criteria are relaxed, it could be concluded that non-steroidal anti-inflammatory drugs and spinal manipulation may have a positive effect.

Weide, Verbeek and Tulder did not consider vocational interventions oth-

er than case management. Two other literature reviews by Battie (I992) and Frank et al. (1996) considered so-called workplace-based interventions, 
such as modified work, light duties and changes in working hours. Frank et al., (I996) noted that 'there are no rigorously controlled studies showing reductions in long-term or recurrent occupational low back pain disability that can be unequivocally attributed to specific workplace interventions'. However, they mention several 'before-and-after' studies showing positive effects of workplace-based interventions. Most of these studies concern early interventions for low back pain patients after a relatively short period of work disability (only one study concerns patients with chronic low back pain: Crook, 1994). The positive effect of modified work is generally supported by the findings of other studies concerning other diagnosis groups (for an overview see, Krause, Dasinger and Neuhauser, I998; Krause and Lund, 2002.)

To sum up, the clinical studies of long-term sick-listed workers with low back pain that have been reviewed here provide mixed evidence about the effects of psychological, medical, socio-demographic, job-related and lifestyle conditions. Studies from other research areas and studies of other populations, however, suggest that these variables may be influential. Only modest evidence of the effect of clinical interventions on the rate of return to work for patients with chronic low back pain has been established. Evidence suggests that workplace-based interventions may have a positive effect on the return to work.

\section{Economic studies}

The observation of a simultaneous decline in male labour force participation and the growth in the number of people entering the disability programmes led economists to enter the area of integration of disabled people (Berkowitz and Johnson, 1974; Parsons, I980; 1984; Haveman and Wolfe, r984a, I984b; Emanuel, de Gier and Konijn, r987; Wolfe and Haveman, I990; Aarts and de Jong, I992). These studies were closely related to traditional labour supply models, where a micro-economic theoretical framework is applied. This approach has been used in most studies following Berkowitz and Johnson (I974).

The basic assumption of most micro-economic models is that a work-disabled person can choose between two options, work and transfer income, e.g. disability benefit. Thus, given the health status of the work-disabled, the outcome will depend on the utility derived from each of the two options. If utility in the work option exceeds utility in the benefit option, the work-disabled person will resume work and vice versa. The utility derived from the 
benefit option may depend on a number of factors, e.g. the disability benefit amount, health status, attitudes, etc., and the utility in the work option may depend on wages, health status, education and age, etc.

In addition to economic incentives, economists have also been interested in the economic cost and benefits of various programmes. Within this area of research, the effects of various vocational rehabilitation programmes have been investigated. Participation in vocational rehabilitation may increase the likelihood of the return to work of sick-listed workers in two different ways. Firstly, it may increase functional ability and work capacity and thereby increase employment opportunities. In economic terms, vocational rehabilitation can be said to increase the human capital of the afflicted person. This type of vocational rehabilitation may be job training, different types of courses and education. Secondly, certain other types of vocational rehabilitation instruments, such as wage subsidies, workplace adoptions and job placement, may create job opportunities for people with reduced work capacity.

\section{Economic incentives and the return to work}

Several economic studies have analysed the return to work of work-disabled people (de Jong, I987; Aarts and de Jong, I992; Butler and Worrall, I985; Meyer and Viscusi, I995; Oleinick, Gluck and Guire, I996; Johnson, Baldwin and Butler, I998). All of these studies applied multivariate statistical techniques, and some of them corrected for unobserved heterogeneity. The studies differed in respect to study populations. De Jong (1987) and Aarts and de Jong (I992) concerned long-term sick-listed workers, whereas the other studies concerned worker injury compensation beneficiaries. In those studies, sick leave was caused by job-related circumstances, and in most cases they included cases of short-term sick leave. In addition to these differences, the studies also differed in other important aspects; such as outcome measurement and how economic incentives were measured. The findings of the studies are summarised in Table 2.2 .

These studies provide mixed evidence. On one hand, the studies of de Jong (I987) and Aarts and de Jong (I992) give no, or only very limited, support for the effect of economic incentives. Thus, they find no effect of variables directly related to different income streams associated with work relative to the disability benefit option. Aarts and de Jong (I992), however, found that 'other household income' affects self-rated work capacity, which in turn affects the probability of a return to work. On the other hand, the workers' compensation studies suggest in general that economic incentives do have 
Table 2.2 Selected economic studies concerning the importance of economic incentives.

\begin{tabular}{|c|c|c|c|c|}
\hline Study & Population & $\begin{array}{l}\text { Outcome } \\
\text { measure }\end{array}$ & $\begin{array}{l}\text { Incentives } \\
\text { measured as }\end{array}$ & $\begin{array}{l}\text { Effect of eco- } \\
\text { nomic incentives }\end{array}$ \\
\hline $\begin{array}{l}\text { De Jong } \\
(1987)\end{array}$ & $\begin{array}{l}2,418 \text { sickness } \\
\text { beneficiaries } \\
\text { incapacitated } \\
\text { for } 17 \text { weeks }\end{array}$ & $\begin{array}{l}\text { RTW versus } \\
\text { disability } \\
\text { benefit } \\
\text { award }\end{array}$ & $\begin{array}{l}\text { Disability benefit } \\
\text { amount divided } \\
\text { by foregone } \\
\text { earnings }\end{array}$ & $\mathrm{No}^{1}$ \\
\hline $\begin{array}{l}\text { Aarts and } \\
\text { de Jong (1992) }\end{array}$ & $\begin{array}{l}2,534 \text { sickness } \\
\text { beneficiaries } \\
\text { incapacitated } \\
\text { for } 17 \text { weeks }\end{array}$ & $\begin{array}{l}\text { RTW versus } \\
\text { disability } \\
\text { benefit } \\
\text { award }\end{array}$ & $\begin{array}{l}\text { Three measures: } \\
\text { expected income } \\
\text { loss and expected } \\
\text { leisure gain of } \\
\text { disability benefit } \\
\text { award, and other } \\
\text { household income }\end{array}$ & $\begin{array}{l}\text { No effect of } \\
\text { income loss and } \\
\text { leisure gain. }{ }^{1} \\
\text { Other household } \\
\text { income reduces } \\
\text { RTW }^{1}\end{array}$ \\
\hline $\begin{array}{l}\text { Butler and } \\
\text { Worall (1985) }\end{array}$ & $\begin{array}{l}\text { Temporary } \\
\text { total worker's } \\
\text { beneficiaries } \\
\text { with low back } \\
\text { injuries }^{2}\end{array}$ & $\begin{array}{l}\text { Duration of } \\
\text { benefit claim }\end{array}$ & $\begin{array}{l}\text { Benefit level and } \\
\text { pre-injury wage }\end{array}$ & $\begin{array}{l}\text { No significant } \\
\text { effect (but tendency } \\
\text { of higher benefit } \\
\text { levels and lower } \\
\text { wages increases the } \\
\text { duration of benefit } \\
\text { claim) }\end{array}$ \\
\hline $\begin{array}{l}\text { Meyer and } \\
\text { Viscusi (1995) }\end{array}$ & $\begin{array}{l}6,822 \text { Temporary } \\
\text { total worker's } \\
\text { beneficiaries }\end{array}$ & $\begin{array}{l}\text { Duration of } \\
\text { benefit claim }\end{array}$ & Benefit level & $\begin{array}{l}\text { Higher benefit } \\
\text { levels significantly } \\
\text { increase the dura- } \\
\text { tion of benefit claim }\end{array}$ \\
\hline $\begin{array}{l}\text { Oleinick, } \\
\text { Gluck and } \\
\text { Guire (1996) }\end{array}$ & $\begin{array}{l}2,184 \text { worker's } \\
\text { compensation } \\
\text { beneficiaries, } \\
\text { back injuries, } \\
\text { incapacitated } \\
\text { more than } 8 \text { weeks }\end{array}$ & $\begin{array}{l}\text { Time to first } \\
\text { return to } \\
\text { work }\end{array}$ & $\begin{array}{l}\text { Weekly compen- } \\
\text { sation amount }\end{array}$ & $\begin{array}{l}\text { Results interpreted } \\
\text { as relatively low } \\
\text { replacement rates } \\
\text { promote RTW }\end{array}$ \\
\hline $\begin{array}{l}\text { Johnson, } \\
\text { Baldwin and } \\
\text { Butler (1998) }\end{array}$ & $\begin{array}{l}\text { 3,731 permanent } \\
\text { partial worker's } \\
\text { compensation } \\
\text { beneficiaries }\end{array}$ & RTW & Replacement rate & $\begin{array}{l}\text { Relatively low replace- } \\
\text { ment rates increase } \\
\text { the RTW }\end{array}$ \\
\hline
\end{tabular}

Note: RTW is an acronym for return to work.

1 Estimated in a structural model where economic incentives may affect self-perceived work incapacity that affects the RTW

2 No information on cohort size 
an effect. This includes the study of back beneficiaries who were work disabled for more than 8 weeks (Oleinick, Gluck and Guire, I996). Krueger (1990), who also studied workers' compensation beneficiaries also found support for an effect of economic incentives (referred from Loeser and Hernserlite, I995).

These differences in findings may be associated with institutional differences. Thus, the lack of an incentive effect in the Dutch study may be caused by the fact that almost all beneficiaries are entitled to full wages. It has been estimated that in 1990,95 percent of all workers were entitled to full wages during sick leave (Aarts and de Jong, I992). In contrast, replacement rates are generally considerably lower in the United States. In the study by Johnson, Baldwin and Butler (I998), beneficiaries had an average replacement rate of 69 percent.

\section{The effects of vocational rehabilitation}

In the United States, there is a long-standing tradition of applying cost-benefit analysis to public-funded programmes, including vocational rehabilitation programmes. This tradition is rooted in a need to justify the cost effectiveness of programmes - that generated benefits exceed programme costs and economic analysis was applied as early as the 1920 s to evaluate vocational rehabilitation programmes (Lewis et al., I992).

In general, vocational rehabilitation is found to yield positive net future earnings (see e.g. Lewis et al., I 992; Dean and Dolan, I99 I; for an overview see Berkowitz et al., I988). It may be problematic, however, to generalize findings in cost-benefit studies to the question of the return to work of sicklisted workers. Positive net benefits in terms of increased earnings for participants may not necessarily reflect that these people return to work more often than nonparticipants. Instead, increased earnings among those who resume work could be the cause.

Some studies have considered the effect of vocational rehabilitation on the resumption of work or the likelihood of reporting fit for duty (Bergendorff et al., 1997; Hennessey and Muller, I995; Veerman and Palmer, 200I; Heshmati and Engström, 200I; Frölich, Heshmati and Lechner, 2000; Høgelund and Holm, 2002). The findings of these studies are summarized in Table 2.3.

Apparently the evidence of these studies is mixed. Thus, in some studies (Bergendorff et al., 1997; Veerman and Palmer, 200I; Høgelund and Holm, 2002) vocational rehabilitation measures have no or a negative effect, whereas in others they have a positive effect (Heshmati and Engström, 
Table 2.3 Selected economic studies concerning the importance of vocational rehabilitation (VR).

Study Population $\begin{aligned} & \text { Outcome Analyticalmethod Effect of } V R \\ & \text { measure }\end{aligned}$

\begin{tabular}{lllll}
\hline $\begin{array}{l}\text { Bergendorff } \\
\text { et al.(1997) }\end{array}$ & $\begin{array}{l}\text { 6o,ooo people } \\
\text { sick-listed for } \\
\text { 6o days or more }\end{array}$ & $\begin{array}{l}\text { Reporting } \\
\text { fit for work }\end{array}$ & $\begin{array}{l}\text { Simple logistic } \\
\text { regression }\end{array}$ & $\begin{array}{l}\text { VR measures includ- } \\
\text { ing education and } \\
\text { job training: } \\
\text { negative RTW effect }\end{array}$ \\
\end{tabular}

\begin{tabular}{|c|c|c|c|c|}
\hline $\begin{array}{l}\text { Hennessey } \\
\text { and Muller } \\
(1995)\end{array}$ & $\begin{array}{l}4,400 \text { people } \\
\text { entitled to disa- } \\
\text { bility benefit in } \\
1980 / 81\end{array}$ & $\begin{array}{l}\text { Time to RTW } \\
\text { and time to } \\
\text { medical } \\
\text { recovery, } \\
\text { respectively }\end{array}$ & $\begin{array}{l}\text { Competing risk } \\
\text { (Cox) survival model }\end{array}$ & $\begin{array}{l}\text { Job or vocational } \\
\text { training and general } \\
\text { education, respec- } \\
\text { tively, have a positive } \\
\text { effect on the RTW' }\end{array}$ \\
\hline $\begin{array}{l}\text { Veerman } \\
\text { and Palmer } \\
(2001)\end{array}$ & $\begin{array}{l}2,106 \text { workers } \\
\text { from six nations } \\
\text { sick-listed for } \\
13 \text { weeks or } \\
\text { more }\end{array}$ & $\begin{array}{l}\text { RTW after } 1 \\
\text { and } 2 \text { years, } \\
\text { respectively }\end{array}$ & $\begin{array}{l}\text { Simple logistic } \\
\text { regression }\end{array}$ & $\begin{array}{l}\text { Education and train- } \\
\text { ing: no or a negative } \\
\text { effect after } 1 \text { year and } \\
\text { a positive effect in one } \\
\text { nation after } 2 \text { years.' }\end{array}$ \\
\hline
\end{tabular}

\begin{tabular}{|c|c|c|c|c|}
\hline $\begin{array}{l}\text { Heshmati } \\
\text { and } \\
\text { Engström } \\
(2001)\end{array}$ & $\begin{array}{l}8,839 \text { people } \\
\text { sick-listed for } \\
6 \text { o days or more }\end{array}$ & $\begin{array}{l}\text { RTW status } \\
\text { at end of sick } \\
\text { leave }\end{array}$ & $\begin{array}{l}\text { Estimation of simul- } \\
\text { taneous probit model } \\
\text { of participation in VR } \\
\text { and probability of } \\
\text { RTW.Correction for } \\
\text { unobserved hetero- } \\
\text { geneity }\end{array}$ & $\begin{array}{l}\text { VR measures inclu- } \\
\text { ding job training and } \\
\text { education: positive } \\
\text { RTW effect }\end{array}$ \\
\hline
\end{tabular}

\begin{tabular}{|c|c|c|c|c|}
\hline $\begin{array}{l}\text { Frölich, } \\
\text { Heshmati } \\
\text { and Lechner } \\
\text { (2000) }\end{array}$ & $\begin{array}{l}6,287 \text { people } \\
\text { sick-listed for } \\
60 \text { days or more }\end{array}$ & $\begin{array}{l}\text { Employment } \\
\text { status at end } \\
\text { of sick leave }\end{array}$ & $\begin{array}{l}\text { Matching of VR } \\
\text { participants with } \\
\text { otherwise similar } \\
\text { non-participants }\end{array}$ & $\begin{array}{l}\text { In general VR has no } \\
\text { positive employment } \\
\text { effect. Education and } \\
\text { passive measures (e.g. } \\
\text { test of work capacity) } \\
\text { have a negative effect. } \\
\text { Workplace-based VR } \\
\text { (e.g.job training) has } \\
\text { the largest employ- } \\
\text { ment effect among the } \\
\text { considered measures, } \\
\text { but the effect is insig- } \\
\text { nificant compared to } \\
\text { no rehabilitation }\end{array}$ \\
\hline
\end{tabular}




\begin{tabular}{|c|c|c|c|c|}
\hline $\begin{array}{l}\text { Høgelund } \\
\text { and Holm } \\
(2002)\end{array}$ & $\begin{array}{l}443 \text { workers } \\
\text { sick-listed for } 13 \\
\text { weeks or more } \\
\text { with low back } \\
\text { pain }\end{array}$ & $\begin{array}{l}\text { Time to } \\
\text { RTW with } \\
\text { the old and } \\
\text { with a new } \\
\text { employer, } \\
\text { respectively }\end{array}$ & $\begin{array}{l}\text { Piecewise constant } \\
\text { hazard model. } \\
\text { Simultaneous est- } \\
\text { imation of dura- } \\
\text { tion until parti- } \\
\text { cipation in VR } \\
\text { and duration } \\
\text { until RTW. Cor- } \\
\text { rection for unob- } \\
\text { served heterogeneity }\end{array}$ & $\begin{array}{l}\text { Education: insignif- } \\
\text { icant net RTW effect }\end{array}$ \\
\hline
\end{tabular}

Note: RTW and VR are acronym for return to work and vocational rehabilitation, respectively. Measures without vocational elements, e.g. medical and social rehabilitation, are not considered.

1 Findings regarding vocational rehabilitation measures that are logically tied to the RTW are not referred.

200I; Hennessey and Muller, I995). This divergence persists if we look only at the highest quality studies, where problems of unobserved differences between vocational rehabilitation participants and non-participants are encountered. It should nevertheless be noted that the contents of 'vocational rehabilitation' differs in these studies, resulting in the fact that in some studies a positive effect of one measure, e.g. job training, may be mixed with the negative effects of other measures, e.g. education.

In summary, the reviewed literature provides no clear answers with regard to whether or not vocational rehabilitation has a positive employment effect among sick-listed workers. Thus, the findings suggest that certain measures may have a positive effect whereas other measures such as education on average may have no or even a negative effect.

\section{Public policy studies}

This section considers research related to how social security schemes affect the labour market attachment of disabled people. These studies consider the importance of the legal and formal characteristics of relevant schemes, as well as how they are administered.

Different dimensions may affect the attractiveness of social security schemes and how they are used, including how such schemes are organised, how they are financed and how the benefits are provided (see Kvist, I999).

The organisational dimension concerns how schemes are administered. Questions such as who has the overall administrative responsibility and 
who has the daily responsibility are addressed. From this perspective, the actors involved, their interests, and their power becomes crucial because actors involved in the administrative process are assumed to pursue their own interest through their administration policy.

Benefit schemes may be financed in different ways, including public (tax) funds, employer contributions, worker contributions, and by private insurance funds. The financial structure will provide different economic incentives for those involved, which in turn may lead to differences in how the schemes are used.

The main issues related to the provision of benefits are eligibility criteria and benefit formulae. Eligibility criteria regulate the group of people covered by the scheme, e.g. all citizens or only workers, and the conditions which must be fulfilled in order to be eligible for the benefit, e.g. a 50 percent reduction of the earnings capacity. The benefit formulae specify how the benefit is calculated, i.e. the amount of benefit and the duration of benefit payments (Kvist, I999). In addition, the administration of eligibility criteria and benefit formulae may have an important influence on access to benefit programmes.

These various aspects of organisation, financing, and administration may influence whether sick-listed workers stay out of work, and may thereby affect whether (or when) they return to work. Thus, in contrast to conditions such as health status and the level of unemployment that may influence the opportunity and possibility to enter and stay on the work pathway, the organisational and administrative characteristics of social security schemes affect the opportunity and possibility to enter and stay on the disability pathway.

\section{The importance of benefit schemes}

These social policy dimensions have been studied frequently, and in general it is found that they have a significant influence on how sickness benefit, rehabilitation and disability schemes are used. Compared to clinical and economic studies, however, those within the public policy sphere are often faced with methodological problems due to the fact that the organisational and financial structures and the benefit provisions often are the same within a nation. Consequently, researchers often have to rely on within-nation time series or crossnational comparisons, and therefore conclusions are often based on a combination of data and contextual interpretations. There are, however, some studies concerning within-nation differences in the administration of benefit provisions based to some extent on multivariate 
quantitative analyses. Selected public policy research findings are summarized below in Table 2.4 .

Some of the findings may need some additional comments. The study by Hetzler and Eriksson (I98I) illustrates the influence that the organisational structure may have for the use of disability schemes. In Sweden, the insurance funds, which are part of the public sector, can apply for disability benefit on behalf of their clients. In the I970s, the number of awarded disability benefits initiated by insurance funds increased, whereas the number of awarded benefits initiated by beneficiaries decreased. The authors stress that this development was facilitated by the institutional structure. The fact that the supervisory body for the sickness and disability benefit schemes, Riksförsäkringsverket, was also the supervisory body for the insurance funds made it possible for the Riksförsäkringsverket to use insurance funds applications as a strategy to stop the growth in the level of sickness absenteeism.

Aarts and de Jong (I 998) stress that the financial structure of social security schemes may have contributed to the high number of disability beneficiaries in the Netherlands. The fact that the sickness and disability schemes used to be funded by national pay-as-you-go contributions implied that those in charge of the administration - employers and workers - did not directly bear the economic costs of an increase in the use of the sickness and disability schemes. Aarts and de Jong also found the incentive structure and administrative practices to be the reason why public vocational rehabilitation has been almost completely absent in the Netherlands. In I993, on a per-capita basis, Germany spent 42 times more on vocational rehabilitation than the Netherlands (ibid.).

Findings concerning the provision of benefits primarily relate to four issues: disqualification for continued sickness benefits, eligibility for disability benefit, differences in the daily administration of benefit schemes and different schemes serving the same purpose.

Disqualification for sickness benefit seems to be a rarely studied topic. De Jong (1987) included the number of medical check-ups performed during the first 5 months of the sick leave as a proxy for the rigidity of the work incapacity check. The variable had no significant effect on the likelihood of return to work among long-term sick-listed workers. Closely related to regulations concerning disqualification for benefits are regulations of 'followup' procedures. Followup procedures include the administrative evaluation of how the case should be treated in order to facilitate a return to work, such as an assessment of the need for various vocational rehabilitation instruments. Palmer (I990) describes an experiment with an early followup in a large Swedish production company. The results suggest that there may be a positive return-to-work effect of early screening. 
Table 2.4 Selected public policy studies concerning the importance of how benefit schemes are organised and financed and how benefits provisions are stipulated and administered.

Dimension Type ofanalysis Finding
and study

Organisation

Hetzler and Timeseries, Organisational structure allowed central authorities in

Eriksson (1981) contextual Sweden to use the disability benefit scheme to reduce long-term sickness absenteeism

\begin{tabular}{lll}
\hline $\begin{array}{l}\text { Aarts and } \\
\text { de Jong (1996a) }\end{array}$ & Contextual & $\begin{array}{l}\text { Organisational structure with social partners in charge } \\
\text { of daily administration allowed Dutch employers to use } \\
\text { the disability scheme to shed labour }\end{array}$ \\
$\begin{array}{l}\text { Aarts and } \\
\text { de Jong (1996b) }\end{array}$ & Contextual \\
$\begin{array}{l}\text { Wadensjö and } \\
\text { Palmer(1996) }\end{array}$ & Contextual \\
\hline $\begin{array}{l}\text { Financing } \\
\begin{array}{l}\text { Aarts and } \\
\text { de Jong (1998) }\end{array}\end{array}$ & Contextual & $\begin{array}{l}\text { Pay-as-you-go financing of Dutch sickness and disability } \\
\text { benefits gave limited incentives to limit benefit awards at } \\
\text { the administrative level }\end{array}$ \\
\hline
\end{tabular}

Benefit provision and program administration

De Jong (1987) Quantitative, Proxy for the harshness in the Dutch assessment of multivariate disqualification for continued sickness benefit receipt was insignificant for RTW

Palmer(1990) Case study Experiment in large Swedish company suggests that early followup in cases of sick leave may enhance the RTW

\begin{tabular}{lll}
\hline $\begin{array}{l}\text { Jacobs, Kohli } \\
\text { and Rein (1991) }\end{array}$ & $\begin{array}{l}\text { Time series, } \\
\text { contextual }\end{array}$ & $\begin{array}{l}\text { A significant drop in disability benefit awards followed } \\
\text { tightening of German eligibility criteria }\end{array}$ \\
$\begin{array}{l}\text { Frick and } \\
\text { Sadowski } \\
\text { (1996) }\end{array}$ & $\begin{array}{l}\text { Time series, } \\
\text { contextual }\end{array}$ & \\
\hline $\begin{array}{l}\text { Aarts and } \\
\text { de Jong (1992) }\end{array}$ & Quantitative & $\begin{array}{l}\text { Disability benefit applicants' unemployment problems } \\
\text { were taken into consideration in the Dutch disability } \\
\text { benefit assessment. It is estimated that in 1980 29 to } \\
\text { 48 percent of the new beneficiaries were able to perform } \\
\text { a suitable job }\end{array}$ \\
\hline
\end{tabular}




\begin{tabular}{lll}
$\begin{array}{l}\text { Koitz, Kollman } \\
\text { and Neisner } \\
(1992)^{1}\end{array}$ & Quantitative & $\begin{array}{l}\text { Administration of the U.S.government disability benefit } \\
\text { scheme differed across states }\end{array}$ \\
\hline $\begin{array}{l}\text { Bengtsson } \\
\text { (1987) }\end{array}$ & $\begin{array}{l}\text { Quantitative, } \\
\text { multivariate }\end{array}$ & $\begin{array}{l}\text { Significant differences in the regional administration of } \\
\text { the public disability benefit scheme when account was } \\
\text { taken for various differences between regions }\end{array}$ \\
\hline $\begin{array}{l}\text { Van der Veen } \\
(1990)^{2}\end{array}$ & $\begin{array}{l}\text { Qualitative } \\
\text { (interview with } \\
\text { gate keepers) }\end{array}$ & $\begin{array}{l}\text { Dutch disability benefit gatekeepers applied own infor- } \\
\text { mal rules reducing the effect of changes in formal rules }\end{array}$ \\
\hline $\begin{array}{l}\text { Berkowitz and } \\
\text { Burkhauser } \\
\text { (1996) }\end{array}$ & $\begin{array}{l}\text { Time series, } \\
\text { contextual }\end{array}$ & $\begin{array}{l}\text { Significant drop between 1977 and 1980 in the number of } \\
\text { disability benefit award was probably causes by informal } \\
\text { political pressure on gatekeepers }\end{array}$ \\
\hline $\begin{array}{l}\text { Einerhand } \\
\text { et al. (1995) }\end{array}$ & $\begin{array}{l}\text { Crossnational, } \\
\text { contextual }\end{array}$ & $\begin{array}{l}\text { Suggest that the high disability rate in the Netherlands } \\
\text { compared to Belgium merely reflect differences in the } \\
\text { use of different benefit schemes }\end{array}$ \\
\hline
\end{tabular}

Note: RTW is acronym for return to work.

1 Referred from Berkowitz and Burkhauser (1996).

2 Referred from Aarts and de Jong (1996b).

The studies of eligibility criteria for disability benefits suggest that these criteria play a crucial role for the number of benefits that are awarded (Jacobs, Kohli and Rein, I991; Frick and Sadowski, I996; Aarts and de Jong, I992).

Several findings support the fact that administrative practices influence the number of awarded benefits. Thus, identical official rules yield different outcomes because of differences in the administration. This problem has also been shown to exist when one compares different regions in the same country (Berkowitz and Burkhauser, 1996; Bengtsson, 1987), in comparisons between gatekeepers in the same administration (van der Veen, I990), and in comparisons of the same scheme over time (Berkowitz and Burkhauser, I996).

Finally, it should be noted that the study by Einerhand et al. (I995) concludes that the high work incapacity rate in the Netherlands compared to Belgium merely reflects differences in the use of exit routes, i.e. disability benefit in the Netherlands and early retirement in Belgium. In relation to the analysis of the consequences of national disability policies, this aspect has farreaching consequences: not only should the functioning of the sickness and disability benefit schemes be taken into consideration, but also the effects of different possible exit schemes.

In conclusion, research suggests that legal-formal characteristics of sick- 
ness benefit and disability benefit schemes and how they are administered influence how these schemes are used. This may in turn affect the labour market attachment of work-disabled people. For some issues, such as eligibility criteria, evidence seems to be relatively clear: these conditions have an effect. However, in most other aspects the picture is rather blurred. It seems likely that financial and organisational conditions are very important, but their possible effects are difficult to measure. The same seems to be true when it comes to the impact of other social security schemes and other institutional conditions.

\section{Sociological studies}

Sociological research related to work disability and work resumption can be divided between studied based on a micro approach and those based on a macro approach. The micro, or behavioural, approach emphasises that factors related to the behaviour of the individual and the surroundings of the individual, apart from the impairment, will affect whether a sick person will become disabled. The macro perspective looks to societal conditions in terms of push factors, e.g. poor working conditions and unemployment, in order to explain the level of work disability.

\section{The micro approach}

Several behavioural characteristics may influence whether a work-disabled person with an injury or disease will return to work or end up in the disability benefit system. Consequently, people may perceive symptoms of the same impairment differently and act differently. Some people may find the incapacitating effects of a symptom to be modest, whereas others may find them severe. As a result, the extent of functional limitations may vary considerably from person to person, and thereby also the extent of work disability. Similarly, people may have different perceptions of the social, psychological and economics consequences of being 'disabled'.

The choice between work and disability can be understood as a choice between two different roles, a worker role and an illness, or disability, role. These roles are associated with different expectations as to how the 'sick' or the 'disabled', worker should behave (see Mechanic, I962; Nagi, I965; Lindqvist, I995). The sick or disabled person is exempted from the normal roles associated with work. However, other expectations are associated with the disabled role, seeking competent help, cooperating with such help, 
and resuming usual activities as soon as the condition permits (Nagi, I965; I969). Whether or not a work-disabled person will adapt to the disability role depends on, among other things, the severity of the illness, the individual's reaction to and perception of the situation, and the reactions to the individual of others.

A related approach stresses that health status may be affected by an individual's social network, including family members, close friends or colleagues, and social support, e.g. emotional, informative and practical support systems (Lindqvist, I995; Höög and Stattin, I995; Stattin, I998; Hanson I990). A social network and social support can be seen as resources that enable a work-disabled person to cope better with stress and demands, thereby increasing the potential for work resumption.

\section{Disabled role, social support and return to work}

Five empirical studies applying a micro-sociological approach were found. Four of the studies address the importance of the 'disability role' relative to long-term sick-listed workers and use return to work as the outcome variable (de Jong, I987; Aarts and de Jong, I992; Marklund, I995; Veerman and Palmer, 200I). The fifth study, which addresses the importance of social support, concerns a different population (people living in the country) and outcome variable (disability benefit award) (Höög and Stattin, I995). The findings of these studies are summarized in Table 2.5.

The studies support to a large extent the importance of 'the disability role' relative to the resumption of work. In general terms, de Jong (I987) and Aarts and de Jong (I992) found that people who are relatively strong oriented towards 'work' have a high probability of work resumption. Marklund (1995) found in a similar manner some evidence supporting that sick-listed workers may be socialised into the disabled role through their wives. The influence of 'work orientation' is not supported by Veerman and Palmer (200I).

The two studies of social support give only limited support to its importance. Veerman and Palmer (200I) found that the social support of longterm sick-listed workers' in their old job increases the return to work rate in only one out of the six nations included in the study. The authors also found that social support from other sources such as family member does not increase the probability of returning to work. The study by Höög and Stattin (I995) found indications that a reduction in social networks and social support may have a positive effect on the probability of citizens becoming enrolled in the disability benefit scheme (this effect was however only persis- 
Table 2.5 Selected sociological studies concerning the importance of social support and socialisation into the role as a disabled person.

\begin{tabular}{|c|c|c|c|c|}
\hline Study & Population & $\begin{array}{l}\text { Outcome } \\
\text { measure }\end{array}$ & $\begin{array}{l}\text { Measure of'role as } \\
\text { disabled' } \\
\text { (social support) }\end{array}$ & Findings \\
\hline De Jong (1987) & $\begin{array}{l}2,534 \text { sickness } \\
\text { beneficiaries } \\
\text { incapacitated for } \\
17 \text { weeks }\end{array}$ & $\begin{array}{l}\text { RTW versus } \\
\text { disability } \\
\text { benefit } \\
\text { award }\end{array}$ & $\begin{array}{l}\text { Psychological } \\
\text { inclination to } \\
\text { postpone RTW } \\
\text { measured as job } \\
\text { satisfaction and } \\
\text { how easily adop- } \\
\text { tion to a workless } \\
\text { situation has } \\
\text { happened }\end{array}$ & $\begin{array}{l}\text { Low job satisfac- } \\
\text { tion and easy adop- } \\
\text { tion to workless } \\
\text { situation reduces } \\
\text { the RTW }{ }^{1}\end{array}$ \\
\hline $\begin{array}{l}\text { Aarts and } \\
\text { de Jong (1992) }\end{array}$ & $\begin{array}{l}2,534 \text { sickness } \\
\text { beneficiaries } \\
\text { incapacitated for } \\
17 \text { weeks }\end{array}$ & $\begin{array}{l}\text { RTWversus } \\
\text { disability } \\
\text { benefit } \\
\text { award }\end{array}$ & $\begin{array}{l}\text { Job satisfaction } \\
\text { and work ethics } \\
\text { measured as vari- } \\
\text { ous aspects of atti- } \\
\text { tudes towards work }\end{array}$ & $\begin{array}{l}\text { Weak work ethics } \\
\text { and low job satis- } \\
\text { faction reduces } \\
\text { the RTW }\end{array}$ \\
\hline $\begin{array}{l}\text { Marklund } \\
\text { (1995) }\end{array}$ & $\begin{array}{l}2,030 \text { sickness } \\
\text { beneficiaries } \\
\text { incapacitated for } \\
\text { at least } 60 \text { days }\end{array}$ & $\begin{array}{l}\text { RTW }^{2} \\
\text { versus } \\
\text { disability } \\
\text { benefit } \\
\text { award }\end{array}$ & $\begin{array}{l}\text { Having a spouse } \\
\text { who receives dis- } \\
\text { ability benefit }\end{array}$ & $\begin{array}{l}\text { Spouse who recei- } \\
\text { ves disability bene- } \\
\text { fit reduces the prob- } \\
\text { ability of RTW }\end{array}$ \\
\hline $\begin{array}{l}\text { Höög } \\
\text { and Stattin } \\
\text { (1995) }\end{array}$ & $\begin{array}{l}52,000(61,000) \\
\text { people awarded } \\
\text { disability benefit } \\
\text { in } 1988 \text { (1993) } \\
\text { and a random } \\
\text { sample of citizens } \\
\text { in } 1988 \text { (1993) }\end{array}$ & $\begin{array}{l}\text { Disability } \\
\text { benefit award } \\
\text { versus no } \\
\text { benefit award }\end{array}$ & $\begin{array}{l}\text { Change of family } \\
\text { status from coha- } \\
\text { biting to single } \\
\text { prior to benefit } \\
\text { application is as- } \\
\text { sumed to indicate } \\
\text { a reduction in the } \\
\text { social network and } \\
\text { social support }\end{array}$ & $\begin{array}{l}\text { Evidence support- } \\
\text { ing that a reduction } \\
\text { in social support } \\
\text { increases the proba- } \\
\text { bility of a disability } \\
\text { benefit award (in } \\
1988 \text { data but not } \\
\text { in } 1993 \text { data) }\end{array}$ \\
\hline $\begin{array}{l}\text { Veerman and } \\
\text { Palmer (2001) }\end{array}$ & $\begin{array}{l}2,106 \text { workers } \\
\text { from six nations } \\
\text { sick-listed for } 13 \\
\text { weeks or more }\end{array}$ & $\begin{array}{l}\text { RTW after } \\
1 \text { and } 2 \text { years, } \\
\text { respectively }\end{array}$ & $\begin{array}{l}\text { Social support in } \\
\text { old job and support } \\
\text { from other sources } \\
\text { (including family } \\
\text { members). } \\
\text { Attitudes toward } \\
\text { work }\end{array}$ & $\begin{array}{l}\text { Social support in } \\
\text { old job increases } \\
\text { the RTw in one } \\
\text { nation (no effect in } \\
\text { the other nations) } \\
\text { No positive effects } \\
\text { of social support } \\
\text { from other sources } \\
\text { and attitudes to- } \\
\text { ward work }\end{array}$ \\
\hline
\end{tabular}

Note: RTW is an acronym for return to work.

1 Estimated in a structural model where measures of 'disabled role' affect self-perceived work incapacity, which affects RTW

2 This is an approximation. Marklund (1995) calls this group 'rehabilitated', and it consists of 85 percent who returned to work and 15 percent with another status, e.g. under education or outside the labour force. 
tent in one of the two studied cohorts, see Table 2.5). In sum, there is evidence suggesting that return to work may be affected by variables related to the micro-sociological approach, especially variables concerning the disability role.

\section{The macro approach}

The push perspective, or the 'exclusion model' (see, e.g. Kolberg, I99I; Marklund, 1995; Stattin, I998), stresses that work related factors and labour market conditions may push people out of the labour market and into work disability.

Push factors may be related to working conditions (and thus overlap with medical studies). For example, strenuous work and a poor work environment are often assumed to contribute to sickness and work disability. In a similar vein, an increasing level of job demands (e.g. demand for skills and flexibility) produces more work-disabled people because more people are unable to meet the stricter work demands.

Labour market conditions are also assumed to affect the level of work disability. It is often assumed that the level of unemployment affects the level of exit from the labour market and, correspondingly, the number of disability benefit recipients (see, e.g. Kohli and Rein, I99I; Marklund, I995; Höög and Stattin, I995; Stattin, I998). In relation to the labour market attachment of disabled people, a high level of unemployment is assumed to reduce the employment opportunities of people with a reduced capacity for work, and thereby reduce their labour market attachment.

Most studies applying a macro-sociological approach have investigated the influence of push factors, primary in terms of the level of unemployment, on the disability incidence rate among people in the labour force (see, e.g. Kolberg, I991; Piachaud, I986; Bengtsson, I987; Disney and Webb, I990; Holmes, Lynch and Molho, r99 I; Frick and Sadowski, I996; Höög and Stattin, I995). In general these studies provide strong support for the importance of push factors. The importance of push factors in relation to sick-listed workers has been investigated in several studies (Aarts and de Jong, I992; Johnson, Baldwin and Butler, I998; Johnson and Ondrich, I990; Veerman and Palmer, 200I). These studies use multivariate analyses and use the return to work or the duration of absence from work as the outcome variable. Table 2.6 summarises the findings of these studies concerning labour market conditions and working conditions (the findings of Veerman and Palmer, 200I are described in Table 2.I).

Based on these few studies, there seems to be some evidence that working 
Table 2.6 Selected studies concerning the importance of working conditions and labour market conditions for return to work among long-term sick-listed workers.

\begin{tabular}{lll}
\hline Study Population & $\begin{array}{l}\text { Outcome } \\
\text { measure }\end{array}$ & $\begin{array}{l}\text { Measure ofworking Findings } \\
\text { conditions/labour } \\
\text { marketconditions }\end{array}$
\end{tabular}

Working Conditions

\begin{tabular}{|c|c|c|c|c|}
\hline $\begin{array}{l}\text { Aarts and } \\
\text { de Jong } \\
(1992)\end{array}$ & $\begin{array}{l}\text { 2,534 sickness } \\
\text { beneficiaries } \\
\text { incapacitated } \\
\text { for } 17 \text { weeks }\end{array}$ & $\begin{array}{l}\text { RTW } \\
\text { versus } \\
\text { disability } \\
\text { benefit } \\
\text { award }\end{array}$ & $\begin{array}{l}\text { Firm specific } \\
\text { disability benefit } \\
\text { incidence rate }\end{array}$ & $\begin{array}{l}\text { Workers from com- } \\
\text { panies with a high dis- } \\
\text { ability benefit inci- } \\
\text { dence rate have a rela- } \\
\text { tively low probability } \\
\text { of RTW }\end{array}$ \\
\hline $\begin{array}{l}\text { Johnson, } \\
\text { Baldwin } \\
\text { and Butler } \\
(1998)\end{array}$ & $\begin{array}{l}\text { Permanent } \\
\text { partial worker's } \\
\text { compensation } \\
\text { beneficiaries } \\
\text { with back pain } \\
\text { (3,731 people) } \\
\text { and other } \\
\text { diagnoses } \\
\text { (5,900 people) }\end{array}$ & RTW & $\begin{array}{l}\text { Occupational sector } \\
\text { is a proxy for physical } \\
\text { demanding jobs }\end{array}$ & $\begin{array}{l}\text { Males employed in } \\
\text { sector with physical } \\
\text { demanding jobs have a } \\
\text { relatively low } \\
\text { probability of RTW }\end{array}$ \\
\hline $\begin{array}{l}\text { Johnson and } \\
\text { Ondrich } \\
(1990)\end{array}$ & $\begin{array}{l}\text { 1,040 } \\
\text { permanent } \\
\text { partial worker's } \\
\text { compensation } \\
\text { beneficiaries }\end{array}$ & $\begin{array}{l}\text { Duration } \\
\text { of absence } \\
\text { from work }\end{array}$ & $\begin{array}{l}\text { Occupational sector } \\
\text { is a proxy for physical } \\
\text { demanding jobs }\end{array}$ & $\begin{array}{l}\text { Weak evidence } \\
\text { suggesting that } \\
\text { physical demanding } \\
\text { jobs increase dur- } \\
\text { ation of work absences }\end{array}$ \\
\hline
\end{tabular}

Labour market conditions

\begin{tabular}{|c|c|c|c|c|}
\hline $\begin{array}{l}\text { Aarts and } \\
\text { de Jong } \\
(1992)\end{array}$ & Cf.above & Cf.above & $\begin{array}{l}\text { Individual estimates } \\
\text { of the probability of } \\
\text { becoming unem- } \\
\text { ployed respectively } \\
\text { the probability of } \\
\text { re-employment }\end{array}$ & No effect \\
\hline $\begin{array}{l}\text { Johnson, } \\
\text { Baldwin and } \\
\text { and Butler } \\
(1998)\end{array}$ & Cf.above & Cf.above & $\begin{array}{l}\text { Geographic region is } \\
\text { a proxy for the } \\
\text { unemployment } \\
\text { level }\end{array}$ & $\begin{array}{l}\text { A high level of unem- } \\
\text { ployment reduces the } \\
\text { RTw for non-back } \\
\text { diagnoses (effect is } \\
\text { insignificant for back } \\
\text { diagnoses) }\end{array}$ \\
\hline
\end{tabular}

Note: RTW is an acronym for return to work. 
conditions have a significant effect on the rate of return to work among the sick-listed workers, which is in accordance with the findings of clinical studies (cf. above). This is supported by studies finding that workers with good working conditions are more likely to remain employed than those with poor working conditions (Lund and Borg, I999; Boll, 200I). Surprisingly, the evidence about the importance of unemployment is mixed. On the one hand, studies suggest that unemployment affects the disability incidence rate among people in the labour force. On the other hand unemployment does not seems to influence whether or not sick-listed workers return to work. In other words, it appears that unemployment conditions affect whether people become work disabled in the first place, but once being work disabled the effect decreases. ${ }^{4}$

\section{Summary and conclusions}

Literature from four major research disciplines, clinical studies, economics, public policy and sociological studies have been reviewed in this chapter in order to provide an overview of how various factors affect the labour market integration of disabled people.

It is striking that the review does not offer clear answers to the question under study. Taken alone, none of the research disciplines seems able to offer a convincing explanation of why some people remain firmly attached to the labour market whilst others are not. Neither has the review revealed a handful of variables that beyond doubt are important factors. Each of the four described theoretical disciplines seems to contribute to an explanation of the phenomenon and several variables may be of importance; however, the review does not allow one to draw firm conclusions about the relative importance of various variables. Furthermore, in many cases variables that are found to be important in some studies are found to be insignificant in other studies.

There are a number of reasons why this current state of affairs is not as surprising as it might seem. Firstly, studies concerning factors related to one research approach seldom involve factors related to other approaches. This may imply that the effect of some or all of the factors found to be significant in one study would be altered if variables from other disciplines had been included. Secondly, most of the reviewed studies have been designed differently, making a comparison of findings doubtful or impossible. The major differences are: I) the population under study; 2) the length of the observation period; and 3) the definition of the outcome variable. Thirdly, different re- 
search approaches can, to some extent, demand different research strategies. Thus, as institutional characteristics, e.g. the organisational structure of social security schemes, are normally the same within a nation, a crossnational or study design over time would be needed. Finally, different methodological research strategies yield different types of evidence. National studies using survey and/or register data with a relatively high number of cases are able to produce 'firm' scientific evidence in the sense that the data can be analysed with multivariate techniques. Several independent competing variables might be tested against each other. This is often not possible or at least not possible to the same extent, in crossnational studies where 'nations' or 'social security systems' are treated as observations. As a consequence, research findings tend to be less conclusive.

While this analysis may suggest that it is impossible to be certain about significant effects of specific variables, it can instead be concluded that certain groups of variables seem to have an effect, and that the different theoretical approaches should be considered as complementary rather than competing. In other words, to understand better how disability policies affect the labour market attachment of disabled people, we need to unite the insights of the different theoretical views. 


\section{Bringing the Pieces Together: A Multidisciplinary Approach to Work Disability}

This chapter seeks to bring together the different insights of the clinical, economical, public policy and sociological approaches to work disability. This should help to improve our understanding of how conditions both at the individual level and at a structural level influence the labour market attachment of disabled people. That is, how do disabled people's individual characteristics and family relations lead to different outcomes? How do labour market conditions affect the labour market situation of work-disabled people? Which policy instruments may be of importance, and how do they interact with individual characteristics to produce diverse labour market outcomes?

\section{Choosing the approach}

Why do some individuals with health problems remain firmly attached to the labour market whilst of working age while others remain non-working for most or all of their adult years? In order to develop a framework that can shed light on this question, several issues and choices have to be dealt with. One issue concerns the type of model we should construct. What types of explanatory factors should be included? How should they be allowed to interact? And how should we define the outcome, 'labour market attachment'?

The literature review revealed that each of the four theoretical disciplines, the medical, economical, public policy, and sociological, may contribute to explain why the labour market attachment of people with health problems differs. The review also showed that studies in this field integrate insights and variables from other approaches only to a limited degree. This may lead to erroneous conclusions as important variables are omitted from the analysis. We should therefore demand that a labour market attachment model is eclectic; it should integrate insights from the four different research approaches by regarding them as complementary rather than competing. 
The analytical level applied in the different theoretical disciplines differs. Whereas medical and economic studies concentrate on the importance of individual level factors such as health status and replacement rates, public policy studies focus on the importance of macro-level conditions such as policy instruments. A comprehensive model must reflect variables at both levels. I will assume that macro-level conditions either directly or through various actors affect disabled individuals, which in turn determines their labour market attachment (this approach is called methodological individualism, see Elster, I985 and Colbjørnsen, I986). Therefore, I assume that the disabled person is someone making a choice between work and non-work. This choice will depend on the individual's resources such as health status and human capital, as well as resources and constraints imposed upon the individual by other people and structural conditions at the macro level. ${ }^{\mathrm{I}}$ For example, the provision of cash benefits directly affects disabled people, while quota jobs affect disabled people through employers' obligations to employ disabled people.

Having chosen to focus on disability policies and their impact on the labour market attachment of disabled people, it is necessary to specify how and through which mechanisms disability policies may affect actors in the disability area. To this end, I assume policies to be (combinations of) policy instruments, which may be defined as: ' ... the set of techniques by which governmental authorities wield their power in attempting to insure support and effect or prevent social change' (Vedung, I998:2 I). For instance, to achieve the goal of providing income protection to disabled people, the parliament may enforce an act stipulating that work-disabled people under certain conditions are eligible to a disability benefit financed through general taxes. Building on Vedung (1998) and Elmore (1987) I distinguish between four different types of policy instruments. Regulation consists of formulated rules and directives that demand receivers to act in accordance with the stipulations of the rules and directives. With economic means the government seeks to obtain a desired outcome by either handing out or taking away material resources in terms of cash or in-kind. Capacity-building instruments transfer money to individuals or agencies for the purpose of investment in future material, intellectually, and human resources. Information or moral suasion aims to make people act in a desired way through the transfer of knowledge, communication of reasoned argument, and persuasion.

Policy instruments differ in respect to the degree of constrain they involve (Vedung, I998). Regulation is more constraining for receivers than economic means and capacity-building instruments, which again are more constraining than information or moral suasion. For instance, quota regula- 
tions are more constraining than wage subsidies offered to employers employing disabled people, which are more constraining than campaigns with the aim of convincing employers to hire more disabled people. A principle advantage of regulation is that all actors independent of capacities and resources must comply. However, Elmore (1987) argues that in practice regulations are often characterised by incomplete compliance because avoidance of the regulation is associated with benefits. Economic means instruments do not suffer from these problems, but are instead burdened with problems of variation, i.e., as recipients differ in capacities, preferences and objectives, variations will exist in the degree to which policy goals are met. Clearly, this is also a problem for information and moral suasion. As capacitybuilding instruments involves investment, the problem is that it is uncertain if and when investment will yield returns.

Finally, before proposing a model, we need to specify more precisely what the model should explain. To be helpful the model must help us to understand why some individuals with health problems enter employment and remain employed during (most of) their working life, while others do not. ${ }^{2}$ Formulated in this way, the question can be split in two: what determines whether a non-working person with health problems resumes or starts to work? And what influences whether a working person with a limiting health condition continues to work? Even though the two questions are similar in the sense that they both concern the causes of 'work and non-work' they differ with respect to context. The first question concerns non-working people, whereas the second question concerns working people. In other words, the people in question are facing the world from two different positions, making their choices in different contexts. Consequently, the two outcomes may to a certain extent be determined by different conditions. The limited empirical evidence to hand supports this. Johnson, Baldwin and Butler ( I998), who studied workers' compensation beneficiaries, found that some variables both affect whether or not the workers return to work and the labour market attachment after returning to work, whereas other variables only influence one of the two outcomes.

\section{A model for the labour market integration of disabled people}

Whether or not a non-working person with a limiting health condition starts working is assumed to depend on conditions related to three spheres:

I) the disabled individual; 2) the employment conditions; and 3) the exit conditions (Figure 3.I). 


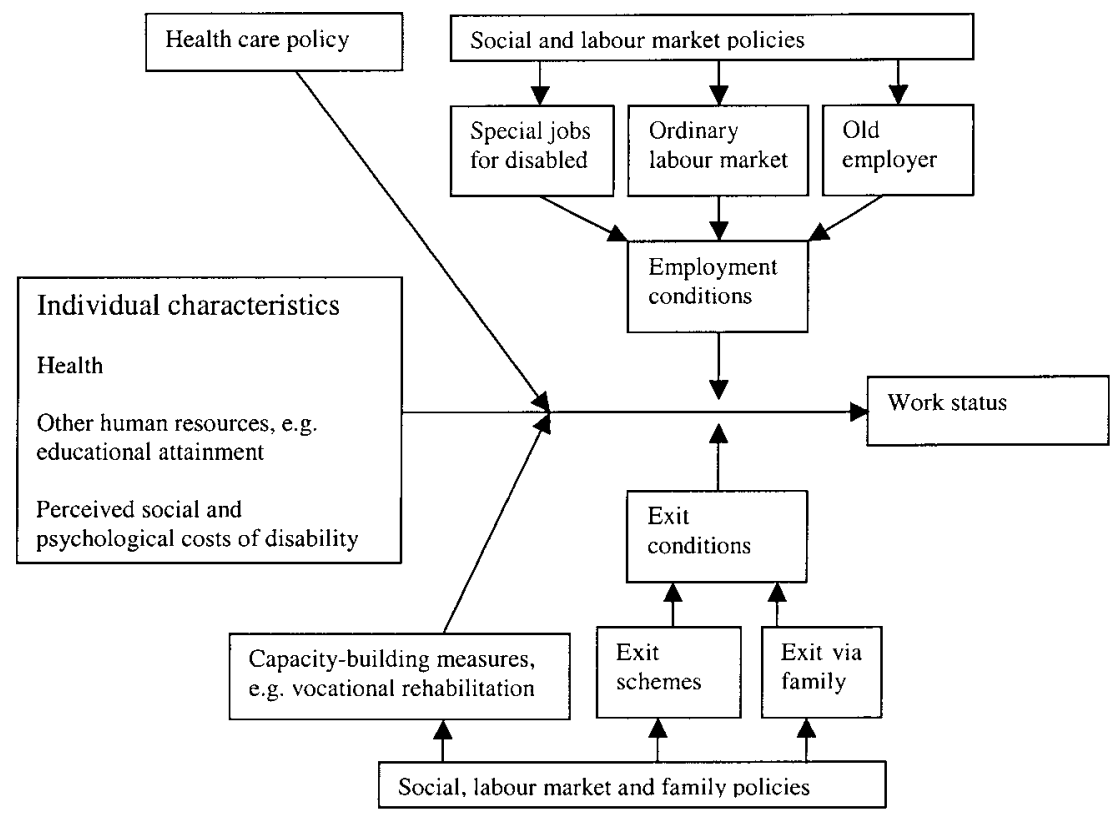

Figure 3.1 A model for the labour market status of non-working disabled people.

The individual possesses resources that directly influence whether the disabled person will begin to work. Resources comprise the disabled person's health condition and other personal and occupational skills. In addition to resources, the individual may perceive the situation of being work-disabled as more or less socially and psychologically costly, which will influence the inclination to work. A disabled person with relatively good health, good personal and occupational skills and who perceives it socially and psychologically costly to be disabled, is likely to become integrated into the labour market.

Independent of individual resources and perceptions, structural conditions in terms of employment and exit conditions may either facilitate or limit the possibility of starting working. Employment conditions make it more or less easy to a find job. It is possible to distinguish between employment opportunities in the ordinary labour market, in special jobs created for disabled people and, in the case of sick leave, in the same workplace as prior to becoming sick. Exit conditions deal with the economic possibility of staying out of work. This concerns the chance of entering and staying on various cash benefit schemes and the possibility of being supported by other family members. When employment conditions are good and exit conditions are 
poor, there is a high probability that a disabled person will start to work, and vice versa.

The effect of variables in the three groups of factors may be interrelated. For instance, it is possible that the state of health interacts with exit and employment conditions. If the health condition is poor it can be argued that the effect of other variables diminishes, whereas their effect may be considerable when the health condition is good. Similarly, individually perceived social and psychological costs of disability may interact with the exit conditions so exit opportunities only matter little if the disabled person attaches importance to work. The existence of such interaction effects are for some reason rarely investigated (or at least have virtually not been found in the literature reviewed in Chapter 2). The model is discussed in more detail below.

\section{Individual characteristics}

A person's health condition, viewed as functional capacities, is supposed to affect a disabled person's labour market integration in the following way. The pathological processes of an injury or disease will by definition involve an impairment, that is, a physiological or anatomical loss or other abnormality (e.g. Nagi, I 969:Io). An impairment will to varying degrees alter the ability to function. As a consequence the severity and development of an injury or disease becomes crucial for the level of the functional capacity, which in turn influences the ability to work.

In some cases the pathological process resulting from an injury or disease may develop over time and therefore the functional capacity and the possibility to start working may change as time elapses. The state of health may either directly affect the possibility of starting working because it reduces the ability to perform various job tasks or indirectly because it reduces the chance of participating in capacity-building measures such as vocational rehabilitation.

The health care system is an important structural condition that may affect the health status and thus indirectly influence whether or not a disabled person will begin to work. The availability of various medical treatments may improve the functional capacity directly (e.g. physical exercise) or through the pathological process (e.g. surgery), which in turn may affect the functional consequences of an impairment.

Human resources (in addition to health) determine the individual's value at the ordinary labour market, thereby affecting his or her employment opportunities. Following the human capital theory, formal educational attainment and skills acquired on the job are two important variables that influ- 
ence a person's productivity. Other important variables may relate to skills such as flexibility, responsibility and self-dependency. In the short run these resources will not change, but they may in the long run. Human resources may deteriorate. For instance, on-the-job skills tend to decrease with the time a disabled person has been out of work. At the same time, human resources may increase, e.g. a non-working person may improve his or her human resources through participation in capacity-building measures such as vocational rehabilitation. This suggests that access to measures such as adult education and vocational rehabilitation are important structural conditions.

At any point in time a non-working disabled person is assumed to choose between the role of 'worker' and 'disabled'. The two roles are associated with different expectations as to how the disabled person should behave (see, Mechanic, 1962; Nagi, I965; Lindqvist, 1995). The disabled person is exempted from expectations associated with the worker role but is instead expected to act as disabled, e.g. to seek competent help in order to improve their health. In other words, the disabled role is associated with social and psychological costs, and the higher these costs, the higher the chance that a disabled person starts to work. These costs are assumed to reflect the individual's attitudes toward work and disability. The perceived psychological and social costs of the disabled role are expected to be high when the disabled person attaches importance to work-related values (cf. Aarts and de Jong, I992).

In addition, a disabled person's perception of the costs of the disabled role relatively to the worker role is expected to depend on the reaction of significant others, e.g. their spouse, other family members and friends. If they accept that the individual is 'disabled', the social and psychological costs will be limited and so will the disabled person's inclination to work.

This suggests that the social and psychological costs of disability may also depend on the afflicted person's labour market attachment. Thus, we may expect that a sick-listed worker and his or her social network will adapt gradually to the workless situation concurrently with the duration of the sick leave. In other words, the sick-listed worker is socialized into the disabled role. Consequently, the social and psychological costs of disability and the likelihood that the worker will resume work decreases as time elapses. Following this argument, we should expect that the social and psychological costs of disability are very limited for disabled people with little or no prior labour market attachment. 


\section{Employment opportunities}

Employment conditions involve two dimensions: the availability of jobs and the characteristics of vacant jobs. To put it very simply, if there are no vacant jobs or if the vacant jobs do not match to the disabled person's capabilities it is unlikely that the disabled person will begin to work. It is possible to distinguish between job opportunities in three distinct spheres: I) in the ordinary labour market; 2 ) in connection with special jobs for disabled people; and, in case of previous labour market attachment, also 3 ) the old employer.

Disabled people without the possibility of returning to work with a previous employer are forced to look for a job in the ordinary labour market or a special job for disabled people. In the ordinary labour market, the possibility of finding a job will depend on the characteristics of the afflicted person (cf. above) and on the supply and demand for labour. The supply and demand of labour is a structural condition that constrains the individual's opportunity to become employed. Thus, independent of individual resources, the possibility of finding a job is low when labour supply exceeds demand and vice versa.

In an ideal world, an individual's health would be a resource that employers compare to other resources such as educational attainment. In practice, however, it is possible that employers discriminate against disabled people, i.e. otherwise qualified applicants may be disregarded simply because of their health status. Discrimination may, for instance, take place as 'statistical discrimination', that is, when employers recruit new workers they use 'disability' as a criterion to sort out workers they expect have a relatively low economic value (Sattinger, I998). Statistical discrimination will be especially prevalent in times with an excessive supply of labour. Discrimination should be considered as a structural condition that limits some disabled people's chance of finding employment.

Employment possibilities are also assumed to depend on the availability of special jobs for work-disabled people where job demands are adjusted to meet the work capacities of disabled people. Such jobs may comprise wagesubsidised jobs where employers in the open labour market are economically compensated for the relatively low productivity of the disabled people, quota jobs where employers are obliged to employ a certain number of disabled people, and sheltered or protected jobs in a protected environment not exposed to competition from the ordinary labour market (see Bergeskog, 200 I pp. I 5-20 for a detailed description).

Sick-listed workers may return to their old employer either in the same job or in another job, and their tasks may be the same as prior to the sick leave or 
they may be less demanding. The possibility for work resumption will depend on the employer and on firm-specific characteristics. If the sick-listed worker is unable to return to his old job, work resumption may only be feasible if the workplace is adapted or the worker is offered another job. The employer's willingness and ability to meet these conditions may vary. In certain cases, the employer may be willing to establish the necessary conditions, but may lack the possibilities to do so because no suitable job is available within the company. For example, all the jobs in the company may be too demanding and/or necessary job adaptations may be impossible to establish. In other cases, the employer may be reluctant to adapt working conditions or to offer the worker a new job even though it would be feasible. The employer may prefer another worker without (previous) health problems, e.g. a newly recruited substitute for the sick-listed worker. This choice may depend on the personal relationship between the employer and the sicklisted worker and on economic considerations. The latter may involve the employers' expectations about: when the sick-listed worker will return to work, how costly the waiting time will be in terms of e.g. payments of sickness benefit, how productive the sick-listed worker will be after returning to work, the productivity of a substitute, the costs of recruitment and on-thejob training of a substitute and how costly it is to dismiss the sick-listed worker.

Social and labour market policies make up structural conditions that influence disabled peoples' employment opportunities. The social policy may to varying degrees provide special jobs for disabled people through either regulations of quota jobs and sheltered jobs or economic means for employers hiring disabled people. In a similar manner, anti-discrimination regulations may, together with information and moral suasion, influence employers in the ordinary labour market to employ more disabled people. Regulations for the job protection of sick-listed workers, employers' obligations to e.g. adapt the workplace to help sick-listed workers return to work, and employers responsibilities for the financing of exit schemes may influence the extent to which they will retain sick-listed workers. Although these kinds of regulation may enhance the labour market attachment of sick-listed workers, they may also reduce the labour market integration of people with health problems without recent labour market attachment. As sick absenteeism is more costly, employers will be reluctant to recruit people with an above-average risk of falling ill, and as a consequence statistical discrimination may become more prevalent (see Chapter 8 ). While this behaviour may be rational at an aggregate level because disabled people are on average sicklisted more often than non-disabled people, it will at an individual level re- 
sult in discrimination against disabled people with little absenteeism due to sickness.

\section{Exit conditions}

Exit conditions refer to the availability of financial resources outside the labour market. When exit conditions are good, that is, when disabled people have easy access to financial resources, the likelihood of labour market integration is assumed to be low. Financial resources may stem from various sources such as accumulated capital, other family members' income and social security benefits.

Clearly, social security schemes make up structural conditions that affect disabled people. But in contrast to, for example, vocational rehabilitation and special jobs for disabled people that provide opportunities and resources that may promote labour market integration, exit schemes enable disabled people to stay outside the labour market, which may hamper their integration in the labour market.

To what extent social security schemes provide good exit conditions depends on the existence of cash benefit schemes, the possibility of entering and staying on these schemes and the amount of benefit received. This involves both legal formal aspects in terms of conditions that should be fulfilled to become eligible, how long the benefit can be received (criteria for entitlement and disqualification), the size of the benefit, and administrative aspects in terms of who are involved in the administration of the benefit scheme and how is it financed (see Chapter 2). When eligibility criteria are broad, benefits can be received for a long time, the amounts are high and the administrative policy is lenient, exit conditions are good.

The model's assumptions about how policies influence the labour market integration of disabled people can be summarised in the following way. Some policy instruments aim to increase the capacities of disabled people, which in turn may improve their employment prospects. Examples of such instruments are vocational rehabilitation and medical treatment. Other policy instruments regulate the supply of jobs for disabled people. In addition to sheltered jobs outside the ordinary labour market, these instruments influence employers' creation of jobs for disabled people. This may take place in regulations, e.g. quota jobs and job protection of sick-listed workers, by economic means, e.g. wage subsidies and grants for workplace adaptations, and through moral suasion, e.g. campaigns persuading employers to recruit disabled people. Finally, some instruments such as cash benefit schemes affect to what extent disabled people financially can afford to stay outside the labour market. 


\section{The labour market attachment of workers with health problems}

The mechanisms that determine whether a disabled person starts working and the mechanisms that determine whether a working person with health problems remains working may differ, but only to a certain degree. The former mechanisms concern non-working people, whereas the latter concern working people. This means that the individuals are located in different contexts, which may influence their choices. On the other hand, the mechanisms that determine the outcome of the two situations may share important aspects because both situations have the same outcome: work or nonwork. Consequently, we may expect similarities as well as differences.

It is reasonable to assume that individual characteristics (health status, human resources and the social and psychological costs of disability) also affect whether a worker with health problems continues to work. Workers with a relatively good health status and many human resources who consider the social and psychological costs of disability to be high are expected to have a high chance of remaining in work.

In the model for non-working disabled people (see Figure 3.I) employment conditions are related to three spheres: I) the ordinary labour market; 2) special jobs for disabled people; and 3 ) the former employer. In contrast to this, circumstances related to the present employer seem to be especially important for a working person because these circumstances have an immediate impact on the well being of the disabled person. This is not the case for conditions related to the ordinary labour market and special jobs for disabled people. For the same reason, exit conditions may also play a less dominant role. For example, job demands and possibilities for continued employment with the present employer affect the worker more directly than potential possibilities for economic support in an eventual case of unemployment. This is not to say that exit conditions do not matter, but stresses that we may expect them to be less important.

\section{Discussion and critique}

The model involves the simplification of a complex reality and important aspects may therefore be downplayed or overlooked. The discussion below seeks to repair this problem.

According to the micro-sociological approach to work disability, the choice between work and disability can be understood as a choice between the role as a worker and the role as a disabled person. In both stages of the 
model, this choice is affected by the disabled person's attitudes toward work and disability and the interplay between the disabled person and significant others such as family members and friends. However, other actors may also affect the psychological and social costs of choosing the role as disabled. In the non-working stage, for example, the reaction of actors within the health care system, e.g. the general practitioner and medical specialists, and the social security system, e.g. social security officers and vocational rehabilitation staffs, may reinforce or confirm the work-disabled person in the role as disabled and thereby reduce the likelihood of resuming work. For example, the emphasis on medical clarification and the resultant diagnosis may add to the perception of being disabled (Gerhardt, I989, Lindqvist, I995). In contrast to the assumptions made in the model above, the net effects of medical treatment and vocational rehabilitation do not, therefore, need to be positive. In the working stage, actors other than family members may affect the individual. For instance, the employer and colleagues may through their attitudes toward work and sick leave affect the disabled person's decision about whether or not to continue to work.

The 'medical' and 'social' system not only affects work-disabled people. Thus, a more general view would stress that individual norms and attitudes of all citizens are formed within the context of societal institutions. Disabled people, employers, medical staff and significant others are all affected by the social and cultural context in which they live. Similarly, the national economic situation will have an impact on all those involved through the context in which they act. More effects leading from societal variables to the individual's perception of the social and psychological costs of disability, and more societal variables and actors should be represented in the model shown in Figure 3.I.

Another type of critique relates to the use of methodological individualism as an underlying assumption of the model. It is assumed that structural conditions influence the outcome by imposing constraints upon actors, and providing them with certain opportunities, which influence their scope of choice. It also seems relevant, however, to include reverse effects, from micro-level actors to actors at the structural level, because such feedback mechanisms may help to explain the way welfare state policies change. If, for example, the exit conditions were extremely good, as would be the case if disability benefit amounts were equal to the applicant's previous wage and benefits were awarded to all applicants, the number of beneficiaries would probably swell. This would have damaging consequences for the supply of labour and the scope of financial resources allocated to the disability programme, which in turn would put pressure towards policy changes. As a 
consequence, politicians and other important actors involved in the policy area could choose to alter the disability policy, in this case by limiting access to the disability benefit scheme. Correspondingly, labour market conditions may lead to changes in the exit conditions. In times of sluggish labour markets, politicians and actors involved in the administration of exit schemes may adjust eligibility criteria to ease the social consequences associated with an excessive labour supply (Höög and Stattin, I995).

To sum up, in contrast to the often-fragmented theoretical understanding of disabled peoples' labour market integration that dominates the literature, the model proposed in this chapter seeks to incorporate different theoretical views and explanations of labour market integration. This should facilitate a broader and more comprehensive understanding of the mechanisms that may determine the labour market attachment of people with health problems. The model operates with two stages in the integration process, thereby recognizing that factors important in one stage may be of less importance in another. The model suggests that individual resources, labour market conditions and exit conditions determine the labour market attachment of disabled people. Consequently, policies in various areas affect disabled peoples' situation in the labour market. Furthermore, within one policy area identical goals can be pursued with different policy instruments. In the following chapters I argue that this is in fact true with respect to the Dutch and Danish disability policies. 


\section{Economic Miracles Bypassing Disabled People}

During the I960s and I970s the social security systems of advanced nations matured. Social insurance programmes covered more social risks and more people became eligible to still better benefits. When the economic downturn and an increasing supply of labour appeared in the I970s and I980s, the consequences were harsh. The number of people who temporarily or permanently left the labour market soared, and so did social security expenditure. The response to and consequences of this pressure varied across nations. This chapter uses national macro indicators to give a brief overview of the development of the Dutch and Danish welfare states over the last thirty years. Did the Netherlands and Denmark manage the economic crisis better than other European nations? To what extent were passive benefit awards and active labour market instruments used to manage the crisis? And to what extent have the Dutch and Danish 'miracle economies' during the I990s succeeded in reducing the size of the disability benefit rolls?

\section{From economic growth to crisis}

During the I960s the Netherlands and Denmark experienced like most western nations a 'golden age'. Within the European Union nations the GDP per capita grew on average at an annual rate of 3.7 percent between I960 and I968, and by 4.2 percent between 1968 and 1973 (Table 4.I). During this period, the growth rates in the Netherlands and Denmark were close to the European Union average.

The growth was accompanied by record low unemployment rates, which in the Netherlands and Denmark were well below the European Union average of 2.I percent in I960-68 and 2.7 percent in I968-73 (Table 4.2). However, this economic growth in the Netherlands and Denmark reflected somewhat different developments. In Denmark economic growth was obtained against the background of a high and increasing employment. During I 960 to $1967,71.4$ percent of the population aged between I 5 and 64 was em- 
Table 4.1 Real GDP growth per capita 1960-2000 (average annual change as a percentage)

\begin{tabular}{llllllll}
\hline & $1960-68$ & $1968-73$ & $1973-79$ & $1979-85$ & $1985-90$ & $1990-95$ & $1995-2000$ \\
\hline The Netherlands & 3.5 & 3.7 & 1.9 & 0.2 & 2.5 & 1.4 & 3.1 \\
Denmark & 3.8 & 3.3 & 1.6 & 1.9 & 1.2 & 2.2 & 2.2 \\
EU-15 & 3.7 & 4.2 & 2.0 & 1.0 & 2.8 & 1.0 & 2.4
\end{tabular}

Source: 1960-85: OECD (1987), 1985-95: OECD (1999), 1995-2000: OECD (2002).

Table 4.2 Labour market indicators 1960-2000

\begin{tabular}{|c|c|c|c|c|c|c|c|}
\hline & $1960-67$ & $1968-73$ & $1974-79$ & $1980-85$ & $1986-90$ & 1991-95 & $1996-2000$ \\
\hline \multicolumn{8}{|c|}{ Unemployment rate } \\
\hline The Netherlands & 0.7 & 1.5 & 4.9 & 11.1 & 9.0 & 6.8 & 4.6 \\
\hline Denmark & 1.6 & 1.0 & 6.1 & 9.2 & 6.8 & 8.8 & 5.8 \\
\hline EU-15 & 2.1 & 2.7 & 4.8 & 9.4 & 9.9 & 10.2 & 9.9 \\
\hline \multicolumn{8}{|c|}{ Employment - population ratio } \\
\hline The Netherlands & 60.5 & 58.0 & 54.0 & 52.8 & 58.3 & 63.8 & 69.5 \\
\hline Denmark & 71.4 & 74.5 & 73.1 & 73.1 & 77.6 & 74.5 & 74.7 \\
\hline EU-15 & 65.5 & 64.0 & 62.4 & 58.8 & 59.6 & 60.9 & 61.3 \\
\hline \multicolumn{8}{|c|}{ Male labourforce participation rate } \\
\hline The Netherlands & 95.4 & 89.1 & 81.4 & 79.5 & 78.6 & 80.0 & 82.2 \\
\hline Denmark & 97.3 & 91.4 & 90.3 & 87.8 & 89.1 & 86.6 & 83.5 \\
\hline EU-15 & 94.1 & 90.5 & 86.1 & 82.3 & 80.2 & 79.0 & 77.2 \\
\hline \multicolumn{8}{|c|}{ Female labourforce participation rate } \\
\hline The Netherlands & 26.6 & 28.3 & 31.7 & 38.8 & 48.9 & 56.4 & 63.1 \\
\hline Denmark & 48.1 & 58.9 & 65.1 & 73.0 & $77 \cdot 3$ & 76.7 & 75.0 \\
\hline EU-15 & 41.1 & 41.9 & 45.6 & 47.9 & 52.1 & 56.7 & 58.9 \\
\hline
\end{tabular}

Source: OECD (1987), OECD (1992b), OECD (1999), OECD (2001c).

ployed and this figure increased to 74.5 percent between I968 and I973. In contrast, economic growth in the Netherlands was obtained with a relatively low and decreasing employment rate, that is, 60.5 percent during 1960 to I 967 and 58.0 percent between I968 and I973. This crossnational difference relates to the female labour force participation. While the Dutch fe- 
male labour force only increased by 2.5 percentage points between I960 and I974, it increased by II.9 percentage points in Denmark (OECD, I987).

Starting with the oil crisis in 1973 , western nations were hit by an economic downturn. Economic growth stopped while unemployment increased. Denmark and especially the Netherlands were also hit by the crisis. In Denmark the annual growth rate in GDP per capita fell to an average of I.6 percent between 1973 and 1979 and I.9 percent between 1980 and I 985 (Table 4.I). In the Netherlands it fell even further, to an average of I.9 percent between 1973 and 1979 and to a record low of 0.2 percent between I980 and I985. In Denmark unemployment rose from I percent of the labour force during the golden age to an average of 6.I between 1974 and I979, and 9.2 percent between I980 and I985 (Table 4.2). An even more dramatic development took place in the Netherlands where unemployment rose from I. 5 percent of the labour force to an average of 4.9 percent between I 974 and I 979 and further to I I.I percent between I 980 and I 985 .

As during the economic upturn, the employment situation was better in Denmark during the crisis than in the Netherlands and in most other European Union nations. While the employment rate only fell by about I percentage point in Denmark, it decreased about 5 percentage points in the Netherlands and in the average European Union nation. With only small differences in the unemployment rates, the different employment trajectories mainly mirrored a faster growing labour force in Denmark than in the Netherlands. That is, the Danish male labour force decreased more slowly than the Dutch and more Danish women entered the labour market compared to their Dutch counterparts. In other words, the Dutch and Danish developments during the economic upturn and downturn were quite similar in terms of GDP and unemployment growth, but the underlying labour market structures were different. Both the Danish labour force and employment were larger in scope, and grew faster than the Dutch.

\section{Crisis management: paid exit and active labour market measures}

The explosion in social security transfers

During the golden area and until the beginning of the I980s social security programmes were extended. More social risks were insured, eligibility criteria in existing programmes were broadened and benefit levels were raised. In the Netherlands, for example, a disability scheme for private sector wage earners was enacted in 1967, and in 1976 a universal disability scheme was 
implemented. As we will see in Chapter 5 , these schemes had wide eligibility criteria and high benefit levels. In Denmark, for example, the old age pension scheme became universal in I960, eligibility criteria in the disability benefit scheme were significantly widened in 1965 , and sickness and unemployment benefit levels were considerably increased in 1972 (Jonasen, I998). When the crisis during the I970s showed to be lasting the number of people withdrawing temporarily or permanently from the labour market, while receiving a social benefit, soared, and, so did social expenditures. In the European Union nations social security transfers rose from an average of I I percent of GDP between I 960 to I967 to I6.4 percent between I 974 and I979, and to I9.I in the first half of the I980s (Table 4.3).

The development in Denmark was close to the European average with social transfers rising from around 8 percent during the I 960 s to I 4 percent in the late I970s, and to more than I7 percent in the first half of the I980s. In contrast, the Netherlands was one of Europe's high spenders. Not only were social transfers well above the European average before the crisis, they also grew faster during the crisis. Between I968 and 1973 Dutch social security transfers equalled an average of 17.7 percent of GDP, which was almost 5 percentage points above the European average. In the mid-r980s Dutch social security transfers had risen by Io percentage points compared to a European average of 6 percentage points.

\section{Exit pathways}

Increasing social expenditure in Denmark and the Netherlands reflect the fact that an increasing number of people permanently or temporary left the labour market. Labour market exit may happen through different pathways, i.e. via unemployment insurance, social assistance, sickness and disability benefit and early retirement schemes (cf. Figure I.I in Chapter I). The Netherlands is among other things known for the 'Dutch disease', referring to a heavy load on the disability pathway. The truth of this attribute is clearly illustrated in Table 4.4 Looking at the main pathways, the disability pathway was clearly the most used pathway in the Netherlands during the crisis in the second half of the I970s and in the I980s. In 1985 around a third of the labour force were receiving some form of social security benefit, with disability and sickness benefits alone accounting for more than half.

Although the social assistance and unemployment pathways were less frequently used than the disability pathway, the social assistance pathway in particular grew considerably during the I 980 os. In I980, the number of social assistance beneficiaries corresponded to 4.0 percent of the labour force 
Table 4.3 Social security expenditure as a percentage of GDP, 1960-1999.

\begin{tabular}{llllllll}
\hline & $1960-67$ & $1968-73$ & $1974-79$ & $1980-85$ & $1986-90$ & $1991-95$ & $1996-1999$ \\
\hline The Netherlands & -- & 17.7 & 23.5 & 27.5 & 26.0 & 25.8 & $22.2^{1}$ \\
Denmark & 8.2 & 11.1 & 14.0 & 17.3 & 17.1 & 20.5 & $19.3^{1}$ \\
EU-15 & 11.0 & 13.0 & 16.4 & 19.1 & 17.4 & 19.2 & $19.8^{1}$ \\
\hline
\end{tabular}

Source: OECD (1987), OECD (1999), and Eurostat (2001a) for the period 1996-1999.

Note:"--": Not available.

1 Estimated figures. The figures for 1996-1999 are equal to the OECD figures for 1991-1995 adjusted for the development between 1991-95 and 1995-99 according to the Eurostat data.

Table 4.4 Social security beneficiaries in the Netherlands as a percentage of the labour force.

\begin{tabular}{llllllll}
\hline & 1970 & 1975 & 1980 & 1985 & 1990 & 1995 & 2000 \\
\hline Social assistance & -- & -- & 4.0 & 9.9 & 7.4 & 6.6 & 4.1 \\
Unemployment & 0.9 & 2.9 & 2.8 & 4.3 & 2.6 & 5.3 & 2.4 \\
Sickness & 4.6 & 5.3 & 5.4 & 4.2 & 5.1 & 3.0 & 1.3 \\
Disability & 4.5 & 7.0 & 12.2 & 13.2 & 12.8 & 11.6 & 11.8 \\
Early retirement & 0.0 & 0.0 & 0.4 & 1.2 & 1.9 & 2.1 & 1.4 \\
(VUT-schemes) & & & & & & & \\
\hline Total & -- & -- & 24.8 & 32.8 & 29.8 & 28.6 & 21.0 \\
\hline
\end{tabular}

Source: Cstv (1996, table 2.1.), Lisv (1998, table 2.1.), Lisv (2001, table 2.1.), OECD (1991, table 3.0.), $\operatorname{OECD}$ (2001c:12-13).

Note:"--": Not available.

and unemployment beneficiaries to 2.8 percent. In I 985 the number of social assistance beneficiaries had more than doubled to almost ten percent of the labour force, while the number of unemployment beneficiaries grew to 4.3 percent. In other words, the Dutch development during the late I970s and the first half of the I 980 os was not only a disability crisis, but also a more general crisis of labour market exit.

Because valid time-series data are lacking, it is difficult to describe the use of exit pathways in Denmark. The figures of the number of social assistance and unemployment beneficiaries and especially sickness beneficiaries are inaccurate. In spite of these problems, the available evidence seems to suggest that Denmark suffered less from disability problems during the second half of the I970s and in the I980s than the Netherlands. In Denmark the number of disability beneficiaries made up 5 percent of the labour force in I970, 
Table 4.5 Social security beneficiaries in Denmark as a percentage of the labour force

\begin{tabular}{llllllll}
\hline & 1970 & 1975 & 1980 & 1985 & 1990 & 1995 & 2000 \\
\hline Social assistance $^{1}$ & -- & -- & 3.4 & 3.7 & 4.0 & 3.7 & $3.3^{3}$ \\
Unemployment $^{2}$ & 1.0 & 4.3 & 6.0 & 7.1 & 7.3 & 8.3 & 4.4 \\
Disability & 5.0 & 6.0 & 5.7 & 8.4 & 8.7 & 9.7 & 9.3 \\
Early retirement & 0.0 & 0.0 & 2.0 & 3.5 & 3.4 & 4.9 & 6.3 \\
\hline Total & -- & -- & 17.1 & 22.7 & 23.4 & 26.6 & 23.3 \\
\hline
\end{tabular}

Source: Various issues of Statistiske Efterretninger, Statistisk Årbog, and Statistisk tiårs oversigt from Statistics Denmark.

Note:"--": Not available.

1 Families (1980) that have received social assistance and full-year recipients (1985 to 2000).

2 Full-time recipients ultimo the year $(1970,1975)$, average number of insured recipients during the year $(1980,2000)$ and full-year recipients (1985-1995).

3 Figure from 1998.

which is almost the same rate as in the Netherlands. But in contrast to the Dutch rate, which almost tripled between 1970 and I985, the Danish rate only increased by 67 percent (Table 4.5).

No complete national registration of sickness benefit receipt exists in Den-

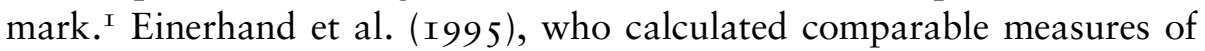
short-term and long-term work incapacity in six countries in I990, found that the short-term work incapacity rate was considerably lower in Denmark (4.4 percent) than in the Netherlands (7.I percent). Statistics for private sector workers in Denmark between I980 and I990 suggest that the level of absenteeism due to sickness dropped in I980 and I98 I and then remained fairly constant during the rest of the I980s (Dansk Arbejdsgiverforening, I996). In other words, we can conclude that Denmark did not suffer from the Dutch disease during the I970s and I980s.

Rather than disability benefit exit, it appears that Denmark relied on exit through the unemployment pathway. Thus, unemployment beneficiaries in percent of the labour force grew from I.O percent in I 970 to 7.I percent in I98 5 meaning that the number of unemployment beneficiaries was almost equal to the number of disability beneficiaries (Table 4.5). It should also be noted that the early retirement pathway has been used more frequently in Denmark than in the Netherlands. In 1985 the number of early retirement beneficiaries corresponded to 3.5 percent of the labour force in Denmark compared to I.2 percent in the Netherlands.

The lack of good comparable data makes it difficult to assess the overall 
labour market exit in the Netherlands and Denmark. The figures of social expenditures (Table 4.3) and beneficiaries (Table 4.4 and Table 4.5 ) seem to tell the same story. While labour market exit increased considerably in both nations during the second half of the I970s and the first half of the I980s, labour market exit reached higher levels in the Netherlands than in Denmark. The growth, however, stagnated in the Netherlands during the second half of the I 980 , but continued well into the r 990 in Denmark (an issue discussed in more detail below and in Chapter 9).

In brief, it is correct to say that the Netherlands suffered from a disability crisis during the second half of the I970s and the early I980s, but it is also fair to say that the disability problem was (an important) part of a more general exit problem. In Denmark the paid labour market exit was smaller in scope during this period and more evenly spread over different exit routes.

\section{Active labour market policies}

Active labour market policies aim at reversing the flow of people out of the labour force. Active labour market policies may be directed toward sickness, social assistance, and unemployment beneficiaries, and they comprise the provision of active measures, such as subsidised job training, subsidised education, and job search courses, that may bring people back into ordinary employment. ${ }^{2}$ Also active labour market policies regard the linking of benefit receipt to participation in activation measures and active job search (see, Hvinden, Heikkilä and Kankare, 200I).

Statistics published by the OECD suggest that during the r980s active measures for unemployed and work-disabled people were used more often in Denmark than in Netherlands. In I986 Denmark used 0.75 percent of GDP on activation of unemployed in terms of labour market training, youth measures, and subsidised employment, whereas the Netherlands only used 0.35 percent (calculated from OECD, I992a). This crossnational difference in activation increased during the second half of the I980s until the midI 990 , when Denmark's spending corresponded to I. 53 percent of GDP and Dutch spending to 0.35 percent (calculated from OECD, I992a, I996, $\mathrm{I} 998,200 \mathrm{Ib})$. However, this difference is exaggerated. Firstly, as unemployment in the second half of the I990s was lower in the Netherlands than in Denmark, the need for activation was lower in the Netherlands (Hvinden, Heikkilä and Kankare, 200I). Secondly, if expenditure to public employment services and administration are included, the crossnational difference in the mid-r 990 os tends to disappear. ${ }^{3}$

Denmark has also been more active than the Netherlands with respect to 
the vocational rehabilitation of work-disabled people. In Denmark vocational rehabilitation measures accounted for 0.I6 percent of GDP in 1986. Throughout the second half of the I 980 s and during the I990s vocational rehabilitation expenditures grew steadily and in 2000 they equalled 0.33 percent of GDP. In contrast, the Netherlands has not devoted resources to vocational rehabilitation; public expenditure remained below 0.005 percent of GDP during the I980s and I990s (OECD, I992a, I996, I998, 200Ib, see also Aarts, de Jong and Burkhauser, I996).

In summary, we can conclude that both the Netherlands and Denmark were seriously affected by the economic crisis at the beginning of the r970s. In both countries economic growth stopped while unemployment and social expenditure soared. The two nations managed this crisis differently. In Denmark employment was kept relatively high and labour market exit low, whilst the emphasis was put on active labour market measures. In contrast, in the Netherlands little emphasis was put on active labour market measures and labour market exit was massive, especially through the disability pathway.

\section{From crisis to recovery}

During the late I980s most Western nations recovered somewhat from the economic crisis. In the European Union the growth rate rose from I percent during the first half of the I980s to 2.8 percent during the second half (Table 4.I). The development in the Netherlands mirrored this trend; GDP growth per capita rose from an average of 0.2 percent between 1979 and 1985 to 2.5 between 1985 and 1990 . The Danish experience was somewhat different. Compared to most other nations, Denmark had higher GDP growth rates in the first half the I980s, lower rates in the second half, and higher growth rates during the first half of the I990s, see Table 4.I. In other words, the timing of the economic crisis and recovery was somewhat different in Denmark than in the Netherlands and the average European nation.

In terms of unemployment Denmark and in particular the Netherlands have fared much better in the I990s than the European Union average. While unemployment has remained at a high level in many European nations, it has decreased significantly in the Netherlands and Denmark. The European average unemployment rate remained around 9 to ro percent since the first half of the I 980 os, but dropped from 9 to less than 6 percent in Denmark and from I I to less than 5 percent in the Netherlands in the second half of the I990s (Table 4.2). During the last two or three years unemployment has in fact been as low as 3 percent in the Netherlands. 
The impressive Dutch development was caused by a significant job growth and increasing female labour force participation. The number of employed people as a percentage of the population increased from an average of 52.8 percent between I980 and 1985 to 69.5 percent in the second half of the I 990 os. In the same period female labour force participation increased by almost 25 percentage points, from 38.8 percent in the first half of the I 980 os to 63.I percent in the second half of the I990s. During the same period, employment only increased slightly in Denmark and the labour force remained constant. In other words, the Netherlands is catching up on Denmark in terms of employment and labour force participation. It should be noted, however, that the female labour force participation in the Netherlands still is more than Io percent below the level in Denmark, and that (female) parttime employment is much more common in the Netherlands than in Denmark. In 200032 percent of all Dutch jobs were part-time, in contrast to only I 6 percent in Denmark (OECD, 200IC). ${ }^{4}$

The Netherlands is also catching up on Denmark in terms of social security benefit expenditure and labour market exit. During the first half of the I 990 s social security expenditure was brought to a halt in the Netherlands, whereas in Denmark it continued to rise (Table 4.3). In a similar vein, the number of social beneficiaries relative to the labour force decreased in the Netherlands, while they continued to increase and Denmark (Tables 4.4 and $4.5)$. The Dutch development was caused by a declining number of people receiving social assistance and unemployment benefits and to a much lesser extent by a decreasing number of disability beneficiaries. In Denmark the development was caused by an increasing number of people leaving the labour force through early retirement and disability benefits. In other words, even though Denmark survived the crisis during the late I970s and the 1980 os better than the Netherlands, Denmark had more exit problems during the first half of the I990s. In particular one can speak of a sneaking disability problem in Denmark, as the steady growth in the disability roll during the I 980 os continued into the I990s.

Despite these somewhat different developments it can be concluded that the disability pathway has been and still is the most important exit route both in the Netherlands and Denmark. Furthermore, while the improved economic situation during the I990s, especially in the second half of the decade, enabled the two nations to significantly reduce the number of unemployed people, it apparently has only had a small effect on the number of people receiving disability benefits. In other words, the period with economic growth has apparently improved the labour market situation of unemployed people without health problems but to a large extent bypassed 
people with disabilities. As we will see in Chapters 5 and 6, this is not because efforts to increase labour market integration and to reduce the number of disability beneficiaries have been lacking. Furthermore, as illustrated in Chapter 9, it does not, at least in Denmark, reflect that it has been impossible to limit entry into the disability rolls. Rather it reflects that it is possible to get people off social assistance and unemployment insurance schemes when the economic conditions improve, but it is much more difficult to bring disability beneficiaries back into the labour market. 


\section{Dutch Disability Reforms: Redefining Responsibilities}

In 1990 the Dutch Prime Minister declared the Netherlands 'a sick country' and that he would resign if the number of disability beneficiaries grew beyond I million (Aarts and de Jong, I 996b). At that time the disability problem had become synonymous with the crisis in the Dutch welfare state. It reflected an increasing problem of paid inactivity: the number of people receiving social benefits relative to the number of employed people had become alarmingly high. For every Ioo employed more than 80 people were receiving some form of social security benefit (including old age pension) (Visser and Hemerijck, I 997). Combined with very luxury social security benefits this caused an economic crisis of serious dimensions. Not only did rising public expenditure and foreign debt threaten the functioning of the social security system, increasing taxes and social contributions also raised companies' costs, thereby reducing their ability to earn money on international markets. The disability problem had also become synonymous with a seemingly ungovernable system: a first round of welfare reforms in I 985 and 1987 had almost no visible impact on the number of beneficiaries. More fundamental changes seemed necessary.

In I99I the Dutch government launched a welfare reform package, which was the first step towards a major overhaul of the Dutch welfare system and in particular of the sickness and disability benefit programmes. During the I990s changes within the organisation of the Dutch welfare system and insurance covering unemployment, sickness and disability aimed to restrict paid labour market exit and increase employment. The reforms were harsh. Eligibility criteria and entitlements to social security benefits were narrowed and benefit levels were reduced. Furthermore, organisational amendments significantly changed the institutional 'rules of the game' in that the influence of the social partners (unions and employers associations) was considerably restricted, while market forces were allowed to play an influential role in social security. This development has been labelled 'managed liberalisation' (Visser and Hemerijck, I997; van der Veen and Trommel, I999). 
This chapter looks into the background of the disability crisis and into the reforms of the Dutch disability policy. The disability problem did not arise overnight, and had been known since the early I 980 s, so why were the problems allowed to become so out of control? And how did the reforms come about, and what do they imply for the principles on which the Dutch disability policy rests?

\section{A sick nation}

In crude terms, the Dutch disability crisis can be said to reflect problems at all levels in society. That is, at the welfare state, the political and the administrative level, as well as in the disability benefits scheme and among employers and workers.

\section{Problems at the welfare state level}

At the level of the welfare state, the Netherlands was characterized by strong conservative attributes like, for example, Germany, France and Italy (Esping-Andersen, I990; I999). These nations have traditionally had a very low female labour supply and the economy has been based on a limited but highly productive male labour force. To ensure high productivity, companies invested in equipment while shedding the least productive labour. When the number of beneficiaries increases because of economic stagnation as during the crisis in the mid-r970s, taxes and social contributions increase, and so companies' wage costs increase. When employers approach this problem by shedding more labour a negative spiral is started. In the Dutch case this happened by letting mainly older workers exit through the disability pathway. In contrast, the Scandinavian nations have to a greater extent solved economic crises with policies, such as active labour market measures, that increase the labour supply and reduce the number of beneficiaries (Esping-Andersen, I996b; Visser and Hemerijck, I997).

\section{Problems at the political level}

At the political level at least two problems stand out. As Visser and Hemerijck (I997) emphasise, in the period between I97I and I98 I various governments aimed to reduce unemployment and limit public expenditures through modest wage increases. Since the Second World War and until I963, agreement between governments, unions, and employer associations 
about wage restraint had successfully secured very low labour costs, improved international competition, and economic growth. This policy failed after the mid-I96os, wages soared because of tight labour markets and tripartite agreement could not be obtained. In order to restore the low-wage consensus policy the governments tried to make a 'social contract' with unions trading wage restraint for income distribution and extensive social protection. In other words, social security retrenchment was forgiven for wage restraint. This policy was costly. To induce unions to limit wage demands, social security benefits became linked to the wage development in the private sector. This meant that not only were benefits linked to inflation, as wages were automatically tied to inflation, it also meant that social security beneficiaries got their share of the annual increases in the national income. Unions did not, however, exercise wage moderation. Consequently, the governments (den Uyl, I973-77; van Agt, I978-8I and I98I-82) could neither steer the wage development nor the rise in public expenditures. ${ }^{\mathrm{I}} \mathrm{In}$ this way as much as up to 60 percent of the rise in the annual budgets was out of government control (ibid.).

A second problem relates to the corporate structures where political decisions in practice often presupposed consensus between the governing political parties and various committees mostly dominated by the social partners (see Cox, I993 for a description of the various committees). While this model might be second to none in times of consensus, such as during the wage restraint period in the I950s, it may effectively block necessary reforms in times of disagreement. In that case, compromising becomes time consuming, decisions are delayed and any agreements that are finally obtained tend to be toothless. According to Aarts and de Jong (I996b) this was exactly what happened before 1987 .

\section{Problems at the administrative and organisational level}

The corporate structure also gave rise to problems at the administrative level. Dutch social security programmes are organised in three tiers; the people's insurance providing old age pension and survivor's benefit as well as sickness and disability benefits for people who are not covered by the labour market insurance; the labour market insurance dealing with unemployment, sickness and disability benefits; and the social assistance scheme, providing a safety-net for needy citizens that are not (sufficiently) covered by other programmes. Local authorities (municipalities) administer the social assistance scheme. Before 1995 the social partners were to a large degree responsible for the daily administration of both the peoples insurance and es- 
pecially the labour market insurance. The Social Insurance Council (svr), a tripartite institution with a third of their members appointed by the government and the remaining members appointed by the social partners, was in charge of the administration of the peoples insurance. Industrial Insurance Boards headed by members appointed by unions and employer associations were responsible for the administration of the labour market insurance.

The organisation of the administration meant that the Industrial Insurance Boards, and therefore the social partners, were delegated great autonomy over the administration. This autonomy may have limited importance in programmes where benefit awards involve little discretion as in programmes covering demographic risks and unemployment. In such cases the assessment of eligibility only demands information about, for example, age (old age pension) and work record (unemployment). In contrast, eligibility to disability benefits involves medical and occupational aspects and the assessment therefore comprises a great deal of subjectivity (see Stone, I984 and Chapter I in this book). The importance of this is demonstrated by a study by van der Veen (I990) showing that Dutch gatekeepers apparently applied their own subjective criteria in terms of 'deservingness' and 'need' when awarding disability benefits (referred from Aarts and de Jong, 1996b).

The administrative discretion in the disability programme was apparently used more for excessive benefit awards than to return the work-disabled to work. A report from the Public Audit Office in 1992 and a later parliament inquiry with television-transmitted hearings in 1993 revealed that although benefit applications were handled on time and correctly, rehabilitation and reintegration were almost completely lacking. This was related to the fact that there were no incentives to facilitate rehabilitation and reintegration. On the contrary, the Industrial Insurance Boards financial resources' were linked to the number of beneficiaries so more beneficiaries meant more resources (Visser and Hemerijck, I997).

The organisational structure of the disability benefit scheme, the sickness benefit scheme, and of the vocational rehabilitation instruments gave rise to problems. A close connection between the sickness and disability benefit schemes probably contributed to the growing number of disability benefit recipients. The Industrial Insurance Boards administered both schemes. In case of illness or work injury all workers were covered by the sickness benefit act, which gave entitlement to a benefit equal to 80 percent of the wage with a relatively high ceiling. The ceiling corresponded to 2-3 times the statuary minimum wage, and so (in I978) the average income earner had a net replacement rate on 90 percent (Emanuel, I987). In addition, most workers were covered by collective agreements giving them roo percent after tax 
wage compensation (Haveman, Halberstadt and Burkhauser, 1984). The benefit period expired after I 2 months of sickness, but eligibility for disability benefit was automatically assessed before this time limit was reached (Emanuel, I987). In combination with the low eligibility threshold in the disability benefit scheme, cf. below, this facilitated a massive transition of long-term sick-listed workers from the sickness benefit scheme to the disability benefit scheme.

While the sickness and disability benefit schemes were highly integrated this was much less the case with the vocational rehabilitation instruments. The instruments comprised: rehabilitation measures for work incapacitated people in the sickness and the disability schemes, wage subsidies for both partially sick-listed workers ('therapeutic work resumption') unemployed handicapped people as well as quota legislation.

Except for therapeutic work resumption (Van Groenestijn, I99I), these schemes were not used to any notable extent. The quota legislation was never enforced among other reasons because no organisation was appointed to inspect whether the law was followed (Emanuel, Halberstadt and Petersen, I984). Vocational services for people in the sickness and the disability schemes were organised under the disability benefit scheme and administrated by the Industrial Insurance Boards. These services were almost only directed towards disability beneficiaries and were predominantly used to alleviate the social consequences of disability rather than to ensure reintegration into the labour market (Haveman, Halberstadt and Burkhauser, I984; Emanuel, Halberstadt and Petersen, I984). Vocational measures for sicklisted workers were almost completely lacking. To establish these measures, the Industrial Insurance Boards were supposed to report relevant cases to another administrative unit, the Gemeenschappelijke Medische Dienst. This seldom happened. In 1977 only 8,664 requests for rehabilitation services were reported out of a total of more than I I0,000 (Emanuel, I987). In other words, no coherent reintegration policy existed; instruments were split between several laws, the administration was poorly organised and implemented, measures were to a large extent applied after a disability benefit had been awarded, and they aimed only in part at labour market integration.

In brief, the integrated organisation of the sickness and disability schemes in combination with a disordered organisation of vocational rehabilitation instruments ensured that people remained on the disability pathway once having entered it. 


\section{Problems at the programme level}

The many disability benefit awards and the lack of vocational rehabilitation also seem related to a very 'luxurious' disability benefit scheme. In contrast to disability schemes in many other nations, no distinction in the Dutch scheme is made between work-related disability and disability caused by other circumstances. The only thing that matters is the presence of a condition that limits work capacity. The Dutch scheme also has a remarkable low eligibility threshold (Einerhand et al., I995). The scheme operates with seven disability categories ranging from an invalidity degree as low as I 5 percent up to roo percent. ${ }^{2}$ In contrast, the scheme in Denmark and many other nations demands an invalidity degree of above 50 percent.

Work capacity was assessed in relation to the applicant's former job or a similar job and not to 'a generally accepted' job. The applicant's work capacity was estimated as the amount the applicant with a present (reduced) work capacity would earn in the previous job or in a similar job as a percentage of the earnings of a non-disabled person with otherwise similar characteristics in a similar job. If, for example, the disabled person would be able to earn I000 NGL in his present job, while a similar but healthy person would earn $3000 \mathrm{NGL}$, the work capacity would be 33 percent. The invalidity degree was then calculated as Ioo percent minus the estimated work capacity, in this example 67 percent. As disabilities often are work related (Bengtsson, 1997) the earnings potential in the previous job was very limited, and consequently many applicants were granted full disability benefit. If the work capacity, as it is today, was instead assessed in relation to a generally accepted job many applicants would have a significant earnings capacity despite their disability, e.g. the painter with a lung disease would be able to work as an unskilled factory worker.

The bias towards awarding full benefits was reinforced by the principle of anti-discrimination. Partially disabled people, entitled to partial disability benefit, should exploit their remaining work capacity in ordinary employment. It was, however, acknowledged that partially disabled people could have difficulty finding a job similar to their previous job either because vacant jobs were lacking or because employers discriminated against them. In the legislation, it was mentioned that gatekeepers should take such problems into consideration. In practice, it was impossible to separate unemployment caused by disability and that caused by labour market circumstances. These problems were, therefore, solved administratively by treating the partially disabled as if they were fully disabled and consequently partial benefits were seldom awarded (Aarts and De Jong, I992). In I980, as many 
as 85 percent of the beneficiaries received full benefit (Emanuel, I987). In other words, the scheme had also become an unemployment insurance scheme. The unemployment component has been estimated to account for between I9 and 5I percent of the disability benefit volume in I980/8I (Aarts and De Jong, I996b).

\section{Problems at the level of actors}

At the individual level the Dutch policy gave incentives to exploit the disability pathway. The disability programme was attractive for employers who could use the scheme as a cheap and easy way to 'get rid of' low-productivity workers. The disability programme was financed through uniform contributions paid by employers and workers. As employers' contributions were related to total wage payments, the individual employer had no incentive to avoid benefit awards. That is, the cost of the enrolment of one additional worker in the disability benefit scheme was spread among all employers and workers and therefore did not affect the individual employer. Dismissal was an alternative solution, which was often more costly and administratively difficult than disability benefit awards. The dismissal of especially older workers could only take place after a notice period of up to I 3 weeks and after approval from the regional labour market authorities. Collective dismissals were even more complicated. The employer had to notify the work council and the union, in addition to the regional labour market authorities, and allow the involved people to negotiate a 'social plan' for the redundant workers (Visser and Hemerijck, I997; Hassink, van Ours and Ridder, I997).

Enrolment in the disability benefit scheme was attractive for workers wishing to withdraw from the labour market. Compared to the unemployment benefit, the disability benefit amount was higher and it could be obtained for longer, i.e. until eligibility to the old age pension was obtained. In other words, in times of slack labour markets disability exit was attractive for employers and often the least poor solution for redundant workers.

This description of the Dutch policy during the I980s suggests that the problems cannot be isolated to one or two areas: problems existed at all levels. The policy of wage restrainment was abortive; the administration, which was delegated great autonomy, focused more on passive income protection than reintegration; the integrated organisation of the sickness and disability benefit schemes in combination with a diffuse organisation of the vocational rehabilitation instruments promoted a focus on income protection rather than reintegration; and the policy gave all those involved incen- 
tives to use the disability pathway. It explains why the disability problem could get so out of control, and, at least at the beginning of crisis, there was no political will to intervene, and problems were so extensive that no simple operation could solve them.

\section{Ineffective changes}

At the beginning of the I 980 s the focus was on the growing public expenditure and the rising unemployment figures. Disability was not yet considered as the major problem. The changes in 1985 and 1987 did not therefore particularly focus on sickness and disability but on a reduction in public expenditure in general. In I985, the replacement rate in the unemployment, sickness and disability schemes was lowered from 80 to 70 percent of the previous wage. In I987, eligibility to unemployment benefits was narrowed and the duration of benefit receipt was shortened. The disability benefit scheme was changed in order to abolish the labour market considerations from the invalidity assessment. Partially disabled people were only to be awarded a full disability benefit when substantial evidence showed that the applicant's poor employment prospects were caused by employers' discrimination. If poor employment prospects were caused by a lack of jobs the applicant should be granted a partial disability benefit in combination with a partial unemployment benefit. In other words, the disability scheme should no longer function as an unemployment scheme (Aarts and de Jong, I 996b).

Steps were also taken to advance the labour market integration of workdisabled people. In I 987 a new act on reintegration of disabled people was introduced (WAGW). The act made it obligatory for employers to adjust job demands and working conditions to the abilities of impaired workers (Aarts and de Jong, I996b). Administrative authorities were given the right to fine employers who dismissed a disabled worker, and a new quota measure was launched to increase the employment of disabled people. If the employment of disabled people remained unsatisfactory 3 years after the introduction of the quota measure, Industrial Branches could be demanded to employ between 3 and 7 percent disabled people. These punitive measures were never used to any significant extent. Although the act did not introduce significant new effective measures, it was recognized for the first time that it was necessary to reduce the number of disability beneficiaries and that public intervention in the labour market was necessary to achieve this goal (Van Oorshot and Boos, 2000).

The 1987 changes apparently had some effect, but it was much smaller 
than anticipated (Aarts and de Jong, I996a). It was increasingly felt that the growth in the number of social beneficiaries was unstoppable and the crisis was therefore no longer merely seen as financial, but also as a crisis of governability. Focus was removed from unemployment figures to the more general notion of inactivity problems: too many people were inactive and receiving social benefits, while too few were working (Visser and Hemerijck, I997). In this context, it was increasingly recognised at the political level that more radical measures were necessary to bring back governability in the Dutch welfare policy. Here the seemingly unstoppable growth in the disability rolls came high on the political agenda. When the Prime Minister, Ruud Lubbers, declared the Netherlands a sick nation in September I990, he emphasized the need for changes to the Dutch culture in respect to work absenteeism and disability claims (Aarts and de Jong, I996b). The problems were recognized by unions and employers associations and in October I990 during the annual social economic summit of leaders from unions, employer associations, and cabinet delegates agreement was reached that considerable efforts were necessary. These efforts were however restricted to changes within the existing administrative procedures and did not alter the basic structure of the disability policy (Aarts and de Jong, I996b). The government was not satisfied with this agreement and asked a tripartite institution, the Social Economic Council, to make a proposal to reduce the number of disability beneficiaries. The Council could not reach agreement because one of the major unions (FNV) refused to compromise. This enabled the government to neglect tripartite consensus and launch its own and more radical policy in the summer of I99I (Visser and Hemerijck, I997). ${ }^{3}$

\section{The beginning of a reform}

The first major piece of legislation, the Act on the Reduction of the Number of People with a Work Disability (TAV), came into effect in March I992. The act increased employers' incentives for the integration of partially disabled people. Employers who hired a partially disabled person for at least a year received a bonus of 6 months salary, while employers should pay a socalled 'malus' (fine) if one of their workers became disabled. The malus was abolished in 1995 , because of massive opposition from employers and practical difficulties in implementing the measure. In addition to the one-off bonus, employers were given a 20 percent wage subsidy for hiring partially disabled people, and administrative authorities were given a larger budget for vocational rehabilitation (van Oorschot and Boos, 2000). 
The act also affected the financing of sickness benefits. The uniform contributions paid by employers and workers were replaced by contributions depending on the level of sickness absenteeism within industrial branches, so employers in branches with a high absenteeism rate had to pay more than employers in branches with a low rate.

In August 1993 another act, the Act on the Reduction of the Number of Disability Benefit Claims, that aimed at reducing the number of disability beneficiaries was enacted (ТВA). In several aspects the new legislation made the disability benefit programme less attractive compared to the unemployment programme, for example. Eligibility criteria were narrowed in two ways. The act stipulated that eligibility demanded a direct and objective association between illness, physical defects and a reduction in the applicant's earning capacity. This should be compared to the earlier regulation where eligibility only demanded that illness and physical defects should lead to an expected reduction in the applicant's earning capacity. Secondly, the determination of the invalidity degree should refer to generally accepted work and not to the former job or a similar job. As a consequence more jobs would in principle be available to applicants, meaning that less applicants would be entitled to a disability benefit, and more applicants would be awarded partial benefit instead of full benefit (see above and Aarts and de Jong, I996b). All new beneficiaries should have their benefit re-assessed after a year and again after 5 years. The new and stricter eligibility criteria were also to be applied to existing beneficiaries younger than 50, who should have their invalidity degree reassessed.

Entitlement criteria were also tightened. For new beneficiaries the benefit level in the labour market insurance was made dependant on age. Now the benefit period was split in two subperiods. In the first period the benefit was related to the pre-disability wage level (with a ceiling). The length of this period depended on the claimant's age. In the second period the beneficiary was entitled to a basic amount equal to 70 percent of the minimum wage and an age-related benefit supplement. The difference between the benefit level in the first period and the second period, the so-called waO gap, has been compensated in collective agreements for an estimated 60 percent of the workers (van Oorschot and Boos, 2000).

The Act on Reducing Sickness Absence (TZ), which came into effect in January 1994, strengthened the individual employer's incentive to limit sickness absenteeism. Since 1992 sickness benefits had been financed by employer and worker contributions that were depending on the sickness rate within industrial branches. Consequently, the individual employer had no incentive to limit sickness absenteeism. With the new act employers were 
now made responsible for the financing of sickness benefits of their own workers for the first 6 weeks ( 2 weeks for employers with less than I 6 workers). Employers were allowed to reinsure this risk with private insurance companies or to take the risk themselves.

Parallel to the Act on Reducing Sickness Absence, the existing act on working circumstances (Arbowet) was changed so employers became obliged to implement a sickness absence and control policy. The individual employer was demanded to contract a private consultancy company (Arbodienst) to assist in the implementation of a prevention and sickness absence policy. In addition to preventive issues, the Arbodienst was to assist the employer by providing counselling to sick-listed workers and support the reintegration of workers on sick leave. In the act, which was gradually enforced, the responsibility of employers for reintegration was strengthened. Employers were made responsible for drawing up reintegration plans for sick-listed workers after 13 and 26 weeks of work incapacity, respectively. It was also emphasised that employers should maintain regular contact with sick-listed workers, and 'do everything within the scope of the company to limit the duration of the sick leave so that the employee can return to work as quickly as possible...' (Ministerie van Sociale Zaken en Werkgelegenheid, I995). If the employer can justify that he is unable to provide a suitable job for a sick-listed worker, the socio-medical supervision of the worker is taken over by the administrative authorities, which should consider opportunities for employment with another employer (Beljaars and Prins, I997).

In brief, we can conclude that the changes to the Dutch disability policy during the beginning of the I990s not only constituted harsh retrenchment in terms of lowering benefits and restricting access to benefits. They also represented an attempt to strengthen incentives to limit work disability and increase labour market integration, to introduce market mechanisms, and to give employers a larger responsibility for policy implementation.

\section{Redefining responsibilities}

In the I 994 elections, the Lubbers/Kok government was punished for its retrenchment and voted out of office. Even though the Social Democrats (PvdA) lost a quarter of their votes, Lubbers's Christian Democrats (CDA) lost even more, a third. As a consequence, the Social Democrats remained the largest party and they formed a new government together with two liberal parties (VvD, D 66) leaving out the Christian Democrats (Visser and Hemerijck, I997). The new government carried on with the reforms of the 
disability policy, which had been started by the former government, and they went on to reduce the influence of social partners on the administration of social security. This happened in the light of an increasing political and public consensus on the responsibility that the social partners had had for the disability problems. Thus, during the beginning of the I990s the social partners came under attack for their administration of the labour market insurance and their influence and participation in the supervision of social policy. This critique was amongst others expressed in I99I by crown members of the Social Economic Council (SER), by the Public Audit Office in I992, and in a Parliamentary Inquiry in 1993.

\section{Reforming the disability policy}

The efforts to reduce work disability and strengthen employers' responsibility continued in March I996 with the Act on the Enlargement of Wage Payment during Sickness (wULBZ). The sickness benefit scheme was almost completely privatised. Employers' are now obliged to finance sickness benefits for their sick-listed workers for a year, such that the national sickness fund only covers special groups such as workers on temporary contracts and partially disabled workers. ${ }^{4}$ Employers can choose to reinsure this risk with a private insurance company, which approximately 80 percent have done.

In I 998, the disability benefit scheme underwent an almost similar reform (РЕмВА). The law aimed to reduce the number of disability beneficiaries by making employers more directly responsible for future developments in the number of beneficiaries. Before the new act, all employers paid the same contributions (i.e. a uniform percentage of wages). Now employers were obliged to finance disability benefits for their workers for up to 5 years, either by paying a strongly increased insurance contribution when their workers enter the disability benefit programme, or by leaving the public disability insurance and paying the benefits themselves. The premium differentiations started in 1998 and they will be fully completed in 2003 . As in the sickness benefit scheme, employers can choose to reinsure the risk with a private insurance company.

The efforts to improve working conditions and enhance the labour market integration of disabled people were also continued. In I 995 a new act (AMBER) stipulated that employers were exempted from wage payment in the case of the sickness of a partially disabled worker. The wage subsidy introduced by the TAV was extended, and disabled people who would lose income by accepting a job were granted a wage supplement. Moreover, employers who employed a partially disabled person for a trial period of 3 months 
could receive a roo percent wage subsidy during this period. The act on the reintegration of handicapped people (REA) in I 998 has strengthened employers' economic incentives to hire disabled people. Employers are given a fixed budget when they recruit a disabled person. The budget can be used to pay for necessary workplace adaptations and to ease access to the workplace. Employers can also get a reduction in their contribution to the disability benefit scheme if wages paid to disabled workers constitute more than 5 percent of the total wage expenditures. In addition, on an experimental basis, disabled people are granted a budget to buy vocational services to facilitate their labour market integration. Also in 1998 , the act on working conditions was changed. It was specified that employers' policies on working conditions should be tailormade and administrative authorities were delegated the power to fine employers without the interference of a judge (Van Oorshot and Boos, 2000).

In order to further increase reintegration and reduce the number of disability benefit awards, the act on gatekeeper improvements was implemented in April 2002 (Wet Verbetering Poortwachter). The act increases and specifies in details the obligations of workers and especially of employers during sick leave. For example, the employer, together with the Arbodienst, is obliged to assess whether an action plan should be made and, based on this, the Arbodienst should advise the employer and the worker of the opportunities for the worker quickly returning to work. This must take place within 6 weeks after the first day of sick leave. The employer and the worker should then make a so-called action plan and based on this they should together produce a reintegration report. This report is necessary if the worker is going to apply for disability benefit. If the employer or the worker does not fulfil their requirements they may be fined, that is, the employer's obligation to pay wage during sick leave may be extended and the worker may lose his or her protection against dismissal or the worker's wage payments may be stopped. While the act represents a cultivation of the existing policy in that the responsibility of employers is increased, it also introduces new elements in respect to the obligations of sick-listed workers. Before the act was implemented the obligations of sick-listed workers were very limited.

The most significant changes during the I 990 s seem to be the increased responsibility of employers. These changes should be seen in relation to the existing, restrictive, job-protection legislation (Buitengewoon Besluit Arbeidsverhoudingen, ввА). In principle sick-listed workers are protected against dismissal for up to 2 years. Employers that want to dismiss a worker must obtain permission to end the contract from the regional employment council or from a district court. In the case of sick leave, the permission can 
only be obtained under specific circumstances, for instance, if it is obvious that the worker never will be able to perform a job within the company or if the employer can justify that continuation of the employment contract will seriously damage the company's economic performance. Without the restrictive job protection of sick-listed workers, the financial responsibility of employers and the obligation to facilitate reintegration would be meaningless. That is, if employers have no obligation to offer the worker a vacant job it makes no sense to demand that they reintegrate workers (Høgelund, 2002).

In other words, the job protection of sick-listed (and the failed quota policy) suggests that the principle of making employers responsible for work disability is not alien to Dutch disability policy. Seen in this light, the disability reforms are not so pathbreaking as they might appear at first sight.

\section{Reforming the organisational structure}

Since the mid-I990s the organisational structure of the social security system has undergone important changes that gradually decimated the influence of the social partners. The influence of unions and employers associations on the administration of social security programmes has roots going back to the Industrial Injuries act of I 90 I. From I 952 until I 995, the social partners had almost autonomous influence on the administration of the labour market insurance and considerable influence on the supervision of social security programmes. They were entirely in charge of the Industrial Insurance Boards that were responsible for the daily administration of the labour market insurance, and they had the majority of votes on the board at the central supervisory and administrative level, the Social Insurance Council (de Sociale Verzekeringsraad, svr). In 1995 the Social Insurance Council was divided into two institutions whereby supervisory tasks were separated from central administrative tasks. This meant a reduction in the influence employers associations and unions had on supervisory tasks as three independent members managed the new supervisory board. The central administration was carried out by a temporary organisation governed by the social partners and an independent chairman.

In 1997, the social partners' influence on the daily administration was reduced. The central administration was now placed in the hands of a new institution (Lisv). This institution was governed by a board of representatives from employers associations, unions, independent members and a chairman appointed by the government. The industrial insurance boards were officially abolished; instead the daily administration was contracted out to gov- 
ernment-approved administrative bodies in the shape of the former industrial insurance boards.

In 2000 the 'managed liberalisation' of the social security administration was reversed. A majority in parliament feared that in a liberalised system commercial interests would influence decisions about benefit awards (Terpstra, 2002). In 2002 the central administration (Lisv) and the units responsible for the administration of the labour market insurances were merged into one large organisation, the Administrative Institute for Workers Insurance (UWv). The Administrative Institute for Workers Insurance is governed by the state and is thus without representation of the social partners.

The Administrative Institute for Workers Insurance cooperates closely with local Centres for Work and Income. In these centres several organisations cooperate and compete, for example the Public Employment Service, municipalities, social security units representing the Administrative Institute for Workers Insurance, and in some cases also private employment agencies. The Centres for Work and Income are responsible for the administration of social assistance and unemployment insurance, for collecting information about the clients' situation, assessing barriers for returning clients to work, mediate jobs, and for the visitation of clients to active measures. By means of cooperation and competition between the different organisations represented in the Centres for Work and Income, it is hoped to alleviate the previous imbalance between the administration of benefits and reintegration efforts. So far the centres have not apparently been successful, probably because a coherent national policy in the area is lacking and, closely related to this, because of conflicting interests of the participating organisations (ibid.).

With the organisational changes the social partners lost their influence on the administration and supervision of the labour market insurances. Unions and employers associations do however still have some formal influence vis á vis their representation in various advisory boards such as the Social Economic Council (SER) and the new Council for Work and Income (RWI).

\section{Conclusion}

No single factor can explain the extraordinary load on the Dutch disability pathway during the I980s. Rather, it seems that a whole range of factors contributed to the Dutch disease. An abortive wage restraint policy during the I970s, an autonomous administration that kept the focus more on passive income protection than on labour market integration, an integrated or- 
ganisation of the sickness and disability benefit schemes combined with a disordered organisation of the vocational rehabilitation instruments, an easy accessible disability benefit scheme and a system giving the central actors incentives to use the disability pathway are some of them. Seen in this light it can hardly be surprising that fundamental changes were necessary and that it took a considerably amount of time and political struggle before they were launched and carried out.

The pressure for changes to the Dutch social policy was enormous. As we saw in Chapter 4, public expenditure during the I980s was at a record high by international standards and the economic performance was only modest. The pressure was fortified when the first attempts in 1985 and 1987 to limit social security benefit receipt failed. The notion of problems changed, from a financial and unemployment crisis to a crisis of inactivity and governability, and broad political awareness emerged that more radical measures were necessary. With among other things a television transmitted parliament inquiry, it became public wisdom that the social partners had violated their administrative duties and that many employers had exploited the disability scheme to shed redundant labour. This opened the door to reforming the disability policy.

The first significant changes, which took place between I99I and I995, not only involved harsh retrenchment in terms of narrowing eligibility criteria, cutting benefits and shortening benefit periods, they were also directed towards one of the 'public villains': employers. Thus, the amendments aimed to improve employers' incentives to limit the number of disability beneficiaries by increasing their responsibility for the financing of sickness and disability benefits, on the one hand, and by subsidizing their employment of disabled people on the other.

This policy development gained further momentum in the second half of the I990s with the privatisation of the sickness benefit scheme in 1996 and the changes to the disability benefit scheme in 1998 . The increasing responsibility of employers indirectly undermined the influence of the social partners: when employers finance benefits fewer administrative tasks are left to the social partners. The social partners were also under direct attack. The administrative changes starting in 1995 reduced their influence on both the daily administration and on the monitoring of the administration, and today the social partners are without influence on the administration of the social security schemes.

The reforms seem to have two important implications for the Dutch disability policy. From a policy with predominant emphasis on benefits and little emphasis on reintegration, the policy has moved towards more emphasis 
on reintegration and less emphasis on benefits. The responsibility of the actors involved in the implementation of the disability policy has changed. The responsibility (and influence) of the social partners has been nullified, while the responsibility of employers in combination with public and private sector agents has increased. This has been labelled a move towards 'managed liberalisation', reflecting that although market forces have come to play a larger role in the disability policy, the scope for free choices is restricted by state regulation (van der Veen and Trommel, I999). In principle, however, this shift does not significantly alter the state's ability to steer policy implementation; while the implementation used to be dependent on unions and employers' associations, it is now predominantly depending on the efforts of employers (and the services they buy in the market). In other words, the success of the policy is dependent on the strength of the system incentives that affect how employers and market providers act. 



\section{Danish Disability Policy:Small Steps, Big Change?}

In contrast to the Netherlands, Denmark has never been involved in a direct fight against disability problems. The development in the number of disability beneficiaries has evolved much more slowly than in the Netherlands (see Chapter 4 ), which is probably the reason why disability problems has not been a contested issue in the political landscape. Danish disability policy has instead developed in the wake of efforts to limit public expenditure and later in the I990s in the wake of the general discourse of an active labour market policy. The development has not involved radical reforms, but a series of adjustments that cultivated the existing policy, where public authorities are almost entirely responsible for the financing, administration and implementation of the disability policy.

This chapter provides an outline of the Danish disability policy and how it has developed over the last two decades. The chapter concludes with a comparison of the principles on which the Dutch and Danish disability policies rest. I argue that a very important difference concerns the emphasis they put on different actors; in Denmark the responsibility for the disability policy rests to a large degree with the public sector, whereas in the Netherlands this responsibility has been delegated to the individual employer. As a consequence, actors in Denmark and the Netherlands face very different constraints and opportunities, giving them very different incentives both in respect of the work retention of sick-listed workers and integrating non-employed disabled people.

\section{Danish disability policy in the 1980 s}

With the social reform between 1972 and 1976 the responsibility for the Danish social policy was to a large extent delegated from the state to the local level, in the shape of I 4 counties and 275 municipalities. The reform was based on the notion of a one-string system: in the case of a social contingency the individual would only have to address himself or herself in one 
place, the municipality (Andersen, I97I). ${ }^{\mathrm{I}}$ A municipal worker would then handle the case, be it a question of social assistance, sickness benefit, disability benefit or vocational rehabilitation. Benefits paid by the municipality were in varying degrees refunded by the state. In other words, the organisation, administration and financing of cash benefits and reintegration instruments for the work-disabled was highly integrated.

In the event of sickness, wage earners and the self-employed were covered by the sickness benefit act. ${ }^{2}$ Benefits were paid from the first day of work incapacity and until recovery. Employers financed benefits for the first 5 weeks and the municipalities for the remaining period, with 75 percent of their expenditure being reimbursed from a public fund. Benefit amounts were equal to 90 percent of the previous wage with a ceiling of 90 percent of the average wage in the industrial sector.

All adult citizens were covered by a public disability benefit scheme. Eligibility was conditional on invalidity caused by physical or psychological impairment. Work capacity should be permanently reduced with at least 50 percent and improvements through vocational rehabilitation should be impossible. The benefit could be received until eligibility to old age benefit was attained or until recovery, which in practice happened very seldom. There were three benefit categories: full ( Io० percent invalidity degree), medium (67-99 percent), and low (50-66 percent). Benefits were flat rate and meanstested, and were financed by municipalities and contributions from employers (depending on wage expenditure). The municipalities' expenditure on disability benefits was fully reimbursed by the state. The municipalities performed the preparation of benefit applications, but 15 regional state committees were responsible for decisions about benefit awards. ${ }^{3}$

The reintegration instruments were also based on the so-called one-string system. The municipal case managers were supposed to evaluate all cases of sickness benefit, social assistance and, in principle, other cases where vocational rehabilitation seemed to be needed in order for clients to support themselves and their family. In order to assess the need for vocational rehabilitation the case manager could call for medical and vocational expertise, e.g. a test of work capacity. The basic instruments were: general and specific education, job training, wage subsidies and full or partial financing of special equipment and tools. In I977, I9,035 families received economical support according to the provision concerning vocational rehabilitation. In I984 this figure had risen to 37,700 families, corresponding to I.3 percent of the labour force (Valbak and Wamsler, I986).

Finally, it should be noted that the Danish policy allowed (and still does) employers to dismiss workers after a relatively short period of sick leave. 
The white-collar act (funktionærloven) stipulated that employers, if specified in the employment contract, could dismiss a sick-listed worker with one-month's notice when the absence had lasted for I 20 days within one year. The notice of dismissal should be given in direct connection with the I 20 days' sick leave, meaning that this provision could not be used at other times during sick leave (Andersen, I998). Outside the I 20 days, dismissal of sick-listed workers was somewhat more difficult and costly. Formally, dismissal should be motivated by 'reasonable circumstances' related to the company or the worker. In practice 'reasonable circumstances' were settled by court decisions. In relation to the dismissal of sick-listed workers, it appears that in many circumstances it was (and still is) legal to motivate dismissal by conditions either directly or indirectly related to sickness absence. 4

The dismissal of blue-collar workers was (and still is) regulated in several collective agreements and, therefore, the stipulations varied across industrial sectors. Many blue-collar workers were covered by a 'central agreement', which stated that workers with 9 months' seniority could not be dismissed within the first 4 months of sick leave. After this period dismissal could take place with normal notice, with the length depending on seniority. In brief, within the first 4 months of sick leave many blue collars workers were better protected against dismissal than white-collar workers, whereas after 4 months the protection of white-collar workers was relatively good.

A comparison of the Danish and Dutch disability policy in the I980s reveals several similarities and especially differences. Firstly, both nations' sickness benefit schemes appear to have been quite generous with high benefit levels and in practice no limit on benefit receipt. That is, while no legal maximum duration for benefit payments existed in the Danish scheme, Dutchmen losing entitlement to sickness benefits had easy access to disability benefits.

Secondly, the Dutch disability benefit scheme was much more comprehensive and generous than the Danish scheme. Not only did the Danish scheme demand a much higher degree of invalidity than the Dutch scheme, access to full benefits as well as benefit amounts was also much stricter in the Danish scheme. In I 980 , only 30 percent of the Danish beneficiaries received full benefit compared to 85 percent in the Netherlands (Lavindkomst Kommissionens Betænkning, I 982 and Emanuel, I987). In the Netherlands an average wage earner with full disability benefit was in 1978 entitled to an estimated net replacement rate of $80-85$ percent (Emanuel, I 987). In contrast, a Danish male unskilled worker in 1978 was entitled to a net replacement rate of 75 percent (full benefit), 60 percent (medium), and 26 percent (low), respectively (Knudsen, I979). 
Thirdly, vocational rehabilitation seems to have been a much more integrated element in the Danish policy than in the Dutch policy. Thus, in Denmark one law covered vocational rehabilitation (the social assistance act) and only one administrative unit (the municipality) was responsible for benefit payments and the implementation of vocational rehabilitation. In the Netherlands, in contrast, reintegration instruments were split between several laws and the administration was poorly organised (see Chapter 5 ).

Fourthly, the responsibility of employers in terms of legal restrictions as regard the dismissal of sick-listed workers was much more comprehensive in the Netherlands than in Denmark. While it was often impossible for Dutch employers to dismiss a sick-listed worker within the first 2 years of sick leave, dismissal was often possible after 4 months in Denmark.

\section{Defects in Danish disability policy}

The characteristics mentioned above and the relatively slow development in the number of disability beneficiaries (cf. Chapter 4) suggests that Danish disability policy supported attachment to the work pathway. Still, it is possible to point to several defective elements, both at the organisational/administrative level and at the level of the actors involved in the policy.

\section{Problems at the organisational and administrative level}

Job placement for people who were unemployed after completing vocational rehabilitation was performed by the public employment service (Arbejdsformidlingen) meaning that cooperation between the municipality and the public employment service was needed. Valbak (I988) points to a weakness in this construction. On the one hand, the municipal case manager had a good knowledge of the client's work potential, interests, etc., but was not allowed to establish job placement in ordinary employment. On the other hand, the job placement expert had good knowledge of vacant jobs, but a limited knowledge of the client's work capacity, preferences, etc. Consequently, employment results may have been hampered in cases where cooperation between the two organisations was poor. This problem was further accentuated when the $\mathrm{I} 2$ regional vocational rehabilitation centres were closed and their tasks transfer to the municipalities. Now the public employment service agencies had to cooperate with 275 municipalities instead of I 2 regional offices. Finally, during the recession in the late 1970 s and the $1980 \mathrm{os}$ the load on the public employment service increased due to rising unemploy- 
ment. This might have lead the public employment service agencies to give lower priority to the placement of vocational rehabilitation clients, particularly because the prospects of finding employment for people with reduced work capacity are relatively poor when the demand for labour is low.

At the administrative level, the municipalities often failed to fulfil their duty to monitor sickness benefit cases. In order to assess, among other things, the need for vocational rehabilitation it was stipulated that all sickness benefit cases should be evaluated at the latest within 3 months after the beginning of the period of sickness. In many instances this requirement was not met and vocational rehabilitation was, therefore, considered either not at all or too late. Rørbech et al. ( 1985 ) studied sickness benefit cases lasting more than 5 weeks. Among cases lasting I4-26 weeks the followup evaluation was not performed in 40 percent of the cases. Among cases lasting 2752 weeks and cases lasting more than 52 weeks this figure was 3 and 7 percent, respectively.

Another weakness relates to the administrative interpretation of the principle of 'vocational rehabilitation before disability benefit award'. Awarding a disability benefit was illegal unless the municipality had assessed that vocational rehabilitation could not improve the applicant's work capacity. In most cases this assessment took place without vocational rehabilitation having been applied. In a study, only 7 percent of the disability beneficiaries reported having participated in vocational rehabilitation before being awarded benefit (Bengtsson, I989). In addition, vocational rehabilitation was sometimes established after the application for a disability benefit had been forwarded to one of the I 5 benefit award committees. Bengtsson (1989) found that more than half of the municipalities reported that they always or sometimes established vocational rehabilitation after they, on behalf of the client, had applied for a disability benefit. It is therefore reasonable to assume that in many of these cases vocational rehabilitation was used to justify eligibility to disability benefits rather than to advance labour market integration.

\section{Problems at the level of actors}

The sick-listed worker's economic incentive for participation in vocational rehabilitation was in certain cases hampered. In contrast to sickness benefit, the benefit paid during vocational rehabilitation was determined against spousal income. For sick-listed people whose spouse had a medium to high income, this meant that participation in vocational rehabilitation would lead to a reduction of their income. 
The financing of social security benefits gave municipalities an incentive to use the disability pathway instead of the work pathway. Municipalities were entitled to a roo percent state refund of disability benefits and a 75 percent refund of sickness benefits, whereas they only received a 50 percent refund of vocational rehabilitation costs. In other words, they could reduce their expenditure by 'producing' more disability beneficiaries. Obviously, this incentive structure must have increased the number of disability benefit awards. However, it is difficult to assess the magnitude of this effect. On the one hand, municipalities were not directly involved in decisions about disability benefit awards, as these were in the hands of the state committees. When directly asked, the municipal workers answered that they did not take reimbursement rates into consideration in case management decisions (Bengtsson, I989). On the other hand, municipalities were responsible for decisions about whether or not the client should apply for disability benefit and for the preparation of the applications. This is supported by findings showing that the rate of disability benefit awards is related to administrative characteristics of the municipalities (ibid).

\section{Changes during the 1980s: crisis management}

The changes to the disability policy during the I 980 os did not seek to alleviate the above defects. Rather, the development appears to reflect retrenchment to coping with the economic crisis, on the one hand, and continued 'maturation' of the social security programmes, on the other (see Jonasen, I998). The Schlüter right-wing government that came into office in 1982 had as its declared goal improving the economic situation. According to the government, economic problems were related to unemployment, deficits in the balance of payments, and deficits in the public budget. ${ }^{5}$ Priority was especially given to the last two goals (Jonasen, 1998). To achieve this, among other things, the companies' ability to compete on international markets had to be improved through a slow wage (and price) development, and public expenditure in general, and social security expenditure in particular, had to be reduced. In other words, during the I 980 os changes were motivated by 'economic necessity' rather than considerations about the level of sickness absenteeism and the number of disability benefit beneficiaries.

The efforts to retrench social security expenditures did affect the sickness benefit scheme but not the disability benefit scheme. In 1982 the sickness benefit scheme was changed in a number of dimensions. ${ }^{6} \mathrm{~A}$ maximum duration on benefit payments was introduced: benefits could only be received for 
up to 9I weeks within a period of 36 months. A I-day waiting period for benefit receipt was introduced and employers' financing of benefits was extended from the first 5 weeks of sick leave to 13 weeks. It was argued that employers' cost savings from the I-day waiting period would be 'taxed' away by the extended employer period.

While the right-wing parties saw the extension of the employer period as an economic necessity and the left-wing parties left it unnoticed, the I-day waiting period was met with stiff opposition from the left-wing parties that considered it as socially unjust. When in 1986 the government acknowledged that the waiting period had unjust consequences, mainly affecting public sector workers, and the economic conditions had improved somewhat, the 1982 changes were reversed. In 1987 , the I-day waiting period was abolished and the employer period was reduced from I 3 to 5 weeks. This was later reduced to I week in I 988 and then extended to 2 weeks in I 990 (where it has remained).

Another, more successful, conduct of retrenchment concerns the lowering of the sickness benefit. This happened gradually, starting in I979 when the automatic price indexation of benefits was temporarily suspended and followed in 1982 by a new suspension. Instead benefits were to be regulated ad hoc. With this policy the real value of sickness benefits was reduced by 25 percent between I979 and I985 (Jonasen, I998).

The disability benefit scheme was changed in 1984 . This happened against the background of a report published by a disability benefit committee that was established in 1977 (Betænkning nr. 898, I980). In 1983 the government reached an agreement with the Social Democrats about a new disability benefit act, which to a large extent followed the ideas of the committee.

At the administrative level, the orphans benefit (enkepension) and early old age benefit (førtidig folkepension) were collapsed with the disability benefit. Eligibility to disability benefit was extended to include social criteria, and the number of benefit categories was extended from three to five. The 'lowest' benefit with an invalidity degree of 50-66 percent was split into three categories with entitlement based on: I) only medical causes; 2 ) medical and social causes; and 3) means. The full benefit (invalidity degree roo percent) and medium benefit (invalidity degree 67-99 percent) remained unchanged. The changes implied that the lowest benefit level was raised considerably.

The 1984 reform of the disability scheme implied that two new groups of people became eligible to a disability benefit: I) people over 50 who due to social circumstances could not support themselves; and 2) people between 
I 8 and 66 who partly due to health related circumstances and partly due to social circumstances were not able to support themselves. It has been estimated that the I984 change resulted in an annual increase of 3,000-4,000 beneficiaries (Bengtsson, I989).

In brief, the development of the Danish disability policy during the I980s provides a mixed picture. One the one hand, the sickness benefit scheme was affected by retrenchment measures, which were partly offset when the economic situation improved. On the other hand, the disability benefit scheme was extended both in terms of eligibility and amounts of benefit - a development that seems to represent 'a delayed maturing of social security rights' similar to the development of other social security programmes that took place during the r960s and I970s.

\section{Changes during the 1990s: increased emphasis on activation}

In contrast to the I980s where changes to improve work-disabled peoples' attachment to the work pathway were lacking, the policy during the I990s evolved around the idea of activation. By putting greater emphasis on active measures such as vocational rehabilitation the dependency on social security benefits would be reduced.

\section{Reaching consensus about activation}

The first major and almost unanimous political endorsement to the activation strategy was reached in $1989^{7}$ when the third Schlüter government launched a proposal for a combined revision of the sickness benefit act and the stipulations about vocational rehabilitation (in the social assistance act). ${ }^{8}$ The proposal aimed to curb the increasing expenditure related to work injuries, sickness benefits and disability benefits. 9 To achieve this goal, municipalities needed to increase their efforts in bringing people with health problems back into employment. Entitlement to sickness benefits was reduced to I year within 36 months, which should compel municipalities to strengthen (early) followup activities. More emphasis was put on vocational rehabilitation. The means-tested vocational rehabilitation benefit was replaced by a non-means-tested benefit (bruttorevalideringsydelse) of the same size as the sickness benefit. In this way, economic disincentives for potential participants' enrolment in vocational rehabilitation were levelled out. It was stipulated that the municipality was obliged to draw up a rehabilitation plan with a description of instruments (education, job training, 
etc.) and expected vocational result (type of employment). At the same time a so-called pre-vocational rehabilitation period was introduced. Pre-vocational rehabilitation is established when vocational rehabilitation according to a rehabilitation plan is assessed to be necessary but temporarily unfeasible, for instance because the rehabilitee lacks educational or personal abilities. Prevocational rehabilitation may consist of an examination of the work capacity, vocational maturing activities, courses and education. During pre-vocational rehabilitation the rehabilitee is entitled to his/her previous support, e.g. sickness benefit or social assistance.

Finally, the changes comprised what were labelled administrative simplifications: the employer period was extended from I to 2 weeks, eligibility to sickness benefits was made conditional on a certain employment record ( 20 hours of employment within I 3 weeks), and public employers were obliged to finance sickness benefits for their own employees (for as long as they were employed in the company).

For the Social Democrats who intensively fought retrenchments during the I980s, the narrowing of eligibility and entitlement criteria was not seen as retrenchment, it was argued that those who would be affected by the changes were offered vocational rehabilitation instead. In other words, reductions in the right to social security benefits were exchanged for an improved state commitment to returning the sick-listed to work.

With the 1990 changes two defects in the Danish disability policy had been addressed, namely individuals' disincentives for participation in vocational rehabilitation and municipalities' incomplete followup of sickness benefit cases. In I992 a third defect, municipalities' disincentives to establish vocational rehabilitation, was addressed. All rates for state refunds of social benefits to municipalities were harmonised. Refunds for disability benefits and sickness benefits were reduced to 50 percent and thus made equal to the refunds for vocational rehabilitation benefits. Consequently, municipalities were given economic incentives for the initiation of vocational rehabilitation.

\section{The cultivation of public responsibility}

Having obtained political consensus about the merits of activation, the door was opened for further changes. Thus, the policy development in the early I990s, with a strengthening of municipalities' obligations and incentives to activating sick-listed workers while providing municipalities with more/better integration instruments, was further cultivated throughout the I990s.

Municipalities' obligations were strengthened on several occasions. For 
instance, in 1997 , the obligation to perform a followup evaluation of all sickness benefit cases was advanced from 3 to 2 months after the beginning of sick leave, and the followup should now be repeated at least every second month instead of every third month. The municipality also became obliged to draw up a reintegration plan before a sickness benefit case had lasted 6 months. In 1999, it was stipulated that municipalities could not apply for a disability benefit on behalf of the client unless reintegration measures such as vocational rehabilitation had been applied.

In addition to the reintegration plan, municipalities were provided with better integration instruments. Most importantly, the existing wage subsidy scheme, the 50/50 scheme, was replaced with the flexjob scheme in order to prevent further increases in the number of disability beneficiaries. While the $50 / 50$ scheme operated with a 50 percent wage subsidy to people with permanently reduced work capacity, the flexjob scheme comprises three levels $(33,50$ and 67 percent). The present flexjob scheme is also more attractive for the disabled participants. For example, the flexjob scheme covers more different job types, and in 2000 , people in flexjobs were allowed to move from one municipality to another without loosing their flexjob, and their entitlement to special unemployment benefit was improved.

On several occasions the incentives of municipalities to apply active rather than passive measures have been strengthened. Most importantly, in I999, the state refund for disability benefits was reduced from 50 to 35 percent, hence it has become more costly for the municipality to award a disability benefit than to apply vocational rehabilitation measures or job placement in a flex job. To reduce the number of long-term sick-listed workers, municipalities are now also obliged to finance the payment of sickness benefits when they last longer than the normal sickness benefit period of 52 weeks (sickness benefit payments may be extended beyond 52 weeks if, for example, vocational rehabilitation is expected to be established or assessment for a disability benefit is ongoing).

The effect of this incentive policy has been fortified by the decentralization of the disability benefit award procedure. Prior to I 990 disability benefit awards were a matter for I 5 state committees and the municipalities were only responsible for the preparation of applications. Starting in 1989 on an experimental basis, municipalities were gradually delegated greater competence and in 1998 municipalities were given absolute competence to award disability benefits.

As of yet, the culmination of the municipality-based policy aimed at active instead of passive benefit receipt is a reform of the disability benefit scheme that took place in January 2003. It sustains the principle of vocational reha- 
bilitation and wage-subsidized employment prior to considering an application for disability benefit. That is, eligibility to a disability benefit cannot be considered if the client is able to work in an ordinary job or in a flex job. As flex jobs demand a permanently reduction of work capacity by between 50 and 67 percent, eligibility for disability benefit in principle presupposes a reduction of the work capacity of at least twothirds, compared to 50 percent in the old scheme. The new act also aims to increase the focus on clients' work capacities rather than their inabilities. The old procedure of assessing the extent of reduced occupational capacity, which to a large degree relied on medical diagnoses and their impact on the occupational capacity, was replaced with an assessment of the work capacity based on the applicant's de facto ability to work. Finally, the five disability benefit levels were replaced by one level, where the benefit is equal to the sickness benefit for single people and to 70 percent of the sickness benefit for cohabiting people. In this way, the extent of means testing was reduced. On the top of the flat-rate benefit, certain supplementary benefits exist, covering rebuilding of apartments, aids, reimbursement of additional expenses caused by disability, etc.

Alongside the development emphasising municipalities' responsibility for integration, efforts have been made to increase the (voluntary) participation of employers and other actors such as voluntary organisations and unions in work retention and labour market integration of work-disabled people (Damgaard, 2000; Rosdahl, 200I). Starting in I994, the Social Democrat Minister of Social Affairs, Karen Jespersen, launched a campaign 'it concerns all of us - employers' social responsibility'. At the organisational level the policy is supported by the socalled Local Coordination Committees with representative from e.g. the municipality, unions, employers associations and handicap organisations. These committees are advisory to the municipal councils. Since I 999 all municipalities have been instructed to establish coordination committees. Together with a National Coordination Committee, they aim to facilitate labour market integration taking place at local labour markets.

In brief, policy changes during the I 980 s were characterized by efforts to retrenchment the sickness benefit scheme, on the one hand, and an extension of the disability benefit scheme on the other. The policy in the I 980 os evolved around the necessity to curb the increasing public expenditure where policy options were seen as a 'zero sum game' of the choice between more or less social security protection for work-disabled people. In contrast, the development in the I990s was driven by concern about the increasing number of passive people receiving long-term social security benefits and the notion of activation as a reinvented instrument that could turn the zero sum play into 
a win-win solution. It was no longer a question of more or less social security, but a question of providing social security as a combination of entitlements to cash benefits and opportunities for reinsertion into the labour market.

The development of the Danish disability policy since the I980s can be characterized as a cultivation of a policy within a framework that was founded with the first vocational rehabilitation act in 1960 and the social reforms in 1972 to 1976 . The changes to the sickness, disability benefit and vocational rehabilitation schemes have preserved and developed the basic structures of the system. That is, a disability policy based on an extensive public responsibility for the financing and administration of universal cash and inkind benefit schemes; a public local one-string administration combined with state reimbursements of municipalities' social security expenditures; limited responsibility for employers both in terms of financing of benefits and obligations to integrate work-disabled people.

\section{Dutch and Danish disability policies: different developments}

Despite a disability crisis during the I 980 os that was much more profound in the Netherlands than in Denmark, the two nations' policy developments share some important characteristics. In both nations the economic crisis caused a considerable pressure towards retrenchment during the 1980 s, and in both nations efforts to retrench were not very successful, apparently because political consensus was lacking (see also Green-Pedersen, 200I). At the brink of the I990s, in the Netherlands as well as in Denmark, the increasing numbers of passive social security beneficiaries were considered to be a serious problem, although the public and political debate probably was more heated in the Netherlands than in Denmark. In both nations the subsequent policy changes aimed at reducing the number of sickness and disability beneficiaries and increasing citizens attachment to the work pathway.

When it comes to the political strategies and the instruments applied to obtain the political goals the similarity between the Netherlands and Denmark ceases. While Denmark opted for a cultivation of the existing policy, the Netherlands turned the policy into an at least partly new direction. In Denmark the institutional setup of the disability policy remained intact, with a limited responsibility of employers and with public local authorities having the major responsibility for the financing and administration of cash benefits and of integration measures. In the Netherlands, in contrast, the responsibility for the financing and administration of the disability policy has 
been transferred from a semi-public-corporate level to the individual employer. Thus, in contrast to the Danish development, the Dutch development involved a redistribution of responsibilities for the disability policy. It can be argued, therefore, that the Dutch policy changes were of a more fundamental character than those taking place in Denmark (for a discussion of the character of the Dutch changes, see van der Veen and Trommel, I999).

\section{Dutch and Danish disability policies: different principles}

Different policies toward employers

As a consequence of the different developments today's Dutch and Danish disability policies are of a very different nature both in terms of the role of different actors, the incentives these actors face and the policy instruments applied. It is possible to distinguish between four different types of policy instruments (Vedung, 1998; Elmore, 1987; and Chapter 3 in this book): regulation in terms of formulated rules and directives, economic means that involve the transfer of resources such as money, capacity-building measures that comprise investments in future material, intellectual and human resources, and information or moral suasion that aims to make people act in a desired way through the transfer of knowledge, communication of reasoned argument and persuasion. What divides these instruments is the degree of constraint they involve. Regulation is more constraining for the receivers than economic means and capacity-building measures, which are more constraining than information or moral suasion.

In the Dutch policy, the individual employer is a central actor in facilitating the labour market attachment of work-disabled people, and regulation is the primary instrument applied to make employers act in a desirable way. Examples of this are the solid job-protection legislation that forbids employers to dismiss sick-listed workers, employers' obligation to reintegrate workers on sick leave, their obligation to finance sickness benefits and to contract a private consultancy company to assist with the implementation of a sickness and absence policy. These regulations work in two ways. If employers comply with regulations it will result in desirable outcomes: an absenteeism policy will prevent unnecessary sickness, workers that fall ill will not be dismissed, and employers will apply the necessary measures to facilitate their return to work. At the same time these instruments inflict costs upon the employer. This is clearly the case with the financing of sickness benefits and the contracting of a private consultancy company, but also with respect to the job-protection stipulations because it might be costly to retain 
a sick-listed worker, whose future productivity is lower than that of a healthy, newly recruited worker. A consequence of the Dutch regulations, therefore, is that employers have strong incentives to reduce production costs related to work disability. Employers can achieve this by limiting sickness absenteeism and increasing reintegration among their staff, but also by limiting the recruitment of people with health problems. The latter will make it more difficult to integrate non-employed disabled people into the labour market and it may increase discrimination against disabled people if employers increase statistical discrimination, i.e. disregarding all disabled job seekers because on average they have higher sickness rates.

Although less dominant, the Dutch policy also relies on economic means. Wage subsidies for employers who hire partially disabled people, fixed budgets or subsidies for adaptations of the workplace, and the exemption from sick pay during sick leave of partially disabled workers are measures that enhance employers' incentives to recruit workers with reduced work capacity (cf. Chapter 5).

In the Danish policy, employers have a less central role and the preferred instruments are economic means and moral suasion. The flexjob and skaane-job schemes are economic means instruments where wage subsidies prompt employers to employ work-disabled people. The government campaign 'it concerns all of us - employers' social responsibility' where moral arguments are used to persuade employers to enhance the labour market integration of work-disabled people falls within the category of moral suasion. The Local Coordination Committees that aim to involve employers and other actors in the disability policy also entail elements of moral suasion and information.

We can therefore conclude that the Dutch and Danish policies differ in respect of the instruments they apply to affect employers. Regulation is the preferred instrument in the Netherlands whereas economic means and moral suasion are central instruments in Denmark. Consequently, the Dutch policy is much more constraining for employers than the Danish policy; in the Netherlands policy outcomes are obtained by demanding that employers act in a certain way meaning that in principle all employers will act in a similar way. In contrast, Danish employers' scope of action is left almost unrestricted because the policy makes certain actions more economically and maybe also morally attractive to employers than others. However, as the economic costs of certain actions differ from case to case, for example because the severity of workers' illness varies, it is by no means certain that employers will act in a uniform way. It is this difference in mandated responsibility to act in a specific way that justifies the conclusion that the employer 
is a much more central actor in the Dutch policy than they are in the Danish policy.

\section{Different policies toward administrative authorities}

Striking crossnational differences are also present with respect to the role of public authorities. Clearly, these differences mirror the noted diversities between the roles of employers insofar as tasks that have been delegated to employers in the Netherlands rest with public authorities in Denmark. As this delineation of responsibilities takes place via regulation, it can be argued that in both nations regulation is the preferred instrument used to govern how public administrative authorities act in the implementation of the disability policy. In Denmark regulation is used to delegate influence and obligations to public authorities. In contrast, in the Netherlands certain administrative tasks have been delegated to the individual employers that contract private companies such as insurance companies and consultancy companies (Arbodienst) to perform certain administrative duties. Consequently, it can be argued that in the Netherlands regulations serve to restrict or limit public authorities from the sphere of disability policy more than in Denmark. Furthermore, in contrast to the Dutch policy, economic means seem to be an important instrument in the Danish policy towards administrative authorities. For instance, we have seen that reimbursement rates are actively used to induce municipalities to pursue an active rather than a passive disability policy. In this way economic means instruments support the effect of regulations because they increase the likelihood that public authorities will comply with the intentions of regulations. In other words, the Danish policy is different from the Dutch policy both in terms of the extent to which public authorities are delegated influence and responsibilities for the implementation of the policy and in terms of the instruments that are applied to make administrative authorities act in the desired way.

In fact the Danish policy towards public authorities appears to have much in common with the Dutch policy towards employers. In both instances comprehensive tasks and obligations are delegated to the actors through regulations and economic means. There is, however, one important difference. Whereas the use of regulations in the Dutch case represents an intervention in the labour market, this is much less the case in Denmark where local authorities only to a very limited extent operate directly in the labour market. 


\section{Different policies toward work-disabled people}

Employers and public authorities are important actors that influence the outcomes of disability policies because both of them provide resources and impose constraints and opportunities upon disabled people, which influence their employment possibilities and exit conditions (cf. Chapter 3). Following the arguments above, we may expect that sick-listed workers in the Netherlands have a better chance of returning to work with their previous employer than sick-listed workers in Denmark, because Dutch employers have strong economic incentives to retain sick-listed workers. Similarly, it is likely that disabled people without attachment to an employer fare better in Denmark than in the Netherlands.

On the face of it, publicly provided exit conditions through the sickness and disability benefit schemes appear to be better in the Netherlands than in Denmark. The Dutch disability scheme only demands an invalidity degree of $15-25$ percent compared to 67 percent in the Danish scheme. Furthermore, in the Netherlands sick-listed workers are automatically assessed for eligibility to disability benefit when their entitlement to sickness benefit expires. This is not the case in Denmark where municipalities have to apply on behalf of the client and where possibilities for vocational rehabilitation should be exhausted before an application can be filed. Differences in the administrative practices may however counteract these formal differences and it is therefore difficult to conclude that exit conditions are better in the Netherlands than in Denmark.

Dutch workers also seem to enjoy better income protection during sick leave than Danish workers. Thus, the Danish scheme operates with a relatively low benefit ceiling, ${ }^{10}$ and Dutch workers are through collective agreements entitled to full wages during sick leave more often than Danish workers. In I 998 approximately 90 percent of the Dutch workers were entitled to full wages (Schellekens et al., I999), compared to less than 60 percent of the Danish workers (in I 989) (calculated from Nord-Larsen, I 991).

Capacity-building instruments such as vocational rehabilitation that improve the resources of work-disabled people seem to be a much more integrated element in the Danish policy than in the Dutch policy. This is reflected in much higher public expenditure on vocational rehabilitation in Denmark than in the Netherlands (see Chapter 4 ). However, as Dutch employers are responsible for the reintegration of their sick-listed workers, it is possible that vocational rehabilitation is to a large extent established and financed by employers leading to an underestimation of the supply of capacity-building measures in the Netherlands. I will return to this question in Chapter 7. 


\section{Conclusion}

During the last few decades the development of Danish disability policy seems in many respects comparable to the development that took place in the Netherlands. In the I980s the development was affected by the economic stagnation and efforts to retrench, which only succeeded partly, leaving the institutional structures unchanged. During the r 990 os the emphasis on the labour market integration of disabled people was gradually increased. But in contrast to the Netherlands where the responsibilities have been mandated to the individual employer, the development in Denmark can be characterised as a cultivation of the existing policy. That is, a policy based on an extensive public responsibility for the financing and administration of the sickness, disability, and vocational rehabilitation schemes; a public, local one-string administration combined with state reimbursements of municipalities' social security expenditures, and a limited responsibility of employers both in terms of financing of benefits and obligation to integrate disabled people.

A comparison of the present policy in the Netherlands and Denmark suggests that they differ in important respects. A principal difference seems to be the division of the responsibility for the labour market integration of disabled people. In Denmark the labour market integration of people with health problems is mainly a public responsibility, whereas in the Netherlands it is much more the responsibility of the individual employer. The latter is to a great extent obtained through regulations such as job-protection legislation and obligations to finance sickness benefits. Compared to the Danish policy where instruments such as wage subsidies and persuasion campaigns influence the behaviour of employers, the Dutch emphasis on regulations is much more constraining for employers' scope of choice. On the one hand, it makes work disability expensive for employers and, therefore, provides employers with an incentive to reduce sickness absenteeism and increase the labour market reintegration of sick-listed workers. On the other hand, it may also make the integration of non-employed disabled people more difficult because employers may reduce their future costs if they can avoid recruiting people with a high risk of becoming work-disabled. The consequence that these crossnational differences have for the integration of disabled people is the topic of the following chapters. 



\section{Different Routes to Integration}

The Dutch and Danish disability policies differ with respect to with whom the responsibility for labour market integration of sick-listed workers rests. The responsibility of employers is much more extensive in the Netherlands than in Denmark, and vice versa with regard to the responsibility of public authorities. Workers' income protection during sick leave constitutes another difference: Dutch workers generally seem to enjoy better income protection during sick leave than Danish workers. This and the following two chapters shed light on how these differences influence the labour market integration of work-disabled people.

Extensive employer responsibility makes it costly and difficult for employers to substitute sick-listed workers. Compared to the Danish policy, we should, therefore, expect that the Dutch policy will enhance the labour market attachment of disabled workers. But we should also anticipate that the Dutch policy makes labour market entry difficult for disabled people without attachment to an employer, because employers will be reluctant to recruit people whom they expect have high sickness absenteeism rates. In contrast, the Danish policy stresses a public responsibility for the integration of disabled people. In this respect an extensive public supply of vocational rehabilitation measures is an integrated part of Danish policy. Consequently, we should expect that in Denmark disabled peoples' labour market integration will often be facilitated by such measures.

This chapter seeks to uncover to what extent these institutional differences exist, and how they influence the mechanisms through which labour market integration takes place. Does the solid job-protection legislation in the Netherlands reduce dismissals of sick-listed workers? Does the extensive responsibility of employers increase their efforts in integrating sick-listed workers? Similarly, does the formal emphasis on publicly supplied vocational rehabilitation in Denmark lead to more disabled people participating in such measures? How these differences affect labour market integration of disabled people is studied in the next chapter.

The empirical analyses rest to a large extent on data from a crossnational 
study of long-term sick-listed workers. These data are briefly described in the next section. In the proceeding sections the consequences of crossnational differences in job-protection legislation, the supply of vocational rehabilitation measures, and income protection during sick leave are discussed.

\section{The data}

The study of the consequences of the Dutch and Danish disability policies are mainly based on data from a comparative study, Work Incapacity and Reintegration, carried out under the auspices of the International Social Security Association (Bloch and Prins, I997; 200I). In the six participating nations data was gathered according to common guidelines concerning:

- The demarcation of the cohort

- The observation period

- The timing and frequency of the collection of data

- The contents of the data collection

The national cohorts consisted of workers who: had been continuously sicklisted for 90-I 20 days on admission to the study, were sick-listed with certain low back pain diagnoses, fully work incapacitated and aged between I 8 and 59. Data was collected three times: shortly after admission to the study (wave I), a year after the first day of work incapacity (wave 2), and 2 years after the first day of work incapacity (wave 3). The variables to be measured, their content and response categories were specified for each of the three waves. The common guidelines ensure that the Dutch and Danish data are quite homogenous with regard to duration of sickness absence, diagnoses and age.

The data have two advantages. Most crossnational studies of sick leave and disability policies are based on macro-level data (e.g. Einerhand, et al., I995; Prins, I990; Bergeskog, 200I; EIM, 2002). Consequently, the number of crossnational differences that can be taken into consideration is restricted (Esping-Andersen, I 993). In contrast, the present data allows us to combine macro-level information (e.g., about job-protection legislation) with micro-level data (about sick-listed workers), thus making it possible to take numerous conditions into account. Furthermore, the comparability of studies based on existing macro data may be restricted because the delineation of populations and definitions of policy instruments and other issues of interest varies across nations. 
Some limitations of the data should, however, be noted. Neither of the cohorts is necessarily representative for all Dutch, or Danish, long-term sicklisted workers with a low back pain diagnosis. The Dutch cohort is collected among private sector workers who at the time of selection had hired a private consultancy company to assist in the implementation of a prevention and reintegration policy (the obligation to hire a private consultancy company was not implemented in full when the collection of data began). The Danish cohort is drawn from private sector workers from the 24 largest municipalities in the country. ${ }^{\mathrm{I}}$ This poses a limitation to the reliability of descriptive analyses, whereas it is expected to be of less importance in causal analyses because causal relationships are assumed to be sufficiently similar in different groups of sick-listed workers, for example between workers with residence in small and large municipalities.

The timing of the data collection should also be noted. The collection of data was carried out between I 995 and I997, with the result that several of the changes in the Dutch and Danish disability policies were not yet established. Most importantly the major part of the Dutch financial reforms of the sickness and disability benefit schemes had not been implemented by the beginning of the study. ${ }^{2}$ Consequently the effects of the Dutch reforms were not fully manifest. On the other hand, fundamental crossnational differences between the Dutch and Danish policies with regard to employers' responsibility were present at the time, indicating that a meaningful comparison is feasible.

Information about the two data sets is shown in Table 7.I.

In the Dutch study 547 people were approached for participation and data was gathered for 427 people in the first measurement round, wave I, corresponding to a response rate of 78 percent. In the Danish study 668 people were approached and 565 participated in the first measurement round corresponding to a response rate of 85 percent. For a few selected characteristics there is no sign of significant differences between respondents who participated in the first wave and those who did not (Prins, Veerman and van der Giezen, I996; Høgelund and Modvig, I998). The analyses deal with the complete 2-year observation period and they are based on respondents who participated both in the first and the second wave. 
Table 7.1 Sick-listed workers in the Dutch and Danish data sets.

\begin{tabular}{llllll}
\hline & Dutchdata & Danishdata & & Total \\
\hline Measurement & $\begin{array}{l}\text { Private } \\
\text { workers }\end{array}$ & $\begin{array}{l}\text { Private } \\
\text { workers }\end{array}$ & $\begin{array}{l}\text { Public } \\
\text { workers }\end{array}$ & $\begin{array}{l}\text { Privateand } \\
\text { public workers }\end{array}$ \\
\hline Wave $^{1}$ & 427 & 386 & 178 & 565 & 992 \\
Wave $^{1}$ & 392 & 327 & 166 & 494 & 886 \\
Wave $^{1}$ & 370 & 284 & 156 & 441 & 811 \\
\hline
\end{tabular}

Source: Høgelund (2002)

1 Wave 1 was on average carried out 4 months (NL) and $5^{1 / 2}$ months (DK) after the first day of work incapacity. Wave 2 and wave 3 were on average carried out 13 months and 25 months, respectively, after the first day of work incapacity.

\section{Dismissals during sick leave 3}

Dutch job-protection legislation against dismissal during sick leave is much stricter than the provisions stipulated in Danish legislation and major collective agreements. We should therefore expect to find more workers dismissed during sick leave in the Danish data than in the Dutch. This does indeed seem to be the case.

Half of the private sector workers in the Danish data were dismissed during sick leave whereas this was only the case for I I percent in the Dutch data, see Table 7.2. Thus, dismissals occur $4^{\mathrm{T} / 2}$ times as often in the Danish data as in the Dutch data. Furthermore, among those workers who were dismissed, the average time until dismissal was I I.I months among the Dutch but only 4.I months for the Danes. This gives further support to the importance of job-protection stipulations, because in Denmark the stipulations often allow employers to effectuate dismissals after 4 months of sick leave within a year.

These crossnational differences may be exacerbated, however, because they may also reflect crossnational differences that are unrelated to provisions about job protection during sick leave. Danish employers may for other, e.g. cultural, reasons dismiss their workers more often and quicker than Dutch employers. The differences may also reflect differences between the sampling procedures used to create the two data sets. For example, if workers with low educational attainment are overrepresented in the Danish data and are also dismissed relatively frequently, this may cause the noted differences. Accordingly, adjustments with regard to such circumstances should be made. 
Table 7.2 Dismissals during sick leave among long-term sick-listed workers with low back pain diagnoses (as percentages).

\begin{tabular}{llll}
\hline & $\begin{array}{l}\text { Denmark } \\
\text { Private workers } \\
\text { (percent) }\end{array}$ & $\begin{array}{l}\text { The Netherlands } \\
\text { Private workers } \\
\text { (percent) }\end{array}$ & Significance level \\
\hline Dismissed & 50 & 11 & $* * *$ \\
\hline $\begin{array}{l}\text { Number of cases } \\
\text { used in calculations }\end{array}$ & 319 & 390 & \\
\hline
\end{tabular}

Source: Høgelund (2002).

Note: Dismissed people include people who were dismissed before first returning to work. For 70 people the calculations are based only on the first year of the observation period. The significance level is calculated in a $\chi^{2}$-test: ${ }^{*}$ : significant at a 10 percent level of significance, ${ }^{* *}$ : significant at a 5 percent level, ${ }^{* * *}$ : significant at a 1 percent level, NS: not significant at a 10 percent level.

In order to shed light on this issue, the probability of dismissal during sick leave is estimated in a multivariate regression model. The explanatory variables are supposed to capture conditions that in general are supposed to affect the likelihood of dismissal (Colbjørnsen, I986; Klaas, Brown and Heneman, I998; Langager, I993). At the micro level conditions related to five different types of explanations are considered:
I Productivity
2 Seniority
3 Loyalty
4 Structural resources
5 Company vulnerability

It is anticipated that workers with low productivity have a high risk of dismissal because they have a lower net value for the firm than workers with a high productivity. Productivity is often assumed to be associated with age, educational background, on-the-job training, previous periods of unemployment, sick leave and health (Colbjørnsen, I986, Andersen, I99I). Workers with little seniority are expected to have an above average risk of dismissal because seniority rules often stipulate that 'the last hired is the first fired'. Employers may abstain from the dismissal of workers whom they consider as loyal towards the company or workers they expect to suffer greatly from dismissal. When workers are loyal to their company they make up a steady and compliant labour supply whereby employers' turnover costs are minimised. 
Some workers possess structural resources that give them a certain control over their job, which may protect them from dismissal. This is so because it is complicated to measure the productivity of workers in autonomous jobs, which in turn makes it difficult for employers to determine whether it will be efficient to dismiss the workers in question (Colbjørnsen, I986). Companies in certain branches are particularly vulnerable to fluctuations in the demand for their products and workers in these companies are therefore assumed to run a higher risk of dismissal (Topel, I982).

Finally, at the macro-level, crossnational differences in the dismissal rate during sick leave may be caused by the fact that Danish companies in general dismiss more often than Dutch companies. This may very well be true. Thus, among people who left their job within the past 6 months in 1993I994 dismissals and redundancies occurred more than 3 times as often in Denmark as in the Netherlands (OECD, 1997). This difference may however not only reflect the risk of dismissal but also the chance of finding a new job (ibid.). Such crossnational differences may be caused by differences in national economic conjunctures or by different labour market structures making it more or less difficult or costly to dismiss workers. This may for instance concern job-protection legislation (unrelated to sickness) and the unemployment insurance system that may influence the workers' costs of being dismissed, which in turn may affect their demand for job security and/or compensation in the event of dismissal.

The results of a logistic regression model that estimates the risk of dismissal during sick leave is shown in Table 7.3 (descriptive statistics of the explanatory variables are shown in Appendix A).

The importance of nationality and therefore the importance of provisions concerning job protection is supported: The probability of dismissal is considerably higher among workers in the Danish group than in the Dutch group. A comparison of the estimates in Table 7.3 with those in Table 7.2 suggests that the crossnational difference in the risk of dismissal is not reduced when crossnational differences in other explanatory variables are taken into account. 4

We can also see that educational attainment, pain intensity, gender and seniority are significant. The coefficients of these variables are as expected, i.e. male workers with a high level of education, little pain and long seniority have a low risk of dismissal. The importance of these variables to some extent supports the assumptions about productivity (pain intensity, education), seniority, and structural resources (education, gender).

As the branch is insignificant no support is provided for the assumption that dismissals are caused by companies' vulnerability to fluctuations in the 
Table 7.3 Logistic regression model of dismissal of long-term sick-listed private sector workers with low back pain diagnoses $(n=663)$.

\begin{tabular}{|c|c|c|c|}
\hline Variable & Coefficient level & Std.Error & $\begin{array}{l}\text { Significance } \\
\text { level }\end{array}$ \\
\hline Nationality (Denmark=1) & 2.649 & 0.265 & $* * *$ \\
\hline \multicolumn{4}{|l|}{ Productivity } \\
\hline Age & 0.005 & 0.012 & NS \\
\hline \multicolumn{4}{|l|}{ Educational background: 1} \\
\hline Secondary $($ yes $=1)$ & -0.730 & 0.362 & ** \\
\hline Tertiary $($ yes $=1)$ & -1.719 & 0.545 & $* * *$ \\
\hline Pain intensity, scale 1 to 10 (much pain) & 0.263 & 0.051 & $* * *$ \\
\hline \multicolumn{4}{|l|}{ Number of weeks on sick leave the year } \\
\hline & & & \\
\hline \multicolumn{4}{|l|}{ Seniority } \\
\hline Number of months in present job² & -0.405 & 0.146 & $* * *$ \\
\hline \multicolumn{4}{|l|}{ Loyalty } \\
\hline Living with a spouse? (yes=1) & 0.205 & 0.311 & NS \\
\hline Living together with children? (yes=1) & 0.049 & 0.232 & NS \\
\hline \multicolumn{4}{|l|}{ Structural resources } \\
\hline Sex $($ female $=1)$ & 0.554 & 0.266 & $* *$ \\
\hline Country of birth (not born in & & & \\
\hline country $=1$ ) & 0.517 & 0.388 & NS \\
\hline \multicolumn{4}{|l|}{ Occupation in pre-sick leave job: 3} \\
\hline Sales, service $($ yes $=1$ ) & 0.253 & 0.362 & NS \\
\hline Craft and plant work (yes $=1$ ) & 0.186 & 0.421 & NS \\
\hline Elementary work (yes $=1$ ) & -0.614 & 0.565 & NS \\
\hline \multicolumn{4}{|l|}{ Company vulnerability } \\
\hline \multicolumn{4}{|l|}{ Company branch: 4} \\
\hline Trade (yes=1) & 0.358 & 0.348 & NS \\
\hline Private service (yes $=1$ ) & 0.192 & 0.340 & NS \\
\hline Public, social, educ. sector (yes=1) & -0.065 & 0.372 & NS \\
\hline $\begin{array}{l}\text { Company size: Number of workers in } \\
\text { company }^{2}\end{array}$ & 0.047 & 0.038 & NS \\
\hline \multicolumn{4}{|l|}{ General dismissal tendency } \\
\hline $\begin{array}{l}\text { Company history: (Layoffs within the } \\
\text { year before present sick leave }=1 \text { ) }\end{array}$ & 0.066 & 0.475 & NS \\
\hline $\begin{array}{l}\text { Constant } \\
\text { Log likelihood }\end{array}$ & -1.319 & $\begin{array}{l}0.858 \\
-278.5\end{array}$ & NS \\
\hline
\end{tabular}

Note: All variables are measured at the first interview, wave 1. Significance levels: ${ }^{*}$ : significant at a 10 percent level of significance, ${ }^{* *}:$ significant at a 5 percent level, ${ }^{* * *}:$ significant at a 1 percent level, NS: not significant at a 10 percent level.
1 Reference category: primary education
2 Figure multiplied by 100.
3 Reference category: manager, professional.
4 Reference category: primary and secondary sector. 
demand for products. The general dismissal tendency is also insignificant suggesting that, even though Danish employers in general tend to dismiss their workers more often than Dutch employers, it does not explain why sick-listed workers are dismissed more often in the Danish data than in the Dutch data. ${ }^{5}$

In brief, the data supports the fact that Dutch job-protection legislation makes employers refrain from dismissing sick-listed workers. This may be interpreted as if this legislation increases employers' responsibility for sicklisted workers, because it induces employers to give their sick-listed workers a 'second chance' of returning to work.

\section{The supply of vocational rehabilitation measures}

In principle one can distinguish between two different types of vocational rehabilitation. Capacity-building measures comprise measures that aim to improve the work capacity of disabled people and consequently their chance of finding employment. These measures comprise job training and educational activities. Another type of measure seeks to adjust or reduce job demands in order to meet the abilities of disabled people. These so-called workplace-based measures include workplace adjustments, changes in job tasks and changes in working hours. This section describes how often these two different types of measures are established among Dutch and Danish long-term sick-listed workers.

\section{Educational activities}

While publicly provided, and financed, vocational rehabilitation measures have been an integrated element in Danish policy for many years, such instruments have apparently not been important in Dutch policy (see Chapter 4). This is supported by Table 7.4, which shows long-term sick-listed workers' participation in general educational activities such as secondary level school classes. ${ }^{6}$

The table shows that Io percent of the sick-listed workers in the Danish cohort participated in general education compared to only 2 percent in the Dutch cohort. ${ }^{7}$ 
Table 7.4 Participation in general education during sick leave among long-term sick-listed workers with low back pain diagnoses (as a percentage).

\begin{tabular}{llll}
\hline & $\begin{array}{l}\text { Denmark } \\
\text { Private workers } \\
\text { (percent) }\end{array}$ & $\begin{array}{l}\text { The Netherlands } \\
\text { Private workers } \\
\text { (percent) }\end{array}$ & Significance level \\
\hline $\begin{array}{l}\text { Participated in general } \\
\text { education }\end{array}$ & 10 & 2 & \\
\hline $\begin{array}{l}\text { Number of cases } \\
\text { used in calculations }\end{array}$ & 323 & 390 & \\
\hline
\end{tabular}

Note: For 70 people, calculations are based only on the first year of the observation period. Significance level is calculated in a $\chi^{2}$-test: ${ }^{*}:$ Significant at a 10 percent level of significance, ${ }^{* *}:$ significant at a 5 percent level, ${ }^{* * *}:$ significant at a 1 percent level, NS: not significant at a 10 percent level.

\section{Workplace-based measures}

Many sick-listed workers who return to work may continue to have healthrelated problems and reduced work capacity. The working conditions in the job they return to may therefore be crucial to their possibility of remaining in work. If job demands exceed their work capacity, many of those resuming work may report sick again. To avoid this, employers and the social security office can establish workplace-based vocational rehabilitation measures that reduce job demands.

When a sick-listed worker returns to work with their original employer, i.e. the employer where the sick-listed worker reported sick, the establishment of workplace-based measures will be costly for the employer. This is because it involves a deviation from the pre-sick leave situation. For example, if the sick-listed worker's working hours are reduced it may be costly for the employer because another worker will have to take over some of the jobbased tasks. The establishment of workplace-based vocational rehabilitation measures can therefore be said to reflect the efforts of employers to facilitate integration. Keeping in mind that the incentives of Dutch employers to reintegrate their sick-listed workers are stronger than those of Danish employers, we should expect that in the Netherlands workplace-based measures are established more often among sick-listed workers who return to work with the old employer than among those returning to work with a new employer.

Table 7.5 presents figures for the frequency of workplace-based rehabilitation defined as either workplace adaptation, new tasks or new working hours. 
Table 7.5 Workplace-based rehabilitation measures among long-term sick-listed private sector workers with low back pain diagnoses (as a percentage).

\begin{tabular}{|c|c|c|c|c|c|c|}
\hline & \multicolumn{3}{|l|}{ Denmark } & \multicolumn{3}{|c|}{ The Netherlands } \\
\hline & $\begin{array}{l}\text { Old } \\
\text { employer } \\
\text { (percent) }\end{array}$ & $\begin{array}{l}\text { New } \\
\text { employer } \\
\text { (percent) }\end{array}$ & $\begin{array}{l}\text { Total } \\
\text { (percent) }\end{array}$ & $\begin{array}{l}\text { Old } \\
\text { employer } \\
\text { (percent) }\end{array}$ & $\begin{array}{l}\text { New } \\
\text { employer } \\
\text { (percent) }\end{array}$ & $\begin{array}{l}\text { Total } \\
\text { (percent) }\end{array}$ \\
\hline Workplace adaptations & $36^{*}$ & $23^{*}$ & 28 & $35^{* * *}$ & $13^{* * *}$ & 32 \\
\hline New job tasks & $39^{* * *}$ & $82^{* * *}$ & 64 & $45^{\mathrm{NS}}$ & $49^{\text {NS }}$ & 46 \\
\hline New working hours & $36^{\mathrm{NS}}$ & $48^{\mathrm{NS}}$ & 43 & $67^{* * *}$ & $34^{* * *}$ & 62 \\
\hline At least one measure & $67^{* * *}$ & $85^{* * *}$ & 78 & $81^{* * *}$ & $64^{* * *}$ & 79 \\
\hline Number of observations & 60 & 85 & 145 & 268 & 47 & 315 \\
\hline
\end{tabular}

Note: The analysis concerns respondents that report to be working 1 year (wave 2) and/or 2 years (wave 3 ) after the first day of work incapacity. Differences are tested in a $\chi^{2}$-test: ${ }^{*}$ : significant at a 10 percent level of significance, ${ }^{* *}$ : significant at a 5 percent level, ${ }^{* * *}:$ significant at a 1 percent level, Ns: not significant at a 10 percent level.

The table shows several interesting results. Firstly, we can see that work resumption with the original employer happens much more frequently in the Dutch data than in the Danish data. 85 percent returned to work with their old employer in the Dutch data, whereas this was only true for 4I percent of workers in the Danish data. This marked crossnational difference can be ascribed to institutional differences. In the Netherlands returning to work with the old employer is likely because it is costly and/or difficult for Dutch employers to get rid of sick-listed workers, making it more attractive for employers to retain them. Furthermore, the job search intensity of sicklisted workers will often be restricted as long as they have a vacant job to return to, as is the case in the Netherlands.

Secondly, the table supports the theory that crossnational institutional differences also lead to differences in how often workplace-based vocational rehabilitation is established with the old employer and a new employer, respectively. Thus, in the Dutch data at least one rehabilitation measure is established in $8 \mathrm{I}$ percent of the cases where the sick-listed worker returned to work with the old employer, compared to only 64 percent among those who returned to work with a new employer. The reverse is true in the Danish data: workplace-based measures are established in only 67 percent of the cases where the sick-listed worker returned to work with the old employer, compared to 85 percent among those who returned to work with a new employer (these differences do not change when corrections for other explana- 
tory variables are made, cf. Appendix B).

How can we explain the difference in the Danish data? As noted, workplace-based measures are often costly for the original employer. Nevertheless, this is much less the case when a sick-listed worker returns to work with a new employer. While workplace adaptations are of course costly also for a new employer, new working hours and a change in job tasks will not normally be costly for a new employer because these changes do not represent deviations from a pre-sick leave situation. That is, we may assume that employment contracts entered in the ordinary labour market express the preferences of both jobseekers and employers. In other words, the finding may reflect a 'compensatory strategy' of the sick-listed workers: when the need for workplace-based measures cannot be meet with old employer, because the sick-listed workers are dismissed, the need is accomplished through a job change.

In other words, this suggests that Dutch and Danish disability policies differ in important respects. The differences in employers' formal responsibility toward sick-listed workers seem to lead to different mechanisms both with regard to return to work patterns and the supply of workplace-based vocational rehabilitation. Dutch policy seems to facilitate return to work with the old employer who is induced to establish workplace-based vocational rehabilitation measures. In contrast, Danish policy leads to labour market integration with a new employer, and because this involves a job change it also often allows sick-listed workers to change their working conditions. That is, workplace-based vocational rehabilitation measures are apparently established without public involvement. ${ }^{8}$ The public responsibility for labour market integration of work-disabled people seems to stop at the factory gate: while it is a public responsibility to provide capacitybuilding measures in terms of education that may help people to enter employment, it is left to market forces to establish workplace-based vocational rehabilitation measures that may help workers to remain employed.

\section{Income protection during sick leave}

Crossnational differences in income protection during sick leave are the final issue that will be scrutinized in this chapter. A comparison of the Dutch and the Danish legislation on income protection unveil that Danish workers are entitled to a replacement rate of roo percent up to a quite low ceiling, whereas Dutch workers are guaranteed a replacement rate of 70 percent up to a relatively high ceiling (cf. Chapter 6). We should therefore expect that 
Table 7.6 Entitlement to sickness benefit and wage, respectively, during sick leave among long-term sick-listed workers with low back pain diagnoses (as a percentage).

\begin{tabular}{llll}
\hline & $\begin{array}{l}\text { Denmark } \\
\text { Private workers } \\
\text { (percent) }\end{array}$ & $\begin{array}{l}\text { The Netherlands } \\
\text { Private workers } \\
\text { (percent) }\end{array}$ & Significance level \\
\hline $\begin{array}{l}\text { Entitled to wages } \\
\text { Entitled to sickness benefit }\end{array}$ & 34 & $86^{1}$ & $* * *$ \\
\hline $\begin{array}{l}\text { Number of cases used } \\
\text { in calculations }\end{array}$ & 316 & 283 & \\
\hline
\end{tabular}

Note: Crossnational differences are tested in a $\chi^{2}$-test: ${ }^{*}$ : significant at a 10 percent level of significance, ${ }^{* *}$ : significant at a 5 percent level, ${ }^{* * *}$ : significant at a 1 percent level, NS: not significant at a 10 percent level.

1 The figure includes people who report to receive sickness benefit during sick leave having a replacement rate above 0.95 .

2 The figure does not include people who report to receive sickness benefit during sick leave having a replacement rate above 0.95 .

workers with low incomes have higher replacement rates in Denmark than in the Netherlands, and workers with medium to high incomes have lower replacement rates in Denmark than in the Netherlands.

These differences, however, may be influenced by crossnational differences in the extent to which workers are entitled to full wage during sick leave through either collective or internal company agreements. It is therefore the aim of this section to shed light on two questions: are Dutch workers entitled to full wage payments during sick leave more often than Danish workers? And do we find the expected crossnational differences in net replacements rates among workers that only are entitled to sickness benefit during sick leave.

\section{Entitlement to wages during sick leave}

The net replacement rate is calculated as the post-tax (net) income during sick leave (in terms of sickness benefit or wage) divided by the net income before sick leave. Table 7.6 shows the percentage of workers entitled to sickness benefit and wage during sick leave, respectively.

Table 7.6 shows that sick-listed private sector workers in the Dutch data are entitled to wages during sick leave much more often than private sector workers in the Danish data. Only about one in three of the Danes are entitled to wage during sick leave compared to almost nine out of ten of the 
Table 7.7 Average net replacement rates of long-term sick-listed workers with low back pain diagnoses entitled to sickness benefit during sick leave (standard error).

\begin{tabular}{|c|c|c|c|c|c|}
\hline & \multicolumn{2}{|l|}{ Denmark } & \multicolumn{3}{|c|}{ The Netherlands } \\
\hline & $\begin{array}{l}\text { Private } \\
\text { workers }\end{array}$ & $\begin{array}{l}\text { Number } \\
\text { of cases } \\
\text { used in } \\
\text { calcu- } \\
\text { lations }\end{array}$ & $\begin{array}{l}\text { Private } \\
\text { workers }\end{array}$ & $\begin{array}{l}\text { Number } \\
\text { of cases } \\
\text { used in } \\
\text { calcu- } \\
\text { lations }\end{array}$ & $\begin{array}{l}\text { Significance } \\
\text { level }\end{array}$ \\
\hline $\begin{array}{l}\text { Average net replacement rate } \\
\text { among sickness recipients } \\
\text { with pre-wage income below } \\
\text { the median') }\end{array}$ & $0.83(0.012)$ & 97 & $0.80(0.037)^{2}$ & 18 & NS \\
\hline $\begin{array}{l}\text { Average net replacement rate } \\
\text { among sickness recipients } \\
\text { with pre-wage income above } \\
\text { the median') }\end{array}$ & $0.62(0.013)$ & 77 & $0.79(0.043)^{2}$ & 21 & $* * *$ \\
\hline $\begin{array}{l}\text { Average net replacement rate } \\
\text { among all sickness recipients }\end{array}$ & $0.74(0.012)$ & 174 & $0.79(0.028)^{2}$ & 39 & $*$ \\
\hline
\end{tabular}

Note: Entitlement to sickness benefit comprises people with replacement rates below 95 percent. The number of people entitled to sickness benefit during sick leave does not correspond to the number of people mentioned in Table 7.6. because of missing values on replacement rates. The significance level is calculated in a two-tailed T-test: ${ }^{*}$ : significant at a 10 percent level of significance, ${ }^{* *}$ : significant at a 5 percent level, ${ }^{* * *}$ : significant at a 1 percent level, NS: not significant at a 10 percent level.

1 Includes sickness recipients who before the beginning of the sickness spell had a net wage income below/above the median net pre-wage income among all sick-listed, i.e. among sicklisted entitled to wage during sick leave and sick-listed entitled to sickness benefit.

2 The figure does include people who report to receive sickness benefit during sick leave and have a replacement rate below 0.95 .

Dutchmen. It therefore seems that Dutch workers in the private sector are covered by collective agreements or company-based agreements giving them entitlement to wage during sick leave much more often than their Danish colleagues.

\section{Entitlement to sickness benefit}

Net replacement rates of sick-listed workers entitled to sickness benefit during sick leave are shown in Table 7.7. Replacement rates for low and high income workers are also shown in order to clarify whether workers with low 
income have relatively good income protection in Denmark, and if workers with high income have a relatively good income protection in the Netherlands. ${ }^{9}$

The figures only partly confirm the expected crossnational differences. As expected, Dutch workers with high pre-wages have higher replacement rates than Danish workers. The average replacement rate for Dutch workers with a high pre-wage income is 0.79 compared to only 0.62 among Danish workers.

We would, however, also expect the average replacement rate of workers with low pre-wages to be higher among Danish workers than among Dutch workers. This is apparently not the case, i.e. the average replacement rate is 0.83 in the Danish data and 0.80 in the Dutch data. The low replacement rates of Danish workers seem to reflect that a large proportion have preearnings above the statuary ceiling and therefore have replacement rates well below roo percent. This is illustrated by the fact that the average net replacement rate is 0.92 among the very few (IO) workers with a monthly net pre-wage income up to DKK 6,000, which is below or near the ceiling. In other words, it is likely that the Danish sickness benefit scheme yields high replacement rates for low wage workers, but only a few workers have such low wage incomes that they enjoy a high replacement rate.

To sum up, this section has shown that Dutch workers through collective agreements and company agreements seem to be entitled to wage during sick leave much more frequently than Danish workers. As regards income protection legislation, the data only allow for tentative conclusions and suggest that high-income groups tend to have better income protection in the Netherlands than in Denmark.

\section{Conclusion}

This chapter has addressed the immediate consequences of some of the important differences between Dutch and Danish disability policies. Most of our expectations have been supported by the data. Compared to the Danish situation, the solid job-protection legislation in the Netherlands apparently leads to fewer dismissals of sick-listed workers. I argue that this finding can to a large extent be attributed to how the nations' policies affect employers' costs when workers are at risk of being marginalised from the labour market. In the Netherlands employers' costs are high because they cannot easily get rid of sick-listed workers, and in recent years also because their responsibility for the financing of sickness and disability benefits has increased. Con- 
sequently, it is much more attractive for Dutch than for Danish employers to retain sick-listed workers, and to provide workplace-based vocational rehabilitation measures that can facilitate their continued employment.

This interpretation is supported by the data. We find that sick-listed workers in the Dutch data returned to work with the old employer much more often than the sick-listed workers in the Danish data. A similar difference appears when we look at workplace-based vocational rehabilitation measures such as workplace adaptations, changes in working hours and new job tasks. Among the Dutch respondents these measures are much more frequently established when the sick-listed worker returns to work with the old employer than is the case when return to work takes place with a new employer. The reverse is true among sick-listed workers in the Danish data.

These differences confirm that Dutch and Danish disability policies rest on very different principles. The Dutch regulation-based policy delegates the responsibility for the labour market integration of disabled people to the individual employer. In contrast, the limited use of regulation instruments in Denmark makes labour market integration more a matter of unrestrained labour market forces combined with public provision of capacity-building measures aiming at an upgrading of work-disabled peoples' resources.

Judging from the issues considered in this chapter, both policies can be said to be effective, but in different respects. The Dutch policy is effective because the regulations guiding employers' obligations seem to work as intended, that is, employers do not dismiss sick-listed workers and they often provide workplace-based vocational rehabilitation measures that can facilitate continued employment. The Danish policy is effective in the sense that it does not interfere with market mechanisms. The findings concerning workplace-based vocational rehabilitation measures illustrate this. When sick-listed workers return to work with a new employer, which is often the case in Denmark, changes in working hours and job tasks do not inflict additional costs upon the employer because these conditions have been agreed upon in an employment contract. In contrast, when sick-listed workers return to work with their original employer, which is often the case in the Netherlands, changes in working hours and job tasks do result in additional costs for the employer because these conditions represent deviations from the pre-sick leave labour contract.

In short, despite the fact that Dutch and Danish policies rest on very different principles, both of them seem to have positive consequences. Unfortunately, as we will see in the next two chapters both policies also comprise drawbacks that counteract the labour market integration of disabled people. 


\section{Appendix A \\ Descriptive statistics for explanatory variables used in the dismissal analysis}

Table 1 Descriptive statistics for variables used in the dismissal analysis. Long-term sick-listed private sector workers. Separate for the Dutch and the Danish data sets.

\begin{tabular}{|c|c|c|c|}
\hline & Denmark & The Netherland & \\
\hline Variable & Mean (SD) & Mean (SD) & $\begin{array}{l}\text { Significance } \\
\text { level }\end{array}$ \\
\hline \multicolumn{4}{|l|}{ Productivity } \\
\hline Age & $39.67(10.21)$ & $39.91(9.43)$ & NS \\
\hline \multicolumn{4}{|l|}{ Educational background: } \\
\hline Primary (yes $=1$ ) & $0.07(0.25)$ & $0.14(0.34)$ & $* * *$ \\
\hline Secondary (yes=1) & $0.81(0.39)$ & $0.80(0.40)$ & NS \\
\hline Tertiary $($ yes $=1)$ & $0.12(0.33)$ & $0.06(0.24)$ & $* * *$ \\
\hline \multicolumn{4}{|l|}{ Number of weeks on sick leave the year } \\
\hline prior to present sick leave & $3.77(7.91)$ & $3.38(6.95)$ & NS \\
\hline Pain intensity, scale 1 to 10 (much pain) & $5.50(2.35)$ & $5.71(2.19)$ & NS \\
\hline \multicolumn{4}{|l|}{ Seniority } \\
\hline Number of months in present job & $71.16(83.28)$ & $119.26(100.05)$ & $* * *$ \\
\hline \multicolumn{4}{|l|}{ Loyalty } \\
\hline Living with a spouse? (yes=1) & $0.79(0.41)$ & $0.91(0.28)$ & $* * *$ \\
\hline Living together with children? (yes $=1$ ) & $0.50(0.50)$ & $0.35(0.48)$ & $* * *$ \\
\hline Sex: (female $=1)$ & $0.45(0.50)$ & $0.38(0.48)$ & $* *$ \\
\hline Country of birth (not born in country=1) & $0.10(0.30)$ & $0.03(0.17)$ & $* * *$ \\
\hline \multicolumn{4}{|l|}{ Occupation in pre-sick leave job: } \\
\hline Manager, professional (yes $=1$ ) & $0.13(0.34)$ & $0.20(0.40)$ & ** \\
\hline Sales, service (yes $=1$ ) & $0.32(0.47)$ & $0.30(0.46)$ & NS \\
\hline Craft and plant work (yes=1) & $0.45(0.50)$ & $0.45(0.50)$ & NS \\
\hline Elementary work $($ yes $=1$ ) & $0.09(0.28)$ & $0.05(0.23)$ & $*$ \\
\hline \multicolumn{4}{|l|}{ Company vulnerability } \\
\hline \multicolumn{4}{|l|}{ Company branch: } \\
\hline Primary, secondary sector (yes=1) & $0.44(0.50)$ & $0.44(0.50)$ & NS \\
\hline Trade (yes $=1$ ) & $0.15(0.36)$ & $0.14(0.35)$ & NS \\
\hline Private Service (yes=1) & $0.19(0.39)$ & $0.19(0.39)$ & NS \\
\hline Public, social, educ. sector (yes=1) & $0.22(0.42)$ & $0.22(0.42)$ & NS \\
\hline $\begin{array}{l}\text { Company size: Number of workers } \\
\text { in company }\end{array}$ & $\begin{array}{l}147.72 \\
(422.39)\end{array}$ & $\begin{array}{l}102.80 \\
(155.87)\end{array}$ & $*$ \\
\hline Company size observed (missing=1) & $0.04(0.19)$ & $0.06(0.25)$ & NS \\
\hline
\end{tabular}




\section{Dismissal tendency}

Company history: (layoffs within the last year before present sick leave $=1$ )

Company history observed (missing=1)

$0.22(0.41)$

$0.14(0.35)$

$0.07(0.26) \quad 0.03(0.16)$

Number of cases

321

390

Note: All variables are measured at the first interview, wave 1.

1 The significance level is calculated in a two-tailed T-test: ${ }^{*}$ : significant at a 10 percent level of significance, ${ }^{* *}:$ significant at a 5 percent level, ${ }^{* * *}:$ significant at a 1 percent level, NS: not significant at a 10 percent level.

To limit the number of missing observations the logistic model in Table $7 \cdot 3$ includes two dummy variables indicating if company size and company history, respectively, are missing. Their coefficients are insignificant (with $\mathrm{p}$ values of 0.448 and 0.889 , respectively) and they are not displayed in Table $7 \cdot 3$. 


\section{Appendix B \\ Logistic regression models of workplace-based vocational rehabilitation measures.}

Table 1 Reduced logistic regression model of workplace adaptation among Dutch long-term sick-listed private sector workers with low back pain diagnoses who returned to work $(n=301)$.

\begin{tabular}{llll}
\hline Variable & Coefficient & Std. Error & $\begin{array}{l}\text { Significance } \\
\text { level }\end{array}$ \\
\hline Returned to work with new employer (yes=1) & -1.288 & 0.484 & $* * *$ \\
Pain intensity, scale 1 to 10 (much pain) & 0.155 & 0.062 & $* *$ \\
Number of months in present job & $-0.256^{1}$ & $0.153^{1}$ & $*$ \\
Occupation in pre-sick leave job ${ }^{2}$ : & & & \\
$\quad$ Sales, service (yes=1) & -0.659 & 0.370 & $*$ \\
$\quad$ Craft and plant work (yes=1) & -0.547 & 0.351 & NS \\
$\quad$ Elementary work (yes=1) & -0.309 & 0.620 & NS \\
Company size: Number of workers in company & $0.158^{1}$ & $0.081^{1}$ & $*$ \\
Constant & 0.436 & 0.744 & NS \\
Log likelihood & & -172.7 &
\end{tabular}

Note: The analysis concerns respondents that report to be working 1 year (wave 2) and/or 2 years (wave 3) after the first day of work incapacity. All explanatory variables are measured at the first interview, wave 1. Significance levels: ${ }^{*}$ : significant at a 10 percent level of significance, ${ }^{* *}$ : significant at a 5 percent level, ${ }^{* * *}$ : significant at a 1 percent level, NS: not significant at a 10 percent level. The model has a p value of 0.480 in a Hosmer-Lemeshow test.

1 Figure multiplied by 100.

2 Reference category: manager, professional.

(Insignificant) variables included in the analysis: age, educational attainment, previous sick leave (number of weeks on sick leave the year prior to present sick leave), living with a spouse, living together with children, sex, physical job demands, and company history (layoffs within the year before present sick leave).

To limit the number of missing observations the logistic model in table I includes a dummy variable indicating if company size is missing. The coefficient is insignificant (with a p value of O.I 50 ) and it is not shown in Table I.

The odds ratio of workplace adaptation (of respondents returning to work with a new employer versus those returning to work with the old employer) calculated from Table 7.5 is 0.28 with a $95 \%$ confidence interval on [0.I I;0.66], and the odds ratio based on the coefficient of the logistic model in Table $\mathrm{I}$ is 0.28 with a $95 \%$ confidence interval on [0.I I ; O.7I]. 
Table 2 Reduced logistic regression model of new job tasks among Dutch long-term sick-listed private sector workers with low back pain diagnoses who returned to work $(n=304)$.

\begin{tabular}{|c|c|c|c|}
\hline Variable & Coefficient & Std. Error & $\begin{array}{l}\text { Significance } \\
\text { level }\end{array}$ \\
\hline Returned to work with new employer (yes $=1$ ) & 0.075 & 0.336 & NS \\
\hline Pain intensity, scale 1 to 10 (much pain) & 0.111 & 0.055 & ** \\
\hline $\begin{array}{l}\text { Physical job demands, index } 1 \text { to } 4 \\
\text { (not demanding) }\end{array}$ & -0.322 & 0.189 & $*$ \\
\hline Constant & -0.285 & 0.644 & NS \\
\hline Log likelihood & & -172.7 & \\
\hline
\end{tabular}

Note: The analysis concerns respondents that report to be working 1 year (wave 2) and/or 2 years (wave 3) after the first day of work incapacity. All explanatory variables are measured at the first interview, wave 1. Significance levels: ${ }^{*}$ : significant at a 10 percent level of significance, ${ }^{* *}:$ significant at a 5 percent level, ${ }^{* * *}$ : significant at a 1 percent level, $\mathrm{NS}$ : not significant at a 10 percent level. The model has a $p$ value of 0.598 in a Hosmer-Lemeshow test.

(Insignificant) variables included in the analysis: age, educational attainment, previous sick leave (number of weeks on sick leave the year prior to present sick leave), seniority, occupation in pre-sick leave job, living with a spouse, living together with children, sex, company size and company history (layoffs within the year before present sick leave).

The odds ratio of new job tasks (of respondents returning to work with a new employer versus those returning to work with the old employer) calculated from Table 7.5 is I.I 7 with a $95 \%$ confidence interval on [0.63;2.17], and the odds ratio based on the coefficient of the logistic model in Table 2 is I.08 with a $95 \%$ confidence interval on $[0.56 ; 2.08]$. 
Table 3 Reduced logistic regression model of working with new working hours among Dutch long-term sick-listed private sector workers with low back pain diagnoses who returned to work $(n=310)$.

\begin{tabular}{|c|c|c|c|}
\hline Variable & Coefficient & Std. Error & $\begin{array}{l}\text { Significance } \\
\text { level }\end{array}$ \\
\hline Returned to work with new employer (yes $=1$ ) & -1.736 & 0.382 & $* * *$ \\
\hline \multicolumn{4}{|l|}{ Occupation in pre-sick leave job ${ }^{1)}$} \\
\hline Sales, service $($ yes $=1$ ) & -0.500 & 0.395 & NS \\
\hline Craft and plant work (yes $=1$ ) & -1.115 & 0.432 & $* *$ \\
\hline Elementary work (yes $=1$ ) & -1.291 & 0.649 & $* *$ \\
\hline Age & -0.036 & 0.015 & ** \\
\hline Sex $($ female $=1)$ & -1.051 & 0.392 & $* * *$ \\
\hline Children & 0.478 & 0.274 & * \\
\hline Constant & 4.875 & 0.920 & $* * *$ \\
\hline Log likelihood & & -185.1 & \\
\hline
\end{tabular}

Note: The analysis concerns respondents that report to be working 1 year (wave 2) and/or 2 years (wave 3 ) after the first day of work incapacity. All explanatory variables are measured at the first interview, wave 1. Significance levels: ${ }^{*}$ : significant at a 10 percent level of significance, ${ }^{* *}$ : significant at a 5 percent level, ${ }^{* * *}$ : significant at a 1 percent level, NS: not significant at a 10 percent level. The model has a p value of 0.476 in a Hosmer-Lemeshow test.

1 Reference category: manager, professional.

(Insignificant) variables included in the analysis: educational attainment, previous sick leave (number of weeks on sick leave the year prior to present sick leave), pain intensity, seniority, living with a spouse, physical job demands, company size and company history (layoffs within the year before present sick leave).

The odds ratio of new working hours (of respondents returning to work with a new employer versus those returning to work with the old employer) calculated from Table 7.5 is 0.25 with a $95 \%$ confidence interval on [0.1 $3 ; .0 .49$ ], and the odds ratio based on the coefficient of the logistic model in Table 3 is 0.18 with a $95 \%$ confidence interval on [0.08;0.37]. 
Table 4 Reduced logistic regression model of workplace adaptation among Danish long-term sick-listed private sector workers with low back pain diagnoses who returned to work ( $n=145$ ).

\begin{tabular}{llll}
\hline Variable & Coefficient & Std. Error & $\begin{array}{l}\text { Significance } \\
\text { level }\end{array}$ \\
\hline Returned to work with new employer (yes=1) & -0.595 & 0.387 & NS \\
Occupation in pre-sick leave job: ${ }^{\prime}$ & & & $*$ \\
$\quad$ Sales, service (yes=1) & -0.930 & 0.533 & $*$ \\
$\quad$ Craft and plant work (yes=1) & -1.221 & 0.473 & NS \\
$\quad$ Elementary work (yes=1) & -1.310 & 0.885 & NS \\
Constant & 0.931 & 0.676 & \\
Log likelihood & & -82.8 & \\
\hline
\end{tabular}

Note: The analysis concerns respondents that report to be working 1 year (wave 2) and/or 2 years (wave 3) after the first day of work incapacity. All explanatory variables are measured at the first interview, wave 1 . Significance levels: ${ }^{*}$ : significant at a 10 percent level of significance, ${ }^{* *}$ : significant at a 5 percent level, ${ }^{* * *}$ : significant at a 1 percent level, $\mathrm{NS}$ : not significant at a 10 percent level. The model has a p value of 0.071 in a Hosmer-Lemeshow test.

1 Reference category: manager, professional.

(Insignificant) variables included in the analysis: educational attainment, previous sick leave (number of weeks on sick leave the year prior to present sick leave), pain intensity, seniority, living with a spouse, living with a children, age, sex, physical job demands, company size and company history (layoffs within the year before present sick leave).

The odds ratio of workplace adaptation (of respondents returning to work with a new employer versus those returning to work with the old employer) calculated from Table 7.5 is 0.53 with a $95 \%$ confidence interval on [0.24; 1.02$]$, and the odds ratio based on the coefficient of the logistic model in Table 4 is 0.55 with a $95 \%$ confidence interval on [0.26; I.I8]. 
Table 5 Reduced logistic regression model of new job tasks among Danish long-term sick-listed private sector workers with low back pain diagnoses who returned to work $(n=145)$.

\begin{tabular}{|c|c|c|c|}
\hline Variable & Coefficient & Std. Error & $\begin{array}{l}\text { Significance } \\
\text { level }\end{array}$ \\
\hline Returned to work with new employer (yes $=1$ ) & 2.487 & 0.469 & $* * *$ \\
\hline \multicolumn{4}{|l|}{ Occupation in pre-sick leave job: ${ }^{1}$} \\
\hline Sales, service $($ yes $=1$ ) & -0.224 & 0.609 & NS \\
\hline Craft and plant work (yes $=1$ ) & 1.181 & 0.550 & ** \\
\hline Elementary work (yes=1) & -0.730 & 0.838 & NS \\
\hline Constant & -3.468 & 0.783 & $* * *$ \\
\hline Log likelihood & & -71.2 & \\
\hline
\end{tabular}

Note: The analysis concerns respondents that report to be working 1 year (wave 2) and/or 2 years (wave 3) after the first day of work incapacity. All explanatory variables are measured at the first interview, wave 1. Significance levels: *: significant at a 10 percent level of significance, ${ }^{* *}$ : significant at a 5 percent level, ${ }^{* * *}$ : significant at a 1 percent level, NS: not significant at a 10 percent level. The model has a p value of 0.736 in a Hosmer-Lemeshow test.

1 Reference category: manager, professional.

(Insignificant) variables included in the analysis: educational attainment, previous sick leave (number of weeks on sick leave the year prior to present sick leave), pain intensity, seniority, living with a spouse, living with a children, age, sex, physical job demands, company size and company history (layoffs within the year before present sick leave).

The odds ratio of new job tasks (of respondents returning to work with a new employer versus those returning to work with the old employer) calculated from Table 7.5 is 7.13 with a $95 \%$ confidence interval on [ $3.79 ; \mathrm{I} 8.2 \mathrm{I}$ ], and the odds ratio based on the coefficient of the logistic model is I 2.02 with a $95 \%$ confidence interval on $[4.80 ; 30.14]$. 
Table 6 Reduced logistic regression model of working with new working hours among Danish long-term sick-listed private sector workers with low back pain diagnoses who returned to work $(n=144)$.

\begin{tabular}{llll}
\hline Variable & Coefficient & Std. Error & $\begin{array}{l}\text { Significance } \\
\text { level }\end{array}$ \\
\hline Returned to work with new employer (yes=1) & 0.886 & 0.369 & ${ }^{* *}$ \\
Pain intensity, scale 1 to 10 (much pain) & 0.134 & 0.072 & ${ }^{*}$ \\
Sex (female=1) & 0.730 & 0.366 & ${ }^{* *}$ \\
Constant & -2.600 & 0.728 & $* *$ \\
Log likelihood & & -91.5 & \\
\hline
\end{tabular}

Note: the analysis concerns respondents who report to be working 1 year (wave 2) and/or 2 years (wave 3) after the first day of work incapacity. All explanatory variables are measured at the first interview, wave 1. Significance levels: ${ }^{*}$ : significant at a 10 percent level of significance, ${ }^{* *}$ : significant at a 5 percent level, ${ }^{* * *}$ : significant at a 1 percent level, $\mathrm{NS}$ : not significant at a 10 percent level. The model has a p value of 0.659 in a Hosmer-Lemeshow test.

(Insignificant) variables included in the analysis: age, educational attainment, previous sick leave (number of weeks on sick leave the year prior to present sick leave), seniority, occupation in pre-sick leave job, living with a spouse, living together with children, physical job demands, company size and company history (layoffs within the year before present sick leave).

The odds ratio of new working hours (of respondents returning to work with a new employer versus those returning to work with the old employer) calculated from Table 7.5 is $\mathrm{r} .64$ with a $95 \%$ confidence interval on [I.I6;4.62], and the odds ratio based on the coefficient of the logistic model in Table 6 is 2.42 with a $95 \%$ confidence interval on [I.I $8 ; 5.00$ ]. 



\section{Different Policies-Different Outcomes}

The Dutch and Danish policies differ with respect to the division of the responsibility for the integration of disabled people into the labour market. In the Netherlands this responsibility mainly rests with the individual employer, whereas in Denmark it is largely delegated to public authorities. This chapter sheds light on some of the consequences that these differences have for the extent to which disabled people are integrated into the labour market.

The Dutch regulations make it costly for employers to marginalise sicklisted workers and we should therefore expect that it will enhance the labour market integration of disabled workers. The drawback, however, might be that Dutch employers will be reluctant to employ people with health problems without prior labour market attachment because they may have an above average risk of becoming long-term sick-listed, which in turn may induce costs upon employers. Another drawback might be that the relatively good income protection during sick leave that Dutch workers enjoy might give them economic incentives to enter and stay on the disability pathway.

Whereas the Danish policy may not suffer from the same drawbacks as the Dutch policy, it is likely that it encounters other problems. The comprehensive public responsibility in terms of vocational rehabilitation is supposed to help work-disabled people to work. But it is an open-ended question if vocational rehabilitation can offset the negative consequences that may stem from the widespread dismissal of sick-listed workers. In spite of vocational rehabilitation, it is possible that these people will be unable to find ordinary employment because of their health problems.

To address these questions, I use the theoretical framework set out in Chapter 3 to identify factors that affect the return to work of long-term sick-listed workers. Within this analytical model it is then possible to disentangle some of the effects that the unique characteristics of the Dutch and Danish disability policies have for the labour market integration of workdisabled people. That is, do dismissals counteract the reintegration of longterm sick-listed workers? Does an extensive income protection reduce rein- 
tegration? Does vocational rehabilitation in terms of education help the sick-listed back to work? And equally important: do the high employer costs in the Netherlands reduce the labour market integration of partially workdisabled people without prior labour market attachment?

\section{The return to work of long-term sick-listed workers}

I have used the framework from Chapter 3 to select variables to be included in the analysis of factors affecting the return to work of sick-listed workers. To recap, three major different groups of factors can be expected to affect the future labour market status of a work-disabled person:

- The disabled individual's characteristics

- Employment conditions

- Exit conditions

Each sick-listed individual possesses resources that influence the possibility of returning to work. These resources concern health and other personal and occupational skills such as educational background. In addition to these resources, the sick-listed worker may find their situation as work-disabled to be associated with social and psychological costs, which will influence their inclination to work: when costs are high the inclination to work is strong. During sick leave individual health resources may be affected by medical treatments, whereas other individual resources may be strengthened through participation in capacity-building instruments such as vocational rehabilitation.

Independent of individual characteristics, structural conditions in terms of employment and exit conditions may facilitate or limit the possibility of resuming work. Employment conditions concern conditions that affect the possibility of returning to work with the old employer, employment possibilities in the ordinary labour market, and employment in special jobs for disabled people. Exit conditions concern the sick-listed worker's access to financial resources that make it possible to stay outside the labour market, e.g. on sickness benefit or financial support from family members.

In the empirical analysis, sick-listed workers' individual characteristics are measured using eight variables. ${ }^{\mathrm{I}}$ Individual bealth resources are measured, as self-perceived pain intensity and whether or not the sick-listed worker in addition to low back pain suffers from other diseases. Other resources are measured in terms of educational attainment, seniority and oc- 
cupation, which may indicate skills that the sick-listed worker possesses, e.g. a professional worker is supposed to possess more job related skills than a manual worker. ${ }^{2}$ Social and psychological costs of work disability are measured as the sick-listed worker's perception of the support that he or she received from colleagues and superiors prior to becoming sick. When job support is comprehensive, the costs of being out of work are expected to be high and so are the chances of resuming work. In addition to these individual characteristics, sex and age are also included.

Employment conditions with the original employer are measured using two variables: physical job demands and dismissal. Because of low back problems, sick-listed workers in physically demanding jobs are supposed to have a relatively low chance of returning to work. We can also assume that workers who are dismissed during sick leave have a very limited chance of returning to work because dismissal indicates that the possibility of returning to work with the original employer is limited. Employment conditions in the ordinary labour market are measured as the ratio between the number of years employed since the age of 20 and the worker's age. This variable expresses the individual's labour market history and 'success and failure' in the labour market and therefore presumably also future employment possibilities (see Jensen, I 997). Clearly, it would have been better to also include a variable that captures the demand for labour such as the local unemployment rate. Due to the lack of data, it is not possible to include such a variable in the crossnational analysis, but its importance will be addressed in a separate analysis based on the Danish data.

Exit conditions are measured using two variables, one measuring the possibilities for labour market exit through the family, another measuring exit conditions related to the social security system. The family variable measures the income of other family members relatively to the sick-listed worker's wage income prior to becoming sick. The social security variable measures the income that the sick-listed worker received during sick leave divided by the wage income prior to becoming sick. The disability benefit scheme is another important potential exit pathway that work-disabled people may use. How the disability benefit award policy of local authorities affect the return to work of long-term sick-listed workers is analysed separately using the Danish data.

\section{The importance of the dismissal and replacement rate}

The empirical analysis of factors influencing the return to work of longterm sick-listed workers is based on a panel of about 700 Dutch and Danish 
Table 8.1 Return to work among long-term sick-listed private sector workers with low back pain diagnoses. Separate for workers who are (not) dismissed during sick leave (as a percentage).

\begin{tabular}{lllllll}
\hline & Denmark & & \multicolumn{3}{l}{ The Netherlands } & \\
& $\begin{array}{l}\text { Not } \\
\text { dismissed } \\
\text { (percent) }\end{array}$ & $\begin{array}{l}\text { Dismissed } \\
\text { (percent) }\end{array}$ & Total & $\begin{array}{l}\text { Not } \\
\text { dismissed } \\
\text { (percent) }\end{array}$ & $\begin{array}{l}\text { Dismissed Total } \\
\text { (percent) }\end{array}$ & \\
& $75^{* * *}$ & $41^{* * *}$ & 59 & $91^{* * *}$ & $26^{* * *}$ & 85 \\
$\begin{array}{l}\text { Returned to work } \\
\begin{array}{l}\text { Number of cases used } \\
\text { in calculations }\end{array}\end{array} 164$ & 155 & 319 & 356 & 34 & 390 \\
\hline
\end{tabular}

Note: Dismissed people include people who were dismissed before first return to work. For 70 people, calculations are based only on the first year of the observation period.

The significance level is calculated in a $\chi^{2}$-test: ${ }^{*}$ : significant at a 10 percent level of significance, ${ }^{* *}:$ significant at a 5 percent level, ${ }^{* *}$ : significant at a 1 percent level, NS: not significant at a 10 percent level.

private sector workers who were long-term sick-listed with low back problems (see Chapter 7 for a description of the data).

Before considering the estimated results of a complete model of returning to work, it might be fruitful to look at the association between dismissal and return to work (see Table 8.I).

From the table we can see that the percentage of long-term sick-listed workers returning to work is much higher in the Dutch cohort, 85 percent, than in the Danish cohort, 59 percent. We can also see that dismissal in both data sets seems to have a strong effect on the chance of returning to work: sick-listed workers who are not dismissed return to work much more often than those who are dismissed. Knowing that the frequency of dismissals is about 50 percent in the Danish data and only Io percent in Dutch data, the crossnational differences in job protection legislation seems to be an important explanation for the high return to work rate in the Dutch cohort.

It is important, however, to remember that dismissals occur in the course of the sick leave, and, therefore, factors may exist that both affect the risk of being dismissed and the chance of returning to work. For instance, if poorly educated workers are often dismissed during sick leave and often do not return to work because they lack educational skills, it is not the fact that they are dismissed that prevents them from returning to work but the lack of educational resources. To isolate the effect of dismissal, we need to take account of such common factors. When observed common factors are taken into consideration, the effect of dismissal remains to be strong and significant (Høgelund, 2002, and Table 2 in appendix C). 
The common causes of dismissal and return to work may also be unknown to us. For example, if we do not measure the sick-listed worker's motivation to work, it is possible that low work motivation prevents them from returning to work, rather than the fact that they are dismissed. One way of dealing with this problem is to make a two-step estimation, first estimating the probability of dismissal and then using these estimates when estimating the probability of returning to work (e.g. Greene, 2000). The results of such estimation are presented in Table 8.2 The findings suggest that in the Dutch cohort dismissal significantly prolongs the time off work, i.e. the median time to return to work for a dismissed person is estimated to be $9^{\mathrm{I} / 2}$ times longer than for a person who has not been dismissed. In contrast, the effect of dismissal is insignificant in the Danish data. ${ }^{3}$ This seems to indicate that the Danish long-term sick-listed workers possess characteristics that increase the chance of dismissal and at the same time reduce the chance of returning to work.

It may appear as a paradox that dismissal has a positive effect on the likelihood of returning to work in the Dutch data but not in the Danish data. It does, however, make sense in the light of the crossnational differences in the institutional setup. The strict Dutch job-protection legislation makes it difficult for employers to get rid of sick-listed workers. As a consequence employers who cannot lay off sick-listed workers have strong incentives to facilitate their return to work, even though the work capacity of these workers may be considerably reduced. This is because the alternative is even more costly. It is costly to keep a vacant job available in case the sick-listed worker should return to work, and since 1996 and 1998 it has become even more costly as employers are obliged to finance sickness and disability benefits.

At the same time this explanation indicates why the chance of returning to work is low when the sick-listed worker is dismissed. These people are forced to find work with a new employer who will be reluctant to offer them a job because their extensive sick leave record indicates that they have a potentially high future risk of disability. In other words, the effect of dismissal may reflect that the Dutch disability policy tends to create an insider/outsider divide between work-disabled people with and without attachment to an employer.

That the Dutch policy causes employment problems for work-disabled outsiders is also supported by other pieces of evidence. After the financial reforms of the sickness benefit scheme, Dutch employers have apparently employed strategies other than reintegration to reduce the financial costs associated with work disability. Thus, it has been observed that employers increasingly employ workers on temporary contracts, meaning that the oblig- 
Table 8.2 Log-logistic survival analysis of time to first returning to work of long-term sick-listed private sector workers with unobserved heterogeneity. Separate for the Dutch and the Danish data sets.

\begin{tabular}{|c|c|c|}
\hline & Denmark & The Netherlands \\
\hline Variable & Coefficient (SE) & Coefficient (SE) \\
\hline \multicolumn{3}{|l|}{ Individual resources, health } \\
\hline Pain intensity, scale 1 to 10 (much pain) & $0.220(0.068)^{* * *}$ & $0.068(0.028)^{* *}$ \\
\hline $\begin{array}{l}\text { Chronic disease, not including } \\
\text { back condition (yes }=1 \text { ) }\end{array}$ & $0.452(0.250)^{*}$ & $-0.365(0.188)^{*}$ \\
\hline \multicolumn{3}{|l|}{ Individual resources, skills } \\
\hline \multicolumn{3}{|l|}{ Educational background: ${ }^{1}$} \\
\hline Secondary (yes=1) & $-1.126(0.462)^{* *}$ & \\
\hline Tertiary $($ yes $=1)$ & $-1.066(0.689)^{\mathrm{NS}}$ & \\
\hline Seniority: number of months in present job ${ }^{2}$ & & $-0.084(0.063)^{\mathrm{NS}}$ \\
\hline \multicolumn{3}{|l|}{ Occupation in pre-sick leave job: ${ }^{3}$} \\
\hline Sales, service $($ yes $=1)$ & $0.669(0.268)^{* *}$ & $-0.002(0.139)^{N S}$ \\
\hline Craft and plant work (yes $=1$ ) & $0.528(0.272)^{*}$ & $-0.340(0.141)^{* *}$ \\
\hline Elementary work (yes $=1$ ) & $0.506(0.372)^{\mathrm{NS}}$ & $-0.134(0.211)^{\mathrm{NS}}$ \\
\hline
\end{tabular}

Individual psychological and social costs of disability

$\begin{array}{lll}\text { Job support, index } 1 \text { to } 4 \text { (much) } & -0.264(0.122)^{* *} & -0.492(0.174)^{* * *} \\ \text { Other individual characteristics } & & -0.409(0.145)^{* * *} \\ \text { Sex: (female=1) } & 0.016(0.009)^{*} & 0.017(0.006)^{* * *} \\ \text { Age } & & \end{array}$

Employment conditions, old employer

Risk of dismissal, between $o$ and 1 (high risk) 4

Physical job demands, index 1 to 4 (low demands)

$0.743(1.370)^{\text {NS }} \quad 2.248(0.784)^{* * *}$

$-0.137(0.106)^{\mathrm{NS}} \quad-0.299(0.081)^{* * *}$

Employment conditions, ordinary labour market

Number of years employed

$-1.097(0.439)^{* *} \quad-0.465(0.250)^{*}$

since the age of 20 divided by age

\section{Exit conditions}

Replacement rate

Replacement rate observed? (missing=1)

Income from other household members

divided by the sick-listed person's pre-sick

$$
\begin{array}{ll}
-0.248(0.417)^{\mathrm{NS}} & -0.025(0.292)^{\mathrm{NS}} \\
-0.352(0.732)^{\mathrm{NS}} & -0.136(0.308)^{\mathrm{NS}} \\
-0.235(0.135)^{*} & -0.011(0.030)^{\mathrm{NS}}
\end{array}
$$

leave wage ${ }^{2}$

Income from other household members

observed? (missing=1)

$-0.370(0.270)^{\mathrm{NS}} \quad 0.133(0.132)^{\mathrm{NS}}$ 


\begin{tabular}{|c|c|c|}
\hline $\begin{array}{l}\text { Constant } \\
\text { Gamma } \\
\text { Unobserved heterogeneity with a } \\
\text { Gamma distribution }\end{array}$ & $\begin{array}{l}3.535(1.186)^{* * *} \\
0.574(0.068) \\
0.549(0.308)^{* *}\end{array}$ & $\begin{array}{l}2.486(0.762)^{* * *} \\
0.373(0.029) \\
0.712(0.146)^{* * *}\end{array}$ \\
\hline Log likelihood & -365.9 & -451.2 \\
\hline Number of cases & 302 & 348 \\
\hline \multicolumn{3}{|l|}{$\begin{array}{l}\text { Note: All variables are measured at the first int } \\
\text { "income from other household members", whi } \\
\text { cance levels: *: significant at a } 10 \text { percent level c } \\
\text { ***: significant at a } 1 \text { percent level, Ns: not signi } \\
1 \text { Reference category: primary education } \\
2 \text { Figure multiplied by } 100 . \\
3 \text { Reference category: manager, professional. } \\
4 \text { Estimated risk of dismissal, cf. Appendix D. }\end{array}$} \\
\hline
\end{tabular}

ation to reintegrate workers on sick leave and pay their sickness benefits ends when the employment contract expires (Sociaal en Cultureel Planbureau, I997). Similarly, employers have also applied health tests to jobseekers to avoid employing people with a high risk of falling ill (ibid.). To counteract this, the Dutch government enacted a law in 1998 that forbids employers to use health examinations and to ask jobseekers questions about their health and past sick leave record unless the job involves special fitness demands. Despite this regulation, employers continue to use health examinations and questions about health status when they recruit new personal (Oorschot and Boos, 2000). Finally, it has been noted that the employment chances of disability beneficiaries has decreased significantly since the privatisation of the sickness benefit scheme. The number of disability benefits terminated because the recipients started to work relatively to the stock of disability beneficiaries has decreased from 6.I percent before privatisation (I995) to approximately 3.5 percent afterwards (I996-1997) (Sociaal en Cultureel Planbureau, 2000, referred from Oorschot, 200I).

The above analysis also indicates that the Danish policy does not suffer from insider-outsider problems. The lax job-protection legislation in combination with limited employer responsibility means that the reintegration of long-term sick-listed workers to a large extent takes place based on market conditions. That is, the old employer will only retain sick-listed workers and promote their reintegration if it is economically worthwhile compared to the option of employing a new and healthy worker. Similarly, a new employer will only recruit a disabled person if it seems profitable. In other words, the integration of disabled people entirely depends on their working potential. 
We can conclude that the institutional structures of the Dutch policy seem to increase the return to work of long-term sick-listed workers: employers refrain from dismissing workers on sick leave which in turn increases their reintegration. The downside of the Dutch policy is related to the fact that employers have to bear the majority of the costs of the policy. They have to pay either for the reintegration that may follow from employing a person with permanently reduced productivity, or for the costs associated with the dismissal of the sick-listed workers. The major drawback of the Danish policy appears to be a limited reintegration of workers with health problems caused by a policy that only provides employers with limited incentives to retain these workers. However, this may have the advantage that it facilitates an efficient job match because employers are not stuck with workers that do not fit the employer's demands for manpower. In other words, the Danish policy does not seem to make the labour market entry of work-disabled people outside the labour market extraordinarily difficult.

Finally, the analysis does not support the fact that the workers' income compensation during sick leave affects whether or not they return to work. As shown in Table 8.2, the replacement rate is very insignificant, with a $p$ value of 0.552 in the Danish model and 0.932 in the Dutch model. Also, there is no indication that the effect of replacement rate differs between groups of sick-listed workers, e.g. that the replacement rate has a positive effect for old people and a negative effect for young people. To test for the existence of such effects, the interactions between the replacement rate and each of the other explanatory variables in Table 8.2 have been tested, but no interactions were significant, either in the Danish or the Dutch model. It is of course possible that the replacement rate affects the return to work of workers sick-listed for shorter periods than those that are under study here. But as suggested in the literature review the evidence on this issue is mixed (see Chapter 2).

\section{The importance of capacity-building measures}

Capacity-building measures in terms of vocational rehabilitation are an important element in the Danish disability policy (EIM, 2002). The increased emphasis on active measures in the I 990 os was at least partly seen as a strategy that could increase the labour market integration of people with health problems without damaging their social rights. That is, a publicly provided supply of capacity-building measures should compensate for a stricter disability benefit award policy (see Chapter 6). Phrased in the context of the present analysis, the question is: does vocational rehabilitation help long- 
term sick-listed workers back to work? To shed light on this question, it is analysed whether participation in general education or vocational education increases the probability of returning to work in the Danish data. As in the estimation of the effect of dismissal, I have used a two-step procedure: the probability of participation in educational activities is estimated and then entered into the return-to-work model in Table 8.2 (see Appendix E for the results of the estimates of participation in education).

The fact that 20 percent of the long-term sick-listed workers participated in education during sick leave confirms that capacity-building measures are an integrated element in the Danish policy. Nevertheless, this does not seem to help the sick-listed back to work. The variable for participation in education is insignificant, although the p value of O.I4I and the negative coefficient of the variable suggest that education may tend to shorten the duration of the absence from work. It could be argued that the lack of an effect is caused by a too-short observation period: at the time when the observation period ends many participants are still under education, and because job search activities decrease during participation in education, the positive effect of having completed an education is not sufficiently captured in the analysis. However, this seems not to be the case. A followup study of the Danish cohort, where the long-term sick-listed workers were interviewed 5 years after their first day of work incapacity, does neither find an effect of participation in education (Høgelund and Holm, 2002). Another objection concerns the lumping together of general and vocational education into one variable. As general education, in contrast to vocational education, does not qualify for a specific job type, it is possible that a positive effect of vocational education is mixed up with a negative effect of general education. Once again, this seems not to be the case. When vocational education alone is entered into the model shown in Table 8.2, it also becomes insignificant (with a p value of 0.295 ). 4

In other words, the Danish capacity-building strategy does not appear to be an effective instrument for integrating work-disabled people in the labour market. This suggests that the exchange of narrower eligibility criteria for disability benefits for the right to participate in capacity-building measures that took place during the I99os in fact resulted in some loss of social rights for the long-term sick-listed workers.

\section{The importance of other variables}

The model in Table 8.2 to a large extent supports the theoretical propositions in Chapter 3. The analysis strongly supports the importance of the 
sick-listed workers' resources in terms of health (cf. the importance of pain intensity, and in the Danish model the presence of a chronic disease) and skills (cf. the importance of occupation and also in the Danish model of education). The high return to work rate among people with a great deal of job support further suggests that the individual perception of the social and psychological costs of work disability is important. That is, we may assume that workers receiving job support find it harder to be without work and therefore also more attractive to resume work than those who do not receive much support.

As argued above the Dutch disability policy remains largely the responsibility of the old employer, whereas labour market integration in Denmark is delegated to take place in the ordinary labour market, i.e. with a new employer. This conclusion, which is based on crossnational differences in the importance of dismissal, gains further support when we look at the effects of the other variables under consideration. While high physical job demands significantly reduce the chance of returning to work in the Dutch data, job demands do not matter in the Danish model. Similarly, the proxy for employment conditions in the ordinary labour market, the number of years employed divided by age, has a larger magnitude and is more significant in the Danish data than in the Dutch data. In other words, when institutional conditions make reintegration a matter of returning to work with the original employer, conditions related to the old job become crucial. Likewise, when you are forced to find a new job in the ordinary labour market, conditions related to this sphere are most influential for the chance of returning to work.

As noted the proxy for employment opportunities at the ordinary labour market is an indirect measure. To include a more direct measure the development in the local unemployment rate has been included in the Danish model. 5 It does not, however, give further support to the importance of external employment conditions, i.e. the variable has a p value of 0.134 , and, surprisingly, there is a tendency that the probability of returning to work increases when the unemployment rate increases. Other studies have found mixed evidence about the importance of unemployment (see Chapter 2). Thus, the absence of an effect could reflect that unemployment conditions do not affect labour market integration at all, that it only has an effect early in the sickness spell or that unemployment conditions are difficult to measure. ${ }^{6}$

Apparently the analysis does not support the theory that good exit conditions hamper reintegration. As noted, the replacement rate is insignificant in both the Danish and the Dutch data. In addition, there is no support for 
the influence of exit conditions through family support. In contrast to what could be expected, sick-listed workers in the Danish data with high-income family members have a high probability of returning to work. ${ }^{7}$

The absence of a good measure of the possibilities of exiting the labour market through the disability pathway is clearly a weakness. In the Danish model, I therefore include an indicator of the exit policy of the 24 municipalities that are included in the Danish data. It measures the extent to which the municipality's annual number of awarded disability benefits in 1996 and I 997 is above or below the national average. As the municipality is responsible for the administration of all cases of sickness benefit, social assistance and disability benefit, and of the establishment of vocational rehabilitation measures, this indicator is supposed to reflect the municipalities' exit policy. In other words, how do municipalities choose the administrative approach to sick-listed workers? Do they use a passive exit policy rather than an active integration policy? We would expect that the probability of returning to work is low when the municipality has an above-average number of benefit awards, and vice versa. ${ }^{8}$ The analysis supports this conclusion. Sick-listed workers from municipalities with many disability benefit awards have a lower probability of returning to work than sick-listed workers from municipalities with few awards ( $p$ value $0.07 \mathrm{I}$ ). In other words, it seems that exit conditions in terms of access to the disability benefit scheme do matter.

It is likely that this effect is even more pronounced today. In I 996 and I997, when the data used in the present study was gathered, municipalities were only responsible for the preparation of applications for disability benefits, whereas I 5 regional state committees took the decisions about benefit awards. Although municipalities could influence disability benefit awards through the preparation of applications, the administrative structures may have dampened the consequences that differences between municipal policies have. Since 1999 municipalities have had full competence to award disability benefits, meaning that they have obtained greater discretion to effect their own award policy, be it a lenient or a harsh policy.

\section{Dutch and Danish disability policies: a question of different rights?}

The analysis suggests that the Dutch policy is more effective in reintegrating long-term sick-listed workers than the Danish policy. In Denmark the combination of the limited responsibility of employers and public responsibility for the provision of reintegration measures does not promote the labour market reintegration of long-term sick-listed workers. The limited employer 
responsibility leads to many dismissals and thus to a marginalization of sick-listed workers who despite public reintegration efforts often remain without work. The Danish policy is nevertheless efficient in the sense that employers only have to bear a minor part of the costs of reintegration, facilitating a flexible labour market.

The comprehensive responsibility of Dutch employers seems to facilitate reintegration because regulations give employers strong incentives to retain sick-listed workers. It does not, however, take place without cost. The policy seems to make it more difficult for disabled people without attachment to an employer to enter the labour market. This creates increasing insider/outsider problems that reduce labour market flexibility.

Furthermore, while the Dutch policy seems effective in returning the longterm sick-listed to work, it seems ineffective in preventing people from becoming long-term sick-listed in the first place. It has been estimated that in I 994 the Netherlands had 2.5 times more people who were sick-listed for 3 months or more than Denmark, I.5 times more than Sweden, and I.75 times more than Germany (Cuelenaere et al., I999). That is, the effectiveness of the Dutch policy in reintegrating long-term sick-listed workers may be more than offset by the high 'production' of long-term sick-listed workers. Or put differently, the Danish policy appears efficient because it prevents people from becoming long-term sick-listed.

It has been suggested that this crossnational difference could be related to differences in job protection during sick leave (Cuelenaere et al., I999; Veerman and Palmer, 200I; Høgelund, 2002). In Denmark a high risk of dismissal may force sick-listed workers to make an early decision about whether to attempt to return to work, whereas the extensive job protection in the Netherlands may prolong this decision. According to the micro-sociological perspective on work disability, a delayed decision will reduce the chance of a successful return to work because the sick-listed worker becomes more and more adapted to the role as work-disabled as the spell of sickness progresses. As a consequence the social and psychological costs of disability will decrease and so will the inclination to resume work.

This interpretation is supported by a study suggesting that Dutch and Danish workers may have very different perceptions of work and work disability (Hohnen, 2002). The study, which is based on in-depth interviews, compares Danish workers in wage-subsidy jobs for people with permanently reduced work capacity and Dutch people receiving a partial disability benefit while working in a wage-subsidised job. Hohnen finds that the Dutch workers to a large extent takes it for granted that they can return to work with their old employer after a relatively long period of work disabili- 
ty, whereas the Danish workers consider their job more as a gift they should be grateful for. In other words, there seems to be a marked difference in what Dutch and Danish workers perceive as their well-earned rights. This may indicate that in the Netherlands work disability is not supposed to have significant consequences for the right to work, whereas in Denmark this right is conditional upon the individual's health. Following this line of argumentation, it may be more socially legal both to report sick from work and to perceive oneself as work-disabled and thus to remain off work for longer time in the Netherlands than in Denmark.

In other words, the issue of job-protection legislation may not merely be a question of return-to-work incentives that are present at certain stages during sick leave, e.g. after I 20 days of sick leave in Denmark, but also a question of culturally different notions about work disability and the right to work. Notions about work and work disability may of course be related to the long-standing differences in job-protection legislation during sick leave, but they may also be caused by other circumstances such as differences in social security schemes. Thus, in contrast to Danish workers, Dutch workers until recently directly contributed to the financing of the sickness and disability benefit schemes with payments depending on their wage. This may in turn mean that Dutch workers more than Danish workers feel they have the right to be work-disabled for shorter or longer periods.

\section{Conclusion}

What does the analysis of Dutch and Danish policies toward disabled people tells us? In a theoretical context, it suggests that the importance of various factors for the integration of work-disabled people depends on the institutional context within which they operate. It is our knowledge of the institutional differences between the Dutch and Danish disability policies that enable us to interpret why the observed effect of dismissal differs between the Dutch and Danish data sets. It hereby follows that any analysis must take account of factors at both the micro- and macro-levels. In a similar vein, support is also given to a multidisciplinary research approach. If we wish to enhance our understanding of the mechanisms that determine whether work-disabled people are integrated into the labour market, it seems insufficient to focus merely on factors related to one or two theoretical disciplines.

The analysis also demonstrates that the institutional differences between the Dutch and Danish disability policies have important consequences for policy outcomes. The Dutch emphasis on employers' responsibility creates 
strong ties between employers and sick-listed workers. These ties have positive effects in terms of the reintegration of long-term sick-listed workers. The drawback appears to be that the policy promotes insider-outsider problems so people with health problems without attachment to an employer encounter difficulties in entering the labour market. Furthermore, it seems likely that the Dutch policy counteracts the reintegration of short-term sicklisted workers, such that more people are becoming long-term sick-listed. The Danish policy seems to suffer neither from the problems of returning the short-term sick-listed to work nor from insider-outsider problems. Instead the most important drawback of the Danish policy seems to be that many long-term sick-listed workers with poor employment prospects are dismissed, and that they - despite extensive public integration efforts - often do not return to work.

It has been argued that one of the most crucial characteristics of the Dutch reforms during the I 990 os has been the introduction of 'managed liberalisation' (Visser and Hemerijck, I997; van der Veen and Trommel, I999). The regulated privatisation of the sickness benefit scheme, the obligation of employers to hire privately owned health service companies (Arbodienst) and the possibility of employers insuring disability risks with private insurance companies are examples that clearly justify this classification. This could suggest that the integration of disabled people in the Netherlands depends much more on market mechanisms than in Denmark where the integration mainly is a public responsibility. However, the present analysis suggests that the reverse is true. The limited responsibility of Danish employers both in terms of financial obligations and how easily they can dismiss sick-listed workers combined with a public system that promotes integration through capacity-building instruments, wage subsidies and persuasion policies makes the integration of work-disabled people take place under market conditions. In contrast, the analysis suggests that the institutional conditions in the Netherlands, especially the delegation of responsibilities to employers, are decisive for the integration of work-disabled people. This may indicate that the 'management' element in the Dutch disability policy is more important for integration outcomes than the 'liberal' element.

In the discussion of the consequences following welfare state reforms, the privatisation of the Dutch sickness benefit scheme has been mentioned as an example of a fundamental change in the institutional rules that have hardly any effect in terms of the outcome (van Kersbergen, 2000). It is argued that the privatisation has not significantly changed the right to social protection. This seems correct when outcomes are measured in terms of income protection during sick leave. In spite of this, the present analysis suggests that the 
change of institutional structures may influence the labour market attachment and thus the welfare of work-disabled people. Consequently, whether the Dutch reforms have had any effects in terms of outcomes may depend on the choice of how the outcome is measured.

In a similar vein, when policy reforms result in a new division of the economic responsibilities for social protection, the present analysis indicates that this will affect insiders as well as outsiders. Methodologically speaking, it may be fruitful, therefore, to consider not only the negative effects that the Dutch disability reforms have had for the integration of outsiders (see Oorschot, 200I), but also possible positive effects on the retention of insiders, i.e. the sick-listed workers. 


\section{Appendix C \\ Descriptive statistics for variables used in models of the time to returning to work}

Table 1 Descriptive statistics for the dependent and the explanatory variables used in the loglogistic survival analysis of the time to first returning to work. Long-term sick-listed private sector workers. Separate for the Dutch and the Danish data sets.

\begin{tabular}{|c|c|c|c|}
\hline \multirow[b]{2}{*}{ Variable } & \multirow{2}{*}{$\begin{array}{l}\text { Denmark } \\
\text { Mean (SD) }\end{array}$} & \multicolumn{2}{|l|}{ The Netherlands } \\
\hline & & Mean (SD) & $\begin{array}{l}\text { Significance } \\
\text { level }\end{array}$ \\
\hline \multicolumn{4}{|l|}{ Individual resources, health } \\
\hline Pain intensity, scale 1 to 10 (much pain) & $5.50(2.35)$ & $5.71(2.19)$ & NS \\
\hline $\begin{array}{l}\text { Chronic disease, } \\
\text { not including back condition (yes=1) }\end{array}$ & $0.12(0.33)$ & $0.06(0.24)$ & $* * *$ \\
\hline \multicolumn{4}{|l|}{ Individual resources, skills } \\
\hline \multicolumn{4}{|l|}{ Educational background: } \\
\hline Primary (yes $=1$ ) & $0.07(0.25)$ & $0.14(0.34)$ & $* * *$ \\
\hline Secondary $($ yes $=1)$ & $0.81(0.39)$ & $0.80(0.40)$ & NS \\
\hline Tertiary $($ yes $=1)$ & $0.12(0.33)$ & $0.06(0.24)$ & $* * *$ \\
\hline $\begin{array}{l}\text { Seniority: number of months } \\
\text { in present job }\end{array}$ & $70.54(83.07)$ & 119.46 (99.90) & $* * *$ \\
\hline \multicolumn{4}{|l|}{ Occupation in pre-sick leave job: } \\
\hline Manager, professional (yes=1) & $0.13(0.34)$ & $0.20(0.40)$ & $* *$ \\
\hline Sales, service (yes $=1$ ) & $0.32(0.47)$ & $0.30(0.46)$ & NS \\
\hline Craft and plant work (yes $=1$ ) & $0.45(0.50)$ & $0.45(0.50)$ & NS \\
\hline Elementary work (yes $=1$ ) & $0.09(0.28)$ & $0.05(0.23)$ & $*$ \\
\hline \multicolumn{4}{|c|}{ Individual psychological and social costs of disability } \\
\hline Job support, index 1 to 4 (much) & $3.36(0.65)$ & $3.30(0.33)$ & * \\
\hline \multicolumn{4}{|l|}{ Other individual characteristics } \\
\hline Sex: $($ female $=1)$ & $0.45(0.50)$ & $0.38(0.48)$ & $* *$ \\
\hline Age & $39.67(10.21)$ & $39.91(9.43)$ & NS \\
\hline \multicolumn{4}{|l|}{ Employment conditions, old employer } \\
\hline $\begin{array}{l}\text { Risk of dismissal, } \\
\text { between o and } 1 \text { (high risk) }{ }^{2}\end{array}$ & $0.49(0.15)$ & $0.09(0.10)$ & $* * *$ \\
\hline $\begin{array}{l}\text { Physical job demands, } \\
\text { index } 1 \text { to } 4 \text { (low demands) }\end{array}$ & $1.90(0.76)$ & $1.68(0.64)$ & $* * *$ \\
\hline
\end{tabular}


Employment conditions, ordinary labour market

Number of years employed since

$0.76(0.22) \quad 0.77(0.22) \quad$ NS

the age of 20 divided by age

\begin{tabular}{|c|c|c|c|}
\hline \multicolumn{4}{|l|}{ Exit conditions } \\
\hline Replacement rate & $0.78(0.23)$ & $0.77(0.39)$ & NS \\
\hline Replacement rate observed? (missing $=1$ ) & $0.02(0.16)$ & $0.18(0.36)$ & *** \\
\hline $\begin{array}{l}\text { Income from other household members } \\
\text { divided with the sick-listed person's } \\
\text { pre-sick leave wage }\end{array}$ & $58.21(57.57)$ & $143.73(235.59)$ & *** \\
\hline $\begin{array}{l}\text { Income from other household members } \\
\text { observed? (missing=1) }\end{array}$ & $0.13(0.34)$ & $0.34(0.48)$ & *** \\
\hline Returned to work? (yes $=1$ ) & $0.59(0.49)$ & $0.09(0.28)$ & *** \\
\hline Time to returning to work & $7.45(6.05)$ & $4.11(3.69)$ & *** \\
\hline Number of cases & 321 & 390 & \\
\hline $\begin{array}{l}\text { Note: All variables are measured at the first } \\
\text { "income from other household members", } \\
1 \text { The significance level is calculated in a th } \\
\text { significance, }{ }^{* *} \text { : significant at a } 5 \text { percent } \\
\text { nificant at a 10 percent level. } \\
2 \text { See Appendix D. }\end{array}$ & $\begin{array}{l}\text { ch are meas } \\
\text { ailed T-test: } \\
\text { al }^{* * *} \text { : signifi }\end{array}$ & $\begin{array}{l}\text { rcept "replacem } \\
\text { at waves } 1 \text { and } 2 \\
\text { nificant at a } 10 \mathrm{p} \\
\text { at a } 1 \text { percent lev }\end{array}$ & $\begin{array}{l}\text { it rate" and } \\
\text { I, Ns: not sig- }\end{array}$ \\
\hline
\end{tabular}


Table 2 Log-logistic survival analysis of the time to first returning to work without unobserved heterogeneity. Long-term sick-listed private sector workers. Separate for the Dutch and the Danish data sets.

\begin{tabular}{|c|c|c|}
\hline & Denmark & The Netherlands \\
\hline Variable & Coefficient (SE) & Coefficient (SE) \\
\hline \multicolumn{3}{|l|}{ Individual resources, health } \\
\hline Pain intensity, scale 1 to 10 (much pain) & $0.189(0.031)^{* * *}$ & $0.116(0.022)^{* * *}$ \\
\hline $\begin{array}{l}\text { Chronic disease, } \\
\text { not including back condition (yes=1) }\end{array}$ & $0.297(0.233)^{\mathrm{Ns}}$ & $-0.338(0.197)^{*}$ \\
\hline \multicolumn{3}{|l|}{ Individual resources, skills } \\
\hline \multicolumn{3}{|l|}{ Educational background: ${ }^{1}$} \\
\hline Secondary (yes $=1$ ) & $-0.977(0.418)^{* *}$ & $-0.142(0.156)^{\mathrm{NS}}$ \\
\hline Tertiary $($ yes $=1)$ & $-1.029(0.469)^{* *}$ & $-0.313(0.261)^{\mathrm{NS}}$ \\
\hline Seniority: number of months in pres-ent job ${ }^{2}$ & $0.010(0.097)^{\mathrm{Ns}}$ & $0.095(0.061)^{N S}$ \\
\hline \multicolumn{3}{|l|}{ Occupation in pre-sick leave job: ${ }^{3}$} \\
\hline Sales, service $($ yes $=1)$ & $0.389(0.230)^{*}$ & $0.019(0.154)^{\mathrm{NS}}$ \\
\hline Craft and plant work (yes $=1$ ) & $0.340(0.239)^{*}$ & $-0.342(0.158)^{* *}$ \\
\hline Elementary work (yes $=1$ ) & $0.502(0.326)^{\mathrm{NS}}$ & $-0.130(0.238)^{N S}$ \\
\hline \multicolumn{3}{|c|}{ Individual psychological and social costs of disability } \\
\hline Job support, index 1 to 4 (much) & $0.008(0.116)^{\mathrm{Ns}}$ & $-0.503(0.166)^{* * *}$ \\
\hline \multicolumn{3}{|l|}{ Other individual characteristics } \\
\hline Sex: $($ female $=1)$ & $0.107(0.174)^{\mathrm{Ns}}$ & $-0.200(0.149)^{N S}$ \\
\hline Age & $0.022(0.008)^{* * *}$ & $0.019(0.006)^{* * *}$ \\
\hline \multicolumn{3}{|l|}{ Employment conditions, old employer } \\
\hline Dismissal (yes $=1$ ) & $1.206(0.154)^{* * *}$ & $2.284(0.265)^{* * *}$ \\
\hline $\begin{array}{l}\text { Physical job demands, } \\
\text { index } 1 \text { to } 4 \text { (low demands) }\end{array}$ & $-0.203(0.096)^{* *}$ & $-0.249(0.082)^{* * *}$ \\
\hline \multicolumn{3}{|l|}{ Employment conditions, ordinary labour market } \\
\hline $\begin{array}{l}\text { Number of years employed } \\
\text { since the age of } 20 \text { divided by age }\end{array}$ & $-1.070(0.383)^{* * *}$ & $-0.444(0.262)^{*}$ \\
\hline \multicolumn{3}{|l|}{ Exit conditions } \\
\hline Replacement rate & $-0.569(0.398)^{\mathrm{NS}}$ & $-0.023(0.281)^{\mathrm{NS}}$ \\
\hline Replacement rate observed? (missing=1) & $-0.774(0.658)^{\mathrm{Ns}}$ & $-0.034(0.296)^{\mathrm{NS}}$ \\
\hline $\begin{array}{l}\text { Income from other household members } \\
\text { divided with the sick-listed person's } \\
\text { pre-sick leave wage }{ }^{2}\end{array}$ & $-0.290(0.132)^{* *}$ & $0.039(0.030)^{\mathrm{NS}}$ \\
\hline $\begin{array}{l}\text { Income from other household members } \\
\text { observed? (missing=1) }\end{array}$ & $-0.115(0.251)^{N S}$ & $0.073(0.134)^{\mathrm{NS}}$ \\
\hline
\end{tabular}




\begin{tabular}{|c|c|c|}
\hline $\begin{array}{l}\text { Constant } \\
\text { Gamma } \\
\text { Log likelihood }\end{array}$ & $\begin{array}{l}2.733(0.903)^{* * *} \\
0.614(0.039) \\
-338.8\end{array}$ & $\begin{array}{l}2.469(0.775)^{* * *} \\
0.495(0.024) \\
-419.5\end{array}$ \\
\hline Number of cases & 302 & 354 \\
\hline \multicolumn{3}{|c|}{$\begin{array}{l}\text { Note: All variables are measured at the first interview, wave } 1 \text {, except "replacement rate" and } \\
\text { "income from other household members", which are measured at waves } 1 \text { and } 2 \text {. The log-logis- } \\
\text { tic accelerated failure time model has been selected among other parametric models (Expo- } \\
\text { nential, Weibull, Log-normal, Gamma) because the log-logistic model (together with the log- } \\
\text { normal model) provides the best fit in an AIC test. The significance levels: }{ }^{*}: \text { significant at a } 10 \\
\text { percent level of significance, }{ }^{* *}: \text { significant at a } 5 \text { percent level, }{ }^{* *}: \text { significant at a } 1 \text { percent lev- } \\
\text { el, Ns: not significant at a } 10 \text { percent level. } \\
1 \text { Reference category: primary education. } \\
2 \text { Figure multiplied with } 100 . \\
3 \text { Reference category: manager, professional. }\end{array}$} \\
\hline
\end{tabular}




\section{Appendix D \\ Estimation of the predicted probability of dismissal in the Danish and Dutch data sets (used in Table 8.2).}

A two-stage estimation presupposes the use of an instrumental variable, that is, we need a variable that influences the probability of dismissal but not the probability of returning to work. Unfortunately, no obvious instruments are to hand. The variables that influence the probability of dismissal, educational attainment, self-rated pain intensity, seniority, and gender (see Table 7.3) may in a theoretical perspective also affect the probability of returning to work. Instead a more pragmatic approach has been chosen. The variables that influence the probability of dismissal have been analysed to see whether or not they influence the probability of returning to work. This has happened in the model similar to the one depicted in Table 8.2., but with the observed values of dismissal. It turns out that seniority $(\mathrm{p}=0.933)$ and gender $(\mathrm{p}=0.853)$ are insignificant in the Danish data, whereas educational attainment is insignificant in the Dutch data (secondary level, $\mathrm{p}=0.538$, tertiary level, $\mathrm{p}=0.189$ ). Consequently, these variables are used as instruments. Table 3 shows the results of the logistic regression model used to estimate the predicted values of dismissal. Table 4 shows the mean and standard deviation of the predicted and observed values of dismissal. 
Table 3 Logistic regression of the probability of dismissal among long-term sick-listed private sector workers. Separate for the Dutch and the Danish data sets.

\begin{tabular}{lll}
\hline & Denmark & The Netherlands \\
\hline Variable & Coefficient (SE) & Coefficient (SE) \\
Pain intensity, scale 1 to 10 (much pain) & $0.195(0.053)^{* * *}$ & $0.571(0.136)^{* * *}$ \\
$\quad$ Educational background: 1 & $-0.490(0.497)^{\mathrm{Ns}}$ & $-1.298(0.480)^{* * *}$ \\
$\quad$ Secondary (yes=1) & $-1.742(0.626)^{* * *}$ & $-0.627(0.772)^{\mathrm{NS}}$ \\
$\quad$ Tertiary (yes=1) & $0.466(0.249)^{*}$ & $0.908(0.426)^{* *}$ \\
Sex: (female=1) & $-0.257(0.146)^{*}$ & $-0.391(0.269)^{\mathrm{Ns}}$ \\
Coniority: Number of months in present job ${ }^{2)}$ & $-0.553(0.596)^{\mathrm{NS}}$ & $-5.266(1.119)^{* * *}$ \\
\hline Number of cases & 316 & 369 \\
\hline
\end{tabular}

Note: All variables are measured at the first interview, wave 1. Significance levels: ${ }^{*}$ : significant at a 10 percent level of significance, ${ }^{* *}$ : significant at a 5 percent level, ${ }^{* * *}:$ significant at a 1 percent level, NS: not significant at a 10 percent level. The model has a p value of 0.704 (DK) and 0.904 (NL) in a Hosmer-Lemeshow test and pesudo $\mathrm{R}^{2}$ of 0.073 (DK) and 0.194 (NL).

1): Reference category: Primary education

2): Figure multiplied with 100.

Table 4 Mean and standard deviation of predicted and observed values of dismissal. Separate for the Dutch and the Danish data sets.

\begin{tabular}{lll}
\hline & Denmark & The Netherlands \\
\hline Variable & Coefficient (SD) & Coefficient (SD) \\
\hline Predicted dismissal & $\begin{array}{l}0.487(0.156) \\
0.487(0.501)\end{array}$ & $\begin{array}{l}0.084(0.102) \\
0.084(0.278)\end{array}$ \\
\hline Observed dismissal & 316 & 369 \\
\hline Number of cases & & \\
\hline
\end{tabular}




\section{Appendix E \\ Estimation of the predicted probability of participation in education before returning to work in the Danish data set.}

The municipalities in Denmark are obliged to assess the need for vocational rehabilitation in all cases of long-lasting sick leave. Following Høgelund and Holm (2002), I assume that the selection into education is influenced by personal characteristics such as health status, educational attainment, seniority, income, and age. I also assume that the selection is influenced by the municipalities' policies in such a way that the probability of participation in education is high when the municipality often uses vocational rehabilitation measures, and vice versa (Aakvik, Heckman and Vytlacil, 2000; Høgelund and Holm, 2002). The municipalities' rehabilitation policy, i.e. their tendency to use vocational rehabilitation, is used as an instrumental variable: It is assumed to influence the selection into education, while it has no effect on the probability of returning to work.

The municipalities' rehabilitation policy is measured as the tendency to initiate vocational rehabilitation when correction is made for structural conditions that may affect the demand for vocational rehabilitation. The tendency to initiate vocational rehabilitation is measured as the number of people receiving vocational rehabilitation benefit in 1996 relative to the number of the municipalities' adult inhabitants. The explanatory variables, also measured relative to the number of adult inhabitants, comprise: the number of people receiving sickness benefit and social assistance, respectively; the number of owned residences; and the number of residences with four rooms. The data are from Statistics Denmark (Danmarks Statistiks Databank). The estimated linear regression model with all (275) municipalities yields an $\mathrm{R}^{2}$-value of 0.24 . Table 5 shows the results of the logistic regression model used to estimate the predicted values of participation in education. Table 6 shows the mean and standard deviation of the predicted and observed values of participation in education together with mean and standard deviation of the municipalities' tendency to initiate vocational rehabilitation. 
Table 5 Logistic regression model of participation in education $(n=310)$

\begin{tabular}{|c|c|c|c|}
\hline Variable & Coefficient & Std.error & $\begin{array}{l}\text { Significance } \\
\text { level }\end{array}$ \\
\hline $\begin{array}{l}\text { Municipalities' vocational rehabilitation } \\
\text { tendency }\end{array}$ & 0.210 & 0.109 & $*$ \\
\hline Pain intensity, scale 1 to 10 (much pain) & 0.120 & 0.068 & $*$ \\
\hline Sex: $($ female $=1)$ & 0.018 & 0.336 & NS \\
\hline Age & -0.057 & 0.018 & $* * *$ \\
\hline \multicolumn{4}{|l|}{ Educational background: ${ }^{1}$} \\
\hline Secondary $($ yes $=1)$ & 0.378 & 0.806 & NS \\
\hline Tertiary $($ yes $=1)$ & -0.335 & 0.951 & NS \\
\hline Living together with spouse (yes $=1$ ) & -0.550 & 0.465 & NS \\
\hline Seniority: number of months in present job ${ }^{2}$ & -0.172 & 0.252 & NS \\
\hline Replacement rate & -1.176 & 0.812 & NS \\
\hline $\begin{array}{l}\text { Income from other household members } \\
\text { divided with the sick-listed person's } \\
\text { pre-sick leave wage }{ }^{2}\end{array}$ & 0.378 & 0.367 & NS \\
\hline $\begin{array}{l}\text { Income from other household members } \\
\text { observed? (missing=1) }\end{array}$ & 0.625 & 0.546 & NS \\
\hline Constant & 0.857 & 1.325 & NS \\
\hline
\end{tabular}

Note: All variables are measured at the first interview, wave 1, except municipalities' vocational rehabilitation tendency. Significance levels: ${ }^{*}$ : significant at a 10 percent level of significance, ${ }^{* *}$ : significant at a 5 percent level, ${ }^{* * *}$ : significant at a 1 percent level, $\mathrm{NS}$ : not significant at a 10 percent level. The model has a $p$ value of 0.849 in a Hosmer-Lemeshow test and pesudo $R^{2}$ of 0.104 . 1 Reference category: primary education

2 Figure multiplied by 100.

Table 6 Mean and standard deviation of predicted and observed values of participation in education and of the municipalities' tendency to initiate vocational rehabilitation.

\begin{tabular}{ll}
\hline & Denmark \\
\hline Variable & Coefficient (SD) \\
\hline Predicted participation in education & $0.203(0.131)$ \\
Observed participation in education & $0.203(0.403)$ \\
Municipalities' vocational rehabilitation tendency & $0.484(1.323)$ \\
\hline Number of cases & 316 \\
\hline
\end{tabular}





\section{Too Much and Too Little - Employers' Responsibility in Denmark and the Netherlands}

The Dutch and the Danish disability policies share the aim of reducing the number of people entering the disability benefit rolls while increasing the labour market attachment of people with health problems. Yet we have seen that during the I990s different policies were enacted in order to reach these goals, and that these policies result in very different outcomes.

The Dutch policy focuses on employers who to a large extent have become responsible for the financing of sickness and disability benefits and the reintegration of disabled people; employers have been given strong economic incentives to retain workers after the onset of a disability. While this policy results in the work retention of long-term sick-listed workers, it apparently suffers from high numbers of long-term sick-listed people and the problems of integrating disabled people with no or limited prior attachment to the labour market.

In contrast, the Danish policy emphasises public responsibility for the provision of social security benefits and integration of work-disabled people. The means to obtain integration and limit the load on the disability pathway is related to a policy that induces public authorities to apply active instruments rather than passive benefit awards. This policy does not encourage reintegration of long-term sick-listed workers, who in spite of publicly provided capacity-building measures have difficulties in returning to work. But in contrast to the Dutch policy, the Danish policy nevertheless seems to limit long-term absenteeism, and it apparently does not increase insider/outsider problems.

The Dutch and Danish policies seem to be associated with different strengths and weaknesses that make it difficult to provide an overall ranking of the two policies. This chapter therefore looks at the Dutch and Danish policies from another angle, and asks whether the policy changes during the I990s succeeded in reaching the goal of limiting the load on the disability benefit schemes. I first set out by looking at the size of the pressures on the Dutch and Danish disability benefit schemes during the I990s, arguing that even though the Dutch disability problems seem much worse than those in 
Denmark they are not. I then discuss whether the policy changes during the I990s succeeded in limiting the load on the disability benefit schemes. I will argue that the Danish policy indeed fulfilled this goal and that the Dutch policy also did, but probably to a smaller extent and in a less visible manner. This is followed by a discussion of how new challenges to the welfare state may affect the two nations' future disability policies. That is, how may we expect that the two policies will cope with pressures from globalisation, changing social risk structures, and ageing populations? It is argued that the pressures may cause more problems in the Netherlands than in Denmark. I will conclude by giving some suggestions for adaptations to the Dutch and Danish disability policies that may enhance integration of disabled people and thus help alleviate future welfare state pressures.

\section{The disability figures reconsidered: an overestimated disability crisis}

Before assessing the effects of the changes to the Dutch and Danish disability policies, it might be useful to briefly consider the economic pressure that the two nations' disability benefit schemes generate. High numbers of disability beneficiaries generate economic pressure for two reasons. On the one hand, the financing of disability benefits puts an economic load on the state, and inactive beneficiaries on the other hand only contribute to the production of welfare to a limited extent.

Figure 9.I. shows that the number of disability beneficiaries as a percentage of the labour force suggests that the economic load generated by the disability benefit rolls throughout the I 990 os was larger in the Netherlands than in Denmark. The figure also indicates that the difference between the Dutch and Danish numbers has been significantly reduced during that period.

In the Netherlands, the number of beneficiaries fell from I 2.8 percent of the labour force in I 990 to II.3 percent in I 997 and increased to I 2.0 percent in 200I. This development reflects an increasing number of beneficiaries (except in the mid-I990s where the number decreased temporarily) and an even faster increasing number of people in the labour force. In contrast, Denmark left the I990s with a net increase in the number of beneficiaries. The number rose from 8.6 percent in 1990 to 9.6 percent in 1998 , and then decreased to 9.2 percent in $200 \mathrm{I}$.

Despite the overall favourable development in the Netherlands and the negative development in Denmark, the figures suggest that at present Dutch disability problems are greater than those in Denmark. It is important to note that there seem to be good reasons why one should be cautious when 


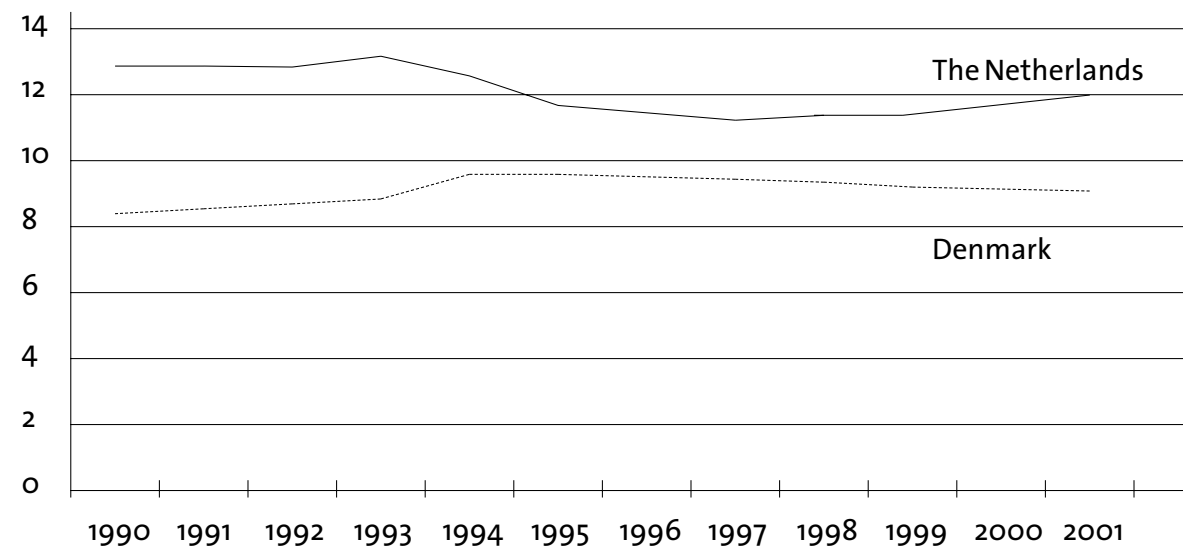

Figure 9.1. The number of disability beneficiaries as a percentage of the labour force Source: Danmarks Statistik (2001, 2002), Lisv (2001), OECD (20016).

Note: Dutch figures include beneficiaries under the wao (wage earners), WAZ (self-employed), and Wajong (young handicapped) scheme.

interpreting the figures. While in broad terms we may assume that the number of disability beneficiaries is a good proxy for the economic resources that society transfers to people receiving these benefits, it may be a poor indicator of beneficiaries' inactivity, at least when we wish to compare the situation in the Netherlands and Denmark. In the Netherlands 22 percent of the disability beneficiaries were working in 1998 (Lisv, 2002) compared to I 4 percent in Denmark (Dansk Arbejdsgiverforening, 2000). ${ }^{\mathrm{I}}$ In other words, the Dutch disability figures imply more ability and less disability than the Danish figures. Compared to the Danish figures, the Dutch figures therefore tend to overestimate the economic load of the disability benefit scheme. To illustrate this: when working people are excluded from the figures, disability beneficiaries make up 9.I percent of the labour force in the Netherlands in I 998 compared to 8.2 percent in Denmark. I will return to explanations for this crossnational difference below.

In summary, this discussion suggests that a mere comparison of the numbers of disability beneficiaries overestimates the paid inactivity present in the Dutch disability scheme. When it is taken into consideration that Dutch beneficiaries work more often than Danish beneficiaries, the economic pressures from the disability benefit schemes are not that different. 


\section{Policy changes - success or failure?}

The development of the Dutch and Danish disability policies may be characterised as a move towards a more active policy and away from a passive policy. More people with health problems should be kept on the work pathway and consequently fewer would be granted disability benefits. The Dutch sickness and disability reforms aimed to fulfil these goals mainly by transferring the responsibility for integration from the collective domain to employers. Thus, in addition to the strict job-protection legislation, the individual employer has become responsible for payments of sickness benefits during sick leave and contributions to the disability benefit scheme are now dependent on how many of the employer's workers that are granted a benefit. The employer has furthermore become obliged to contract a private consultancy company to assist with the implementation of a prevention and sickness absence policy (cf. Chapter 5 ).

In contrast, the changes to the Danish policy involved the strengthening of an already extensive public responsibility. Municipalities were obliged to intensify their followup activities in cases of sick leave, they were given economic incentives to apply active measures such as vocational rehabilitation, and they were delegated responsibility for awarding disability benefits (cf. Chapter 6). In both nations have incentives to limit disability benefit awards and increase integration been fortified, but the pivotal actor differs. The question addressed below is to what extent the Dutch and Danish policy changes have succeeded.

\section{Entry into the disability benefit schemes}

It is difficult to determine whether policy changes have increased the labour market integration of disabled people. This is so because there exists neither a uniform categorisation of disabled people nor a registration of their employment. As a consequence, the following discussion concentrates on whether policy changes have succeeded in the limiting entry into the disability benefit rolls. In this respect the number of awarded disability benefits is a better measure than the stock of beneficiaries. Whereas the former measure only depends on claimants' entry into the disability benefit scheme, the latter also depends on their exit from the scheme. ${ }^{2}$ As we will see below this makes a difference, especially in the Danish case.

Figure 9.2 displays the development in the annual number of disability benefit awards from I990 to 200 I measured relative to the labour force.

Figure 9.2 gives a somewhat different impression of the development in 


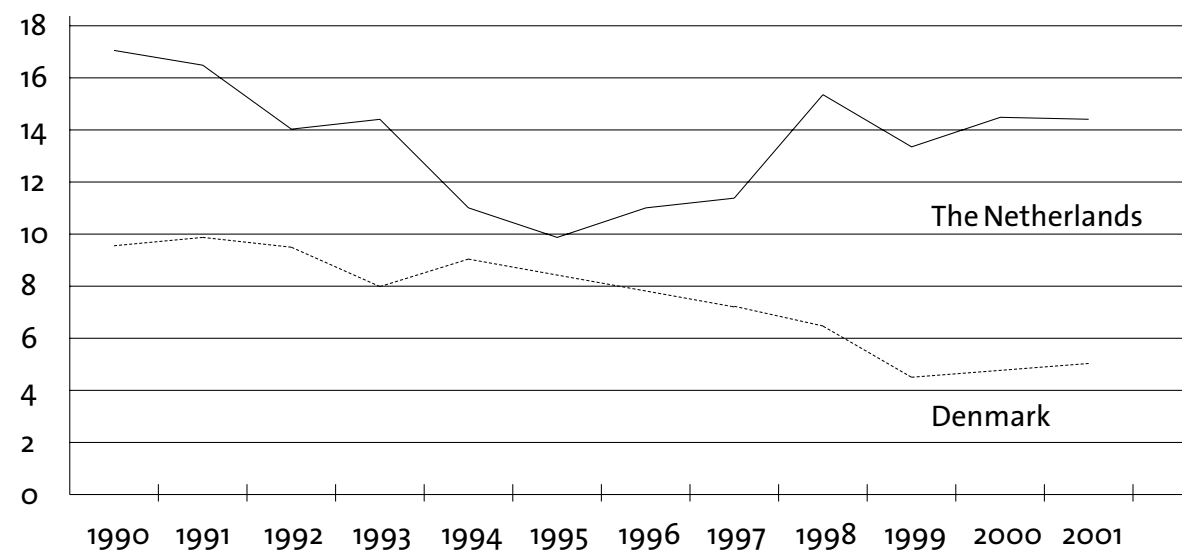

Figure 9.2. The number of disability benefit awards per thousand labour force participants

Source: Statistics Denmark's year book various years, den Sociale Ankestyrelse (2002), and Lisv (2001), $\operatorname{OECD}$ (2001b).

Note: Dutch figures include benefits awarded according to the wao (wage earners), WAZ (selfemployed), and Wajong (young handicapped) scheme.

the Netherlands and Denmark than that given by Figure 9.I. The figure suggests a much more favourable development in Denmark than in the Netherlands. In Denmark the relative number of awarded benefits has almost been halved, reflecting a marked decrease between I99I and I999 followed by a slight increase in 2000 and $200 \mathrm{I}$. Around 5 people per 1000 in the labour force were granted benefit in $200 \mathrm{I}$ compared to more than 9 people per I000 in $1990 .{ }^{3}$

In the Netherlands, in contrast, the number of benefit awards dropped until 1995 and thereafter rose significantly until 1998 reaching a level somewhat below the 1990 level. From 1998, the number first decreased slightly and then returned to almost the same level. In 200I, the number of benefit awards made up 85 percent of the 1990 level or, put differently, for every Iooo people in the labour force I 7 were granted disability benefit in I 990 compared to $14 \frac{1}{2}$ in $200 \mathrm{I}$. In other words, it seems as exit through the Dutch disability benefit scheme declined during the I990s, but to a much lesser extent than in Denmark.

\section{The consequences of policy changes?}

To what extent can we believe that these developments were caused by the policy changes carried out in the I990s? As economic conjunctures influence employment opportunities of disabled people, the economic develop- 
ment could in principle explain the observed patterns. Nevertheless, there seem to be good reasons why economic conditions should not be a decisive factor, at least not in both nations. Firstly, despite increasing employment in both nations in the second half of the I990s, we note that in this period the Dutch and Danish trajectories were very different, with an increasing trend in the Netherlands and a decreasing trend in Denmark. Secondly it seems unlikely that the fast drop of 40 percent in the Danish award rate between I997 and I999 could be caused by an increase in the overall demand for labour alone.

Several amendments were made to the Danish disability policy during the I990s and it is therefore difficult to relate the development in the Danish award rate to specific changes. The decreasing trend during almost the whole period suggests that the development, on the one hand, was largely caused by an accumulation of all the changes rather than one or two specific changes. That is, the declining award rate may be caused by both an improvement of active instruments, an increased legal obligation of municipalities to integrate disabled people and the strengthening of municipalities' incentives to apply active instruments rather than passive benefit awards (for more details see Chapter 6). The decreasing trend in benefit awards gained momentum in the second half of the I990s. This may, on the other hand, indicate that changes to the incentive structure have been especially crucial. That is, the fast drop in the award rate between 1997 and 1999 coincidences with major legal changes that gave municipalities both greater administrative autonomy and incentives to limit benefit awards. Firstly, in I 998 municipalities were given absolute competence to award disability benefits. Secondly, the right of citizens to apply for disability benefits was abolished at the same time, with the result that this decision was now only a matter for municipalities. Thirdly, in 1999 the economic incentives of municipalities to refrain from disability benefit awards were strengthened because the state reimbursement of disability benefits was cut. 4

Figure 9.2 apparently does not give too flattering a picture of the Dutch reforms. The legal changes in I 993 and 1994 may have led to an immediate decrease in the number of awarded benefits, from almost I04,000 in 1993 to 73,000 in 1995 , corresponding to a decrease from less than I 5 awards per roo० people in the labour force to less than io per ı०o०. Among other things the Act on the Reduction of the Number of Disability Benefit Claims in 1993 (твА) led to a reduction of the benefit level, tightening of eligibility criteria, and the re-assessment of existing disability beneficiaries under 50 years of age according to the new and stricter award criteria. ${ }^{5}$ In 1994 the Act on Reducing Sickness Absence (TZ) made the individual employer re- 
sponsible for the financing of sickness benefits for the first 6 weeks of sick leave ( 2 weeks for small employers), while amendments to the Act on Working Circumstances (Arbowet) made employers responsible for the implementation of a sickness absence and control policy under the guidance of a private consultancy company. It is not possible to differentiate between the effects of these three acts because they were implemented at almost the same time. The positive effects may therefore stem from both the reduction in the attractiveness of the disability benefit scheme and the strengthening of employers' incentives to limit work disability. The effect of these changes seems only to have been temporary as the number of awards returned to the old level during the course of 1996 and $1997 .^{6}$

The fact that the number of awarded benefits decreased somewhat in 1999 and then a year later returned to almost the same level as in 1998 suggests that the 1998 reform, which made the individual employer more directly responsible for the financing of disability benefits, has not (yet) had any significant lasting positive effects.

In other words, even though the Dutch disability problems of the I980s were brought to a halt in the I990s, the effect of the policy changes that aimed to make employers more responsible for the integration of work-disabled people has apparently not been an overall success.

Against this, it has been argued that the number of benefit awards under the scheme for workers (WAO) in fact decreased in relative terms, whereas benefits under the scheme for young handicapped people increased (Wajong). As the former group, in contrast to the latter group, is attached to an employer and the reforms were mainly directed at employers, it is argued that the reforms by and large had the intended effect of reducing claim levels (Veerman, 200I). Even though this argument is appealing, it may be problematic to isolate the effects of the reforms to the disability scheme for workers. The analysis in Chapter 8 suggests that high employer costs in the case of work disability do not merely affect employed people but also nonemployed people. While high costs increase the reintegration of disabled workers, they reduce the integration of non-employed disabled people and thus make it more difficult for young disabled people to enter the labour market. The diverging trends in the two disability benefit schemes may therefore reflect that the Dutch reforms had positive effects for insiders and negative effects for outsiders. In contrast, the analysis in Chapter 8 suggests that the Danish policy changes did not fortify insider/outsider problems.

We have to look elsewhere for positive effects of the Dutch employer cost strategy. Firstly, the average age of the Dutch working age population increased during the I990s, cf. Figure 9.3 From the figure we see that the num- 


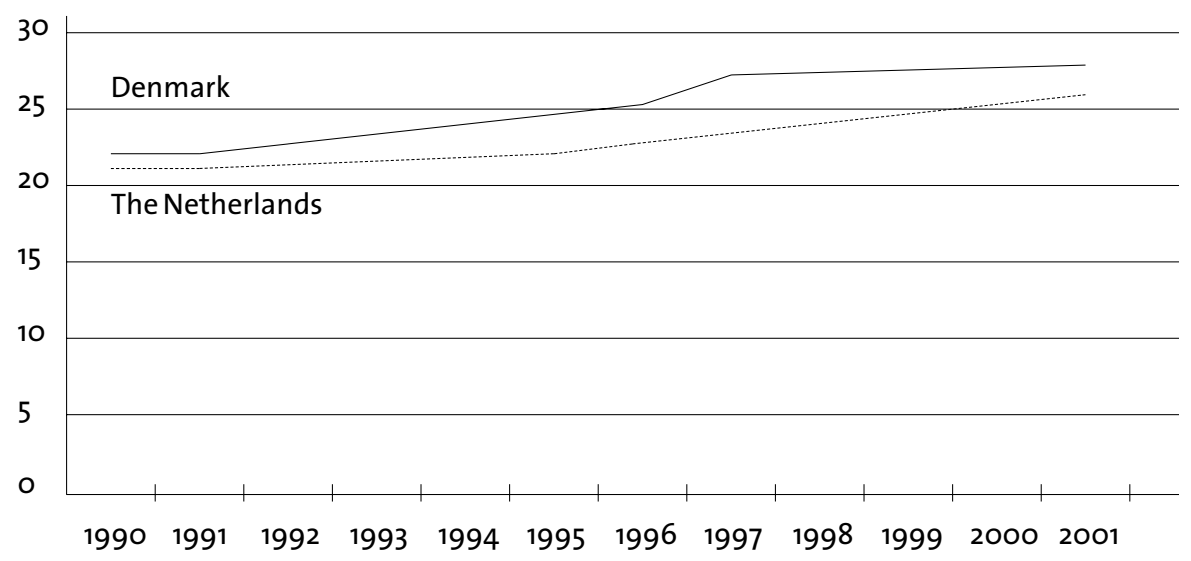

Figure 9.3. The number of people aged between 50-64 in the Netherlands and Denmark as percentages of the number of people between 15-64 years.

Source: OECD On-Line Labour Force Statistics database.

ber of people aged between 50 and 64 as a percentage of the total working age population increased from $2 \mathrm{I}$ in I 990 to 26 in $200 \mathrm{I}$. This development happened at exactly the same time as the number of disability benefit awards started to rise in the second half of the I990s. Knowing that older workers have a high disability risk, this development would in itself cause an increasing trend in the number of disability benefit awards. Consequently, it can be argued that without the policy changes we would have observed an increasing number of benefit awards during this period (see also Veerman, 200I).

From this figure it can be noted that a similar development took place in Denmark, indicating that the effects of the policy changes would have been even more impressive had the average age not increased.

Secondly, it is possible that the job demands of Dutch workers increased during the I990s. This would also have led to higher disability rates had the policy changes not been carried through. This is supported by evidence from a European study on working conditions that suggested that the mental workload increased across Europe during the first half of the I990s, and particularly in the Netherlands. In the European Union as a whole the fraction of workers reporting to work at a high pace all the time or almost all the time increased from I 8 percent in I99I to 25 percent in 1996 and 24 percent in 2000. Whereas the development in Denmark was close to the European Union average, the Dutch figures rose significantly from 26 percent in I99I to 38 percent in I996, and then decreased to 32 percent in 2000 (Paoli, I992; Paoli, I997; Paoli and Merllié, 200I; see also Geurts, Kompi- 
er and Gründemann, 2000). Even though these figures are encumbered with much uncertainty, among other things because of response rates of around 40 percent, the development in the Netherlands is supported by other pieces of evidence. Firstly, Dutch studies find that the work pace of workers increased continuously between I977 and 1997, then it levelled off (Houtman, Otten, and Venema, 2002). Secondly, the Netherlands is characterised by a labour force with a high productivity rate (Geurts, Kompier and Gründemann, 2000). Consequently, when the productivity rate increases between 1993 and 1997 it rose by almost 25 percent in the Dutch manufacturing industries (OECD, 2000) - it is likely that the workload also rises significantly. In other words, it is possible that an ageing labour force and increasing job demands mask the fact that the Dutch policy during the I 990 contributed to limiting labour market exit through the disability benefit scheme.

In summary, exit through the disability benefit scheme decreased in both nations during the I990s, but more in Denmark than in the Netherlands. The development in disability benefit awards indicates that the Danish strategy of enhancing public authorities' incentives to apply active rather than passive measures was successful in limiting the number of benefit awards. Although the Dutch strategy of improving employers' incentives has not had a lasting visible positive effect on the number of awarded disability benefits, it might have prevented further increases in the number of benefit awards that would otherwise have occurred because of an ageing population and increasing work demands.

\section{Explaining the developments}

Some of the important differences between the Dutch and the Danish disability policies, the economic pressures they cause, and the effects of the policy changes during the I990s can be understood in the context of Figure 9.4.

In a simplified way, the figure illustrates conditions that affect the labour market attachment of people with health problems. For the sake of exposition this group is divided into two. One group includes people who are formally attached to an employer by an employment contract. They may be workers who still are able to work in spite of their health problems or workers who are sick-listed because of their health problems. Another group consists of people with health problems who have no attachment to an employer. These people are receiving a social security benefit, e.g. a social assistance, sickness, or disability benefit. For both groups of people, the figure 


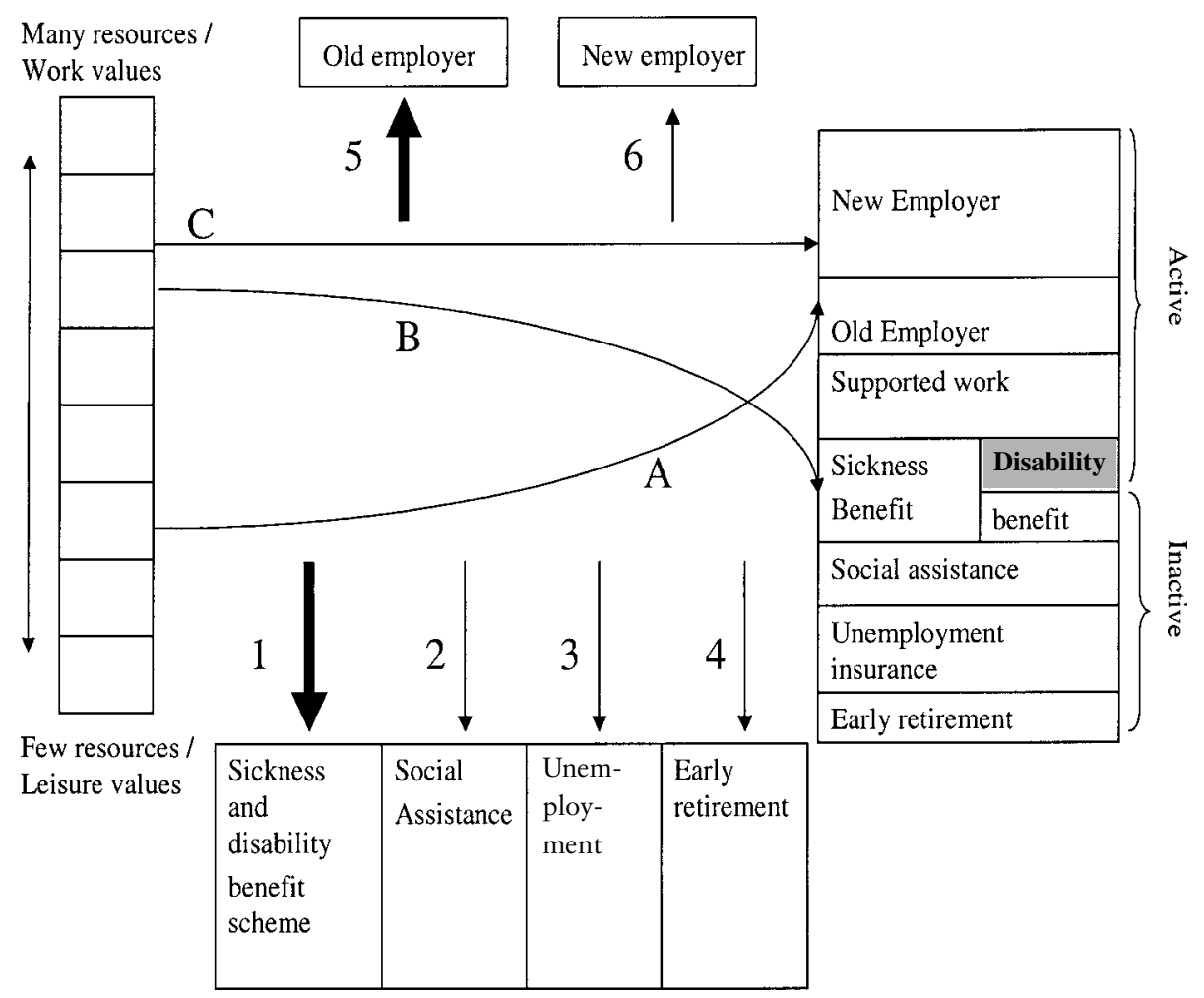

Figure 9.4 Factors affecting the labour market attachment of disabled people.

describes factors that influence the future labour market attachment in terms of work, subsidised work or the receipt of social security benefit. For an employed individual the figure illustrates whether the person continues with their original employer, starts work with a new employer, commences work in a subsidised job or enters (and stays) within a social security scheme. If the person continues with the old employer he or she will move from the left of the figure and into the box labelled 'Old Employer' (indicated by arrow A). If the person instead enters a social security scheme he or she will move to one of the boxes representing the different social security schemes (indicated by arrow B). For people without attachment to an employer, the 'integration process' is depicted in a similar manner. If the person, for example, starts to work he or she will move from the left of the figure and into the box labelled 'New Employer' (indicated by arrow C).

The figure, which draws on Chapter I (Figure I.I) and Chapter 3 (Figure 
3.I), suggests that three types of conditions influence the (re)integration of disabled people: I) the individual characteristics of the disabled person; 2) employment opportunities; and 3) exit opportunities through social security schemes.

People with several resources, e.g. relatively good health, and many educational and vocational skills, have a high probability of becoming (re)integrated. In a similar manner, a person with a 'taste' for work will perceive it as socially and psychologically costly to be without work and he or she will therefore have a high probability of (re)integration. In Figure 9.4 this is illustrated by arrow $\mathrm{C}$ showing a disabled person without attachment to an employer who starts to work because he or she possesses many resources and work-oriented values.

The institutional conditions related to a nation's social security schemes influence whether a work-disabled person will enter one of these schemes and, if so, which of the schemes he or she will enter. This is because social security schemes either directly or through various actors affect the work-disabled individual. Firstly, if exit schemes appear attractive in terms of eligibility criteria, benefit level and benefit duration, it is likely that the afflicted person will enter and stay in one of these schemes. Secondly, institutional conditions in terms of how formal rules are administered and how benefit schemes are organised will also influence whether a person with a limiting health condition will be allowed to enter and stay in a particular exit scheme. In Figure 9.4 this is depicted by arrows I, 2, 3, and 4 'pulling' the disabled individual toward the social security schemes, and thus increasing the probability that the disabled person enters and remains in a benefit scheme. The thickness of the arrow reflects how good exit conditions through the particular scheme are. Figure 9.4 shows a situation where possibilities for exit through the disability pathway are good compared to exit possibilities through other schemes. As a consequence people with health problems will relatively often exit through the sickness and disability schemes (see arrow B).

The chance that a disabled person remains attached to the work pathway is high when employment opportunities are good. Thus, the probability that a worker who is affected by a health problem will remain working is high when the opportunities for returning to work with the old employer are good, cf. arrow 5, or if the possibilities of finding a job with a new employer are good, cf. arrow 6. Similarly, the chance that a disabled person without attachment to an employer starts to work is high when the opportunities of finding a job with a new employer are good. The thickness of the arrows reflects how good the employment opportunities are with the old employer 
and with a new employer, respectively. The figure shows a situation where employment opportunities with the old employer are very good, whereas opportunities for integration into a new job with a new employer are more limited. Consequently, workers that become disabled have a high chance of remaining in work with the old employer (indicated by arrow A).

In summary, Figure 9.4 suggests that disabled peoples' labour market participation will be high when policies support their individual resources, emphasises work oriented values, limit exit opportunities through social security schemes, and create employment opportunities.

This is not to say that all people who encounter a disability are able to work if the employment opportunities are good; in many cases health problems prevent people from continued labour force participation. Nor is it to say that all workers with a limiting health condition will leave the labour force if they are provided with good exit opportunities, as in fact most people with health problems continue to work. Rather, the point is that our actions are influenced by the opportunities and constraints we face, and that social and labour market policies are important in this respect.

\section{The Dutch and Danish polices revisited: the importance of exit schemes}

In the context of Figure 9.4, the previously noted differences between the Dutch and Danish disability figures may reflect that in the Netherlands institutional conditions related to the disability pathway facilitate its use and at the same time make it attractive compared to other exit possibilities. This is less so in Denmark. The comparison of the Dutch and Danish disability policies suggests that the possibility of Dutch workers entering and staying on the disability pathway is somewhat better than in Denmark. As argued in Chapter 8 the whole welfare state context in the Netherlands in terms of how benefit schemes were financed until recently and the extensive job-protection legislation during sick leave probably make it more socially acceptable to report sick and to perceive oneself as work-disabled. This facilitates workers' entry into the disability pathway. In Denmark a tax financed sickness benefit scheme (combined with employers contributions during the first two weeks) and lax job protection does not promote similar results.

When a Dutch worker with health problems has entered the sickness benefit scheme the institutional conditions related to the sickness and the disability benefit scheme facilitate in some respects that the worker stays on the pathway. That is, application for a disability benefit and the following eligibility assessment happens almost automatically, and the low eligibility threshold that only demands an invalidity degree of $\mathrm{I} 5$ percent makes sure 
that most of those sick-listed people who come close to the end of the I-year waiting period are granted benefit. As we have seen there are of course also mechanisms that prompt a return to work such as strong employer incentives and recently also the new followup procedures during sick leave. The point here, however, is that there exist strong incentives and mechanisms that enhance the use of the disability pathway.

When Danish workers have entered the sickness benefit scheme there are mechanisms that counteract their continued attachment to the pathway. The disability benefit scheme operates with a high eligibility threshold, i.e. demanding a reduction in earnings capacity of at least 50 percent (this was increased in 2003 , cf. Chapter 6). In addition, municipalities have strong incentives to apply active measures rather than awarding disability benefits, and to award social assistance instead of disability benefits. In contrast to the Dutch policy, it is furthermore required that applicants participate in active measures before benefit can be awarded. In other words, the Danish policy does not promote that people enter and stay on the disability pathway to the same extent as the Dutch policy. This might be a reason why we observe more disability beneficiaries and more beneficiaries with a potential for work in the Netherlands than in Denmark. Referring to Figure 9.4, the grey area within the disability benefit scheme, indicating that people both receive a disability benefit and work, is larger in the Netherlands than in Denmark.

The apparently limited effect of the Dutch reforms on the number of newly awarded disability benefits can also be interpreted in the light of Figure 9.4. Even though the disability reforms limited the attractiveness of the disability benefit scheme, changes to other social security schemes may at the same time have contributed to restrict exit through other exit pathways. If this is the case, workers who encounter health problems will continue to use the disability pathway more often than other pathways.

This explanation is supported by changes to the unemployment policy. Since the beginning of the r 990 os the Dutch unemployment policy has been changed in order to influence the behaviour of the unemployed and employers (Clasen, Kvist and Oorschot, 200I; Oorschot and Abrahamson, 2003). With respect to the unemployed, the work-related eligibility and entitlement criteria in the unemployment insurance scheme have been tightened. In I 996 the Act on Penalties and Measures increased sanctions on unemployed people unwilling to participate in activation measures. And in 1995 eligibility to unemployment benefits became more closely linked to the previous work record, such that on average more people were entitled to lower benefits for shorter periods (Oorschot and Abrahamson, 2003). In 1997, the Act on Penalties and Measures was also implemented in the social assistance 
scheme, resulting in more rigid and systematic implementation of beneficiaries' obligations, for example, to actively seek work and accept suitable work (Oorschot, 200I). It seems in other words as it has become more difficult for people with health problems to enter and stay on social assistance and especially in the unemployment insurance scheme. Thus, the Dutch disability reforms would probably have had a more visible effect on the number of awarded disability benefits without these changes to the unemployment policy.

In summary, this all suggests that the Dutch and Danish disability policies differ with respect to how exit schemes affect disabled people. The Dutch policy seems to promote the use of the disability pathway more than the Danish policy. This results in somewhat higher disability figures in the Netherlands than in Denmark. But in contrast to the Danish policy, the Dutch policy results in more disability beneficiaries who are working as well as receiving benefit. In short, while the Danish policy aims to secure attachment to the work pathway by preventing people with the potential for work from entering the disability benefit scheme, the Dutch policy combines disability benefit receipt with work. This, an ageing labour force, increasing job demands and perhaps also changes to the Dutch unemployment policy tend to underestimate the effects of the Dutch reforms.

\section{Dutch and Danish polices revisited: employment opportunities}

An important message of the empirical analyses in this book is that Dutch and Danish disability policies differ in respect to how they influence employers' incentives to recruit and retain people with health problems (cf. Chapter 8 ). The Dutch policy exhibits strong elements that signify a Conservative welfare state. By means of regulations the responsibility for the financing of sickness and disability benefits and the (re)integration of disabled people is delegated to the individual employer. As a consequence, employers have strong incentives to retain workers after the onset of a disability (cf. the thick arrow 5 in Figure 9.4). Employers do, however, also have strong incentives to refrain from recruiting disabled people, resulting in disabled people without attachment to an employer having a poor chance of becoming integrated (cf. the thin arrow 6 in Figure 9.4) The policy tends in other words to create a divide between insiders and outsiders.

In contrast, the Danish policy possesses characteristics associated with a Social Democratic welfare state. The financing of benefits is mainly a public responsibility and employers can relative easily dismiss workers with health problems. While this policy does not seem to cause insider/outsider prob- 
lems, it may limit the integration of those disabled people with the poorest employment chances (independent of whether or not they are attached to an employer). If employed, these people are often dismissed, and because of their poor employability they have only a limited chance of returning to work. Unfortunately this chance seems to remain low despite public efforts to help them to work.

\section{Disability policies in the context of future challenges}

Labour market exclusion caused by health problems may turn out to be a problem that will also warrant great concern in the future. Increased globalisation, changing social risk structures and ageing populations seem to promote greater work disability in the coming years. An increasing competition from low-wage nations may necessitate structural adaptations in the labour market because the demand for unskilled and skilled workers will decrease in certain sectors. This may in turn raise labour market exit and the pressure on the disability pathway. An increasing demand for flexible workers may also give rise to health-related labour market exit among workers unable to meet the changing demands. The consequences of ageing populations are more dubious. On the one hand, older people have high disability incidence rates. A decreasing labour supply may on the other hand improve the employment prospects of people with a health condition. How might the increasing pressures influence labour market exit through the disability pathway in the Netherlands and Denmark?

It is likely that increasing globalisation, changing risk structures and ageing populations will exacerbate some of the problems associated with the two nations' disability policies. This seems most evident in the Dutch case. Clearly, increasing health problems among workers caused by changing job demands and an increasing average age will increase exit through the disability pathway. As employers bear the greater part of the costs that follows from an increased use of the sickness and disability benefit schemes, this will force additional costs upon employers. This will in turn raise employers' incentives to limit work disability among their staff, for example, through improvements of working conditions and increased reintegration efforts. However, it is likely that this positive effect will be very limited because employers' incentives to retain sick-listed workers are already very strong.

At the same time increasing costs will make employers even more reluctant to recruit people with health problems. The ageing of the Dutch population, which will reduce the supply of labour and thus improve the employ- 
ment possibilities of work-disabled people, will to some extent offset this tendency. But because of the high and increasing employer costs this effect may also turn out to be very limited. That is, the potential risk (or cost) associated with the recruitment of disabled people may make employers choose other strategies to fulfil their demand for labour. Such strategies could be to prompt workers to retire later, to pay workers to increase their working hours and to facilitate policies that raise the female labour supply.

In addition, it is possible that the pressures toward labour market exclusion unrelated to workers' health problems will also increase exit through the Dutch disability pathway. If increased competition from low-wage nations result in a decreasing demand for certain ty pes of workers, this will put pressure on the disability pathway insofar as this pathway remains more accessible than other exit pathways (see above). It could be argued that it is of little importance whether people with health problems use one or another benefit scheme to exit from the labour market. In the Dutch case, however, it does matter because sickness and disability benefit schemes are almost entirely financed by employers, whereas employers' contributions to other benefit schemes are much more limited. Consequently, this development may increase employers' costs and therefore further add to the existing insider/outsider problems. Whether this would happen may in addition to the development of the unemployment policies also depend on how the recent changes in the followup procedures during sick leave work out in practice. That is, will the increased obligations of sick-listed workers to cooperate with employers in order to return to work increase their attachment to the work pathway and thus limit exit through the disability path?

With unchanged policies, it seems reasonable to expect that the future pressure on the disability pathway will be more limited in Denmark. Because of the institutional conditions related to the disability pathway, relatively few people will be allowed to exit through the disability pathway. Instead people will use other exit schemes. On the one hand, increasing health problems caused by changing job demands and an ageing labour force will probably increase exit through the disability pathway. That is, employers will continue to solve problems with disabled workers through dismissals, which will increase labour market exit. On the other hand, the ageing labour force and the resulting lack of manpower will induce employers to retain more workers with health problems. In a similar manner, an increasing demand for labour may benefit the integration of disabled people without attachment to an employer because employers' future expenditures of employing workers with a high disability risk will remain low despite increasing pressures on the disability pathway. In other words, the recruitment of 
people with a limiting health condition may under certain circumstances be a better option compared to increasing working hours and the retirement age of the existing staff. The negative consequences that may follow from future welfare state pressures therefore seem to be less serious in Denmark than in the Netherlands. As a consequence, the pressure towards new and significant changes in the disability policies will probably be more pronounced in the Netherlands than in Denmark.

\section{Towards a more effective disability policy}

The above considerations point to some of the weaknesses of the Dutch and the Danish policies. In both cases there are the weaknesses related to structures that influence labour market flexibility; in the Netherlands the disability policy limits flexibility, while the Danish policy advances flexibility. It seems that in the Netherlands more flexibility and in Denmark less flexibility may improve the labour market integration of work-disabled people.

We have seen that Dutch employers are to a great extent obliged to continue the employment relationship independent of the worker's abilities. While this may increase the retention of sick-listed workers, it has important drawbacks. Firstly, it has been demonstrated that this obligation counteracts the integration of disabled people without attachment to an employer. Secondly, overly limited flexibility may also lead to an inefficient match between workers and jobs. If employers are forced through regulations to continue the employment of workers who, because of health problems or for other reasons, no longer match job demands it will raise employers' production costs. That is, the employer would be better off with a new worker even though this would be costly in terms of expenditure on recruitment and onthe-job training. At the same time the disabled worker would in principle also benefit from a better job match because it would give more job satisfaction and/or a higher wage. Figure 9.5 illustrates the association between the economic responsibility of employers and the resulting societal efficiency, i.e. the ratio between the total welfare in society and the resources used to obtain that welfare.

If employers costs become too high the benefits of increased retention of workers with health problems is more than offset by the limited integration of outsiders, and by a poor job match of insiders. This is probably what has happened in the wake of the Dutch disability reforms. The apparently limited effects of the premium differentiation within the Dutch disability benefit scheme support this. That is, the lack of a visible net reduction in the num- 


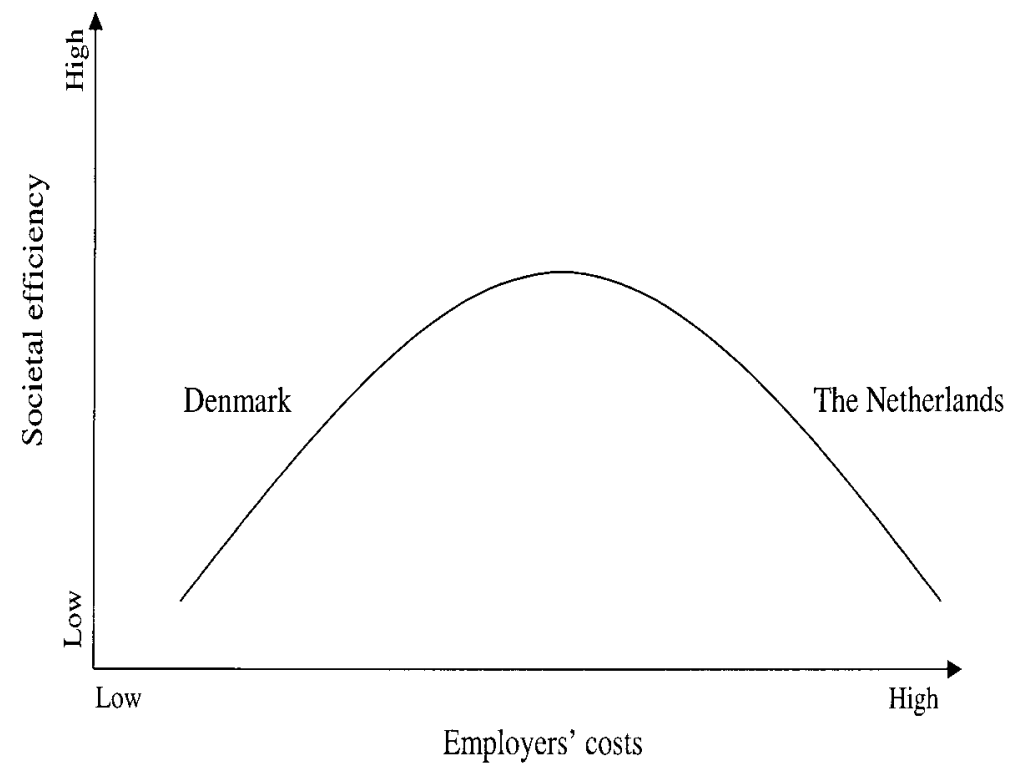

Figure 9.5 Employer costs and the efficiency of disability policies.

ber of awarded disability benefits may indicate that the gains in terms of increased retention of disabled workers is offset by the reduction in the integration of disabled people without attachment to an employer. Consequently, if the regulations that make it costly and difficult for employers to get rid of sick-listed workers are relaxed, it would probably reduce insider/outsider problems and promote a better match between employers' demand for labour and workers' supply of qualifications.

The Danish policy facilitates labour market flexibility. Employers can dismiss sick-listed workers easily and with little cost. While this limits the retention of workers with health problems, it promotes the integration of people with health problems without attachment to an employer because employers do not risk high future costs if a worker becomes disabled. Put another way, the policy facilitates the possibility of employers only employing those workers who produce the desired output at the lowest cost. This is clearly beneficial for employers but not necessarily for society. Let us assume that a worker with health problems is dismissed but returns to work with another employer after 3 years of vocational rehabilitation. Clearly, if the worker had stayed with the old employer instead, e.g. in a new job or in the original job after it had been adapted, it would have been cheaper for society even though it would have been more expensive for the original em- 
ployer. In the context of Figure 9.5, the present Danish policy may thus be inefficient because employers' costs are too low. This suggests that it may be cost-effective to increase employers' incentives to retain disabled workers.

One way to achieve this would be to increase the job protection of sicklisted workers and/or to increase employers' responsibility for the financing of sickness benefits. This would of course increase the risk of insider/outsider problems. ${ }^{7}$ Another way to increase employers' incentives to retain disabled workers would be to provide employers with economic support to establish the necessary measures such as workplace adaptations and job training. However, the problem seems not to be that such support does not exist, but rather that it is not used (Høgelund and Modvig, I998). Consequently, policy changes that facilitate early contact between employers and public authorities would provide employers with more information about available support and thus be a first step towards greater work retention. This could be obtained, for example, by requiring that employers and public authorities come into contact before sick-listed workers are dismissed.

In short, it is argued that an optimal disability policy neither should demand too little nor too much of employers, whose cooperation is after all a precondition for the integration of disabled people. It might therefore be worth considering this aspect when nations consider reforming their disability policies in order to meet future welfare state pressures. 



\section{Tables and Figures}

\section{Tables}

2.I. Selected clinical studies concerning the importance of socio-demographic, medical, psychological, job-related and lifestyle variables

2.2. Selected economic studies concerning the importance of economic incentives

2.3. Selected economic studies concerning the importance of vocational rehabilitation (VR)

2.4. Selected public policy studies concerning the importance of how benefit schemes are organised and financed and how benefits provisions are stipulated and administered

2.5. Selected sociological studies concerning the importance of social support and socialisation into the role as a disabled person

2.6. Selected studies concerning the importance of working conditions and labour market conditions for return to work among long-term sick-listed workers

4.I. Real GDP growth per capita I960-2000 (average annual change as a percentage)

4.2. Labour market indicators I $960-2000$

4.3. Social security expenditure as a percentage of GDP, I960-I999

4.4. Social security beneficiaries in the Netherlands as a percentage of the labour force

4.5. Social security beneficiaries in Denmark as a percentage of the labour force

7.I. Sick-listed workers in the Dutch and Danish data sets

7.2. Dismissals during sick leave among long-term sick-listed workers with low back pain diagnoses

7.3. Logistic regression model of dismissal of long-term sick-listed private sector workers with low back pain diagnoses

7.4. Participation in general education during sick leave among long-term sick-listed workers with low back pain diagnoses 
7.5. Workplace-based rehabilitation measures among long-term sick-listed private sector workers with low back pain diagnoses

7.6. Entitlement to sickness benefit and wage, respectively, during sick leave among long-term sick-listed workers with low back pain diagnoses

7.7. Average net replacement rates of the long-term sick-listed workers with low back pain diagnoses entitled to sickness benefit during sick leave 8. I. Return to work among long-term sick-listed private sector workers with low back pain diagnoses. Separate for workers who are (not) dismissed during sick leave

8.2. Log-logistic survival analysis of time to first returning to work of longterm sick-listed private sector workers with unobserved heterogeneity. Separate for the Dutch and Danish data sets

\section{Figures}

I.I. Exit pathways from the labour force

3.I. A model for the labour market status of non-working disabled people

9.I. The number of disability beneficiaries as a percentage of the labour force

9.2. The number of disability benefit awards per thousand labour force participants

9.3. The number of people aged between 50-64 years in the Netherlands and Denmark as percentages of the number of people aged between I 5-64 years 9.4. Factors affecting the labour market attachment of disabled people

9.5. Employer costs and the efficiency of disability policies 


\section{Notes}

\section{Notes Chapter 1}

I This section draws on these publications.

2 In the simplest form, this model is based on a choice between work and leisure. For a thorough and technical presentation of the model, cf. Aarts and de Jong, ( I 992), and for a general introduction and critique of the push model, see Stattin (I998).

3 As Stone (I984:145-46) notes, this is strategic not fraudulent behaviour.

4 The data was collected as part of the project, Work Incapacity and Reintegration, which was carried out under the auspices of the International Social Security Association, cf. Bloch and Prins (200I).

\section{Notes Chapter 2}

I This chapter is adapted from a chapter published in: Bloch, F.S. and Prins, R. (Eds.): Who Returns to Work \& Why? International Social Security Series. Volume 5. New Brunswick (U.S.A.) and London (U.K.): Transaction Publishers, 200I, pp. 27-54.

2 Furthermore, within the medical discipline the review focuses on sick-listed workers with the same diagnoses as in the present study, i.e. low back pain.

3 Veerman and Palmer (200I) consider variables belonging to the medical, economic and sociological research sphere and the study is therefore also considered in some of the following sections.

4 This is supported by Aarts and de Jong (I992) who found that male workers' (estimated) unemployment risk influences the probability of their enrolment in the disability benefit scheme. At the same time they also found that male workers' unemployment risk affects their probability of becoming long-term sick-listed, but not their transition from long-term sick leave to the disability benefit scheme. 


\section{Notes Chapter 3}

I In principle the reverse is also true: individuals react on structural conditions, which either may reinforce or change existing structural conditions. Such feedback mechanisms are discussed in the final section of the chapter.

2 Thus, the existence of health problems is taken for granted, such that the model does not directly aim to explain why some healthy people become work-disabled in the first place. For such models see, e.g. Aarts and de Jong (I992) and Ilmarinen (I999).

\section{Notes Chapter 4}

I The national statistics cover benefits paid by municipalities. This means that benefit payments during the employer period (varying between 2 and thirteen weeks in the period considered) and almost all benefit payments to public workers (except for 2000) are excluded.

2 With this definition, permanently subsidised employment such as sheltered employment is not regarded as an active measure.

3 Public services and administration is not considered here because it is unclear to what extent it reflects activation. Differences in these expenditures may, therefore, express differences in administration costs.

4 This is reflected in the average weekly working hours, which in 2000 were 36 . I in Denmark and 3 I. 8 in the Netherlands (Eurostat, 200Ib). Consequently, using Danish working hours as reference, the Dutch employment rate in 2000 decreases from 72.9 to 64.2 percent (OECD, 200IC).

\section{Notes Chapter 5}

I A further reason was that public sector wages also were linked to the wage development in the private sector (Visser and Hemerijck, I997).

2 Private sector workers were covered by the wAO scheme (Wet op de Arbeidsongeschiktheids Verzekering) whereas public sector workers were covered by the, almost similar, ABP scheme (Algemeen Burgerlijke Pensioenwet), which operated with invalidity degrees of between 25 and roo percent.

3 Visser and Hemerijck (I997) characterise this development as an example of policy learning, which was one of the important factors that lead to significant policy changes: politicians learned that the existing organisation of the social security administration was ineffective.

4 At the same time wage subsidies to therapeutic work resumption was abolished.

I 82 NOTES CHAPTER 3 


\section{Notes Chapter 6}

I An exception is the unemployment insurance scheme, which was (and still is) administered by unions and financed by contributions from the insured and the state.

2 The description of the sickness and disability benefit schemes is based on the legislation in force January I980 (Bekendtgørelse af Lov om dagpenge ved sygdom eller fødsel, 2 I. februar I978; Bekendtgørelse af Lov om invalidepension m.v., I 5 december I978).

3 The regional committees could (and often did) make their own inquiry in order to provide further information about the applicant (Bengtsson, I987).

4 Andersen (I998) notes that the courts in their decisions have emphasised, the duration of the sickness absence in relation to the worker's seniority, how much the company is affected by the sickness absence, and whether the sickness absence is work related.

5 Statsministerens åbningstale in Folketingets forhandlinger ( 1982 )

6 The description of the 1982 and 1987 changes is based on law proposals with remarks and the following parliament negotiations: Lov om ændring af lov om dagpenge ved sygdom eller fødsel (Karensdag, forlængelse af arbejdsgiverperioden, varighedsbegrænsning m.v.), L 57 I; Lov om ændring af lov om dagpenge ved sygdom og fødsel og ophævelse af lov om begrænsning af løn under sygdom (Ophævelse af karensdag m.v.), L6o.

7 In the same period, a parallel political consensus was reached in the unemployment policy.

8 The following is based on law proposals with remarks and the following parliament negotiations (Lov om dagpenge ved sygdom eller fødsel, L29; Lov om ændring af lov om social bistand, $\mathrm{L}_{3} \mathrm{O}$ ).

9 Remarks to proposal of changes to the social assistance act, $\mathrm{L}_{3} \mathrm{O}$.

Io The Danish sickness benefit scheme gives entitlement to full wage compensation with a daily ceiling of 603 D KK (2002), whereas the Dutch scheme entitles workers to 70 percent wage compensation with a daily ceiling of $842 \mathrm{DKK}$ (converted from Euros to DKK by 1999 Purchasing Power Parities).

\section{Notes Chapter 7}

I The data set does also include public sector workers, but they are excluded from the analysis in order to improve the comparability between the Danish and Dutch data sets.

2 The I-year employer period in the Dutch sickness benefit scheme was introduced in March I996 meaning that it came into effect approximately a year after the re- 
spondents' first day of work incapacity. It is likely therefore that this reform did not affect the respondents in any notable extent.

3 This section draws on Høgelund (2002).

4 On the contrary the correction of explanatory variables seems to increase the crossnational difference in the risk of dismissal. The odds ratio of Danish respondents versus Dutch respondents obtained from Table 7.2 is 8.4 with a $95 \%$ confidence interval on $[5.7 ;$ I 2.8$]$, whereas the odds ratio based on the coefficient from the logistic model is $\mathrm{I} 4.3$ with a $95 \%$ confidence interval on [8.4;23.8].

5 Neither does the analysis support that the general dismissal tendency in combination with company size affects the probability of dismissals (the interaction term has a p-value on 0.626 ).

6 The data also contains information about participation in "vocational education, or job training without public subsidies” (see Bergendorff and Gordon, 200I). However, the inclusion of two different measures within the same category hampers a sound crossnational comparison of how capacity-building measures are provided, because a presumably publicly provided measure, vocational education, is mixed with an employer-provided measure, job training without public subsidies.

7 Because of the low number of people in the Dutch cohort who participated in general education, it is impossible to take account of other explanatory variables.

8 This is supported by Høgelund and Modvig (I998) who find that establishment of workplace-based vocational rehabilitation seldom involves public authorities.

9 The separation into only two groups, a low and a high-income group, is not ideal and it has been chosen due to the fact that very few persons in the Dutch data are entitled to sickness benefit, cf. Table 7.6 A division into more groups would therefore imply that each group would consist of very few persons.

\section{Notes Chapter 8}

I The selection of explanatory variables has been made on the basis of a preliminary analysis.

2 Occupation may to some extent also reflect job demands and may therefore also measure employment conditions with the old employer.

3 The study by Høgelund and Holm (2002) that applies a more robust estimation procedure supports this. The authors find that the effect of separations (dismissals and quits) becomes insignificant in the Danish data (including both private and public sector workers) when unobserved variables are taken into account.

4 Using the same estimation procedure as in the estimation of the effect of general and vocational education, see Appendix E. 
5 It is measured as a (lagged) variable of the quarterly unemployment rate in the residence county of the sick-listed worker, and it is allowed to change value every third month during the sickness spell.

6 The present measure of unemployment conditions, i.e. the quarterly unemployment rate in the sick-listed worker's county of residence, may be too inaccurate. For example, employment opportunities may not depend on the unemployment rate in general but on the unemployment rate within the sick-listed worker's occupation, and maybe also on the unemployment rate in neighbour counties.

7 The actual level of income of other household members and the sick-listed worker's pre-sick leave wage income has also been included in the model, but it does not alter the conclusion. The finding may reflect the fact that the incomes of other household members and/or the sick-listed worker's pre-sick leave wage are endogenous variables and that these exit variables therefore also reflect other conditions. This interpretation is supported by the fact that the influence of the exit variable decreases when correction for unobserved variables is performed, cf. Table 8.2 and Table 2 in Appendix C.

8 It would be unfair to assert that a municipality has a lax exit policy if the municipality has extraordinary social problems that necessitate several disability benefit awards. I therefore use a model by Gregersen (I994) to correct for structural differences between municipalities, e.g. in age composition and the number of social security beneficiaries. More than 40 socio-demographic variables are used to correct for structural differences between the 275 municipalities. The adjusted benefit award rate of the 24 municipalities varies between - I.7 I per thousand inhabitants (harsh policy) and 2.98 (lax policy) with an average of O.I7.

\section{Notes Chapter 9}

I Furthermore, the Dutch beneficiaries who are working seem to work more hours than their Danish counterparts. A Dutch study of people who applied for a disability benefit in 1998 found that among those who were working 6 months later, about 80 percent worked more than 20 hours per week (Molenaar-Cox and van der Giezen, 2000). In contrast, the Danish disability beneficiaries who were working had an annual wage of 29.100 DKK in 1998 (Dansk Arbejdsgiverforening, 2000). This corresponds to approximately 4 hours of work per week, assuming they receive a wage similar to an average production worker.

2 In principle a more complete assessment of labour market exit through the disability pathway would also take into consideration to what extent beneficiaries exit from the disability scheme because they enter employment. In both nations this is a rare event; the lion's share of exit from the disability benefit scheme is caused by compulsory transition into the old age pension system. 
3 The fact that the stock of beneficiaries kept growing well into the I990s (cf. Figure 9.I.) reflects a previous high inflow of young beneficiaries resulting in a low outflow of beneficiaries during the r 990 .

4 It may also have had an impact that municipalities in I 999 were forbidden to consider disability benefit applications unless active measures had been applied (previously it was possible to consider benefits, but not to award them, without having applied active measures).

5 During the first 2 years after its implementation, the reassessment resulted in a withdrawal of the full disability benefit in 50 percent of the reassessed cases. Beneficiaries who lost their benefit were declared fully unemployed, and those who had their benefit reduced were declared partially unemployed (Oorschot and Boos, 2000). As a consequence, many existing disability beneficiaries were partly or fully transferred from the disability benefit scheme to the unemployment insurance scheme. The reassessments meant that the outflow from the disability benefit scheme increased in 1994 and 1995 and for the first time in the history the outflow exceeded the inflow, but in 1996 the situation returned to 'normal' (see Lisv, 200I).

6 The changes seem however to have had a lasting effect on the level of sickness absence, which decreased from 6.2 percent in I 993 to 4.9 percent in 1994 where it stayed during the second half of the I 990 (Geurts, Kompier and Gründemann, 2000).

7 The exact shape of the curve in Figure 9.5. is unknown and we cannot therefore know when higher employers costs yield a positive or negative net effect. 


\section{References}

Aakvik, A., Heckman, J. J. and Vytlacil, E. J. (2000). Treatment effects for discrete outcomes when responses to treatment vary among observationally identical persons: an application to Norwegian vocational rehabilitation programs. Cambridge: National Bureau of Economic Research.

Aarts, L. J. M. and de Jong, P. R. (I992). Economic Aspects of Disability Behavior. Elsevier Science Publishers B.V. Holland: Amsterdam.

Aarts, L. J. M., Burkhauser, R. V. and de Jong, P. R. (I996). Introduction and overview in: Aarts, L. J. M., de Jong, P. H. and Burkhauser, R. V. (Eds.): Curing the Dutch Disease. An International Perspective on Disability Policy Reform. England: Avebury Aldershot.

Aarts, L. J. M. and de Jong, P. R. (I996). The Dutch disability program and how it grew in: Aarts, L.J.M., de Jong, P.H. and Burkhauser, R.V. (Eds.): Curing the Dutch Disease. An International Perspective on Disability Policy Reform. England: Avebury Aldershot.

Aarts, L. J. M. and de Jong, P. R. (I996b). Evaluating the I987 and I993 social welfare reforms: From disappointment to potential success in: Aarts, L. J. M., de Jong, P. H. and Burkhauser, R. V. (Eds.): Curing the Dutch Disease. An International Perspective on Disability Policy Reform. England: Avebury Aldershot.

Aarts, L. J. M. and de Jong, P. R. (1998). Privatization of Social Insurance and Welfare State Efficiency. Evidence from the Netherlands and United States. Paper prepared for the 2nd International Research Conference on Social Security, Session Public versus Private Provision, Jerusalem, 25-28 January, I998.

Andersen, B. R. ( I97I). Grundprincipper i Socialpolitikken. Copenhagen: Socialpolitisk Forening.

Andersen, S. (I99I). Individual Consequences of Plant Closures and Cutback. Århus: Centre for Labour Economics, University of Aarhus and Aarhus School of Business. Working paper 9I-4.

Andersen, L. S. ( I998). Funktioncerret. 2. udgave. Copenhagen: Jurist- og Økonomforbundets Forlag.

Battie, M. C. ( I992). Minimizing the impact of back pain: Work place strategies. Seminars in Spine Surgey, vol. 4, no. I: pp. 20-28. 
Beljaars, P. W. L. M. M. and Prins, R. (I997). Combating a Dutch Disease: Recent Reforms in Sickness and Disability Arrangements in the Netherlands. ABP World, vol. 97, no. I.

Bengtsson, S. (I987). En lov-femten noevn. Regionale forskelle $i$ ansøgning, tilkendelse og afslag på førtidspension. Publication no. I67. Copenhagen: the Danish National Institute of Social Research.

Bengtsson, S. (I989). Førtidspension eller...? Report 89: I I. Copenhagen: The Danish National Institute of Social Research.

Bengtsson, S. (I997). Handicap og funktionshomning i halvfemserne. Report 97:I. Copenhagen: The Danish National Institute of Social Research.

Bergendorff, S. and Gordon, D. (200I). Vocational and Other Non-medical Interventions in: Bloch, F. S. and Prins, R. (Eds.): Who Returns to Work \& Why? A Six-Country Study on Work Incapacity \& Reintegration. New Jersey: Transaction Publishers.

Bergendorff, S. et al. (I997). Resultat av arbetslivsinriktad rehabilitering och köb av tjänst in: Marklund, S. (Eds.): Risk-and Frisk faktorer-sjukskrivning och rehabilitering i Sverige. Redovisar I 997:6. Stockholm: Riksförsäkringsverket.

Bergeskog, A. (200I). Labour market policies, strategies and statistics for people with disabilities. A crossnational comparison. Working paper 200I: I3. Sweden: Office of Labour Market Policy Evaluation.

Berkowitz, M. et al. (Eds.) (I988). Measuring the Efficiency of Public Programs. Costs and Benefits in Rehabilitation. Philadelphia: Temple University Press.

Berkowitz, E. D. and Burkhauser, R. V. (I996). A United States Perspective on Disability Programs, in: Aarts, L. J. M., de Jong, P. H. and Burkhauser, R. V. (Eds.): Curing the Dutch Disease. An International Perspective on Disability Policy Reform. England: Avebury Aldershot.

Berkowitz, M. and Johnson, W. G. (1974). Health and Labor Force Participation. The Journal of Human Resources, vol. IX, no. I: pp. I I7-28.

Betænkning nr. 898 ( ( 980). Betonkning om førtidspension afgivet af udvalget til revision fortidspensionslovgivningen. Betænkning nr. 898, februar.

Bloch, F.S. and Prins, R. (I997). Work incapacity and reintegration: Theory and design of a crossnational study. International Social Security Review, vol. 50, no. 2: pp. 3-24.

Bloch, F. S. and Prins, R. (Eds.) (200I). Who Returns to Work \& Why? A Six-Country Study on Work Incapacity \& Reintegration. New Brunswick and London: Transaction Publishers.

Boll, J. L. (200I). Det fleksible arbejde, ophør og marginalisering. Report o I:4. Copenhagen: the Danish National Institute of Social Research.

Burkhauser, R.V. (I998). Summing Up: Reflections on the Past and Future of Disability Policy in: Rupp, K. and Stapleton, D. C. (Eds.): Growth in Disability Bene- 
fits. Explanations and Policy Implications. Kalamazoo, Michigan: Upjohn Institute.

Butler, R. J. and Worral, J. D. ( 9985 ) Work Injury Compensation and the Duration of Nonwork Spells. The Economic Journal, vol. 95, no. 379: pp. 7I4-24.

Clasen, J., Kvist J. and van Oorschot, W. (200I). On condition of work: Increasing work requirements in unemployment compensation schemes in: Kautto, M., Fritzell, J., Hvinden, B., Kvist, J. and Uusitalo, H. (Eds.): Nordic Welfare States in the European Context. London and New York: Routledge.

Colbjørnsen, T. (I 986). Dividers in the Labor Market. Oslo: Norwegian University Press.

Cox, R.H. (I993). The Development of the Dutch Welfare State. From Workers' Insurance to Universal Entitlement. Pittsburgh: University of Pittsburgh Press.

Crook, J. M. (I994). A longitudinal epidemiological study of injured workers: Prognostic indicators of work disability. PhD Thesis, Canada, Toronto: University of Toronto.

Cstv (1996). Kroniek van de sociale verzekeringen 1996. Wetgeving en volume-ontwikkeling in historisch perspectief. Zoetermeer: College van toezicht sociale verzekeringen.

Cuelenaere, B., Veerman, T. J., Prins, R. and van der Giezen, A. M. (I999). In Distant Mirrors; Return to Work and Work Incapacity in Low Back Pain Patients in the Netherlands and other Countries. Zoetermeer: College van Toezicht Sociale Verzekeringen.

Damgaard, B. (2000). Kommunerne, virksombederne og den aktive socialpolitik. Casestudier af det lokale samarbejde. Report oo: I2. Copenhagen: The Danish National Institute of Social Institute.

Danmarks Statistik (200I). Statistisk Tiärsoversigt 200I. Copenhagen: Danmarks Statistik.

Danmarks Statistik (2002). Statistisk Tiårsoversigt 2002. Copenhagen: Danmarks Statistik.

Dansk Arbejdsgiverforening (1996). Fravaersstatistik I995. Copenhagen: Dansk Arbejdsgiverforening.

Dansk Arbejdsgiverforening (2000). SocialPolitikken \& ArbejdsMarkedet. Copenhagen: Dansk Arbejdsgiverforening.

Dean, D. H. and Dolan, R. C. (I99I). Assessing the Role of Vocational Rehabilitation in Disability Policy. Journal of Policy Analysis and Management, vol. Io, no. 4: pp. 568-587.

De Jong, P. (1987). Work capacity and the probability of entry into the Dutch disability insurance program in: Emanuel, H., de Gier, E. H. and Konijn, P. A. B. K. 
(Eds.): Disability benefits: Factors determining application and awards. Greenwich and London: JAI Press Inc.

Den Sociale Ankestyrelse (2002). Førtidspensioner Årsstatistik 200 I. En kommenteret statistisk oversigt over afgørelser i førtidspensionsager truffet af kommuner og sociale noun. Copenhagen: Den Sociale Ankestyrelse.

De Vroom, B. and Naschold, F. (1993). The Dialectics of Work and Welfare in: Naschold, F. and de Vroom, B. (Eds.): Regulating Employment and Welfare. Company and National Policies of Labour Force Participation at the End of Worklife in Industrial Countries. New York: Walter de Gruyter.

Disney, R. and Webb, S. (I990). Why Social Security Expenditure in the I980s has Risen Faster than Expected: the Role of Unemployment. Fiscal Studies, vol. I I, no. I: pp. I-20.

EIM (2002). Active Labour Market Programmes for people with disabilities. Fact and figures on use and impact. Zoetermeer: EIM Business \& Policy Research.

Einerhand, M. G. K., Knol, G. Prins, R. and Veerman, T. J. (I995)

Sickness and invalidity arrangements. Fact and figures from six European countries. The Hague: Ministerie van Sociale Zaken en Werkgelegenheid.

Elmore, R. F. (1987). Instruments and strategy in public policy. Policy Studies Review, vol. 7, no. I: pp. I74-I 86 .

Elster, J. (I985). Making Sense of Marx. Cambridge: Cambridge University Press. Emanuel, H. (1987). The Dutch Research Program on Factors Determining Social Disability Benefit Recipiency: A Background Paper, in: Emanuel, H., de Gier, E. H. and Konijn, P. A. B. K. (Eds.): Disability Benefits: Factors Determining Application and Awards. Greenwich and London: JAI Press Inc.

Emanuel, H., de Gier, E. H. and Konijn, P. (Eds.) (1987). Disability benefits: Factors Determining Application and Awards. Greenwich and London: JAI Press Inc.

Emanuel, H., Halberstadt, V. and Petersen, C. (I984). Disability Policy in the Netherlands, in: Haveman, R., Halberstadt, V. and Burkhauser, R. V.: Public Policy Toward Disabled Workers. Cross-National Analyses of Economic Impacts. Ithaca and London: Cornell University Press.

Esping-Andersen, G. (I990). Three Worlds of Welfare Capitalism. Cambridge: Polity Press.

Esping-Andersen, G. (I993). The Comparative Macro-Sociology of Welfare States in: Moreno, L. (Eds.): Social Exchange and Welfare Development. Madrid: Consejo Superior de Investigaciones Científicas.

Esping-Andersen, G. (I 996a). Positive-Sum Solutions in a World of Trade-Offs? in: Esping-Andersen, G. (Eds.): Welfare States in Transition, National Adaptations in Global Economies. London: Sage Publications.

Esping-Andersen, G. (Eds.) (I996b). Welfare States in Transition. National Adoptions in Global Economies. London: Sage Publications. 
Esping-Andersen, G. (I 999). Social Foundations of Postindustrial Societies. Oxford: Oxford University Press.

European Commission (I993). Social beskyttelse i Europa. Brussels: European Communities.

Eurostat (200Ia). European social statistics. Social protection. Expenditure and receipts: 1980-99. Luxembourg: Office for Official Publications of the European Communities.

Eurostat (200I b). European social statistics - Labour force, survey results 2000 . Data 2000. Luxembourg: Office for Official Publications of the European Communities.

Frank, J. W. et al. (I995). Occupational Back Pain: An unhelpful polemic. Scandinavian Journal of Work, Environment and Health, vol. 2 I, no. I: pp. 3-I4.

Frank, J. W. et al. (I996). Disability Resulting from Occupational Low Back Pain. Part II: What Do We Know About Secondary Prevention? A Review of Scientific Evidence on Prevention After Disability Begins. Spine, vol. 2I, no. 24: p. 29 I 82929.

Frick, B. and Sadowski, D. (I996). A German perspective on disability policy in: Aarts, L.J.M., de Jong, P.H. and Burkhauser, R.V. (Eds.): Curing the Dutch Disease. An International Perspective on Disability Policy Reform. England: Avebury Aldershot.

Frölich, M., Heshmati, A. and Lechner, M. (2000). A Microeconometric Evaluation of Rehabilitation of Long-Term Sickness in Sweden. SSE/EFI Working Paper Series in Economics and Finance no. 373. Stockholm: Stockholm School of Economics.

Gatchel, R. J., Polatin, P. B. and Mayer, P. D. (I994). Psychopathology and the rehabilitation of patients with chronic low back pain disability. Archives of Physical Medicine and Rehabilitation, vol. 75, no. 6: pp. 666-670.

Gerhardt, U. (I987). Ideas about Illness. London: Macmillan.

Geurts, S., Kompier, M., and Gründemann, R. (2000). Curing the Dutch disease? Sickness absence and work disability in the Netherlands. International Social Security Review, vol. 53, no. 4: pp. 79-103.

Goldthorpe, J. H. ( I 997). Current Issues in Comparative Macrosociology; A Debate on Methodological Issues. Comparative Social Research, vol. I6: pp. I-26.

Green-Pedersen, C. (200I). Welfare-State Retrenchment in Denmark and the Netherlands, I982-I998. The Role of Party Consensus. Comparative Political Studies, vol. 34, no. 9: pp. 963-85.

Greene, W. H. (2000). Econometric Analysis. $4^{\text {th }}$ edition. New Jersey: Prentice-Hall Gregersen, O. (I994). Kommunernes pensionspraksis. Servicerapport. Copenhagen: The Danish National Institute of Social Research. 
Hanson, B. S. (I990). Hur kan en individs sociala nätverk och sociala stöd påverka hälsan? Socialmedicinsk tidsskrift, 67:e årg., häfte I-2: pp. 32-36.

Hassink, W. H. J., Van Ours, J. C. and Ridder, G. (I997). Dismissal Through Disability. De Economist, vol. I45, no. I: pp. 29-45.

Hatland, A. (200I). Changing family patterns: A challenge to social security in: Kautto, M., Fritzell, J., Hvinden, B., Kvist, J. and Uusitalo, H. (Eds.): Nordic Welfare States in the European Context. London and New York: Routledge.

Haveman, R., Halberstadt, V. and Burkhauser, R. V. (I984). Public Policy Toward Disabled Workers. Crossnational analyses of economic impacts. Ithaca and London: Cornell University Press.

Haveman, R. H. and Wolfe, B. L. (I984a). Disability transfers and early retirement: A causal relationship? Journal of Public Economics, Vol. 24, no. I: pp. 47-66.

Haveman, R. H. and Wolfe, B. L. (I984b). The decline in male labor force participation: A comment. Journal of Political Economy, 92, no. 3: pp. 532-54 I.

Hazard, R. G., Bendix, A. and Fenwick, J. W. (I99I). Disability exaggeration as a predictor of functional restoration outcomes for patients with chronic low back pain. Spine, vol. 16, no. 9: pp. 1062-67.

Hennessey, J. C. and Muller, S. L. M (I995). The Effect of Vocational Rehabilitation and Work Incentives on Helping Disabled-Worker Beneficiary Back to Work. Social Security Bulletin. vol. 58, no. I: pp. I-24.

Heshmati, A. and Engström, L. G. (200I). Estimating effects of vocational rehabilitation programs in Sweden in Lechner, M. and Pfeiffer, F. (Eds.): Econometric Evaluation of Labour Market Policies. ZEW Economics Studies I3. New York: Physica-Verlag.

Hetzler, A. and Eriksson, K. (I98 I). Ökad förtidspensionering-en rättssociologisk analys. Lund: Rättssociologiska Institutionen.

Hildebrandt J., Pfingsten, M., Saur, P. and Jansen, J. ( I 997). Prediction of success from a multidisciplinary treatment program for chronic low back pain. Spine, vol. 22, no. 9: pp. 990-I00I.

Hohnen, P. (2002). Work or charity? Individual experiences with Danish and Dutch reintegration policies and discourses of corporate social responsibility. Paper presented at the $7^{\text {th }}$ EASA biennial conference Copenhagen I4-I7 August 2002.

Holmes, P., Lynch, M. and Molho, I. (I99I). Growth in the Numbers Claiming Invalidity Benefit: An Overview. Journal of Social Policy, vol. 20, no. I: pp 87-105.

Houtman, I., Otten, F. and Venema, A. (2002). Kerncijfers arbeid, gezondheid en sociale zekerheid in: Smulders, P. G. W., Houtman I.L.D. and Hesseling, K. (Eds): Trends in arbeid 2002. Alphen a.d Rijn: Kluwer.

Hvinden, B., Heikkilä, M. and I. Kankare (200I). Towards activation? The changing relationship between social protection and employment in Western Europe in Kautto, M., Fritzell, J., Hvinden, B., Kvist, J. and Uusitalo, H. (Eds.): Nordic 
Welfare States in the European Context. London: Routledge.

Høgelund, J. (2002). Reintegration: Public or Private Responsibility? Consequences of Dutch and Danish Policies toward Work-Disabled Persons. International Journal of Health Services, vol. 32 , no. 3.

Høgelund, J. and Holm, A. (2002). Returning Long-Term Sick-Listed to Work. The Effects of Training in a Competing Risk Model with Time Varying Covariates and Unobserved Heterogeneity. Working Paper I 2:2002. Copenhagen: the Danish National Institute of Social Research.

Høgelund, J. and Modvig, J. (I998). Langtidssygemeldte med rygproblemer - en forløbsundersøglse i 24 kommuner. Working paper. Copenhagen: the Danish $\mathrm{Na}$ tional Institute of Social Research.

Höög, J. and Stattin, M. (I995). Orsaker till förtidspensionering in: Marklund, S. (Eds.): Rehabilitering i ett sambällsperspektiv. Second edition. Lund: Studentlitteratur.

Ilmarinen, J. (1999). Aging Workers in the European Union. Helsinki: The Finnish Institute of Occupational Health.

Jacobs, K., Kohli, M. and Rein, M. (I99I). Germany: The diversity of pathways in: Kohli, M, Rein, M., Guillemard, A. M. and van Gunsteren, H. (Eds.): Time for Retirement - Comparative studies of early exit from the labor force. New York: Cambridge University Press.

Jensen, P. ( I997). Ledighedens dynamik, in: Pedersen, L. (Eds.): Er der veje til fuld beskaftigelse? Report 97:I3. Copenhagen: The Danish National Institute of Social Research.

Johnson, W. G., Baldwin, M. L. and Butler, R. J. ( I998). Back Pain and Work Disability: The Need for a New Paradigm. Industrial Relations, vol 37, no. I: pp. 934 .

Johnson, W. G. and Ondrich, J. (I990). The Duration of Post-injury Absences from Work. Review of economics and statistics, vol. 72., no. 4: pp. 578-86.

Jonasen, V. (I998). Dansk Socialpolitik I708-I 998. Aarhus: Den Sociale Højskole i Aarhus.

Karasek, R. and Theorell, T. (I990). Healthy Work: Stress, Productivity and the Reconstruction of Working Life. New York: Basic Books. A Division of Harper Collins Publishers.

Klaas, B. S., Brown, M. and Heneman III, H. G. (I998). The Determinants of Organizations' Usage of Employee Dismissal: Evidence from Australia. Journal of Labor Research, vol. XIX, no. I: pp. I49-64.

Knudsen, R. (1979). De kontante ydelsers størrelser - I978. Publication 88. Copenhagen: The Danish National Institute of Social Research. 
Kohli, M. and Rein, M. (I99I). The Evolution of Early Exit: A Comparative Analysis of Labour Force Participation Patterns, in: Kohli, M, Rein, M., Guillemard, A. M. and van Gunsteren, H. (Eds.): Time for Retirement - Comparative Studies of Early Exit from the Labour Force. New York: Cambridge University Press.

Koitz, D., Kollman, G. and Neisner, J. (I992). Status of the Disability Programs of the Social Security Administration. Washington, DC: Congressional Research Service.

Kolberg, J. E. ( I99I). En empirisk prøvning av utstøtningsmodellen in Hatland, A. (Eds): Trygd som fortjent? Oslo: Ad Notam.

Krause, N., Dasinger, L. K. and Neuhauser, F. (I998). Modified Work and Return to Work: A Review of the Literature. Journal of Occupational Rehabilitation, vol. 8, no. 2: pp. II3-39.

Krause, N. and Lund, T. (2002). Return to Work in: Barling, J. and Frone, M. (Eds.): The psychology of workplace safety. Washington DC: American Psychological Association.

Krueger, A. B. (I990). Workers' Compensation Insurance and the Duration of Workplace Injuries. NBER Working Paper no. 3523, National Bureau of Economic Research.

Kummel, B. M. (I996). Nonorganic signs of significance in low back pain. Spine, vol. 2 I, no. 9: pp. 1077-8 I.

Kvist, J. (1999). New Perspectives in Comparative Social Policy. Unpublished PhD Thesis. Copenhagen: The Danish National Institute of Social Research.

Lacroix, J. M. et al. (I990). Low-back pain. Factors of value in predicting outcome. Spine I 5, no. 6: pp. 495-99.

Langager, K. (I993). Rekruttering, afskedigelse og marginalisering. Report 93:6. Copenhagen: The Danish National Institute of Social Research.

Lavindkomst Kommissionens Betænkning (1982). Lavindkomst Kommissionens Betæenkning. Betænkning nr. 946. Copenhagen.

Lewis, D. R., Johnson, D. R., Chen, T. and Erickson, R. N. (I992). The Use and Reporting of Benefit-Cost Analysis by State Vocational Rehabilitation Agencies. Evaluation Review, vol. I6, no. 3: pp. 266-287.

Lindqvist, R. (I995). Arbete, sjukdom och rehabilitering, in: Marklund, S. (Eds.), Rehabilitering $i$ ett sambällsperspektiv. Lund: Studentlitteratur.

Lisv ( I998). Kroniek van de sociale verzekeringen I 998. Wetgeving en volume-ontwikkeling in historisch perspectief. Zoetermeer: Landelijk instituut sociale verzekeringen.

Lisv (200I). Kroniek van de sociale verzekeringen $200 \mathrm{I}$. Wetgeving en volume-ontwikkeling in historisch perspectief. Zoetermeer: Landelijk instituut sociale verzekeringen. 
Lisv (2002). Jaaroverzicht arbeidsgehandicapten 2000. Zoetermeer: Landelijk instituut sociale verzekeringen.

Livermore, G., Stapleton, D. C. and Zeuschner, A. (I998). Lessons from Case Studies of Recent Program Growth in Five States in: Rupp K. and Stapleton, D. C. (Eds.): Growth in Disability Benefits. Explanations and Policy Implications. Kalamazoo, Michigan: Upjohn Institute.

Loeser, J. D. and Hernserlite, S. E. (I995). Incentive effects of workers' compensation benefits: A synthesis. Medical Care Research and Review, Vol. 52, no I.: pp. 34-6o.

Lund, T. and Borg, V. (I999). Work Environment and Self-Rated Health as Predictors of Remaining in Work 5 Years Later Among Danish Employees 35-59 Years of Age. Experimental Aging Research, vol. 25, no. 4: pp. 429-34.

Marklund, S. (I995). Indledning, in: Marklund, S. (Eds.): Rehabilitering i ett sambällsperspektiv. Second edition, Lund: Studentlitteratur.

Mechanic, D. (I962). The Concept of Illness Behaviour. Journal of Chronic Diseases, vol. I 5 , February: pp. I 89-I94.

Meyer, B. D. and Viscusi, K. W. (I995). Workers' Compensation and Injury Duration: Evidence from a Natural Experiment. American Economic Review, vol. 85 . no. 3.: pp. 322-4I.

Ministerie van Sociale Zaken en Werkgelegenheid (I995). Measures to reduce sick leave and improve labour conditions. SZW Info. The Hague: Ministerie van Sociale Zaken en Werkgelegenheid.

Molenaar-Cox, P. G. M. and van der Giezen, A. M. (2000). Langdurige arbeidsongeschiktheid in I999- Trends I99I-I999. Zoetermeer: Landelijk instituut sociale verzekeringen.

Naschold, F. and B. de Vroom (Eds.) (I993). Regulating Employment and Welfare. Company and National Policies of Labour Force Participation at the End of Worklife in Industrial Countries. New York: Walter de Gruyter.

Nagi, S. Z. (1965). Some Conceptual Issues in Disability and Rehabilitation in: Sussman, M. B. (Eds.): Sociology and rehabilitation. American Sociological Association.

Nagi, S. Z. (1969). Disability and Rehabilitation. Columbus, OH: Ohio State University.

Navarro, V. (I998). Neoliberalism, “Globalisation”, Unemployment, Inequalities, and the Welfare State. International Journal of Health Services, vol. 28, no. 4: pp. 607-82.

Navarro, V. (I 999). The Political Economy of the Welfare State in Developed Capitalist Countries. International Journal of Health Services, vol. 29, no. I: pp. I-53. 
Nord-Larsen, M. (I99I). Langvarig sygdom-Problemer og konsekvenser. Report 9I:5. Copenhagen: The Danish National Institute of Social Research.

OECD (1987). Historical Statistics I960-1985. Paris: Organisation for Economic Co-operation and Development.

OECD (I99I). Labour Force Statistics 1969-1989. Paris: Organisation for Economic Co-operation and Development.

OECD (I992a). Employment Outlook July I 992. Paris: Organisation for Economic Co-operation and Development.

OECD (I992b). Historical Statistics I960-I 990. Paris: Organisation for Economic Co-operation and Development.

OECD ( I996). Employment Outlook July I 996. Paris: Organisation for Economic Co-operation and Development.

OECD ( I 997). Employment Outlook July I 997. Paris: Organisation for Economic Co-operation and Development.

OECD (1998). Employment Outlook June I998. Paris: Organisation for Economic Co-operation and Development.

OECD (I999). oecd Historical Statistics I 960-I997. Paris: Organisation for Economic Co-operation and Development.

OECD (2000). oecd Economic Surveys: Netherlands. March 2000. Paris: Organisation for Economic Co-operation and Development.

OECD (200Ia). Fiscal implications of ageing: projections of age-related spending. ECO/WKP(200I)3 I. Paris: Organisation for Economic Co-operation and Development.

OECD (200Ib). Employment Outlook June 200I. Paris: Organisation for Economic Co-operation and Development.

OECD (200IC). Labour Force Statistics I980-2000. Paris: Organisation for Economic Co-operation and Development.

OECD (2002). Historical Statistics I970-2000. Paris: Organisation for Economic Co-operation and Development.

Oleinick, A., Gluck, J. V. and Guire, K. E. (I996). Factors Affecting First Return to Work Following a Compensable Occupational Back Injury. American Journal of Industrial Medicine, vol. 30, no. 5: pp. 540-55.

Palmer, E. E. ( I 990). Potential Gains from Early Intervention in Sickness Absenteeism at the Workplace: An Overview of the Current State of Knowledge and Trends in Sweden. In: Berkowitz, M. (Eds.): Forging linkages: Modifying Disablity Benefit Programs to Encourage Employment. New York: Rehabilitation International.

Paoli, P. (I992). First European survey on working conditions I99I-I992. 
Dublin: European Foundation for the Improvement of Living and Working Conditions.

Paoli, P. (I 997). Second European survey on working conditions. Dublin: European Foundation for the Improvement of Living and Working Conditions.

Paoli, P. and Merllié, D. (200I). Third European survey on working conditions 2000. Dublin: European Foundation for the Improvement of Living and Working Conditions.

Parsons, D. O. (1980). The Decline in Male Labor Force Participation. Journal of Political Economy, vol. 88, no. I: pp. I I7-34.

Parsons, D. O. (1984). Disability Insurance and Male Labor Force Participation: A Response to Haveman and Wolfe. Journal of Political Economy, vol. 92, no. 3 , pp. 542-549.

Piachaud, D. (I986). Disability, Retirement and Unemployment of Older Men. Journal of Social Policy, vol. I 5, no. 2, pp. I45-162.

Prins, R. (1990). Sickness Absence in Belgium, Germany (FR) and the Netherlands. A Comparative Study. Amsterdam: NIA.

Prins, R., Veerman, T. J. and van der Giezen, A. M. (I996). Werkhervatting na rugklachten, een internationale studie - Deelrapport I: Probleemstelling, opzet en uitvoering van de eerste fase. Report R96/2. Zoetermeer: College van Toezicht Sociale Verzekeringen.

Ragin, C. (1987). The Comparative Method. Moving Beyond Qualitative and Quantitative Strategies. Berkeley: University of California Press.

Rhodes, M. (I996). Globalization and West European Welfare States: A Critical Review of Recent Debates. Journal of European Social Policy, vol. 6, no. 4: pp. 305327.

Rhodes, M. (I997). The Welfare State: Internal Challenges, External Constraints in: Rhodes, M., Heywood, P. and Wright, V. (Eds.): Developments in West European Politics. Basingstoke: Macmillan Press.

Rosdahl, A. (200I). The Policy to Promote Social Responsibility of Enterprises in Denmark. Working Paper. Copenhagen: The Danish National Institute of Social Research.

Rupp, K. and Stapleton, D. C. (I998). Introduction in: Rupp, K. and Stapleton, D.C. (Eds.): Growth in Disability Benefits. Explanations and Policy Implications. Kalamazoo, Michigan: Upjohn Institute.

Rørbech, M., Petersen, L. O., Fridberg, T. and Plovsing, J. (I 985 ). Socialreformundersøgelserne 7. Hvordan går det klienterne? Publication I 36. Copenhagen: The Danish National Institute of Social Research.

Sandström, J. ( I986). Clinical and social factors in rehabilitation of patients with 
chronic low back pain. Scandinavian Journal of Rehabilitation Medicine, vol.I 8, no. I: pp. 35-43.

Sandström, J. and Esbjörnsson, E. (I986). Return to work after rehabilitation. The significance of the patient's own prediction. Scandinavian Journal of Rehabilitation Medicine, vol. I 8, no. I: pp. 29-33.

Schellekens et al. (1999). SZW-Werkgeverspanel Rapportage I997-I998. Ziekteverzuim Arbeidsomstandigheden Reïntegratie Arbeidsongeschiktheid. The Hague: Elsevier.

Sociaal-Cultureel Planbureau (I997). Social and Cultural Report I 996. The Hague: Social and Cultural Planning Office.

Sociaal-Cultureel Planbureau (2000). Sociaal en Cultureel Repport 2000. The Hague: Social and Cultural Planning Office.

Standing, G. (I999). Global labour flexibility: Seeking distributive justice. Basingstoke: Macmillan.

Stapleton, D. C., Coleman, K., Dietrich, K. and Livermore, G. (I998). Empirical Analyses of DI and ss I Application and Award Growth in: Rupp, K. and Stapleton, D. C. (Eds.): Growth in Disability Benefits. Explanations and Policy Implications. Kalamazoo, Michigan: Upjohn Institute.

Stattin, M. (I 998). Yrke, yrkesförändring och utslagning från arbetmarknaden -en studie av relationen mellan förtidspension och arbetsmarknadsförändring. Umeå: Umeå University.

Sattinger, M. ( I998). Statistical discrimination with employment criteria. International Economic Review, vol. 39, no. I: pp. 205-237.

Stone, D. (1984). The Disabled State. Philadelphia: Temple University Press.

Terpstra, J. (2002). Coorporation between social security and employment services: Evaluation of a reform strategy in the Netherlands. International Social Security Review, vol. 55, no. 3: pp. 39-55.

Thompson, H. (I997). The Nation-State and International Capital in Historical Perspective. Government and Opposition, vol. 32, no. I: pp. 84-I I 3 .

Topel, R.H. (1982). Inventories, Layoffs, and the Short-Run Demand for Labour. The American Economic Review, vol. 72, no. 4: pp. 769-87.

Valbak, A. (I988). Idé og Virkelighed - før. Revalideringsarbejdets udvikling og vilkår i tiden op mod bistandsloven in: Jønsson, H. O. and Lange, K. (Eds.): Revalidering - igen. Copenhagen: SIKON.

Valbak, A. and Wamsler, J. (I986). Revalideringsindsatsens erhvervsmoessige effekt - undersøgelse af revalideringssager der er afsluttet 1984 i udvalgte kommuner. Copenhagen: Amternes- og Kommunernes Forskningsinstitut.

Van der Veen, R. J. (I990). De sociale grenzen van beleid. Leiden: Stenfert Kroese. 
Van der Veen, R. J. and Trommel, W. (I999). Managed Liberalization of the Dutch Welfare State. Governance, vol. I 2, no. 3: pp. 289-3 I I.

Van Groenestijn, M. A. J. (I99I). Artikel 30 Ziektewet een (on) Bruikbaarinstrument. Social Maandblad Arbeid, vol. 46, no. 6, June: pp. 374-8I.

Van Kersbergen, K. (2000). The declining resistance of welfare states to change? in Kunhle, S. (Eds.): The survival of the European welfare state. London: Routledge. Van Oorschot, W. (200I). Miracle or Nightnare? A critical review of Dutch activation policies and their outcomes. Paper presented at the COST Action I 5 meeting, Berlin, April 26-28.

Van Oorschot, W. and Abrahamson, P. (2003). The Dutch and Danish Miracles Revisited. A Critical Discussion of Activation. Social Policy and Administration, vol. 37 , no. 3 (in press).

Van Oorschot, W. and Boos, K. (2000). The Battle Against Numbers: Disability Policies in the Netherlands. European Journal of Social Security, vol. 2, no. 4: pp. 343-62.

Vedung, E. (I998). Policy Instruments: Typologies and Theories in: BemelmansVidec M. L, Rist, R. C. and Vedung, E.: Carrots, Sticks \& Sermons. Policy Instruments \& Their Evaluation. New Brunswick and London: Transaction Publishers.

Veerman, T. J. (200I). English summary in: Veerman, T. J.: Prikkels en Privatisering - Integrerende rapportage evaluatie wetgeving rond ziekteverzuim, WAO en reïntegratie. The Hague: Ministerie van Sociale Zaken en Werkgelegenheid/Doetinchem: Elsevier bedrijfsinformatie.

Veerman, T. J. and Palmer, E. (200I). Work Resumption and the Role of Interventions in Bloch, F. S. and Prins, R. (Eds.): Who Returns to Work \& Why. A SixCountry Study on Work Incapacity \& Reintegration. International Social Security Series. Volume 5, pp. 223-72. New Brunswick (U.S.A.) and London (U.K.): Transaction Publishers.

Visser, J. and A. Hemerijck (I997). “A Dutch Miracle'. Job Growth, Welfare Reform and Corporatism in the Netherlands. Amsterdam: Amsterdam University Press.

Waddell, G. (I987). I987 Volvo award in clinical sciences. A new clinical model for the treatment of low-back pain. Spine, vol. I 2, no. 7: pp. 63 2-44.

Wadensjö, E. and Palmer, E. E. (I996). Curing the Dutch disease from a Swedish perspective in: Aarts, L.J.M., de Jong, P.H., Burkhauser, R.V. (Eds.): Curing the Dutch Disease. An International Perspective on Disability Policy Reform. England: Avebury Aldershot.

Weide, W. E. van der, Verbeek J. H. A. M. and Tulder, M. W. v (I997). Vocational outcome of intervention for low-back pain. Scandinavian Journal of Work, Environment and Health, vol. 23, no. 3: pp.165-I78. 
Werneke, M. W., Harris, D. E. and Lichter, R. L. (I993). Clinical effectiveness of behavioural signs for screening chronic low-back pain patients in a work-oriented physical rehabilitation program. Spine, vol. I 8, no. I 6: pp. 24 I 2- I 8.

Wolfe, B. L. and Haveman, R. (I990). Trends in the Prevalence of Work Disability from 1962 to 1984 , and Their Correlates. The Milbank Quarterly, vol. 68, no. I: pp. 53-8o. 


\section{Index of Subjects}

AAW (Dutch disability benefit scheme), see

Disability benefit scheme

Administrative authorities 23, 4I-44

Denmark 93-94, 96-105, I07-I08, I45, I 64

the Netherlands 77-8I, 86, 88-9I, I04-

I05, I07-108

Ageing populations I2, I6-I7, 20-2I, I65I 66, I73-I74

Activation, see Active labour market policies

Active labour market policies I7-I $8,7 \mathrm{I}-72$

AMBER (Dutch Act on Abolishment of Malus and Promoting Reintegration) 86

Arbowet (Dutch Act on Working Circumstances) $85,87, \mathrm{I} 65$

Arbodienst (private consultancy companies in the Netherlands) 85,107

в в (Dutch Act on job protection), see Jobprotection legislation

Capacity-building measures definition of 54 effects of 39-4I, I 42-I 43 expenditures to $7 \mathrm{I}-72$

Denmark 94, IO I, I I 8-I I 9 the Netherlands 79, I I 8-I I 9

CDA (Dutch Christian Democratic Party) 85

Clinical studies 3I-36

Costs of disability, social and psychological 56-58, 62-63, I36, I 44, I 46-I 47

CW I (Dutch Centres for Work and Income) 89

D66 (Dutch Social Liberal Party) 85

Data of the study II 2-I I 4

Day care I3, I5-I7

Disability benefit awards factors influencing $18-25,43-45,163-$ I 72, I 75-I76, see also Disability crisis the number of I62-163

Disability benefit scheme
Denmark 94-95, 97-I03, I08, I45, I64, I70-I7I, I74-I 75

the Netherlands $43-45,78-88,90$, I08, I 47, I64-I 65, I70-I 7I, I73-I75

Disability benefit beneficiaries, the number of Denmark 69-7I, 73-74, I60-I63

the Netherlands 68-7I, 73-74, I60-I 63

Disability crisis 68-7I, 73, 76-83, I60-I6I

Disability pathway

definition of I8-I9

influence on integration in Denmark I44I 45

pressures on 19-25, I70-I74, see also Disability crisis

use of 68-70, 73, I46-I47, I62-I63, I70-

I 74

Disability policy

benefit strategy $24-25$

changes, see reforms

comparing Danish and Dutch 95-96, I04I०8

consequences, see outcomes

eligibility criteria, see Eligibility criteria for disability benefit

effectiveness of 24-25, 82-83, I25, I39-

I 43, I 45 -I 49, I 62-I 67, I 70-I 77

efficiency of 24-25, I75-I 77

exit pressures 20-23, 49-5 I, I73-I75

financial structures $4 \mathrm{I}-44$

financial structures, Denmark 94, 98, IOI-IO2, IO4, I 64

financial structures, the Netherlands $8 \mathrm{I}$, 86, 89-9 I, I04-I05, I 65

future challenges $20,24-25, \mathrm{I} 73-\mathrm{I} 75$

integration into the labour market, see Integration

reforms in Denmark 98-105, I62-I67

reforms in the Netherlands 82-91, I62-

I 67

labour market strategy 24-25

outcomes II 4-I 25, I 37-I 43, I45-I49,

I 62-I 67, I 70-I 73 
theoretical models I 8-23, 53-64, I67-I 70 vocational rehabilitation, see Integration instruments

welfare states I8-23, I72-I 73, see also theoretical models

Discrimination of disabled people 59-6I, I06

Dismissal of sick-listed workers job protection 87-88, 94-95, I05-IO6, I I 4-I I 8 , I 24 -I 25 labour market integration $24-25,60,137-$ I42, I 45-I 48, I 72-I 73

Duration analysis I 40, I 52-I 53

Early retirement, see Exit pathways

Economic crisis 65-7I, 75-77

Economic growth $65-66,72$

Economic studies 36-40

Educational measures, see Capacity-building measures

Eligibility criteria for disability benefit $2 \mathrm{I}$ 24, 44-45, 6I, 63-64 comparing Danish and Dutch I08, I70I7 I

Denmark 94, 97, 99-100, I03 the Netherlands $78-80,82,84$

Employers' responsibilities 60 comparing Danish and Dutch 96, I04106, 109

Denmark 94-95, 99, I03, I09 dismissal of sick-listed workers I I4-I I 8, I 24-I 25

labour market integration I09, I 37-I42, I 44-I 49, I 64-I 65, I 72-I 77

the Netherlands $84-85,86-88$

workplace-based vocational rehabilitation I I 9-I 2I, I 24-I 25

Employers associations $76-78,83,85-86$, 88-89

Employment opportunities I9-20, 55-57, 59-60, I69-I70, I 72-I73

consequences for integration $49-5 \mathrm{I}, \mathrm{I} 36^{-}$ I 42 , I 44

Entitlement to disability benefit 8 I , 84, 94

Entitlement to sickness benefit (or wage) comparing Denmark and the Netherlands 95, I08, I 2 I-I 24 consequences for reintegration $37-39, I_{42}$ Denmark 94, 98-I00, IO2 the Netherlands 78-79

Exit pathways from work I8-I9, 45, 68-7I, 73, I70-I 72, see also Disability pathway

Exit opportunities 42, 55-57, 6I, 63-64, see also Disability pathway and Eligibility criteria for disability benefit definition of 56 comparing Dutch and Danish 108 the consequences for integration $\mathrm{I} 42$, I 44 -I 45

Family patterns I3-I7, 20, 2I

Fertility rate I4, I6-I7

FNV (Dutch Federation of Unions) 83

Globalisation I2-I 7, 23, I73-I75

Incentives of

administrative authorities $4 \mathrm{I}-44,78,89$, 98, IO2, I07, I64, I 7 I

disabled workers 36-39, 8I, 97, IOI, I42, I 4 6-I 47

employers, see Employers' responsibilities

Income protection during sick leave, see Entitlement to sickness benefit

Industrial Insurance Boards, Dutch 78-79, 88,89

Industrial Injuries Act 88

Inequality, wage I3, I 5-I7

Insiders and outsiders I6-I7, I39-I42, I47I 49, I65, I74-I77

Integration (into the labour market)

a model for I 8-23, 53-64, I67-I 70

disability role 46-49, 58, 62-63, I 46-I 47 dismissal 24-25, 60, I37-I42, I45-I48, I72-I73

economic incentives, see Incentives employment conditions, see Employment opportunities

employers, see Employers' responsibilities health variables, see individual resources individual resources 33-34, 56-59, 62, I 40, I43-I 44, I68-I69 interventions, clinical $35-36$ interventions, workplace-based 35-36, see also Workplace-based rehabilitation job-related variables 33-34, 49-5 I, I37, I 40, I 44 lifestyle variables $33-34$ replacement rate $37-39, \mathrm{I}_{4} 2$ socio-demographic characteristics 33-34, $\mathrm{I} 4 \mathrm{O}$ social support $47-48,58$, I 40 , I 44 psychological variables $33-34$, see also social and psychological costs of disability pull factors 2I, 23, I69 push factors I9-2 I, 22-23, 49 social and psychological costs of disability $56,58,62-63$, I 37, I 44, I 46 -I 47 theories of $3 \mathrm{I}-32,36-37,4 \mathrm{I}-42,46-47$, 49 , see also a model for 
unemployment 49-5 I, I 44 vocational rehabilitation, effects of 39 4 I, I 42-I 43 worker role $46-47,58$

Instrumental variables I 54, I 56

Integration instruments, see also Capacitybuilding measures and Workplace-based rehabilitation

economic means 54-55, 60-6I, I05-IO7 see also Wage subsidies

information and moral suasion 54-55, 6I, I03, $105-106$

quota jobs $54-55,59-6 \mathrm{I}, 79,82$

regulations 54-55, 60, I05-I07, I 72 see

also Dismissal of sick-listed workers

Job demands, see Integration, job-related variables

Job-protection legislation, see also Dismissal of sick-listed workers

Denmark 94-95 the Netherlands $87-88$

Job training

effects of 39-4I

expenditures to $7 \mathrm{I}$

Labour market marginalisation, see Marginalisation and Integration

Labour market flexibility I7, I9-2I, I46, I75-I76

Labour market regulation 54-55, 60-6I, I05-I07, I 25, I 4 I, I 45-I47, I 75-I 76

Labour force participation I3-I4, I6, 6667,73 , see also Integration and Work pathway

Lisv (Dutch Institution for the Coordination of Social Security Schemes) 88-89

Local Coordination Committees, Danish I03, 106

Low back pain patients, integration of 32 36, I36-I 45

Marginalization, labour market I9-23, 49$5 \mathrm{I}$, see also Integration

Methodological individualism 54, 63-64

Municipalities, see Administrative authorities

Organisational structures, see Administrative authorities

Parliamentary inquiry, Dutch $78,86,90$ ремв (Dutch Act on Premium Differentiation and Market Competition in the dis- ability Insurances) 86

Policy instruments, types of 54-55, IO5-108

Public Audit Office, Dutch 78, 86

Public Employment Service 7I, 89, 96-97

Public policy studies 4I-46

Public responsibilities, see Administrative authorities

Pull factors and labour market marginalisation 2I-23, see also Exit opportunities

Push factors and labour market marginalisation I9-2 I, 49-5 I, see also Employment opportunities

PvdA (Dutch Social Democratic Party) 85

Quota jobs 54-55, 59-6I, 79, 82

REA (Dutch Act on the Reintegration of Handicapped People) 87

Replacement rate during sick leave, see Entitlement to sickness benefit

Responsibilities, see Employers' responsibilities and Administrative authorities and Incentives

Retrenchment

Denmark 98-IOI, IO3-IO4

the Netherlands $82,84-85$, I 7 I-I 72

Returning to work, see Integration

RWI (Dutch Council for Work and Income) 89

SER (Dutch Social Economic Council) 83, 86,89

Sickness benefit scheme, see also Entitlement to sickness benefit comparing Dutch and Danish 95, I08

Denmark 94, 98-100

the Netherlands $78-79,86, \mathrm{I}_{4} 8$

Sociaal-Cultureel Planbureau I98

Social Democrats

Denmark 99, IOI, IO3

the Netherlands 85

Social partners $76-78,83,85-86,88-89$

Social risk structures I3-I7, 20-2I, I73-I75

Social support, see Integration

Sociological studies 46-5 I

Social security expenditures $67-69,73$

Structural conditions, definition of 54,56

Summary of the book 27-30

svr (Dutch Social Insurance Council) 78,88

TAV (Dutch Act on the Reduction of the

Number of People with Work Disability) 83

тв A (Dutch Act on the Reduction of the 
Number of Disability Benefit Claims) 84 , I 64

Tz (Dutch Act on Reducing Sickness Absence) $84, \mathrm{I} 64$

Unemployment, see also Employment opportunities consequences for integration 49-5 I, I 44 Denmark and the Netherlands 65-74 disability pathway 2I-23, I7I-I72 unemployment pathway I8-I9, 68-7I welfare state pressures I 2 - I $4,20-2 \mathrm{I}$

Unions $76-78,83,85-86,88-89$, I03

Unobserved variables I 38 -I 39

UWV (The Administrative Institute for Workers Insurance in the Netherlands) 89

Vocational rehabilitation, see Integration instruments

VUT (Dutch early retirement schemes), see Exit pathways

VVD (Dutch Liberal Party) 85

Wage subsidies 24-25, 39-4I, 54-55, I46-

I 47

Denmark 94, I02-103, I06

the Netherlands 79, 83, 86-87, 106

WAGW (Dutch Act on Work for Disabled People) 82

Wajong (Dutch disability benefit scheme for young handicapped people) I 65

WAO (Dutch disability benefit scheme for workers), see Disability benefit scheme

Welfare state pressures I 2-I 4, 2O-2 I

Welfare state regimes I 4-I 7, 76, I 72-I 73

Work pathway I 8-19, 24-25, see also Integration

Work resumption, see Integration

Working conditions, see Integration and jobrelated variables

Workplace-based rehabilitation 24-25, 3536, 59-60, 87, I06, I 25, I 77 the supply of II 8-I2I

wULBZ (Dutch Act on the Enlargement of Wage Payment During Sickness) 86

wVP (Dutch Act on Gatekeeper Improvements) 87

ZW (Dutch sickness benefit Act), see Sickness benefit scheme 


\section{Index of Names}

Aakvik, A. I 56, I 87

Aarts, L. J. M. I8-I9, 21, 23, 32-33, 36, 37, $38,39,43,44,45,47,48,49,50,58,72$, $75,77,78,80,8$ I $, 82,83,84$, I8 I, I 82, I 87, I 88 , I9I, I99

Abrahamson, P. IO, I7 I, I98

Andersen, B. R. 94, I87

Andersen, L. S. 95, I83, I 87

Andersen, S. I I 5 , I 87

Baldwin, M. L. $33,37,38,39,49,50,55$, I93

Battie, M. C. $35, \mathrm{I} 87$

Beljaars, P. W. L. M. M. 85, I 88

Bendix, A. 32, 33, 34, 192

Bengtsson, S. 45, 49, 80, 97, 98, І 00, I 83 , I 88

Bergendorff, S. 39,40 , I 84 , I 88

Bergeskog, A. 59, I I 2, I 88

Berkowitz, E. D. 23, 45, I 88

Berkowitz, M Io, 36, 39, I88, 196

Betænkning nr. 898 99, I 88 ,

Bloch, F. S. 9, I I 2, I 8 I, I 88, I 99

Boll, J. L. 5I, I 88

Boos, K. 82, 83, 84, 87, I4 I, I 86, I 99

Borg, V. 5I, I95

Brown, M. I I 5 , I 93

Burkhauser, R. V. I 8, I9, 23, 45, 72, 79, I 87, I 88, I90, I9I, I92, I99

Butler, R. J. 33, 37, 38, 39, 49, 50, 55, I89, I93

Chen, T. I 94

Clasen, J. I7I, I 89

Colbjørnsen, T. 54, I I 5, I I 6, I 89

Coleman, K. I98

Cox, R. H. 77 , I 89

Crook, J. M. 36, I89

Cstv 69

Cuelenaere, B. 9, I46, I 89

Damgaard, B. I03, I 89
Danmarks Statistik I 56, I6I, I 89

Dansk Arbejdsgiverforening 70, I6I, I85, I 89

Dasinger, L. K. 36, I94

Dean, D. H. 39, I 89

De Gier, E. H. 36, I 89, I90

De Jong, P. R. I 8, I9, 2 I, 23, 32, 33, 36, 37, $38,39,43,44,45,47,48,49,50,58,72$, $75,77,78,80,8$ I, 82, 83, 84, I8 I, I82, I 87, I 88 , I 89, I9I, I99

De Vroom, B. I 8, I90, I 95

Den Sociale Ankestyrelse I63, I90

Den Uyl 77

Dietrich, K. 198

Disney, R. 49, I90

Dolan, R. C. 39, I89

EIM II 2, I42, I90

Einerhand, M. G. K. 45, 70, 80, I I 2, I 90

Elmore, R. F. 54, 55, I05, I90

Elster, J. 54, I90

Emanuel, H. 36, 78, 79, 8 I, 95, I89, I90

Engström, L. G. 39, 40, I92

Erickson, R. N. 194

Eriksson, K. 43, 44, 92

Esbjörnsson, E. 32, 33, 34, I98

Esping-Andersen, G. IO, I2, I3, I4, I 7, 26, 76, I I 2, I 90

European Commission I4, I9I

Eurostat 69, I 82, I9I

Fenwick, J. W. 32, 33, 34, I 92

Frank, J. W. 32, 35, 36, I9I

Frick, B. 20, 22, 44, 45, 49, I9I

Fridberg, T. 197

Frölich, M. 39, 40, I9I

Gatchel, R. J. 32, 34, I9I

Gerhardt, U. 63, I9I

Geurts, S. I 66, I67, I 86, I9 I

Gluck, J. V. 33, 37, 38, 39, I 96

Goldthorpe, J. H. 26, I9I 
Gordon, D. I 84, I 88

Greene, W. H. I39, I9I

Green-Pedersen, C. I04, I9I

Gregersen, O. IO, I 85, I9I

Gründemann, R. I67, I 86, I9 I

Guire, K. E. 33, 37, 38, 39, I96

Halberstadt, V. I 8, 79, I90, I92

Hanson, B. S. 47, I92

Harris, D. E. 32, 33, 34, I99

Hassink, W. H. J. 8I, I 92

Hatland, A. I4, I92, I94

Haveman, R. I 8, 36, 79, I90, I92, I97, 200

Hazard, R. G. 32, 33, 34, 192

Heckman, J. J. I 56, I 87

Heikkilä, M. 71, I92

Hemerijck, A. 75, 76, 78, 8 I , 83, 85, I48, I 82, I99

Heneman III, H. G. I I 5, I 93

Hennessey, J. C. 39, 40, 4I, I 92

Hernserlite, S. E. 39, I95

Heshmati, A. 39, 40, I91, I 92

Hetzler, A. 43, 44, I 92

Hildebrandt, J. 32, 34, I 92

Hohnen, P. IO, I46, I92

Holm, A. Io, 39, 4I I I 43, I 56, I 84, I 93

Holmes, P. 49, I92

Houtman, I. 9, I67, I 92

Hvinden, B. 7I, I 89, I 92

Høgelund, J. 3, 39, 4 I, 88, I I3, I I 4 , I I 5 , I 38, I 43, I 46, I 56, I 77, I 84 , I 93

Höög, J. 47, 48, 49, 64, I 93

Ilmarinen, J. I 82, I93

Jacobs, K. 44, 45, I93

Jansen, J. I 92

Jensen, P. I37, I93

Jespersen, K. IO3

Johnson, D. R. 194

Johnson, W. G. 33, 36, 37, 38, 39, 49, 50, 55, I 88, I93

Jonasen, V. 68, 98, 99, I93

Kankare, I. 7I, I92

Karasek, R. 2I, I93

Klaas, B. S. II 5 , I 93

Knol, G. I90

Knudsen, R. 95, I93

Kohli, M. I 8, 44, 45, 49, I94

Koitz, D. 45, I94

Kolberg, J. E. 49, I 94

Kollman, G. 45, I93

Kompier, M. I67, I86, I9I
Konijn, P. 36, I89, I90

Krause, N. 33, 36, 194

Krueger, A. B. 39, I94

Kummel, B. M. 32, 33, 34, I94

Kvist J. IO, 4I, 42, I7I, I 89, I92, I 94

Lacroix, J. M. 32, 33, 34, I 94

Langager, K. I I 5, I94

Lavindkomst Kommissionens Betænkning 95, I94

Lechner, M. 39, 40, I9I, I92

Lewis, D. R. 39, I94

Lichter, R. L. 32, 33, 34, I99

Lindqvist, R. 22, 46, 47, 58, 63, I94

Lisv 69, 88, 89, I6 I, I63, I86, I94, I95

Livermore, G. 23, I95, 198

Loeser, J. D. 39, I95

Lubbers, R. 83,85

Lund, T. 33, 36, 5I, I94, I95

Lynch, M. 49, I 92

Marklund, S. 9, I9, 33, 47, 48, 49, I88, I93, I94, I95

Mayer, P. D. 32, 34, I9I

Mechanic, D. 46, 58, I95

Merllié, D. I66, I97

Meyer, B. D. 37,38 , I95

Ministerie van Sociale Zaken en Werkgelegenheid 85 , I90, I95, I99

Modvig, J. IO, II 3, I77, I 84, I93

Molenaar-Cox, P. G. M. I 85 , I95

Molho, I. 49, I92

Muller, S. L.M 39, 40, 4I, I92

Nagi, S.Z. 32, 46, 47, 57, 58, I95

Naschold, F. I 8, I90, I95

Navarro, V. I3, I95

Neisner, J. 45, I94

Neuhauser, F. 36, I94

Nord-Larsen, M. I08, I96

OECD I4, I6, 66, 67, 69, 7I, 72, 73, II6, I6I, I63, I66, I67, I 82, I96

Oleinick, A. 33, 37, 38, 39, I96

Ondrich, J. 49, 50, I93

Otten, F. I67, I92

Palmer, E. E. $32,33,34,39,40,43,44,47$, 48,49, I 46, I 8 I, I96, I 99

Paoli, P. I66, I96, I97

Parsons, D. O. 36, I97

Petersen, C. 79, I90

Petersen, L. O. I97

Pfingsten, M. I92 
Piachaud, D. 49, I97

Plovsing, J. IO, I 97

Polatin, P. B. 32, 34, I9I

Prins, R. 9, 8 5, I I 2, I I3 , I 8 I , I 88, I 89, I90, I97, I99

Ragin, C. 26, I97

Rein, M. I 8, 44, 45, 49, I93

Rhodes, M. I3, I4, I 97

Ridder, G. 8I, I92

Rosdahl, A. I03, I97

Rupp, K. I9, 20, I 88, I95, I97

Rørbech, M. 97, I97

Sadowski, D. 20, 22, 44, 45, 49, I9I

Sandström, J. 32, 33, 34, I97, I98

Sattinger, M. 59, 198

Saur, P. I92

Schellekens I08, I98

Schlüter, P. 98, I00

Standing, G. I3, I98

Stapleton, D. C. I9, 20, 2 I, 22, 23, I88, I95, I97, I98

Stattin, M. I9, 47, 48, 49, 64, I8 I, I93, I98

Stone, D. 22, 78, I8 I, I98

Terpstra, J. 89, I98

Theorell, T. 2 I, I93

Thompson, H. I3, I98

Topel, R.H. I I6, I98

Trommel, W. 9, 75, 9I, I05, I48, I 98

Tulder, M. W. V. 35, I99

Valbak, A. 94, 96, 198

Van Agt 77

Van der Giezen, A. M. 9, I I3, I 85, I89, I95, I97

Van der Veen, R. J. 9, 45, 75, 78, 9I, I05, I 48, I 98

Van Groenestijn, M. A. J. 79, I99

Van Kersbergen, K. I48, 199

Van Oorschot, W. 83, 84, I4 I, I49, I7 I, I72, I 86, I 89, I99

Van Ours, J. C. 81, I 92

Vedung, E. 54, 105, I99

Veerman, T. J. 9, 32, 33, 34, 39, 40, 47, 48, 49, II 3 , I46, I65, I66, I 8 I, I 89, I 90 , I97, I99

Venema, A. I67, I92

Verbeek J. H. A. M. 35, I99

Viscusi, K. W. 37, 38, I95

Visser, J. 75, 76, 78, 81 , 83, 85, I48, I82, I 99

Vytlacil, E. J. I 56, I 87
Waddell, G. 32, I99

Wadensjö, E. 44, I99

Wamsler, J. 94, I98

Webb, S. 49, I90

Weide, W. E. van der 35, I99

Werneke, M. W. 32, 33, 34, I99

Wolfe, B. L. 36, I92, I97, 200

Worral, J. D. 37, I 89

Zeuschner, A. 23, I95 
